\title{
Fetal Hypoxia : a novel risk factor for cardiovascular Disease
}

Citation for published version (APA):

Tintu, A. N. (2007). Fetal Hypoxia : a novel risk factor for cardiovascular Disease. [Doctoral Thesis, Maastricht University]. Universiteit Maastricht. https://doi.org/10.26481/dis.20070913at

Document status and date:

Published: 01/01/2007

DOI:

10.26481/dis.20070913at

Document Version:

Publisher's PDF, also known as Version of record

\section{Please check the document version of this publication:}

- A submitted manuscript is the version of the article upon submission and before peer-review. There can be important differences between the submitted version and the official published version of record.

People interested in the research are advised to contact the author for the final version of the publication, or visit the DOI to the publisher's website.

- The final author version and the galley proof are versions of the publication after peer review.

- The final published version features the final layout of the paper including the volume, issue and page numbers.

Link to publication

\footnotetext{
General rights rights.

- You may freely distribute the URL identifying the publication in the public portal. please follow below link for the End User Agreement:

www.umlib.nl/taverne-license

Take down policy

If you believe that this document breaches copyright please contact us at:

repository@maastrichtuniversity.nl

providing details and we will investigate your claim.
}

Copyright and moral rights for the publications made accessible in the public portal are retained by the authors and/or other copyright owners and it is a condition of accessing publications that users recognise and abide by the legal requirements associated with these

- Users may download and print one copy of any publication from the public portal for the purpose of private study or research.

- You may not further distribute the material or use it for any profit-making activity or commercial gain

If the publication is distributed under the terms of Article $25 \mathrm{fa}$ of the Dutch Copyright Act, indicated by the "Taverne" license above, 


\title{
Fetal Hypoxia
}

\section{A Novell Risk Factor for Cardiovascular Disease}

\author{
PROEFSCHRIFT
}

ter verkrijging van de graad van doctor aan de Universiteit Maastricht op gezag van de Rector Magnificus, Prof mr. G.P.M.F. Mols

volgens het besluit van het College van Decanen, in het openbaar te verdedigen

op donderdag 13 september 2007 om 16:00 uur

door:

Andrei Nicolae Ţințu

geboren op 23 juli 1976

te Boekarest 


\section{Promotores:}

Prof. dr. W.H. Lamers

Prof. dr. M.J.H.M. Jacobs

Prof. dr. F.A.C. le Noble (Max Delbrück Center for Molecular Medicine, Berlin, Germany)

\section{Copromotor:}

Dr. E.V. Rouwet (Atrium Medisch Centrum, Heerlen)

\section{Beoordelingscommissie:}

Prof. dr. E. Heineman (voorzitter)

Prof. dr. A. Ahmed (University of Birmingham, United Kingdom)

Dr. L. Hofstra

Dr. B. Janssen

Prof. dr. A.F.M. Moorman (Universiteit van Amsterdam)

\section{Vormgeving en layout}

D\&L. graphics

www.dlgraphics.nl

Druk

Schrijen-Lippertz-Huntjens

ISBN: 978-90-8590-022-1

Financial support by the Netherlands Heart Foundation for the publication of this thesis is gratefully acknowledged.

The study described in this thesis was supported by a grant of the Netherlands Heart Foundation (NHF-2002T011). 


\section{DANKWOORD}

Om te beginnen wil ik iedereen bedanken die heeft bijgedragen aan de totstandkoming van dit proefschrift.

Ten eerste, mijn promotieteam. Ferdinand en Ellen voor het initiëren en begeleiden van dit onderzoeksproject. Ik hoop dat we nog lange tijd succesvol samenwerken onder het moto "un pour tous, tous pour un". Beste prof. Jacobs, van u heb ik geleerd dat wetenschap niet alleen een creatieve hobby is, maar ook een zakelijke aangelegenheid. Dank voor uw belangenbehartiging. Beste Wout, dank voor je wijze woorden en adviezen. Zoals je reeds voorspelde: alles is goedgekomen.

Verder van de capgroep anatomie/embryologie Paul, Johan en Chiel voor hun vakkundige hulp bij het embryowerk. Chiel, sorry dat ik je lab roze heb gekleurd. Paul en Johan, sorry voor de kuikens en alle rotte eieren.

De capgroep fysiologie, in het bijzonder Uli Schotten die mij de beginselen van de electrofysiologie heeft bijgebracht. Marc van Bilsen en Peter Willemsen die mij goed op weg hebben geholpen in de moleculaire biologie.

Van de capgroep cardiologie kan Leo Hofstra niet ongemerkt de revue passeren. Leo G of Leojee, eeuwige optimist en beroeps motivator, hartstikke bedankt dat je me een hart onder de riem hebt gestoken als ik het even niet meer zag zitten.

Collega jonge onderzoekers: Mark, Blanche, Joost, Pascal, Erik, Roy, Vincent, Selvi, Kitty, Sander en Henny. Inhoudelijk hebben we weinig met elkaar te maken gehad, maar in ieder geval bedankt voor de gezelligheid en waardevolle discussies.

De mensen van twee deuren verderop: Rick, Xavier en Femke, dank voor jullie vriendschap. Rick, filmpjes en plaatjes, het is toch mooi dat je van onze hobby jouw werk hebt kunnen maken. Succes met je opleiding tot radioloog...en amateur golfer. $\mathrm{Na}$ je promotie een weekje Salamanca? Xavier, time flies -in jouw geval dives- when you're having fun. Blijf vooral jezelf, dan word je vast een goed chirurg. Lieve Femmiebemmie, ook namens de kleine bedank ik jou en Jobje en de rest van de dieren voor alle keren dat jullie voor ons klaarstaan, voor jullie hartelijkheid en voor het (h)eerlijke eten als Elliebellie weer 'ns niets had. Hoop dat we dit nog lang voortzetten.

Zo tegen het einde aan was ik bijna mijn oudste en beste vriend vergeten...Arjan. Dude, als we elkaar moeten gaan bedanken voor alles wat we hebben beleefd dan kunnen we v2.0 van dit proefschrift gaan uitbrengen. Kick some asses at Google.

Lieve papa, mama en Ana, ik kan jullie niet genoeg bedanken voor de adviezen, steun en inspiratie die jullie mij gegeven hebben, ondanks de zorgen van en voor papa.

Lief popje, vind je lief...zo samen achter 't computerke. Er zijn maar weinig mensen die zo met elkaar kunnen genieten van het uitdenken, plannen en doen van proefjes. Ik hoop dat we dit voor altijd blijven doen. 


\section{CONTENTS}

Chapter 1 Fetal origin of cardiovascular disease

Identification of fetal hypoxia as a risk factor for CVD 7

Chapter 2 Cellular response to hypoxia

Chapter 3 Hypoxia disturbs fetal hemodynamics and growth 49

Chapter 4 Hypoxia induces aortic hypertrophic growth, left ventricular dysfunction and sympathetic hyperinnervation in the chick embryo

Chapter 5 Prenatal hypoxic stress programs for cardiomyopathy involving cardiomyocyte specific

VEGF-ANEGFR-2/NRP1 signaling

Chapter 6 Prenatal hypoxia causes diastolic dysfunction

Chapter $7 \quad$ Summary / Samenvatting 


\section{List of Abbreviations}

\begin{tabular}{|c|c|}
\hline $\mathrm{ACh}$ & Acetylcholine \\
\hline$A G A$ & Appropriate for Gestational Age \\
\hline ANF & Atrial Natriuretic Factor \\
\hline AT & Acceleration Time \\
\hline CAD & Coronary Artery Disease \\
\hline CAM & Chorioallantoic Membrane \\
\hline CVD & Cardiovascular Disease \\
\hline DCM & Dilated Cardiomyopathy \\
\hline E & Embryonic day \\
\hline E/A ratio & Early-to-Atrial inflow velocity ratio \\
\hline ET & Ejection Time \\
\hline FGR & Fetal Growth Restriction \\
\hline $\mathrm{FIH}-1$ & Factor Inhibiting HIF-1 \\
\hline Flk-1 & Fetal liver kinase 1 (also VEGFR-2) \\
\hline Flt-1 & FMS-like tyrosine kinase 1 (also VEGFR-1) \\
\hline FP & Fetal Programming \\
\hline HE & Hematoxylin \& Eosin \\
\hline HIF-1 & Hypoxia-Inducible Factor 1 \\
\hline$H R$ & Heart Rate \\
\hline HRE & Hypoxia Responsive Element \\
\hline ICT & Isovolumetric Contraction Time \\
\hline IRT & Isovolumetric Relaxation Time \\
\hline LBW & Low Birth Weight \\
\hline LV & Left Ventricle/Ventricular \\
\hline MAP & Mean Arterial Pressure \\
\hline Mod-MPI & Modified Myocardial Performance Index \\
\hline$N E$ & Norepinephrine \\
\hline NRP1 & Neuropilin-1 \\
\hline NT-proBNP & N-terminal pro-Brain Natriuretic Peptide \\
\hline$P$ & Postnatal \\
\hline PAS & Periodic Acid Schiff \\
\hline PDGF & Platelet Derived Growth Factor \\
\hline PHD & Prolyl Hydroxylase Domain \\
\hline Phent & Phentolamine \\
\hline PIGF & Placental Growth Factor \\
\hline PLI & Preload Index \\
\hline SE & Standard Error \\
\hline Sema3A & Semaphorin $3 \mathrm{~A}$ \\
\hline sFlt-1 & Soluble FMS-like tyrosine kinase 1 \\
\hline SGA & Small for Gestational Age \\
\hline Tyr & Tyramine \\
\hline VEGF & Vascular Endothelial Growth Factor \\
\hline VEGFR-2 & Vascular Endothelial Growth Factor Receptor 2 (also Flk-1) \\
\hline VHL & Von Hippel-Lindau \\
\hline
\end{tabular}


CHAPTER 1

\section{Fetal Origin of CVD}

Identification of Prenatal Hypoxia as a Risk Factor for CVD

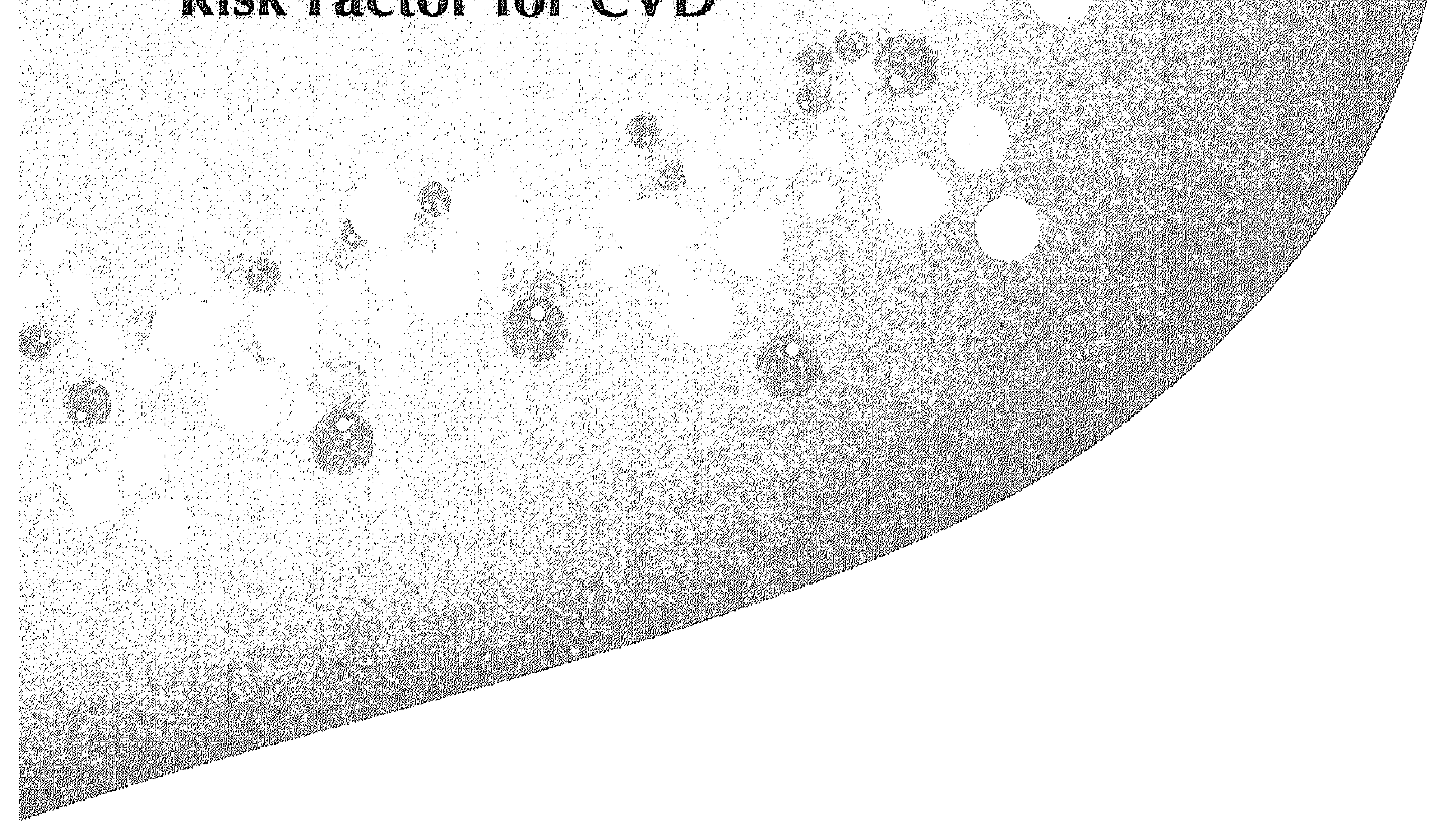




\section{Cardiovascular Disease}

One in three adult men and women has some form of cardiovascular disease (CVD), including coronary heart disease, hypertension, heart failure, stroke, and peripheral arterial disease. CVD is the no. 1 killer in the Western world, accounting for $37 \%$ of all deaths. CVD claims more lives each year than the next four leading causes of death combined, which are cancer, chronic lower respiratory tract diseases, accidents, and diabetes mellitus. If all forms of major CVD were eliminated, life expectancy would rise by almost seven years. In addition to the health burden, the economic burden of CVD is extremely high. The direct and indirect costs of CVD are twice as high as the costs of all cancers. Heart disease is therefore the most costly medical condition, weighing heavily on the healthcare budget (statistics American Heart Association).

Well known risk factors for CVD are tobacco smoking, high blood cholesterol, physical inactivity, obesity, and diabetes mellitus. In addition to these classic risk factors and a genetically based propensity for acquiring CVD, it is becoming clear that epigenetic influences prior to birth may determine the susceptibility to develop CVD in later life. Identification of and intervention with the embryonic origin of CVD may provide a novel target in the prevention and early treatment of CVD.

\section{The Fetal Programming Concept of CVD}

Barker et al. in 1989 for the first time showed in large retrospective studies that low birth weight (LBW) was associated with an increased risk of hypertension, stroke, and coronary artery disease (CAD) at adult age. ${ }^{1,2} \mathrm{He}$ also demonstrated that low birth weight, independent of gestational age, was related to an increase in the classic risk factors of CVD, including hypercholesterolemia, hypercoagulability, and non-insulin dependent diabetes mellitus in adults. ${ }^{3,4}$ Based on these observations it was suggested that adverse conditions during human fetal development, as reflected in low birth weight, play a crucial role in the progression of chronic noncommunicable diseases in adult life, especially cardiovascular disease. The concept that exposure to an adverse fetal environment leads to an increased risk of disease in adult life is widely known as fetal programming (FP). Common synonyms include Barker hypothesis, fetal origins of adult disease, and developmental origins of adult disease. Since the original reports of Barker, over 7000 clinical studies have investigated the subject of FP. The results of these studies are summarized in excellent recent reviews. ${ }^{5}$ 
Table 1 Association of low birth weight and CVD

\begin{tabular}{lc}
\hline CVD and CVD risk factors associated with low birth weight & References \\
\hline Hypertension & 6 \\
Coronary artery disease & 7 \\
Stroke & 8 \\
Diabetes mellitus type 2 & 9,10 \\
Hypercholesterolemia & 11 \\
Obesity & 12,13 \\
Endothelial dysfunction & 14,15 \\
Chronic renal disease & 16,17 \\
\hline
\end{tabular}

Despite all evidence linking low birth weight to disease outcomes in adult life, the essential issues of the FP concept remain to be elucidated, namely when and how fetal programming takes place.

\section{When Does Fetal Programming Occur?}

The large population studies that form the basis for the FP concept mainly rely on historical data from birth records, such as weight and length. At present, there are no prospective longitudinal studies that provide insight into maternal health status, fetal development and postnatal follow-up until manifestations of CVD in the offspring. The available clinical studies are not able to discern between a prenatal or postnatal origin of CVD. It is crucial to know at what stage of pre- or postnatal life CVD develops in order to plan interventions and screening strategies.

\section{Hypotheses}

A number of theoretical models have been proposed to explain the relationship between birth weight and long-term disease risk. The original fetal origins hypothesis suggests that organ structures and functions undergo programming during fetal life in response to intrauterine events, which determines the set point of physiologic and metabolic responses that carry into adulthood. Thus, events in utero, which reduce fetal growth, might result in developmental adaptations in the fetus that produce permanent structural, functional, and metabolic changes that predispose a person to diseases in adult life. This initial model was later refined in an evolutionary context. 
The "thrifty phenotype" hypothesis proposes that the fetus responds to an adverse environment through developmental adaptations and reducing growth in the expectation of a future deprived postnatal environment. However, if the postnatal environment does not match the predictive adaptive responses, then these same adaptations may be inappropriate and might increase disease risk ${ }^{5,18-20}$

Another hypothesis proposes that alterations in postnatal metabolism amplify the risk of adult CVD. As a consequence, accelerated growth in childhood in low birth weight children, i.e. catch-up growth, is associated with increased risk of coronary artery disease, hypertension, and type-2 diabetes mellitus. ${ }^{21-26}$

\section{How Does Programming Occur?}

The etiology of cardiovascular diseases with a presumed fetal origin is complex, consisting of many different components. For example, stroke is usually due to thromboembolism of a carotid artery atherosclerotic plaque. But then, which aspect or aspects of this -simplified-process has or have an origin in the fetus? A prothrombotic state? Progression of atherosclerotic lesions? Instability of the atherosclerotic plaque? And if so, which factor in the complex atherosclerotic process? Or is it due to an increased risk of hypertension related to fetal programming? Which aspects of a cardiovascular disease are programmed and which pathophysiologic mechanisms are involved?

\section{Fetal Growth Restriction}

The fetal programming hypothesis is based on the observation that low birth weight babies, i.e., those weighing less than $2500 \mathrm{~g}$ at birth, are predisposed to CVD in adulthood. In fact, it is not birth weight per se, but rather relatively low birth weight for a given gestational age that determines the risk for CVD, i.e., restricted fetal growth. Fetal growth restriction (FGR) is defined as a decrease in fetal growth rate that prevents an infant from obtaining its complete growth potential. ${ }^{27,28}$ The incidence of FGR in developed countries is estimated at 5$10 \% .{ }^{28,29} \mathrm{FGR}$ infants are small for gestational age (SGA) if their birth weight measures less than $3-10 \%$ of the mean at a given week of gestation using standard growth curves. ${ }^{28}$

Fetal growth and development are determined by the interaction between the fetal genome and the intrauterine environment, which, in turn, is determined by maternal health, the external environment, and the uteroplacental unit. Disturbances in any of these components can lead to fetal growth restriction and 
low birth weight. The major causes of FGR in Western societies are placental insufficiency, cigarette smoking, preeclampsia, chronic maternal vascular disease due to hypertension, diabetes mellitus, renal disease, or collagen vascular disease, and thrombophilia. ${ }^{20,30,31}$ In contrast, in developing countries maternal malnutrition and infections are most important. ${ }^{28}$ The question remains what links this large variety of conditions to CVD in the offspring?

\section{Prenatal Insults and Potential Mechanisms of Programming}

Retrospective clinical studies are unsuitable to identify the cause of the presumed relationship between events during fetal development and later CVD. Therefore animal models have been designed. The common consequence of the heterogeneous etiologies of FGR is impaired delivery of oxygen and nutrients to the developing fetus. ${ }^{32-34}$ Based on the notion that oxygen and nutrient supply limitations are the components of the intrauterine environment that limit fetal growth and that low birth weight is related to later CVD, many animal models have been designed to investigate pathophysiologic mechanisms underlying fetal programming. ${ }^{35-37}$ Experimental animals used include rat, sheep, rabbit, guinea pig, and chick embryos. Manipulations that mimic the human condition of fetal growth restriction comprise global maternal food or protein restriction, maternal hypoxia, impaired uterine perfusion, and prenatal glucocorticoid treatment. These studies have revealed a number of potential mechanisms that may link fetal growth restriction with adult disease, ${ }^{36}$ the most common of which are displayed in Table 2.

A major drawback of these animal models is that the experimental interventions that induce fetal growth restriction have combined effects, leading to deficiencies in both oxygen and nutrient delivery to the fetus. In addition, the experimental manipulations are applied to the mother animal, not directly to the fetus. Because of interference of maternal cardiovascular, metabolic and endocrine systems it is impossible to investigate the pure effect of experimental conditions on fetal development and to identify molecular mechanisms underlying fetal programming of CVD. Moreover, virtually no study has demonstrated that changes in the cardiovascular system in the offspring persist into adulthood, which is the basis of the FP concept.

Another problem with the available animal studies is that one of the most frequently tested experimental conditions, maternal malnutrition, is not a major issue in developed countries. Malnutrition is an important cause of FGR in developing countries. However, most common Western etiologies of FGR, including uteroplacental insufficiency, preeclampsia, maternal smoking, and maternal cardiovascular or pulmonary disease, are associated with prolonged 
fetal hypoxia. Cordocentesis studies have shown that FGR fetuses exhibit hypoxemia. ${ }^{38-40}$ Prenatal hypoxia is a common event in Western societies: an estimated $5-10 \%$ of all newborns suffered from hypoxia during fetal development. The known consequences of prenatal hypoxia are fetal growth restriction, prematurity and stillbirth. ${ }^{27,28,41}$ It is not known whether fetal hypoxia is implied in the origin of CVD.

Table 2

\begin{tabular}{lc}
\hline Potential mechanisms linking FGR with adult CVD & References \\
\hline Dysregulation of the hypothalamic-pituitary-adrenal axis, excess glucocorticoids & $42-44$ \\
Altered neuroendocrine and autonomic nervous control & 45,46 \\
Abnormalities in the renin-angiotensin system & 47,48 \\
Alterations in renal structure and function, reduction in nephron number, & \\
disturbed glomerular filtration rate & 48 \\
Insulin resistance; impairment in insulin secretion and action, & \\
up-regulation of glucose production & 49,50 \\
Modification of the growth hormone/insulin-like growth factor axis & 51 \\
\hline
\end{tabular}




\section{AIMS OF ThIS THESIS}

At present it is unclear how, when, and to what extent fetal hypoxia influences cardiovascular development, and whether this relates to the establishment of CVD. Since the design of the cardiovascular system takes place before birth, we hypothesize that exposure of the fetus to hypoxia at critical stages of development induces permanent alterations in the structural and functional design of the circulatory system before birth, which program for or contribute to CVD. To investigate the role of fetal hypoxia in the origin of CVD we designed a novel experimental model in the chick embryo and subsequently extrapolated the experimental findings to the human situation.

\section{Rationale for the Chick Embryo Model}

The choice for the chick embryo as the experimental model was based on the following. First, an outstanding feature of avian embryos is their development independently of the mother animal. This allows investigation of the effect of experimental conditions on embryonic development without interference by maternal cardiovascular, metabolic and endocrine systems. In contrast, in human and other mammals it is virtually impossible to discern between malnutrition and hypoxia, since conditions affecting the fetal environment, such as uteroplacental insufficiency, affects both nutrient and oxygen supply. Furthermore, the chick embryo is easily accessible for observation and manipulation in vivo throughout development without elaborate invasive surgery and anesthesia.

Second, the effect of hypoxia on fetal development of the cardiovascular system can be studied in isolation by changing the ambient oxygen tension. Gas exchange in the avian embryo is provided by the chorioallantoic membrane (CAM), a highly vascularized membrane which lines the inside of the eggshell and is regarded as the avian homologue of the mammalian placenta. ${ }^{52}$ Oxygen from surrounding air and $\mathrm{CO}_{2}$ and water from the embryo diffuse through small pores in the eggshell and shell membranes into the capillaries of the CAM. The CAM vein and artery, corresponding to the mammalian umbilical vessels, transport oxygenated and deoxygenated blood to and from the embryo, respectively. Nutrients are provided to the chick embryo by the albumen and yolk-sac compartments. Thus, oxygen delivery to the developing chick embryo can be influenced without affecting nutrient supply.

Third, the avian embryo is a commonly used experimental model in developmental cardiovascular ${ }^{53}$ and neurobiological research. ${ }^{54}$ Development of the chick embryo is closely related to the fetal sheep, which is considered to 
be the standard model for the study of fetal physiology. ${ }^{55}$ Cardiovascular responses in chick embryos are largely similar to those in mammalian species, including humans. For example, sympathetic and parasympathetic control of the avian heart is functional from embryonic day 15 onwards and is fully functional at the time of hatching ${ }^{56}$ comparable with the human fetus at birth. The conservation of factors involved in the regulation of cardiovascular development makes the chick embryo a reliable model for the developing vertebrate circulatory system.

\section{The main objectives of this thesis are}

1. To assess whether chronic hypoxia induces aberrant cardiovascular development in the embryo. To this end, chick embryos were exposed to an ambient oxygen level of $15 \%$ throughout development. The effects of chronic fetal hypoxia on the structural and functional development of the heart, vascular system, and sympathetic nervous system were investigated (Chapters 3 to 6).

2. To determine the mechanism underlying hypoxia-induced alterations in cardiovascular development. A key cytokine induced by hypoxic stress is vascular endothelial growth factor (VEGF). VEGF plays a pivotal role in many aspects of embryonic cardiovascular development, including formation of blood vessels, cardiac morphogenesis, and development of the autonomic nervous system (Chapter 2). VEGF levels have to be maintained within a narrow range to ensure proper cardiovascular development and embryo survival. The involvement of VEGF in the development of embryonic CVD was investigated in Chapter 5.

3. To assess whether hypoxia-induced changes in the fetal cardiovascular system persist after birth. To this end, cardiac structure and function were investigated in adult chickens prenatally exposed to hypoxia (Chapters 5 and 6).

4. To define the effects of prolonged hypoxia on human cardiovascular development. To this end, cardiac performance and structure were investigated in human fetuses with evidence of hypoxia (Chapters 5 and 6 ). 


\section{REFERENCES}

1. Barker DI, Bull AR, Osmond C, Simmonds SI. Fetal and placental size and risk of hypertension in adult life. BM] 1990;301(6746):259-62.

2. Barker DJ, Osmond C, Golding J, Kuh D, Wadsworth ME. Growth in utero, blood pressure in childhood and adult life, and mortality from cardiovascular disease. BM] 1989;298(6673):564-7.

3. Barker DJ, Martyn $\mathrm{CN}$, Osmond $\mathrm{C}$, Hales $\mathrm{CN}$, Fall $\mathrm{CH}$. Growth in utero and serum cholesterol concentrations in adult life. BMJ 1993;307(6918):1524-7.

4. Barker DI, Meade TW, Fall CH, et al. Relation of fetal and infant growth to plasma fibrinogen and factor VII concentrations in adult life. Bmj 1992;304(6820):148-52.

5. Gluckman PD, Hanson MA. Living with the past: evolution, development, and patterns of disease. Science 2004;305(56,91):1733-6.

6. Alexander BT. Fetal programming of hypertension. Am J Physiol Regul Integr Comp Physiol 2006;290(1):R1-R10.

7. Barker DJ. Fetal programming of coronary heart disease. Trends Endocrinol Metab 2002;13(9):364-8.

8. Lawlor DA, Ronalds G, Clark H, Smith GD, Leon DA. Birth weight is inversely associated with incident coronary heart clisease and stroke among individuats born in the 1950s: findings from the Aberdeen Children of the 1950s prospeclive cohort study. Circulation 2005;112(10):1414-8.

9. Hales CN, Barker D), Clark PM, et al. Fetal and infant growth and impaired glucose tolerance at age 64. Bmj 1991;303(6809):1019-22.

10. Ravelli AC, van der Meulen JH, Michels RP, et al. Glucose tolerance in adults after prenatal exposure to famine. Lancet 1998;351(9097):173-7.

11. Davies AA, Smith GD, Ben-Shlomo Y, Litchfield P. Low birth weight is associated with higher adult total cholesterol concentration in men: findings from an occupational cohort of 25,843 employees. Circulation 2004;110(10):1258-62.

12. Sayer AA, Cooper C. Fetal programming of body composition and musculoskeletal development. Early Hum Dev 2005;81(9):735-44.

13. McMillen IC, Adam CL, Muhlhausler BS. Early origins of obesity: programming the appetite regulatory system. ) Physiol 2005;565(Pt 1):9-17.

14. Leeson CP, Kattenhorn M, Morley R, Lucas A, Deanfield JE. Impact of low birth weight and cardiovascular risk factors on endothelial function in early adult life. Circulation $2001 ; 103(9): 1264-8$.

15. Leeson CP, Whincup PH, Cook DG, et al. Flow-mediated dilation in 9-to 11-year-old children: the influence of intrauterine and childhood factors. Circulation 1997;96(7):2233-8. 
16. Ingelfinger IR. Pathogenesis of perinatal programming. Curr Opin Nephrol Hypertens 2004;13(4):459-64

17. Zandi-Nejad K, Luyckx VA, Brenner BM. Adult hypertension and kidney disease: the role of fetal programming. Hypertension 2006;47(3):502-8.

18. Gluckman PD, Hanson MA. Developmental origins of disease paradigm: a mechanistic and evolutionary perspective. Pediatr Res 2004;56(3):311-7.

19. Gluckman PD, Cutficld W, Hofman P, Hanson MA. The fetal, neonatal, and infant environments-the long-term consequences for disease risk. Early Hum Dev 2005;81(1):51-9.

20. Lau C, Rogers JM. Embryonic and fetal programming of physiological disorders in adulthood. Birth Defects Res C Embryo Today 2004;72(4):300-12.

21. Eriksson 3, Forsen T, Tuomilehto J, Osmond C, Barker D. Fetal and childhood growth and hypertension in adult life. Hypertension 2000;36(5):790-4.

22. Fagerberg $B$, Bondjers $L$, Nilsson P. Low birth weight in combination with catch-up growth predicts the occurrence of the metabolic syndrome in men at late middle age: the Atherosclerosis and Insulin Resistance study. I Intern Med 2004;256(3):254-9.

23. Forsen T, Eriksson 1, Tuomilehto 1, Reunanen A, Osmond C, Barker D. The fetal and childhood growth of persons who develop type 2 diabetes. Ann Intern Med 2000;133(3):176-82.

24. Barker DJ, Eriksson JG, Forsen T, Osmond C. Fetal origins of adult disease: strength of effects and biological basis. Int I Epidemiol 2002;31(6):1235-9.

25. Eriksson JG. The fetal origins hypothesis--10 years on. BM) 2005;330(7500):1096-7.

26. Barker DJ, Osmond C, Forsen TJ, Kajantie E, Eriksson JG. Trajectories of growth among children who have coronary events as adults. N Engl I Med 2005;353(17):1802-9.

27. Lee PA, Chernausek SD, Hokken-Koelega AC, Czernichow P. International Small for Gestational Age Advisory Board consensus development conference statement: management of short children born small for gestational age, April 24-October 1, 2001. Pediatrics 2003;111(6 Pt 1):1253-61.

28. Brodsky D, Christou $\mathrm{H}$. Current concepts in intrauterine growth restriction. I Intensive Care Med 2004;19(6):307-19.

29. Ergaz $Z$, Avgil M, Ornoy A. Intrauterine growth restriction-etiology and consequences: what do we know about the human situation and experimental animal models? Reprod Toxicol 2005;20(3):301-22.

30. Lin CC, Santolaya-Forgas J. Current concepts of fetal growth restriction: part I. Causes, classification, and pathophysiology. Obstet Gynecol 1998;92(6):1044-55.

31. Baschat AA. Pathophysiology of fetal growth restriction: implications for diagnosis and surveillance. Obstet Gynecol Surv 2004;59(8):617-27.

32. Illanes S, Soothill P. Management of fetal growth restriction. Semin Fetal Neonatal Med $2004 ; 9(5): 395-401$. 
33. Peebles DM. Fetal consequences of chronic substrate deprivation. Semin Fetal Neonatal Med 2004;9(5):379-86.

34. Peebles DM. Fetal growth restriction. Semin Fetal Neonatal Med 2004; 915):355-6.

35. Fowden AL, Forhead AJ. Endocrine mechanisms of intrauterine programming. Reproduction 2004;127(5):515-26.

36. McMillen IC, Robinson IS. Developmental origins of the metabolic syndrome: prediction, plasticity, and programming. Physiol Rev 2005;85(2):571-633.

37. Fernandez-Twinn DS, Ozanne SE. Mechanisms by which poor early growth programs type-2 diabetes, obesity and the metaloolic syndrome. Physiol Behav 2006;88(3):23443.

38. Economides DL, Nicolaides $\mathrm{KH}$, Campbell S. Metabolic and endocrine findings in appropriate and small for gestational age fetuses. I Perinat Med 1991;19(1-2):97-105.

39. Soothill PW, Nicolaides KH, Campbell S. Prenatal asphyxia, hyperlacticaemia, hypoglycaemia, and erythroblastosis in growth retarded fetuses. Br Med ) (Clin Res Ed) 1987;294(6579):1051-3.

40. Pardi G, Cetin I, Marconi AM, et al. Diagnostic value of blood sampling in fetuses with growth retardation. N Engl I Med 1993;328(10):692-6.

41. Bell R, Glinianaia SV, Rankin J, Wright C, Pearce MS, Parker L. Changing patterns of perinatal death, 1982-2000: a retrospective cohort study. Arch Dis Child Fetal Neonatal Ed 2004;89(6):F531-6.

42. Kapoor A, Dunn E, Kostaki A, Andrews MH, Matthews SG. Fetal programming of hypothalamo-pituitary-adrenal function: prenatal stress and glucocorticoids. J Physiol 2006;572(Pt 1):31-44.

43. Ward AM, Syddall HE, Wood PJ, Chrousos GP, Phillips DI. Fetal programming of the hypothalamic-pituitary-adrenal (HPA) axis: low birth weight and central HPA regulation. J Clin Endocrinol Metab 2004;89(3):1227-33.

44. Seckl IR, Meaney MI. Glucocorticoid programming. Ann NY Acad Sci 2004;1032:63-84.

45. Phillips DI, Walker BR, Reynolds RM, et al. Low birth weight predicts elevated plasma cortisol concentrations in adults from 3 populations. Hypertension 2000;35(6):1301-6.

46. Phillips DI, Jones A. Fetal programming of autonomic and HPA function: do people who were small babies have enhanced stress responses? ) Physiol 2006;572(Pt 1):45-50.

47. Dodic $M$, Baird R, Hantzis V, et al. Organs/systems potentially involved in one model of programmed hypertension in sheep. Clin Exp Pharmacol Physiol 2001;28(11):952-6.

48. Amann K, Wanner C, Ritz E. Cross-talk between the kidney and the cardiovascular system. I Am Soc Nephrol 2006;17(8):2112-9.

49. Fowden AL, Giussani DA, Forhead A). Endocrine and metabolic programming during intrauterine development. Early Hum Dev 2005;81(9):723-34.

50. Simmons R. Developmental origins of adult metabolic disease: concepts and controversies. Trends Endocrinol Metab 2005;16(8):390-4. 


\section{chapter 1}

51. Holt Rl. Fetal programming of the growth hormone-insulin-like growth factor axis. Trends Endocrinol Metab 2002;13(9):392-7.

52. Metcalfe J, Stock MK. Current topic: oxygen exchange in the chorioallantoic membrane, avian homologue of the mammalian placenta. Placenta 1993;14(6):605-13.

53. Kirby ML, Waldo KL. Neural crest and cardiovascular palterning. Circ Res 1995:77(2):211-5.

54. Le Douarin NM. The avian embryo as a model to study the development of the neural crest: a long and still ongoing story. Mech Dev 2004;121(9):1089-102.

55. van Golde J. Chick Embryo as a model in Fetal Physiology. Maastricht: Maastricht University; 1999.

56. Higgins D, Pappano AJ. Development of transmitter secretory mechanisms by adrenergic neurons in the embryonic chick heart ventricle. Dev Biol 1981;87(1):148-62. 
CHAPTER 2

Cellular Response to Hypoxia

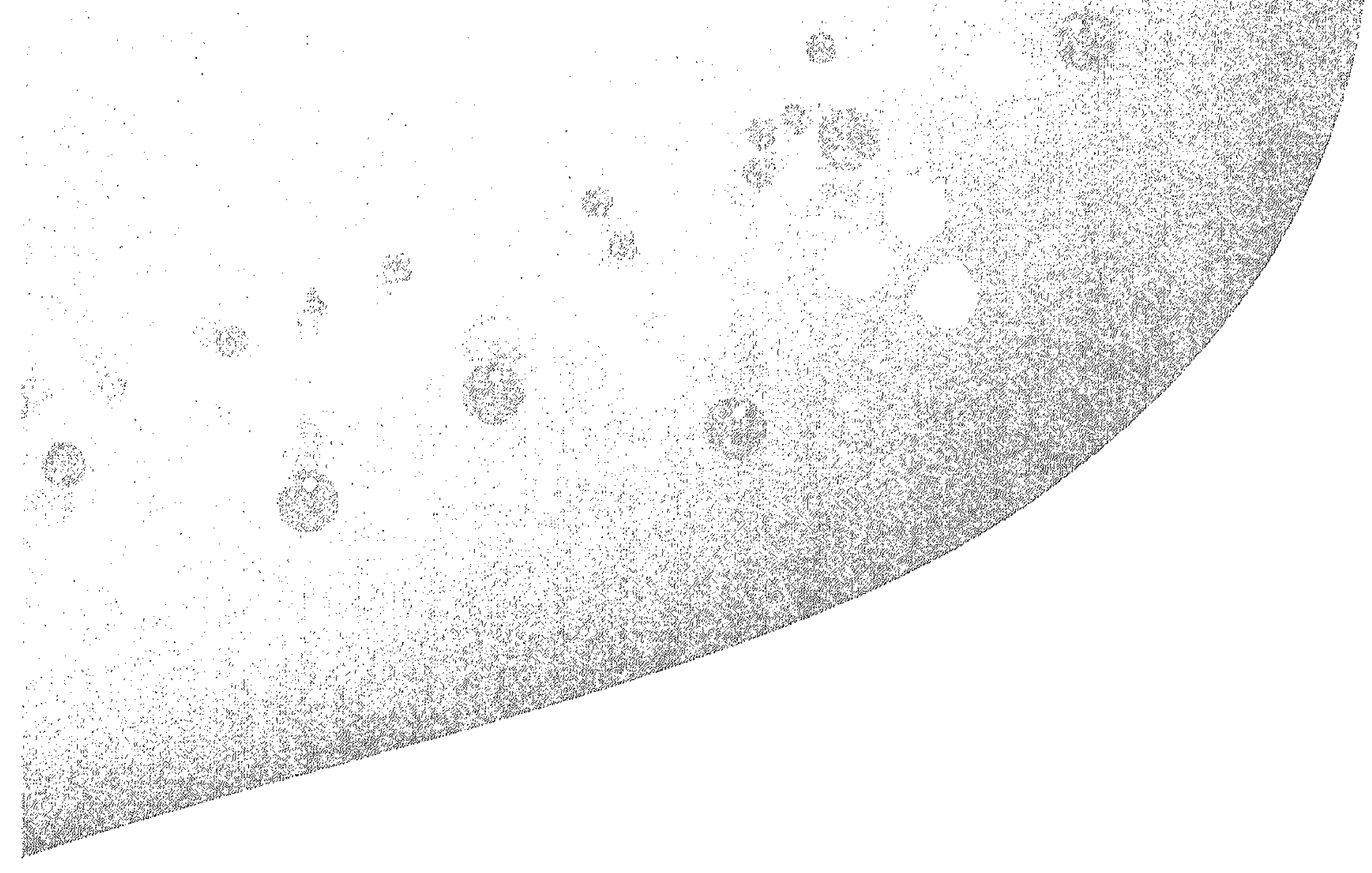




\section{HyPOXIA-INDUCIBLE FACTOR}

Adaptations to decreased cellular oxygen supply are being achieved via hypoxia-signaling pathways. A key molecule in the cellular response to changes in oxygen availibility is the transcritption hypoxia-inducible factor 1 (HIF-1). HIF-1 triggers genes that induce metabolic changes and increase $\mathrm{O}_{2}$ delivery to cells by stimulating angiogenesis to ensure cell survival.

In the early 1990's, Semenza and colleagues described the role of HIF-1 as a global regulator of $\mathrm{O}_{2}$ homeostasis. ${ }^{1,2}$ This revolutionary finding initially resulted from analysis of the molecular mechanism by which erythropoietin gene transcription was activated in response to hypoxia. At present, more than 100 genes have been identified that appear to be under control of HIF-1, and their number continues to increase. The main purpose of HIF-1 target genes is to maintain oxygen homeostasis during periods of oxygen deprivation. In order to do so, oxidative phosphorylation has to be decreased at cellular level, hereby relying on glycolysis as primary means of ATP production. In order to achieve this goal, glycolytic enzymes that ensure survival under depressed $\mathrm{O}_{2}$ conditions and glucose transport channels are being upregulated. Furthermore, due to upregulation of erythropoietin, erythrocyte production booms hereby increasing the oxygen carrying capacity of the blood. Moreover, in order to increase oxygen supply to the hypoxic tissue, additional blood vessels are required. To stimulate proliferation of blood vessels, angiogenic factors are upregulated. One of the most important and potent angiogenic factors that are upregulated by HIF-1 is vascular endothelial growth factor (VEGF).

In addition to HIF-1, two other HIF's have been discovered, HIF-2 and HIF-3. ${ }^{3}$ We will focus on HIF-1. HIF- 1 is a heterodimeric transcription factor composed of an oxygen-dependent inducible HIF-1 $\alpha$ subunit (the oxygen sensor) and a non-oxygen dependent, constitutively expressed HIF-1, subunit, both located in the cytoplasma. HIF-1 $\alpha$ and HIF-1 1 contain a basic helix-loophelix (bHLH) and a PER-ARNT-SIM (PAS) motifs, which are required for dimerization of the two subunits, and for binding to the DNA in order to activate transcription of target genes (Fig. 2). ${ }^{4}$

\section{Oxygen Sensing}

HIF-1 activation is an oxygen-controlled multi-step process involving HIF-1 $\alpha$ protein stabilisation, nuclear translocation, heterodimerization, DNA binding and transcriptional activation, and interaction with other proteins. HIF- $1 \alpha$ is activated in vitro at a threshold value of about $5 \% \mathrm{O}_{2}$ (equivalent to $40 \mathrm{mmHg}$ or $5.35 \mathrm{kPa}$ ), and progressively increases its level of activity with a decrease in 
oxygen gradient down to $0.2-0.1 \% \mathrm{O}_{2}$ (equivalent to $1.6-0.8 \mathrm{mmHg}$ or 0.21 $0.10 \mathrm{kPa}$ respectively), close to anoxia. ${ }^{5}$

Under normoxic conditions HIF-I $\alpha$ subunits undergo ubiquitination and are subjected to proteasomal degradation. ${ }^{6}$ Two mechanisms are responsible for HIF degradation under normoxia (Fig. 1).

The first one involves the prolyl hydroxylase domain/von Hippel-Lindau (PHDNHL) pathway. The PHD's are dependent on cellular $\mathrm{O}_{2}$ as a cosubstrate, which provides the molecular basis for their $\mathrm{O}_{2}$ sensing properties. ${ }^{5}$ The PHD enzyme family consists of three members: PHD1, PHD2, and PHD3. PHD2 seems to be the limiting enzyme targeting HIF-1 $\alpha$ for degradation under normoxic conditions. ${ }^{7}$ The physiological roles of PHD1 and PHD3, which are active under chronic hypoxia, are under investigation. ${ }^{8}$ Hydroxylation of HIF-1 $\alpha$ by PHD2 leads to rapid interaction with the tumour-suppressor protein VHL (Fig. 1). ${ }^{9,10}$ Due to the fusion of HIF-1 $\alpha$ with VHL, HIF- $1 \alpha$ becomes marked with polyubiquitin chains that drive it to destruction by the proteasomal system. ${ }^{1}$ Cells lacking expression of VHL maximally express HIF- $1 \alpha$ and HIF-2 $\alpha$ under normoxic conditions.

The second molecular mechanism that is active during normoxia relies on the action of factor inhibiting HIF-1 $(\mathrm{FIH}-1){ }^{12}$ This enzyme was found to hydroxylate a conserved residue of the HIF-1 $\alpha$ protein (Fig. 1). Due to this covalent

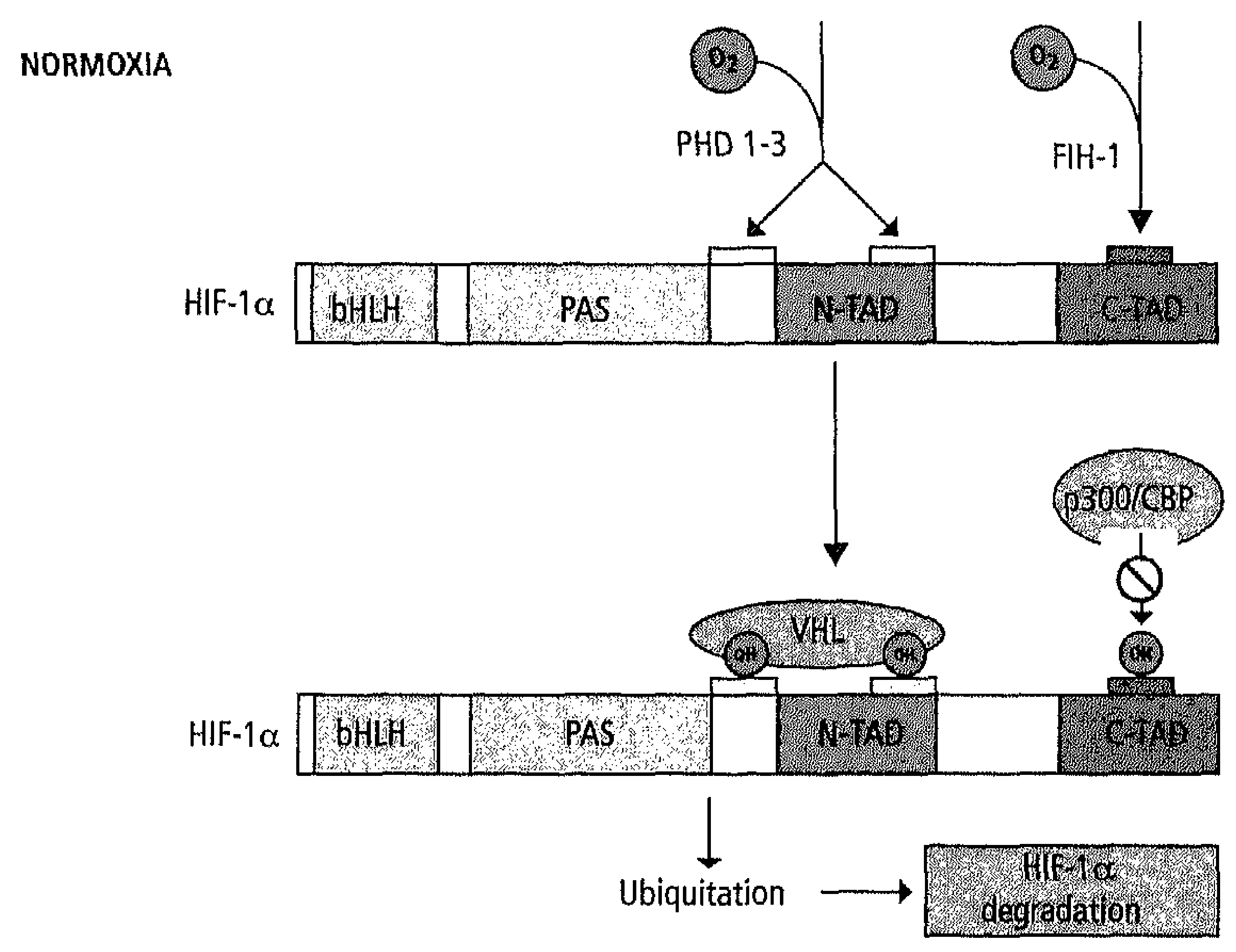

Figure 1 Regulation of $H I F-1 \alpha \cdot$ under normoxic conditions 
modification, binding of HIF- $1 \alpha$ with transcriptional co-activators such as p300 and CAMP-response element-binding protein (CBP) is abrogated. ${ }^{13}$ Thus, the two metabolic sensors, PHD2 through degradation and $\mathrm{FH}-1$ through inactivation of the HIF-1 $\alpha$ subunit, ensure full repression of the HIF-1 pathway in welloxygenated cells.

Under hypoxic conditions, ubiquitination and degradation of the $\alpha$ subunit is inhibited, resulting in dimerization of $H I F-1 \alpha$ with $H I F-1 B$, leading to rapid accumulation of the active HIF-1 protein in the nucleus. ${ }^{14}$ Active HIF-1 protein binds to the hypoxia-responsive element (HRE) present in the promoter region of target genes, resulting in transcription of HIF regulated target genes during hypoxia (Fig. 2). One of the best studied HIF-1 target genes is VEGF.

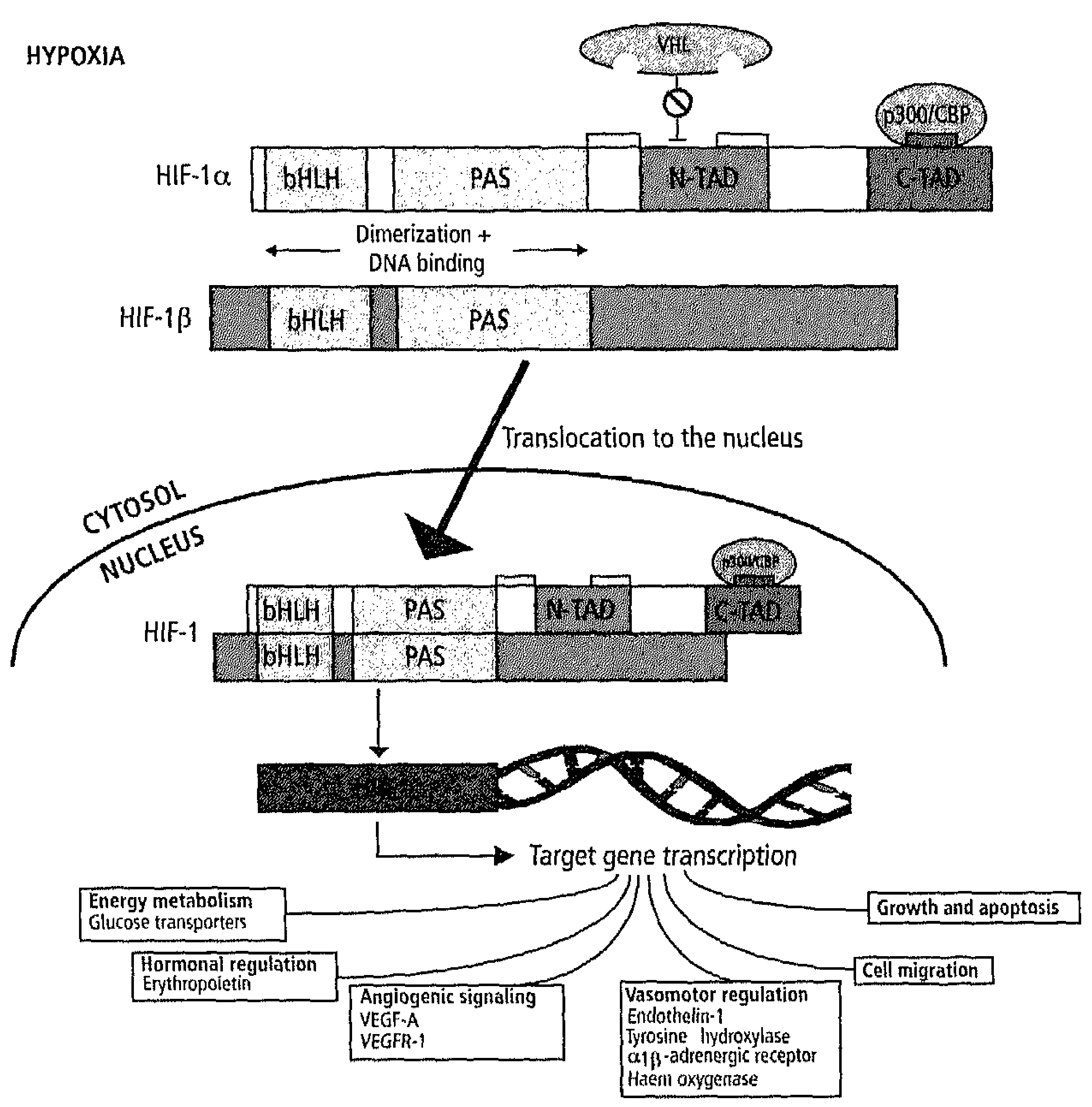

Figure 2 Regulation of HIF-1 $\alpha$ under hypoxic conditions 


\section{Vascular Endothelial Growth Factor}

VEGF is a homodimeric glycoprotein with a molecular weight of approximately $45 \mathrm{kDa}$. VEGF, is a member of the platelet-derived growth factor family. Other family members include placental growth factor (PIGF), VEGF-B, VEGF-C, VEGF-D, VEGF-E, and sVVEGF (snake venom VEGF), all showing variable degrees of homology with VEGF-A.

These family members differ by their tissue distribution and affinities for different VEGF tyrosine kinase receptors: VEGFR-1, VEGFR-1, and VEGFR-3. Furthermore, Neuropilin-1 (NRP1) and NRP2 act as co-receptors for some members of the VEGF family. NRP1 and NRP2 are receptors for Semaphorins, molecules involved in axonal guidance during neuronal development. ${ }^{15,} 16$

VEGFNEGF-receptor complexes have been shown to play a key role in the complex process of angiogenesis that also includes many other angiogenic modulators, stimulators and inhibitors. VEGFR-3 and its ligands VEGF-C and VEGF-D (Fig. 3) are important regulators of lymphangiogenesis. PIGF has been shown to be involved in arteriogenesis, the formation of collateral arteries from pre-existing arterioles. The focus of this chapter will be VEGF-A (also referred to as VEGF).

\section{Regulation of VEGF Expression}

VEGF expression during hypoxia is being accomplished at different levels. First, the HIF-1 pathway mediates the transcriptional activation of VEGF under hypoxic conditions by binding to the HRE in the promoter region of VEGF mRNA. Hypoxia increases the transcriptional rate of VEGF 2 to 3-fold. Hypoxiainducible VEGF expression can be largely abolished by inhibiting HIF- 1 binding, either through mutation of the HRE-binding site or by preventing the heterodimerisation of HIF- $1 \alpha$ with its obligatory partner HIF- $13.17,18$

VEGF mRNA is extremely labile under normoxic condition with a half-life of only 15-40 minutes. Levy et al. showed that hypoxia itself regulates VEGF expression by stabilization of the VEF mRNA 3 to 8 -fold. This increase in MRNA is associated with a commensurate increase in VEGF protein production and release. ${ }^{17}$

VEGF expression is also subject of fast translational regulation, hereby securing efficient production of the protein even under unfavourable stress conditions. This is the third level of VEGF regulation. ${ }^{17}$ 


\section{VEGF-A}

Since the first reports about VEGF describing it as a potent inducer of vascular permeability, ${ }^{19}$ and subsequent cloning of the gene in $1989,{ }^{20,21}$ it is now apparent that VEGF is not just a permeability factor. VEGF-A is a powerful mitogen for endothelial cells, and a regulator of different endothelial functions, including proliferation, sprouting, migration, tube formation, and survival of endothelial cells. ${ }^{22}$ VEGF-A promotes endothelial cell survival by inducing expression of anti-apoptotic factors such as $\mathrm{BCl}-2$ and $\mathrm{A} 1$, through activation of phosphatidylinositol-3 kinase and $\mathrm{BCl}-2$ pathways. ${ }^{23}$ It also plays a crucial role during embryogenesis, but also in numerous physiological and pathological conditions including ocular neovascularisation, tumor progression, endometriosis, and CVD. ${ }^{22}$ VEGF has also vasodilator properties through induction of endothelial nitric oxide (eNOS) and the subsequent increase in nitric oxide (NO) production. ${ }^{24-26}$ Overexpression of VECF-A produces a pronounced strong angiogenic response in different tissues, but the resulting vessels are often large, dilated, and leaky. ${ }^{27-29}$ However most studies have focused on the role of VEGF-A on endothelial cells, actions of VEGF-A on other cell types have also been described.

VEGF-A is also a mitogen for retinal pigment endothelial cells and neuronal Schwann cells. Moreover, VEGF-A has neuroprotective properties in hypoxic motor neurons, and is a modifier of amyotrophic lateral sclerosis. ${ }^{30}$ Furthermore, the role of VEGF-A in vascular smooth muscle cell proliferation and migration has also been described. ${ }^{31}$ VEGF-A is also been reported to induce colony formation by subsets of granulocyte-macrophage progenitor cells and regulate hematopoietic cell survival through a autocrine loop mechanism ${ }^{32}$ and promotes monocyte chemostasis. ${ }^{33}$

VEGF-A mRNA can be spliced in several alternative isoforms. In humans, these isoforms are 121, 144, 165, 189 and 206 amino acids long, with the 165isoform being most predominant. All transcripts contain exons 1 to 5 , and exon 8. Exons 1 to 5 encode for the VEGFR binding sequence (also known as the VEGF/PDGF homology domain). Exon 6 encodes a heparin binding domain, while exons 7 and 8 encode a domain that mediates both NRP1 and heparin binding. VEGF 121 lacks exons 6 and 7, VEGF 165 lacks exon 6, and VEGF 189 is encoded by all 8 exons. The large isoforms $\left(\mathrm{VECF}_{165}, \mathrm{VEGF}_{189}\right.$ and $\left.\mathrm{VEGF}_{206}\right)$ are basic and bind to isolated heparin and heparin proteoglycans on cellular surfaces and extracellular matrix, whereas $V_{E G F}{ }_{121}$ is acidic and is more freely diffusible. 


\section{VEGF RECEPTORS}

The physiological effects of VEGF are mediated through three receptors, VECF receptor-1 (FMS-like tyrosine kinase 1, Flt-1, VEGFR-1), VEGFR-2 (kinase-insert domain receptor, KDR/fetal liver kinase, Flk-1), and VEGFR-3 (FMS-like tyrosine kinase-4, Flt-4), and two co-receptors, NRP1 and NRP2 that lack an intracellular domain (Fig. 3). Guided by the binding properties of the ligands, these receptors are able to form both homodimers and heterodimers ${ }^{34}$ leading to activation of the receptor-kinase activity resulting in autophosphorylation of the receptors. Phosphorylated receptors attract interacting proteins and induce activation of signaling pathways that are involved in cell survival, cell proliferation, cell migration, actin remodeling, vascular permeability, and angiogenesis. In the nervous system NRP1 and NRP2 are know to form dimers with plexin (receptor) and Sema3 (ligands), mediating neuroguidance cues. ${ }^{15}$

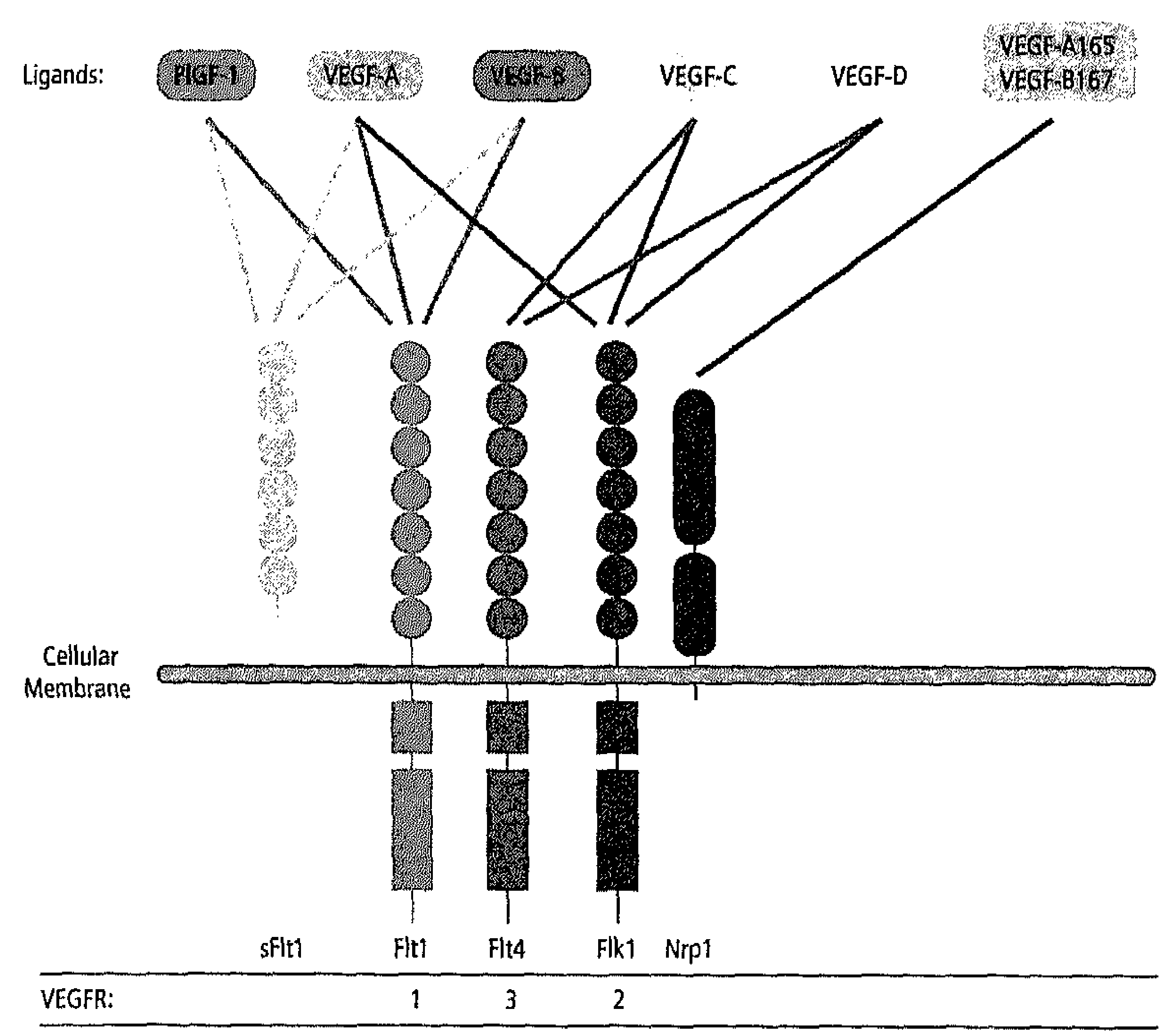

Figure 3 Representation illustrating receptor-binding specificity of VECF family members 


\section{Binding Combinations of VEGF-A to its Receptors}

VEGFR- 1 binds VEGF-A and PIGF-1; VEGFR-2 binds all VEGF-A isoforms, VEGF-C and VEGF-D, and VEGFR-3 binds only VEGF-C and VEGF-D. In addition, the semaphorin class 3 receptors NRP1 and NRP2 act as VEGF coreceptors that selectively bind VEGF ${ }_{165}$. NRP1 appears to function as a VEGFR-2 co-receptor, and selectively assisting the binding of $\mathrm{VEGF}_{165}$ (and none of the other VEGF-A isoforms) allowing its biological effects. ${ }^{35}$ In the nervous system NRP1 is also a co-receptor for Sema3A that binds PlexinA. Sema3A is known as a signaling molecule involved in the development of the nervous system.

\section{VEGFR-1}

VEGFR-1 consists of two forms. A freely diffusible, soluble form without an intracellular domain, and a membrane connected form, which mediates the signal transduction. Both forms are upregulated during hypoxic episodes. The membrane-linked VEGFR-1 is a functional receptor for trophoblasts, mediating nitric oxide release, and for monocytes/macrophages, mediating expression of tissue factor, chemotaxis, and transmigration through endothelial cells. VEGFR-1 and VEGFR-2 are structurally highly similar, but their biochemical features are very different. VEGFR-1 has a 10-fold higher affinity for VEGF-A than VEGFR-2, but its kinase activity is 10 times lower than that of VEGFR-2. ${ }^{36-38}$

The physiological role of VEGFR-1 was studied in different transgenic models. In the first model, the tyrosine kinase (TK) of VEGFR-1 was deleted (VEGFR-1 ${ }^{\text {TK-I- }}$ ). This transgenic model revealed that the TK domain of VEGFR-1 is dispensable for embryonic angiogenesis and development, thus questioning the role of this receptor as a signaling tyrosine kinase. ${ }^{39}$ This suggests that VEGFR-1 performs its role in angiogenesis primarily as a decoy to regulate the bioavailability of VEGF for VEGFR-2 during development. To further clarify the role of VEGFR-1 in angiogenesis and development, the transmembrane (TM) domain of VEGFR-1 was ablated resulting in a truncated VEGFR-1 (VEGFR-1 ${ }^{\text {TMTK }^{-1}}$ ). The TM of VEGFR-1 is important for embryonic development since $50 \%$ of the mouse embryos died due to vascular defects. ${ }^{40}$ Knocking out the entire VEGFR-1 gene (VEGFR- $1^{-1}$ ) resulted in embryonic lethality around between E8.5 and E9 due to excessive formation of differentiated endothelial cells that coalesce in a disorganised vascular network (Table 1). ${ }^{41}$

Blocking VEGFR-1 signaling using an antibody, suppresses neovascularisation in tumors and ischemic retinas. ${ }^{42}$ Administration of PIGF/VEGF-A recombinant heterodimers or a combination of VEGF-A and PIGF increased angiogenesis in ischemic myocardium to a higher extent than VEGF-A alone. ${ }^{43}$ This enhanced angiogenesis can be attributed to the formation of VEGFR- 
1NEGFR-2 heterodimers which can induce a greater angiogenic response than the respective homodimers alonve, suggesting that VEGFR-1 acts as an amplifier of VEGFR-2 signalling (Table 1).43

\section{VEGFR-2}

VEGFR-2 is the earliest marker of angioblast precursors and the major receptor for VEGF-A. VEGFR-2 is expressed in primitive endothelial cells and subsequently in most capillaries in developing organs, but also by circulating endothelial progenitor cells, pancreatic ductus cells, retinal progenitor cells, and megakaryocytes. ${ }^{22}$ VEGFR-2 induces intracellular signaling and mediates endothelial proliferation, migration, survival, and vascular permeability. VEGFR-2 expression increases during hypoxia. ${ }^{44}$ This thesis shows that VEGFR2 is overexpressed in response to hypoxia in cardiomyocytes in both the chick embryo and the human fetus (Chapter 5).

VEGFR- ${ }^{-/-}$mice die in utero at E8.5 due to complete absence of organized blood vessels or haematopoietic cells. ${ }^{45,}{ }^{46}$ The observation that lack of VEGFR-2 results in a different phenotype in VEGF-A ${ }^{-/-}$mice, suggesting the involvement of different, unidentified VEGF-related ligands, or rescue by maternal VEGF (Table 1).

\section{VEGFR-3}

VEGFR-3 is expressed in the early embryo in blood vessels. It is also the most specific marker of lymphatic vessels in normal and pathological conditions, and has been shown to be active during lymphangiogenesis.

VEGFR $-3^{-1}$ mice die around E12.5 due to impaired remodeling of the expanding embryonic vasculature without disrupting vasculogenesis and angiogenic sprouting (Table 1). ${ }^{47}$ These findings suggest its involvement in the development of the vascular system before its role in lymphangiogenesis.

\section{Neuropilins}

NRP1 and NRP2 are key players in neuronal development during embryogenesis but are also involved in angiogenesis. ${ }^{48}$ Neuropilins are co-receptors for class 3 semaphorins, molecules that mediate repulsive signals during neuronal axon guidance. NRP1 also binds VEGF 165 , and acts as a co-receptor enhancing VEGF-A/VEGFR-2 interactions. Chimeric mice overexpressing NRP1, show excessive formation of capillaries and blood vessels and hemorrages in addition to cardiac malformations (Table 1). ${ }^{49}$ It is postulated that NRP1 is required for cardiovascular development because it could regulate the bioavailability of VEGF $_{165}$ for VEGFR-2. It has been shown that in chick embryos NRP1 is mostly 
expressed in arterial endothelial cells, whereas NRP2 mostly marks venous endothelial cells. ${ }^{50} \mathrm{NRP} 2$ has also been shown to be expressed lymphatic endothelial cells, and NRP2 ${ }^{-\%}$ mice display abnormalities in the formation of small lymphatic vessels and lymphatic capillaries (Table 1). ${ }^{51}$

\section{VeGF-A in Cardiovascular Pathology}

VEGF-A expression is increased in ischemic tissue, as has been demonstrated in various clinical conditions, including ischemic heart disease, peripheral artery disease, and cerebral ischemia. ${ }^{18,52}$ Current therapies are aimed at stimulating angiogenesis in ischemic tissue by either stimulating VEGF-A expression or by direct delivery of VEGF-A to the tissue. ${ }^{53}$ Congruent with its effect in the ischemic heart, application of VEGF also improves neurological outcome after cerebral ischemia. ${ }^{54}$

\section{Depletion of VEGF-A Leads to Cardiovascular Dysfunction}

Homozygous VEGF-A knockout mice die between E8 and E9 due to severe cardiovascular dysfunction. Heterozygous VEGF-A mice die between E11 and E12 due to compromised endothelial proliferation and differentiation which prevents the establishment of a normal circulatory system and leads to tissue necrosis and lethality (Table 1). ${ }^{55,56}$

To investigate the specific role of VEGF in cardiac development, Giordano et al. generated a cardiomyocyte-specific VEGF knock-out mouse (cmVEGF-null). ${ }^{57}$ This deletion resulted in viable mice with loss of all cardiac VEGF-A isoforms. These mice displayed thin-walled, dilated, hypovascular hearts, contractile dysfunction, and reduced body weight. Contrary to VEGF-A $A^{+/-}$and VEGF-A ${ }^{-1}$ mice, the cmVEGF-null mice appeared entirely normal, had normal aorta and coronary macrovasculature, and apart from a reduced number of microvessels, no significant histological abnormalities in the myocardium at E13.5 or adulthood were observed (Table 1). ${ }^{57}$ This suggests that secretion of VEGF by non-myocytes in the heart tissue can partially rescue cardiac development. Further analysis revealed the role of cardiomyocytes as secretory cells, and determined that the myocardium is the major source of VEGF in the heart. ${ }^{57}$ Since the hearts are hypovascular, the contractile dysfunction observed in the hearts of the cmVEGF-null adult mice could be due to ischemia-induced myocardial dysfunction. Severe prolonged myocardial ischemia can lead to increased cardiomyocyte necrosis and impaired contractile function. However, cmVEGF-null hearts do not show evidence of necrosis or fibrosis suggesting that 
the left ventricular pump dysfunction may be a form of myocardial stunning or hibernation, similar to that seen in some patients with coronary artery disease. ${ }^{58,}$ ${ }^{59}$ On the other hand, the possibility of impaired embryonic development and postnatal cardiac growth leading to contractile dysfunction should also be considered. These thin-walled and dilated left ventricles might have a starting mechanical disadvantage based primary on their morphology. This implies that a single gene defect in the heart alone can affect the whole body growth. In this manner, early cardiac development may define adult heart function. ${ }^{57}$

In order to further investigate the role of HIF- $1 \alpha$-induced VEGF expression during cardiovascular development, a HIF-1 $\alpha$ knockout mouse model was used. Some HIF-1 $\alpha^{-/}$embryos displayed cardia bifida, while cardiac looping was disturbed in others. These defects did not result from abnormal cardiomyocyte differentiation. It is postulated that these defects relate to defective ventricle formation caused by reduced expression of myocyte enhancer factor $2 \mathrm{C}$ and the basic helix-loop-helix transcription factor eHAND. Additionally, aortic oufflow tract formation and cephalic blood vessels were abnormal in HIF- $1 \alpha^{-1 /}$ embryos. These malformations could be induced by defective migration of the neural crest cells. Impaired migration of the neural crest cells might be related to insufficient levels of Sema3A in HIF-1 $\alpha^{-1-}$ embryos. Survival of these embryos could partially be rescued by hyperoxia. Thus, HIF-1 $\alpha$ could be of crucial essence for proper cardiac development by modulating both neural crest migration and ventricle formation. ${ }^{60}$

In a following study the hypoxia responsive element (HRE) of the VEGF gene was disabled (VEGF-A ${ }^{\delta / \delta}$ mouse). Due to the loss of the HRE region, hypoxia-induced HIF-1 is not capable anymore to bind the promoter region of the VEGF gene during ischemic or hypoxic episodes, hereby inhibiting HIF-1 induced VEGF-A expression. VEGF-A ${ }^{\delta / \delta}$ mice develop a motor neuron disease similar to amyotrophic lateral sclerosis (ALS) in humans, suggesting that motor neurons are particularly sensitive to reductions in the levels of VEGF. ${ }^{61}$ The neurodegeneration seemed to be due to reduced neural vascular perfusion. Additionaly, Oosthuyse et. al showed that administration of $\mathrm{VEGF}_{165}$ promoted survival of motor neurons during hypoxia through binding VEGFR-2 and NRP1. ${ }^{61}$ More recently, it has been shown that single intramuscular injections of a VEGF-expressing lentiviral vector delayed the onset and slowed the progression of ALS in VEGF-A $A^{\delta / \delta}$ mice. ${ }^{62}$ On the other hand, Shiote et al. showed in vivo that inhibiting VEGFR-2 expression by using antisense oligodeoxynucleotides against the VEGFR-2 motor neuron loss could be induced in the rat spinal cord. ${ }^{63}$ These findings suggest a direct role of VEGF in neuroprotection, and the involvement of VEGFR-2 into mediating this response. 


\section{Increased Levels of VEGF-A in Cardiovascular Pathologies}

Modest overproduction of VEGF-A in mice (VEGF lacZ-KI) lead to aberrant coronary development, cardiac failure and embryonic lethality at E12.5-14 (Table 1). ${ }^{64}$ This phenotype was furthermore characterized by heart malformations that affected septation, development of the myocardium and development of the coronary vasculature. ${ }^{64}$

Moreover, Dor et al. conditionally induced VEGF overexpression in the myocardium using a tetracycline-regulated transgenic system. Switching the myocardial VEGF over-production "on" during different stages of the embryonic

Table1

\begin{tabular}{|c|c|c|}
\hline Genotype & Phenotype & Reference \\
\hline VEGF $=A^{+1}$ & Embryonic lethality at E10-11, defective vascular development & 55 \\
\hline VEGF-A & Embryonic lethality at E8.5-9.5, more severe defects in vascular development & 55,56 \\
\hline VEGF-A $^{120 / 120}$ & $\begin{array}{l}50 \% \text { die shortly after birth due to multiple organ hemorages. } \\
\text { Surviving embryos die before P14 due to cardiac failure, } \\
\text { impaired myocardial angiogenesis, ischemic cardiomyopathy, skeletal defects, } \\
\text { defects in vascular outgrowth, and patterning of the retina. }\end{array}$ & $73-76$ \\
\hline VEGF-A $^{164 / 164}$ & Viable and healthy. & 73 \\
\hline VEGF-A $^{1881188}$ & $\begin{array}{l}\text { Viable, but impaired retinal arterial development, dwartism, } \\
\text { defective epiphisal vascularisation, impaired development of growth plates } \\
\text { and secondary ossification centers, as well as knee joint dysplasia. }\end{array}$ & 73,74 \\
\hline cmVEGF-null & $\begin{array}{l}\text { Viable, but thin-walled, dilated, and hypovascular hearts, } \\
\text { contractile dysfunction, and reduced body weight. }\end{array}$ & 57 \\
\hline $\begin{array}{l}\text { VEGF*A } \\
\text { overexpression }\end{array}$ & $\begin{array}{l}\text { Embryonic lethality, aberrant coronary development, cardiac failure, } \\
\text { extreme thining of the atrial wall, impaired formation of ventricular rtabeculae, }\end{array}$ & $64,66-69$ \\
\hline VEGFR-1\% & $\begin{array}{l}\text { Embryonic lethality between E8.5-9.5, elevated hemangioblast commitmant, } \\
\text { and vascular disorganisation due to endothelial-cell overgrowth. }\end{array}$ & 41 \\
\hline VEGFR-1 TK- & Normal development, decreased tumor angiogenesis. & 39 \\
\hline VEGFR-1 TMTK- - & $50 \%$ of the mice die during embryonic development due to vascular defects. & 40 \\
\hline VEGFR- $2 \%$ & Embryonic lethality due to impaired blood-island formation and angiogenesis. & 45,46 \\
\hline VEGFR-3\% & $\begin{array}{l}\text { Embryonic lethality at E12.5-E14 before formation of lymphatics due } \\
\text { to cardiovascular failure. Embryos show signs of pericardial oedema } \\
\text { and vascular remodelling defects. }\end{array}$ & 47 \\
\hline $\begin{array}{l}\text { Nrp-1 } \\
\text { overexpression }\end{array}$ & $\begin{array}{l}\text { Cardiovascular defects, heart malformation, excessive blood-vessel formation, } \\
\text { dilated blood-vessles, haemorrhage, anomalities in nervous system and limbs. }\end{array}$ & 49 \\
\hline
\end{tabular}


development, resulted in heart abnormalities that resemble human congenital defects, ${ }^{65}$ including extreme thinning of the atrial wall and impaired formation of ventricular trabeculae (Table 1). ${ }^{66}$

In order to evaluate the role of VEGF overexpression in the adult murine heart, Dor et al. used the same tetracycline-regulated transgenic system which was able to selectively switch VEGF on and off in the adult mouse heart. As long as the VEGF expression stimulus was active, exaggerated angiogenic responses and destruction of normal cardiac architecture were noted. Nonetheless, adequate regulation of VEGF regulation induced a long-term improvement of organ perfusion, suggesting a possible therapeutic role of VEGF in the management of ischemia-induced heart damage. The drawback of this putative effect of VEGF is that VEGF levels sufficient for induction of new vessels also cause severe tissue edema. ${ }^{67}$

In an avian model using quail embryos, administration of VEGF, hereby increasing endogenous VEGF levels, led to a higher mortality, and more moribund embryos. The heartbeat of the VEGF-treated moribund embryos was weak and irregular. At structural level, the hearts of the VEGF-treated quail embryos displayed dilated atria and thin walled ventricles comparable with VEGF overexpressing mouse embryonic hearts described above. Additionally, the perineural vascular plexus was affected as characterised by dilatation of the vasculature. The venous area of the vasculature is more affected by VEGF overexpression than the arterial one, leading to severe embryonic malformations of the venous system (Table 1). ${ }^{68}$ Moreover, overexpression of VEGF in the limb bud of the quail embryo exclusively resulted in hypervascularization as reflected by an increase in vascular density and a markedly increase in vascular permeability, leading to edema. ${ }^{69}$

In line with these findings, we show that excessive VEGF-A in the chick embryo is deleterious for cardiac development (Chapter 5). Chick embryos exposed to mild hypoxia $\left(15 \% \mathrm{O}_{2}\right)$ throughout development show increased expression of VEGF-A mRNA. Additionally, the hypoxic embryos displayed dilated left ventricles, loss of contractile function, elevated levels of the heart failure biomarker ANF, glycogen accumulation, cardiomyocyte apoptosis, and disarray of cardiomyocyte myofibrils just before hatching. This study showed that fetal hypoxia induces cardiomyopathy prenatally.

Based on these studies it is now well established that VEGF plays a pivotal role in several essential parts of cardiovascular remodelling including morphogenesis of the vascular system, the heart, and the nervous system. Extrapolating these findings to the human situation, we postulate that heart development might be disturbed at functional and structural level due to hypoxic insults associated with excessive and badly timed VEGF production. 


\section{VEGF-A Involvement in Cardiac Function}

Cardiac contractility is regulated tightly as an essential homeostatic mechanism. ${ }^{70,71}$ Some of the control is neuro-humoral, but much appears intrinsic to the heart. Several research groups have shown that VEGF, besides its role in angiogenesis, also is a regulator of cardiac function in the adult and the fetus. All these studies emphasise the importance of tight regulating VEGF expression.

In zebrafish and rat neonatal cardiomyocytes it has been postulated that VEGF-A regulates cardiac contractility through the phopholipase $C_{\gamma} 1$ (PLC $\gamma 1$ ) pathway in a VEGFR-1 dependent manner. Blocking VEGF-PLC 1 signaling, decreases calcium transients in rat neonatal cardiomyocytes, whereas VEGF-A administration not only restored, but increased calcium transients. ${ }^{72}$

Recently, we showed that incubation with $V_{E G F}{ }_{16,5}$ isoform but not $V_{E G F}{ }_{121}$ or VEGF family member PIGF-1, has a direct negative inotropic effect on the contractile capacity of left ventricular muscle bundles originating from normoxic chick embryos. The negative inotropic effect of $V_{E G F}{ }_{165}$ was abolished by blocking VEGFR-2 with the tyrosine-kinase inhibitor (SU5416). This indicates that VEGFR-2 signaling is crucial for VEGF 165 action. The marked difference in effect of VEGF 165 and $V E G F_{121}$ on cardiac contractility may reflect the inability of VEGF 121 and PIGF-1 to bind NRP1. Keeping that in mind, and that the angio-architecture is not disrupted in the hypoxic chick embryos, we suggest that VEGF-A can modulate embryonic cardiomyocyte function directly, independent of angio-architecture or oxygen tension (Chapter 5).

To test the critical involvement of excessive VEGF-A levels in the hypoxic chick embryo, we reduced its biological availability by scavenging with soluble VEGFR receptor 1 (sFlt-1). Prenatal treatment of hypoxic chick embryos with sFlt-1 prevented the hypoxia-evoked left ventricular dilatation, restored cardiac contractility and improved survival (Chapter 5). This shows that hypoxia associated elevated VEGF-A levels during intra uterine development may initiate cardiomyopathy.

\section{Role of VEGF-A Splice Isoforms During Cardiovascular Development}

To further elucidate the role of VEGF-A, isoforms transgene mouse models have been developed: VEGF ${ }^{120 / 120}$ (expressing only VEGF ${ }^{121}$ ), $\operatorname{VEGF}^{165 / 165}$, and VEGF ${ }^{188 / 188}$. VEGF-A ${ }^{164 / 164}$ mice are viable, healthy, and fertile (Table 1). ${ }^{73}$ The retinal vascular development was normal in VEGF ${ }^{165 / 165}$ mice when compared with wild-type mice. This indicates that this isoform contains all necessary information for normal outgrowth and remodelling of blood vessels. 
A fraction of the VEGF-A ${ }^{188 / 188}$ mice died in utero (Table 1). The surviving mice were lighter, less fertile and had smaller litter sizes when compared with wild type mice. VEGF- $A^{188 / 188}$ mice have impaired retinal arterial development. By $\mathrm{P} 5$, only half of the normal number of blood vessels was present in the retina. Since these vessels did not express ephrin-B2 (a well established arteriolar marker) or smooth muscle actin, they were morphologically identified as venules. At P6 however, ephrin-B2 was detected in rudimentary retinal arterioles, suggesting that arterial specification was delayed but not lost. At P9 only the half of the normal arterioles was developed and the retina was smaller in size than a control retina. In contrast to the arterial defects, VECF ${ }^{188 / 188}$ mice displayed largely normal venous and capillary development. The venules were somewhat enlarged and capillary pruning was decreased, possibly due to arterial underdevelopment and abnormal retinal perfusion. In addition to this vascular phenotype, VEGF $188 / 188$ mice showed signs of dwarfism, defective epiphyseal vascularization, impaired development of the growth plates and secondary ossification centres, and knee-joint dysplasia. ${ }^{73,74}$

Approximately $50 \%$ of VEGF-A $\mathrm{A}^{120 / 120}$ mice die within few hours after birth due to hemorrhages in multiple organs (Table 1). The surviving VEGF-A $A^{120 / 120}$ mice die before P14 owing to impaired myocardial angiogenesis and cardiac failure. They also displayed severe vascular defects, with impaired venous and severely defective arterial development in the retina. The capillaries were dilated and fragile, causing hemorrhages. Furthermore, endothelial cell outgrowth was impaired, affecting all vessel types. In addition to these vascular abnormalities, VEGF-A $A^{120 / 120}$ mice displayed also skeletal defects. ${ }^{73-76}$ Besides these abnormalities, VEGF-A ${ }^{120 / 120}$ mice had enlarged hearts, irregular heart beats, impaired left ventricular contraction and relaxation, and impaired myocardial angiogenesis. These mice also show many features of ischemic cardiomyopathy also seen in patients, including more than $75 \%$ reduction in myocardial perfusion, more severe ischemia in the subendocardial layers and upregulation of hypoxia-inducible genes. ${ }^{77,78}$

The observation that the vascular bed was normal in VEGF-A ${ }^{164 / 164}$ and aimost normal in VEGF-A $A^{188 / 188}$ mice but severely impaired in VEGF-A ${ }^{120 / 120}$ mice, may be due to the fact that $\mathrm{VEGF}_{120}$ is less potent in inducing endothelial cell mitosis ${ }^{79}$ or has reduced affinity for VEGFR-1 ${ }^{80}$ hereby affecting endothelial cell function, survival, and outgrowth. Additionally, the increased solubility and of VEGF 121 and its inability to bind to NRP1 could also account for these vascular abnormalities. Furthermore, the disturbed myocardial angiogenesis and cardiac function in VEGF-A $\mathrm{A}^{120 / 120}$ mice is also the result of loss of VEGF 165 and $V E G F_{188}$ together with the biochemical properties of $V_{E G F}{ }_{121}$. 
In order to create a mature, functional arterial-venous network correct patterning of blood vessels is essential. At molecular level the patterning mechanism is not fully understood. Recently it has been demonstrated that endothelial cells on the vessel sprouts possess filopodia that scan the environment for guidance cues. ${ }^{81}$ These highly specialized endothelial cells are referred to as tip cells. VEGF-A is an attractant cue for tip cells and thus engages endothelial cells to migrate and differentiate. Recently, it has been shown that VEGF-A gradients in the extracellular matrix are necessary in order for filopodia to extend and tip cells to move towards their destination. These gradients are formed by $\mathrm{VEGF}_{164}$ in the developing mouse retina and are distributed mainly along astrocytes, hereby forming a gradient trail which tip cell filopodia can follow. $^{73}$

There are several possible explanations for the defective arterial growth in VEGF $^{188 / 188}$ mice. First, the VEGF ${ }_{188}$ isoform might be unable to provide special guidance or differential cues for retinal arteriolar endothelial cells due to its association with the extracellular matrix. Second, the shorter isoforms are capable of stimulation angioblasts at an earlier stage to form blood vessels. A third possibility relies on the potency of the short isoforms to induce expression of arterial markers such as $\mathrm{Bmx}^{82}$ and DIl4. ${ }^{83}$

The impaired retina vascularisation and myocardial angiogenesis observed in the VEGF-A ${ }^{120 / 120}$ mice could be the result of diffuse distribution of $V_{E G F}{ }_{120}$ due to its solubility. This results in the absence of growth factor gradient trail which filopodia could follow, and random migration of endothelial cells could take place. In addition, the filopodia of VECF-A $A^{120 / 120}$ mice are fewer in number, shorter, extend slower, and extend in several directions, hereby partially explaining the observed phenotype. Thus, accurate distribution of the different VEGF-A isoforms, especially VEGF ${ }_{165}$, is crucial for the development of a vascular network in the retina and in the heart. In other organs, the functional differences between the three major VEGF-A isoforms are not well described yet. In Chapter 5 of this thesis we will present the contribution of the VEGF 121 and $V E G F_{165}$ isoforms in cardiac contractility and the roles of different $V E G F$ receptors herein. 


\section{REFERENCES}

1. Wang CL, Semenza Gl. General involvement of hypoxia-inducible factor 1 in transcriptional response to hypoxia. Proc Natl Acad Sci U S A 1993;90(9):4304-8.

2. Wang GL, Semenza GL. Purification and characterization of hypoxia-inducible factor 1. ) Biol Chem 1995;270(3):1230-7.

3. Schofield C), Ratcliffe PJ. Oxygen sensing by HIF hydroxylases. Nat Rev Mol Cell Biol 2004;5(5):343-54.

4. Jiang BH, Rue E, Wang GL, Roe R, Semenza GL. Dimerization, DNA binding, and transactivation properties of hypoxia-inducible factor 1. I Biol Chem $1996 ; 271(30): 17771-8$

5. Pouyssegur 1, Dayan F, Mazure NM. Hypoxia signalling in cancer and approaches to enforce tumour regression. Nature 2006:441(7092):437-43.

6. Sulter $\mathrm{CH}$, Laughner $\mathrm{E}$, Semenza GL. Hypoxia-inducible factor 1alpha protein expression is controlled by oxygen-regulated ubiquitination that is disrupted by deletions and missense mutations. Proc Natl Acad Sci U S A 2000;97(9):4748-53.

7. Berra $E$, Benizri $E$, Ginouves A, Volmat V, Roux D, Pouyssegur f. HIF prolyl-hydroxylase 2 is the key oxygen sensor setting low steady-state levels of HIF-1alpha in normoxia. Embo ) 2003;22(16):4082-90.

8. Berra E, Ginouves A, Pouyssegur ). The hypoxia-inducible-factor hydroxylases bring fresh air into hypoxia signalling. EMBO Rep 2006;7(1):41-5.

9. Maxwell PH, Wiesener MS, Chang CW, et al. The tumour suppressor protein VHL targets hypoxia-inducible factors for oxygen-dependent proteolysis. Nature 1999;399(6733):271-5.

10. Maxwell PH, Pugh CW, Ratcliffe PJ. Activation of the HIF pathway in cancer. Curr Opin Genet Dev 2001;11(3):293-9.

11. Berra E, Richard DE, Gothie E, Pouyssegur J. HIF-1-dependent transcriptional activity is required for oxygen-mediated HIF-1 alpha degradation. FEBS Lett 2001;491(1-2):85-90.

12. Lando D, Peet DJ, Gorman J), Whelan DA, Whitelaw ML, Bruick RK. FIH-1 is an asparaginyl hydroxylase enzyme that regulates the transcriptional activity of hypoxiainducible factor. Genes Dev 2002;16(12):1466-71.

13. Ema M, Hirota K, Mimura l, et al. Molecular mechanisms of transcription activation by HLF and HIFlalpha in response to hypoxia: their stabilization and redox signal-induced interaction with CBP/p300. Embo / 1999;18(7):1905-14.

14. Semenza GL. HIF-1, O(2), and the 3 PHDs: how animal cells signal hypoxia to the nucleus. Cell 2001;107(1):1-3.

15. Kolodkin AL, Levengood DV, Rowe EG, Tai YT, Giger RJ, Ginty DD. Neuropilin is a semaphorin III receptor. Cell 1997;90(4):753-62. 
16. Chen H, Chedotal A, He Z, Goodman CS, Tessier-Lavigne M. Neuropilin-2, a novel member of the neuropilin family, is a high affinity receptor for the semaphorins Sema $\mathrm{E}$ and Sema IV but not Sema III. Neuron 1997;19(3):547-59.

17. L.evy AP. Hypoxic Regulation of VEGF mRNA Stability by RNA-binding Proteins. Trends Cardiovasc Med 1998;8(6):246-50.

18. Levy AP, Levy NS, Loscalzo l, et al. Regulation of vascular endothelial growth factor in cardiac myocytes. Circ Res 1995;76065:758-60.

19. Senger DR, Galli SI. Dvorak AM, Perruzzi CA, Harvey VS, Dvorak HF. Tumor cells secrete a vascular permeability factor that promotes accumulation of ascites fluid. Science 1983;219(4587):983-5.

20. Leung DW, Cachianes $C_{1}$, Kuang WJ, Goeddel DV, Ferrara N. Vascular endothelial growth factor is a secreted angiogenic mitogen. Science 1989;246(4935):1306-9.

21. Keck PJ, Hauser SD, Krivi $G$, et al. Vascular permeability factor, an endothelial cell mitogen related to PDCiF. Science 1989;246(4935):1309-12.

22. Ferrara N, Gerber HP, LeCouter J. The biology of VEGF and its receptors. Nat Med 2003;9(6):669-76.

23. Gerber HP, Dixit V, Ferrara N. Vascular endothelial growth factor induces expression of the antiapoptotic proteins $\mathrm{BCl}-2$ and $\mathrm{A} 1$ in vascular endothelial cells. J Biol Chem 1998;273(21):13313-6.

24. Hood ID, Meininger CJ, Ziche M, Granger HJ. VEGF upregulates ecNOS message, protein, and NO production in human endothelial cells. Am ) Physiol 1998;27413 Pt 2):H1054-8.

25. Kroll J, Waltenberger I. A novel function of VEGF receptor-2 (KDR): rapid release of nitric oxide in response to VEGF-A stimulation in endothelial cells. Biochem Biophys Res Commun 1999;265(3):636-9.

26. Ahmad S, Hewett PW, Wang $P$, et al. Direct evidence for endothelial vascular endothelial growth factor receptor- 1 function in nitric oxide-mediated angiogenesis. Circ Res 2006;99(7):715-22.

27. Bhardwaj $S$, Roy $H$, Gruchala $M$, et al. Angiogenic responses of vascular endothelial growth factors in periadventitial tissue. Hum Gene Ther 2003;14(15):1451-62.

28. Rissanen TT, Markkanen IE, Gruchala $M$, et al. VEGF-D is the strongest angiogenic and lymphangiogenic effector among VEGFs delivered into skeletal muscle via adenoviruses. Circ Res 2003;92(10):1098-106.

29. Rissanen TT, Rutanen I, Yla-Herttuala S. Gene transfer for therapeutic vascular growth in myocardial and peripheral ischemia. Adv Genet 2004;52:117-64.

30. Takahashi H, Shibuya M. The vascular endothelial growth factor (VEGF)/NEGF receptor system and its role under physiological and pathological conditions. Clin Sci (Lond) 2005;109(3):227-41. 
31. Bhardwaj S, Roy H, Heikura T, Yla-Herttuala S. VEGF-A, VEGF-D and VECiFD(DeftaNDeltaC) induced intimal hyperplasia in corotid arteries. Eur I Clin Invest 2005;35(11):669-76.

32. Gerber IIP, Malik AK, Solar GP, et al. VEGF regulates haematopoietic stem cell survival by an internal autocrine loop mechanism. Nature 2002;41716892):954-8.

33. Clauss $M$, Gerlach $M$, Gerlach $H$, et al. Vascular permeability factor: a tumor-derived polypeptide that induces endothelial cell and monocyte procoagulant activity, and promotes monocyte migration. I Exp Med 1990;172(6):1535-45.

34. Dixclius J, Makinen T, Wirzenius $M$, et al. Ligand-induced vascular endothelial growth factor receptor-3 (VEGFR-3) heterodimerization with VEGFR-2 in primary lymphatic endothelial cells regulates lyrosine phosphorylation sites. I Biol Chem 2003;278(42):40973-9.

35. Soker S, Takashima S, Miao HQ, Neufeld G, Klaysbrun M. Neuropilin-1 is expressed by endothelial and tumor cells as an isoform-specific receptor for vascular endothelial growth factor. Cell 1998;92(6):735-45.

36. Ferrara N, Davis-Smyth T. The biology of vascular endothelial growth factor. Endocr Rev 1997;18(1):4-25.

37. Shibuya M. Role of VEGF-flt receptor system in normal and tumor angiogenesis. Adv Cancer Res 1995;67:281-316.

38. Mustonen T, Alitalo K. Enclothelial receptor tyrosine kinases involved in angiogenesis. J Cell Biol 1995;129(4):895-8.

39. Hiratsuka S, Minowa O, Kuno J, Noda T, Shibuya M. Flt-1 lacking the tyrosine kinase domain is sufficient for normal development and angiogenesis in mice. Proc Natl Acad Sci U S A 1998;95(16):93499-54.

40. Hiratsuka S, Kataoka Y, Nakao K, et al. Vascular endothelial growth factor A (VEGF-A) is involved in guidance of VEGF receptor-positive cells to the anterior portion of early embryos. Mol Cell Biol 2005;25(1):355-63.

41. Fong $\mathrm{GH}$, Zhang $\mathrm{L}$, Bryce DM, Peng J. Increased hemangioblast commitment, not vascular disorganization, is the primary defect in flt-1 knock-out mice. Development 1999;126(13):3015-25.

42. Luttun A, Tjwa M, Moons $L$, et al. Revascularization of ischemic tissues by PIGF treatment, and inhibition of tumor angiogenesis, arthritis and atherosclerosis by antiFlt1. Nat Med 2002;8(8):831-40.

43. Autiero $M$, Waltenberger J, Communi $D$, et al. Role of PlGF in the intra- and intermolecular cross talk between the VEGF receptors Flt1 and FIk1. Nat Med 2003;9(7):936-43.

44. Brusselmans K, Bono F, Collen D, Herbert MM, Carmeliet P, Dewerchin M. A novel role for vascular endothelial growth factor as an autocrine survival factor for embryonic stem cells during hypoxia. J Biol Chem 2005;280(5):3493-9. 
45. Shalaby F, Rossant J, Yamaguchi TP, et al. Failure of blood-island formation and vasculogenesis in Flk-1-deficient mice. Nature 1995;376665351:62-6.

46. Shalaby $\mathrm{F}, \mathrm{HO}$ l, Stanford $W \mathrm{~L}$, et al. A requirement for $\mathrm{Flkl}$ in primitive and definitive hematopoiesis and vasculogenesis. Cell 1997;89(6):981-90.

47. Dumont DJ, Jussila L, Taipale f, et al. Cardiovascular failure in mouse embryos deficient in VEGF receptor-3. Science 1998;282(5390):946*9.

48. Klagsbrun $M$, Takashima $S$, Mamluk R. The role of neuropilin in vascular and tumor biology. Adv Exp Med Biol 2002;515:33-48.

49. Kitsukawa $T$, Shimono A, Kawakami A, Kondoh H, Fujisawa H. Overexpression of a membrane protein, neuropilin, in chimeric mice causes anomalies in the cardiovascular system, nervous system and limbs. Developmenl 1995;121(12):4309-18.

50. Herzog $Y$, Kalcheim C, Kahane N, Reshef R, Neufeld G. Differential expression of nouropilin-1 and neuropilin-2 in arteries and veins. Mech Dev 2001;109(1):115-9.

51. Yuan L, Moyon D, Pardanaud L, et al. Abnormal lymphatic vessel development in neuropilin 2 mutant mice. Development 2002;129(20):4797-806.

52. Kovacs Z, Ikezaki K, Samoto K, Inamura T, Fukui M. VEGF and flt. Expression time kinetics in rat brain infarct. Stroke 1996;27(10):1865-72; discussion 72-3.

53. Hayashi T, Abe K, Itoyama Y. Reduction of ischemic damage by application of vascular endothelial growth factor in rat brain after transient ischemia. I Cereb Blood Flow Metab 1998; 18(8):887-95.

54. Zhang ZG, Zhang L, liang Q, et al. VEGF enhances angiogenesis and promotes bloodbrain barrier leakage in the ischemic brain. I Clin Invest 2000;106(7):829-38.

55. Carmeliet $P$, Ferreira $V, B r e i e r ~ G$, el al. Abnormal blood vessel development and lethality in embryos lacking a single VEGF allele. Nature 1996;380(6573):435-9.

56. Ferrara $\mathrm{N}$, Carver-Moore $\mathrm{K}$, Chen $\mathrm{H}$, et al. Helerozygous embryonic lethality induced by targeted inactivation of the VEGF gene. Nature 1996;380(6573):439-42.

57. Giordano Fl, Gerber HP, Williams SP, et al. A cardiac myocyte vascular endothelial growth factor paracrine pathway is required to maintain cardiac function. Proc Natl Acad Sci U S A 2001;98(10):5780-5.

58. Heusch G. Hibernating myocardium. Physiol Rev 1998;78(4):1055-85.

59. Kloner RA, Bolli R, Marban E, Reinlib L, Braunwald E. Medical and cellular implications of stunning, hibernation, and preconditioning: an NHLBI workshop. Circulation 1998;97(18):1848-67.

60. Compernolle V, Brusselmans K, Franco D, et al. Cardia bifida, defective heart development and abnormal neural crest migration in embryos lacking hypoxiainducible factor-1alpha. Cardiovasc Res 2003;60(3):569-79.

61. Oosthuyse B, Moons L, Storkebaum E, et al. Deletion of the hypoxia-response element in the vascular endothelial growth factor promoter causes motor neuron degeneration. Nat Genet 2001;28(2):131-8. 
62. Azzouz M, Ralph GS, Storkebaum E, et al. VEGF delivery with retrogradely transported lentivector prolongs survival in a mouse ALS model. Nature 2004;429(6990):413-7.

63. Shiote $M$, Nagano I, llieva $H$, et al. Reduction of a vascular endothelial growth factor receptor, fetal liver kinase-1, by antisense oligonucleotides induces motor neuron death in rat spinal cord exposed to hypoxia. Neuroscience 2005;132(1):175-82.

64. Miquerol L, Langille BL, Nagy A. Embryonic development is disrupted by modest increases in vascular endothelial growth factor gene expression. Development 2000;127(18):3941-6.

65. Chien KR. Stress pathways and heart failure. Cell 1999;98(5):555-8.

66. Dor $Y$, Camenisch TD, Itin $A$, et al. A novel role for VEGF in endocardial cushion formation and its potential contribution to congenital heart defects. Development 2001;128(9):1531-8.

67. Dor $Y$, Djonov $V$, Abramovitch $R$, et al. Conditional switching of VEGF provides new insights into adult neovascularization and pro-angiogenic therapy. Enbo I 2002;21(8):1939-47.

68. Feucht $M$, Christ $B$, Wilting J. VEGF induces cardiovascular malformation and embryonic lethality. Am J Pathol 1997;151(5):1407-16.

69. Flamme l, von Reutern M, Drexler HC, Syed-Ali S, Risau W. Overexpression of vascular endothelial growth factor in the avian embryo induces hypervascularization and increased vascular permeability withoul alterations of embryonic pattern formation. Dev Biol 1995;171(2):399-414.

70. Frank GB. Inward movement of calcium as a link between electrical and mechanical events in contraction. Nature 1958;182(4652):1800-1.

71. Schaldach $\mathrm{M}$, Hutten $\mathrm{H}$. A physiological approach to different concepts of rate adaptive cardiac pacing. Med Prog Technol 1990;16(4):235-46.

72. Rollbauer $W$, Just $S$, Wessels $G$, et al. VEGF-PLCgamma1 pathway controls cardiac contractility in the embryonic heart. Genes Dev 2005;19(13):1624-34.

73. Stalmans I, Ng YS, Rohan R, et al. Arteriolar and venular patterning in retinas of mice selectively expressing VEGF isoforms. I Clin Invest 2002;109(3):327-36.

74. Maes C, Stockmans 1, Moermans K, et al. Soluble VEGF isoforms are essential for establishing epiphyseal vascularization and regulating chondrocyte development and survival. J Clin Invest 2004;113(2):188-99.

75. Carmeliet $P, N g Y S$, Nuyens $D$, et al. Impaired myocardial angiogenesis and ischemic cardiomyopathy in mice lacking the vascular endothelial growth factor isoforms VEGF164 and VEGF188. Nat Med 1999;5(5):495-502.

76. Zelzer E, McLean W, Ng YS, et al. Skeletal defects in VEGF(120/120) mice reveal multiple roles for VEGF in skeletogenesis. Development 2002;129(8):1893-904.

77. Vanoverschelde JL, Wijns W, Borgers $M$, et al. Chronic myocardial hibernation in humans. From bedside to bench. Circulation 1997;95(7):1961-71. 
78. Lopaschuk CD, Collins-Nakai RL, Itoi T. Developmental changes in energy substrate use by the heart. Cardiovasc Res 1992;26(12):1172-80.

79. Keyt BA, Berleuu LT, Nguyen HV, et al. The carboxyl-terminal domain (111-16.5) of vascular endothelial growth factor is critical for its mitogenic potency. I Biol Chem 1996;271(13):7788-95.

80. Gitay-Goren $H$, Cohen T, Tessler $S$, et al. Selective binding of VEGF121 to one of the three vascular endothelial growth factor receptors of vascular endothelial cells. I Biol Chem 1996;271(10):5519-23.

81. Gerhardt $H$, Golding $M$, Fruttiger $M$, et d. VEGF guides angiogenic sprouting utilizing endothelial tip cell filopodia. I Cell Biol 2003;161(6):1163-77.

82. Rajantic I, Fkman N, Iljin K, et al. Bmx tyrosine kinase has a redundant function downstream of angiopoietin and vascular endothelial growth factor receptors in arterial endothelium. Mol Cell Biol 2001;21(14):4647-55.

83. Liu Zl, Shirakawa T, LiY, et al. Regulation of Notchl and Dll4 by vascular endothelial growth factor in arterial endothelial cells: implications for modulating arteriogenesis and angiogenesis. Mol Cell Biol 2003;23(1):14-25. 
ChAPTER 3

Hypoxia Disturbs Fetal Hemodynamics and Growth

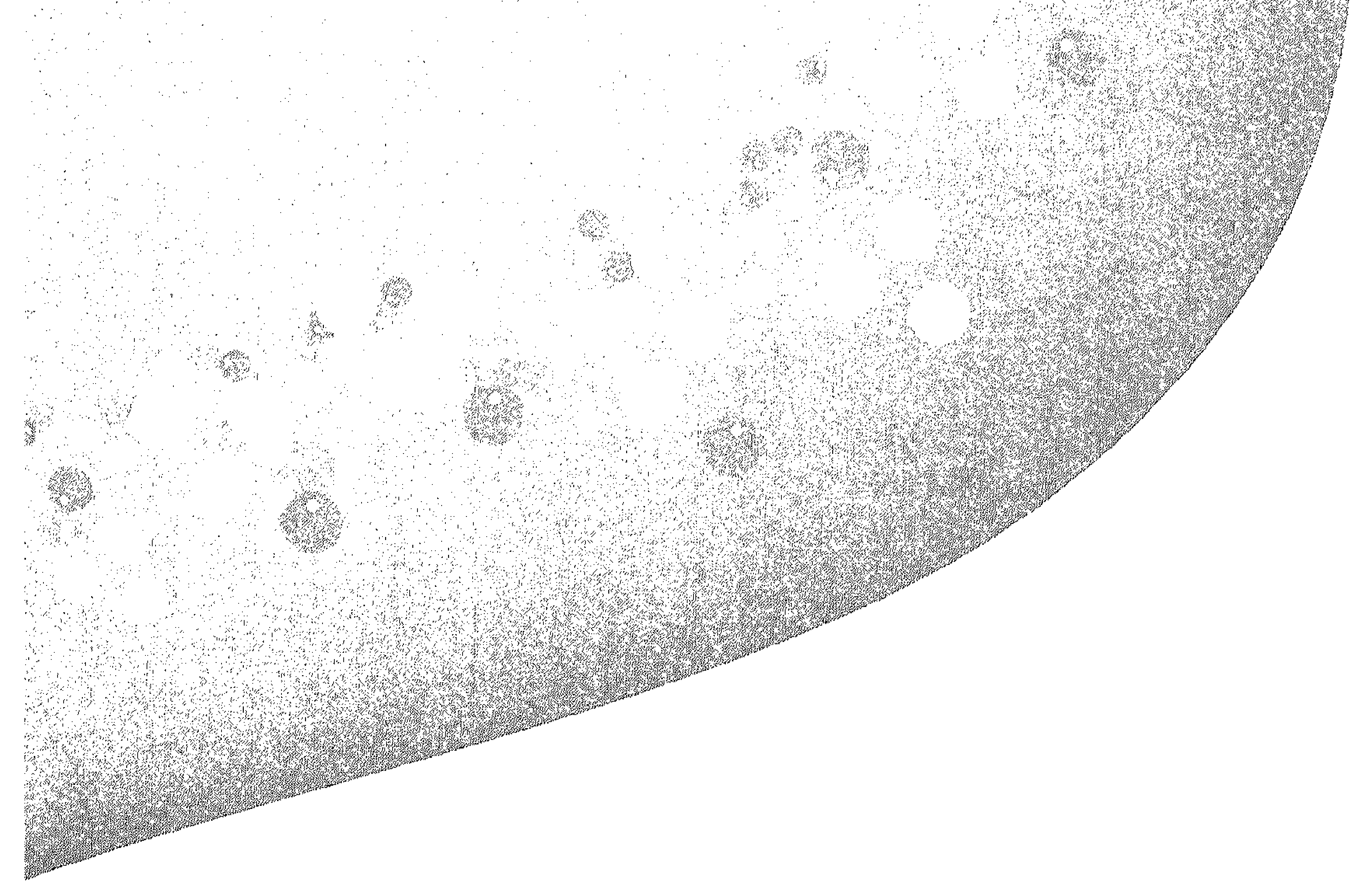




\section{ABSTRACT}

\section{Background}

Fetal growth restriction is associated with an increased incidence of adult cardiovascular disease. Postnatal persistence of alterations in fetal hemodynamic regulation to maintain oxygen homeostasis, including increased resistance in peripheral vascular beds, may progress into adult cardiovascular complications. We examined the changes in cardiovascular control and body weight composition in an experimental model of fetal growth restriction.

\section{Methods}

Chick embryos were incubated under chronically mild hypoxic $\left(15 \% \mathrm{O}_{2}\right)$ or normoxic $\left(21 \% \mathrm{O}_{2}\right)$ conditions. At day 13,17 , and 19 of the 21 -day fetal incubation period we determined in vivo sympathetic arterial tone and systemic hemodynamics, and structural vascular changes using histological techniques. Heart structure was analysed at day 13 and day 17, cardiac function was assessed at day 17 . Body, heart, liver, and brain weights were measured to determine fetal growth rate.

\section{Results}

Three stages of hemodynamic adaptations were identified in hypoxic chick embryos. At day 13 , heart rate $(12 \%)$ and blood pressure $(33 \%)$ were higher in hypoxic chick embryos, indicating a hyperkinetic phase. This was followed by enhanced sympathetic innervation of peripheral arteries $(50 \%)$, resulting in increased vasoconstriction (36\%) during a chemoreflex. Additionally, we observed left ventricular dilatation and decrease of left ventricular contractility at day 17. At day 19, hypoxic chick embryos had a 33\% higher baseline adrenergic vascular tone, but failed to maintain blood pressure during a chemoreflex, indicating cardiac failure. Body, heart, and liver weights were reduced in day 19 hypoxic chick embryos, whereas brain weight was unaffected.

\section{Conclusions}

Chronic hypoxia induces changes in cardiovascular control preceding alterations in body weight distribution. This study for the first time identifies a causal link between disturbances in gestational environment, cardiovascular dysfunction and restricted fetal growth. 


\section{INTRODUCTION}

Epidemiological studies have shown that low birth weight is associated with an increased incidence of cardiovascular diseases (CVD) in adulthood, including hypertension, coronary artery disease, and stroke. ${ }^{1-4}$ Several reports have stressed that it is altered fetal growth rate rather than birth weight that underlies these consequences of intrauterine disturbances. ${ }^{5-7}$ However, the causal pathways linking disturbances in fetal environment to adult CVD remain to be defined.

Leeson et al. demonstrated endothelial dysfunction in children with low birth weights. ${ }^{8,9}$ This indicates that key events in the initiation and progression of CVD are already established at or before birth. We recently established that exposure of chick embryos to mild hypoxic stress throughout development results in low body weight, disturbed hemodynamic control and cardiac pump dysfunction at the end of gestation. ${ }^{10}$ These observations show that cardiovascular alterations are already established before birth.

Fetal hypoxia may thus be a common cause of fetal growth restriction. ${ }^{11}$ We hypothesize that hypoxia-induced alterations in hemodynamic control during development of the cardiovascular system are involved in the fetal origin of CVD. Assessment of the cardiovascular system during chronic fetal hypoxia requires an experimental model that allows detailed in vivo observations of such events. Since the chick embryo develops independently of the mother animal inside an egg, oxygen supply can easily be altered while allowing in vivo measurements of arterial tone and systemic hemodynamics. ${ }^{12}$ In the present study we investigated the effect of chronic hypoxia on cardiac performance, hemodynamic control, and growth during the second half of chick embryo development. 


\section{Materials And Methods}

Experimental procedures were in accordance with the Dutch law on the use of laboratory animals. Fertile White Leghorn eggs were incubated at a temperature of $37^{\circ} \mathrm{C}$ and relative air humidity of $60 \%$, and were exposed either to $21 \% \mathrm{O}_{2}$ in the normoxic $(\mathrm{N})$ group, or to $15 \% \mathrm{O}_{2}$ in the hypoxic $(\mathrm{H})$ group from the first day of incubation onward. Experiments were conducted at embryonic day 13 (E13), E17, or E19 of the 21-day incubation period.

\section{General Characteristics}

Arterial blood $\mathrm{PO}_{2}$ and hematocrit were measured as previously described. ${ }^{10}$ Total body, heart, liver, and brain weights were measured at E13, E17, and E19 to assess fetal growth rate. In separate series survival rate and time to hatching were determined.

\section{Peripheral Arterial Control}

The effect of chronic hypoxia on control of peripheral arterial tone was assessed in vivo by measurement of diameter changes of mesenteric resistance arteries in response to pharmacologic and physiologic stimuli using intravital videomicroscopy, as described previously in detail. ${ }^{12}$ In short, the egg was opened, the chorioallantoic membrane was penetrated, and a segment of the intestine with its mesentery was exposed and stabilized. The egg was placed in a temperature- and air flow-controlled single-egg chamber $\left(37^{\circ} \mathrm{C}, 4 \mathrm{~L} / \mathrm{min}\right)$.

Second-order mesenteric resistance arteries were visualized with an intravital microscope setup equipped with a 20x long-working-distance objective (optical magnification $880 x$, final resolution $1 \mu \mathrm{m}$ ). Images were recorded on videotape, and arterial diameters were analyzed offline with an image-shearing device (model 908, IPM, San Diego, CA). Changes in diameter are presented as percentage of baseline diameter.

Changes in arterial diameter were measured in response to topically applied $20-\mu \mathrm{l}$ aliquots of phentolamine $\left(10^{-3} \mathrm{~mol} / \mathrm{L}\right)$, norepinephrine $\left(10^{-6}-10^{-2} \mathrm{~mol} / \mathrm{L}\right)$, and acetylcholine $\left(10^{6}-10^{-2} \mathrm{~mol} / \mathrm{L}\right)$ to assess baseline $\alpha$-adrenergic tone, $\alpha$-adrenergic vasoconstrictor capacity, and vasodilator capacity, respectively. Additionally, sympathetic nervous control of the peripheral vasculature was assessed by measuring the degree of arterial constriction after application of tyramine $\left(10^{-6}-10^{-}\right.$ ${ }^{2} \mathrm{~mol} / \mathrm{L}$ ). Tyramine releases norepinephrine from perivascular sympathetic nerve endings without affecting presynaptic reuptake. ${ }^{13}$ Since the contractile response to tyramine reflects the total norepinephrine content of the perivascular sympathetic nerve endings, this is a pharmacological method for assessing sympathetic nerve 
function in vivo. Drugs were obtained from Sigma Chemical Co. (St. Louis, MO) and dissolved in HEPES-buffered Krebs solution with the following composition (in $\mathrm{mmol} / \mathrm{L}): \mathrm{NaCl} 143.3, \mathrm{KCl} 4.7, \mathrm{MgSO}_{4} 1.2, \mathrm{KH}_{2} \mathrm{PO}_{4} 1.2, \mathrm{CaCl}_{2} 2.5$, glucose 5.6, HEPES $15 ; \mathrm{pH} 7.4$. Solutions were prepared on the day of the experiment; temperature at the time of administration was $37^{\circ} \mathrm{C}$.

\section{Systemic Hemodynamics}

The influence of chronic hypoxia on central hemodynamic control was determined according to a previously described method. ${ }^{12}$ In short, arterial pressure and heart rate were measured with a catheter that was inserted into a branch of the chorioallantoic artery and connected to a pressure transducer (Baxter Uniflow, Baxter B.V., Uden, the Netherlands). Pressure signals were recorded with a data acquisition system, and mean arterial pressure and heart rate were calculated. Blood pressure, heart rate, and peripheral arterial tone were measured under baseline conditions $\left(21 \% \mathrm{O}_{2}\right)$ and during acute severe hypoxic stress. Acute hypoxia was induced by replacing the ambient air in the egg chamber by $100 \% \mathrm{~N}_{2}$ (4 $\mathrm{L}$ min) for 5 minutes. An acute reduction in blood oxygen level is a standard stimulus for triggering a stress response in the chick embryo and is characterized by bradycardia, enhanced sympathetic nervous activity, and release of catecholamines from the adrenal gland. ${ }^{14}$ Increased sympathetic outflow to peripheral resistance arteries causes release of norepinephrine from sympathetic nerve terminals, which induces arterial constriction by activating $\alpha$ adrenoreceptors on vascular smooth muscle cells, resulting in increased peripheral vascular resistance. This response is aimed at maintaining blood pressure, and contributes to a redistribution of the cardiac output in order to optimize perfusion and oxygenation of the vital organs, i.e. heart, brain, and adrenal glands, at the expense of peripheral vascular beds, including the mesenteric circulation. ${ }^{14}$

\section{Cardiac Performance}

Cardiac morphology was investigated in E13 and E17 hypoxic and normoxic chick embryos. Left ventricular (LV) cavity cross-sectional area was measured on formalin-fixed tissue sections using Imagel software (Image), National Institutes of Health). In a separate series of experiments, isometric contractile force development was measured in LV muscle bundles isolated from hypoxic and normoxic E17 chick embryos. ${ }^{15}$ E17 hearts were perfused with heparin, excised, and subsequently placed in $\mathrm{Ca}^{2+}$-free HEPES buffer gassed with $100 \% \mathrm{O}_{2}$, with the following composition (in mmol/L): $135 \mathrm{NaCl}, 5.4 \mathrm{KCl}, 0.33 \mathrm{NaH}_{2} \mathrm{PO}_{4}, 10$ HEPES, 10 glucose, $1 \mathrm{MgCl}_{2}, 30 \mathrm{BDM}, \mathrm{pH} 7.4$. A thin subendocardial LV bundle was excised in parallel with fiber direction under stereomicroscopic control, and 
mounted in an organ bath between a rigid hook and a force transducer connected to a micromanipulator for length adjustment. Muscles were superfused with BDM-free HEPES buffer $\left(2 \mathrm{mmol} / \mathrm{L} \mathrm{Ca}^{2+}\right.$, $\mathrm{pH} 7.4$, gassed with $\left.100 \% \mathrm{O}_{2}, 37^{\circ} \mathrm{C}\right)$ and stimulated by bipolar electrical field stimulation at $1 \mathrm{~Hz}$ (pulse width $5 \mathrm{~ms}$, $5-10 \%$ above threshold). For standardization purposes all experiments were performed at the optimum of the Frank-Starling curve of the individual muscle bundle. To this end, the muscle bundle was stretched form its resting length until the muscle length providing maximal active force generation was reached. Generated force was defined as peak systolic force minus resting force, and normalized to cross-sectional area $\left(\mathrm{mN} / \mathrm{mm}^{2}\right)$ by optical measurement of the smallest diameter of the bundle assuming cylindrical geometry. ${ }^{15}$ Contractile force was measured in response to increasing levels of extracellular calcium (2$12 \mathrm{mmol} / \mathrm{L}$ ) and, in separate series of experiments, to electrical stimulation (pacing frequencies $0.5-4 \mathrm{~Hz}$; force-frequency relationship).

\section{Data Analysis}

Data are expressed as mean \pm SE. The term $n$ refers to the number of embryos. Comparisons between groups were made with the Mann-Whitney $U$ test. Comparisons within groups were made with the Wilcoxon signed-rank test. Statistical significance was defined as $\mathrm{P}<0.05$. 


\section{RESULTS}

\section{General Characteristics}

Incubation of chick embryos at $15 \% \mathrm{O}_{2}($ Hypoxia, $\mathrm{H}$ ) throughout embryonic development caused a significant decrease in embryonic arterial blood $\mathrm{PO}_{2}$ levels which was accompanied by an increase in hematocrit levels as compared with incubation at $21 \% \mathrm{O}_{2}$ (Normoxia, $\mathrm{N}$ ) at all time points (Fig. 1). Survival rates at E13, 17 and 19 were significantly lower in the hypoxic group (Fig, 2). Fetal growth rates decreased in $\mathrm{H}$ embryos between $\mathrm{E} 13$ and $\mathrm{E} 19$ (Fig. 3). Total body weight was significantly lower in $\mathrm{H}$ as compared with $\mathrm{N}$ embryos at E17 and E19 (Fig. 3A). Similarly, heart and liver weights were significantly lower in $\mathrm{H}$ embryos at day E19 (Fig. 3B and C). In contrast, brain weights were similar in the two groups (Fig. 3D). The time to hatching (day 21 of incubation) was similar in $\mathrm{H}$ and $\mathrm{N}$ chick embryos.
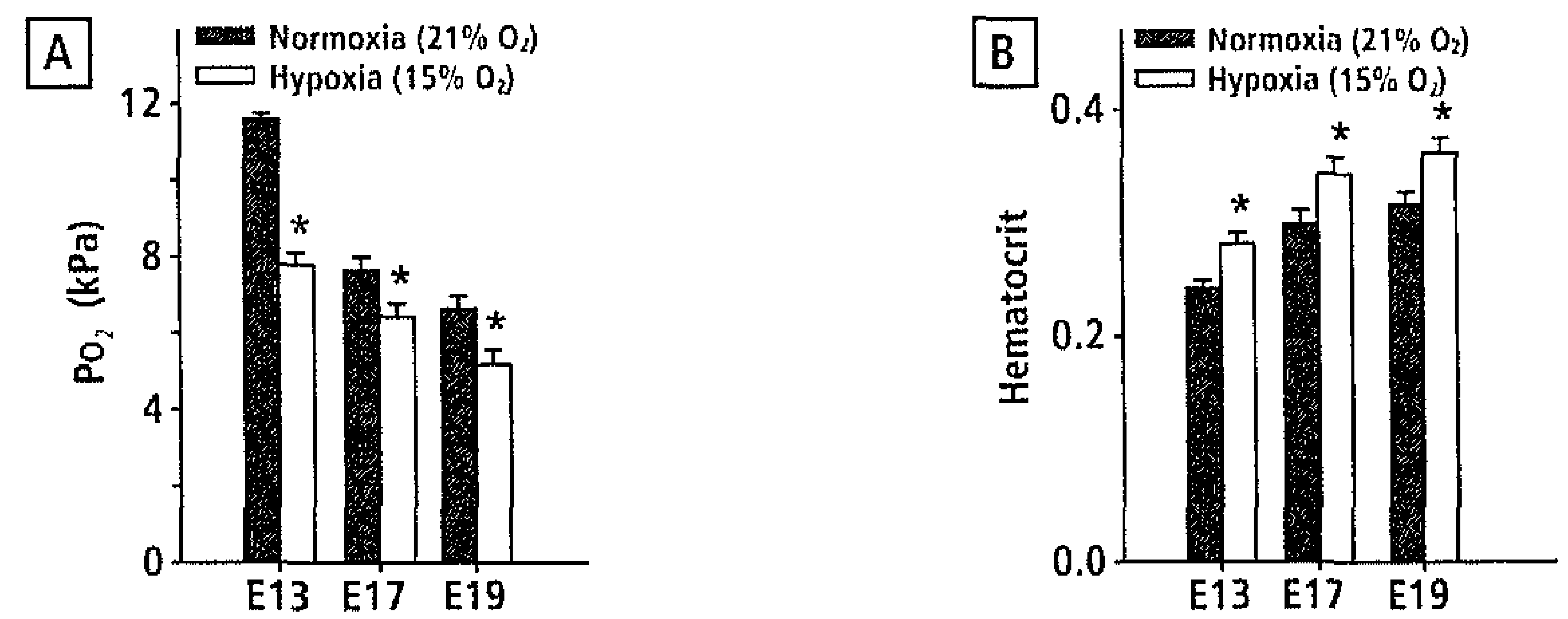

Figure 1 Arterial blood $P_{2}(A)$ and hematocrit $(B)$ at E13, 17, and 19 in normoxic (N) and hypoxic (H) embryos ( $n=7$ in each group). Data are expressed as mean $\pm S E ;{ }^{*} P<$ $0.05 \mathrm{H}$ versus $\mathrm{N}$.

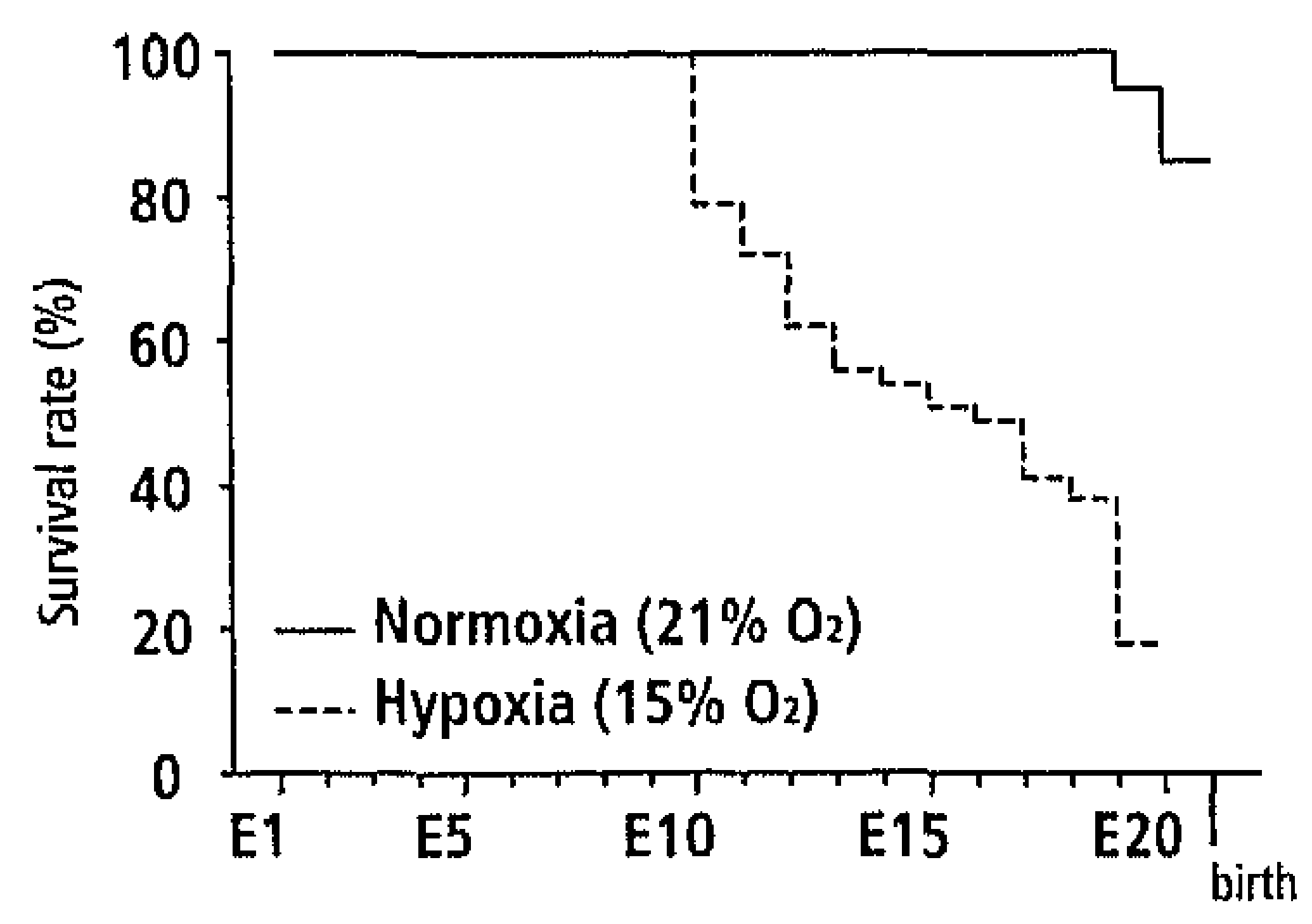

Figure 2 Survival rates in $N$ and H chick embryos ( $n=150$ in both groups at EO). 

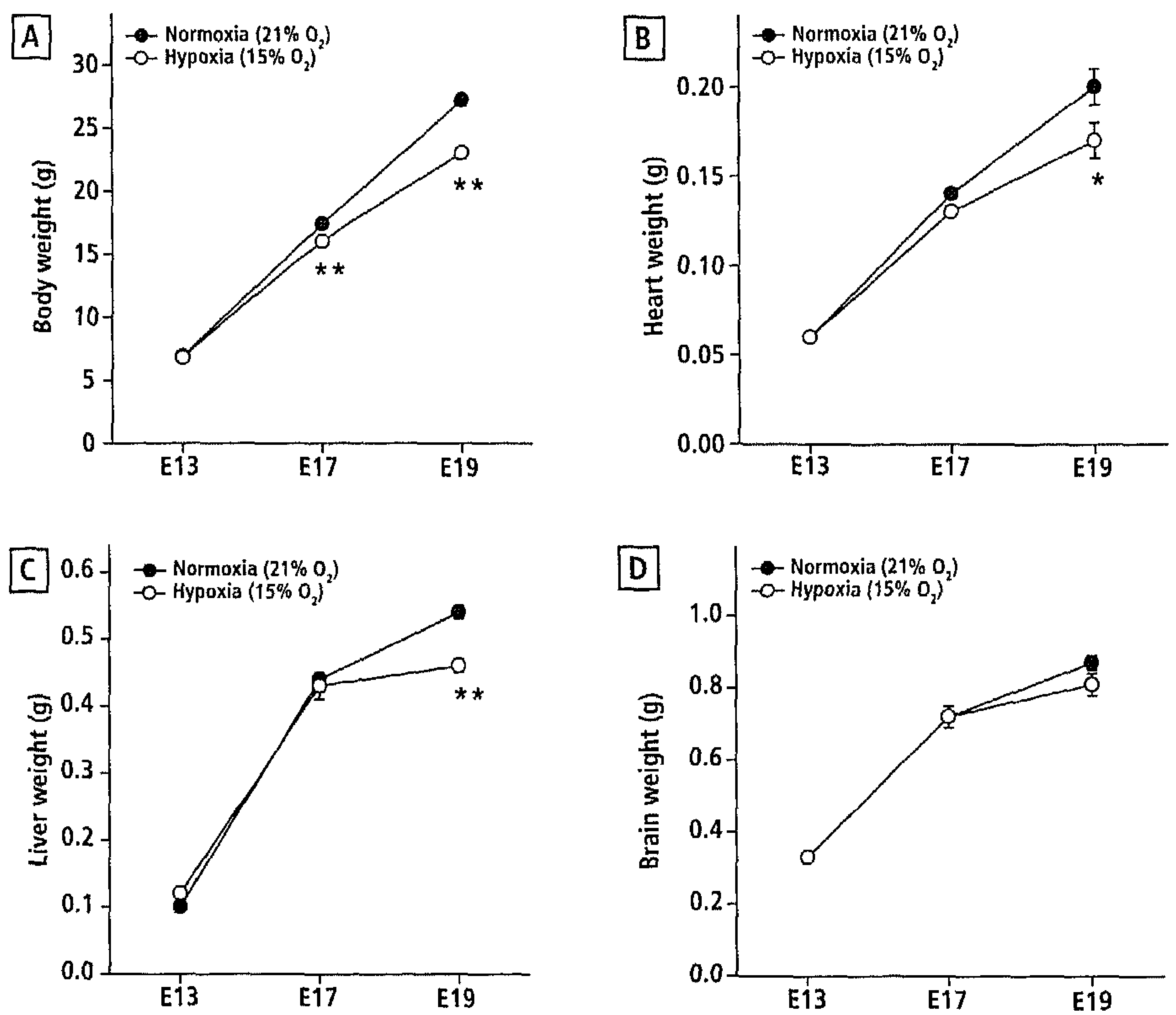

Figure 3 Total body weight (A) at E13, 17, and 19 in $N$ and $H$ embryos $(n=43,23,36$, and $n=36,37,28$, respectively). Heart weight $(B)$, liver weight $(C)$, and brain weight $(D)$ at E13, 17, and 19 in $\mathrm{N}$ and $\mathrm{H}$ embryos $(n=13,15,8$, and $n=10,9,8$, respectively). Data are shown as mean $\pm S E ;{ }^{*} P<0.05,{ }^{* *} P<0.01 \mathrm{H}$ versus $\mathrm{N}$.

\section{Peripheral Arterial Control}

Vasomotor responses to pharmacological stimuli are shown in Table 1. Absolute arterial diameters under baseline conditions were similar in $\mathrm{H}$ and $\mathrm{N}$ embryos at $\mathrm{E} 13$ and E17, but were significantly smaller in the $\mathrm{H}$ group at E19. Alphaadrenoceptor blockade with phentolamine induced a significantly stronger arterial dilation in the $\mathrm{H}$ than the $\mathrm{N}$ group at E19. Application of increasing concentrations of norepinephrine caused a gradual decrease in arterial diameter. Maximal vasoconstrictor responses to $10^{-3} \mathrm{~mol} / \mathrm{L}$ norepinephrine were similar in both groups at all stages. The maximal vasodilator response to $10^{-2} \mathrm{~mol} / \mathrm{L}$ acetylcholine was significantly stronger in the $H$ than the $N$ group at E19. 
Tyramine administration had no effect at E13 in both groups. Application of increasing concentrations of tyramine at E17 and E19 induced a gradual reduction in mesenteric arterial diameter in both groups. At both days, maximal constriction to $10^{-3} \mathrm{~mol} / \mathrm{L}$ tyramine was significantly greater in the $H$ groups than the $\mathrm{N}$ group (Fig. 4).

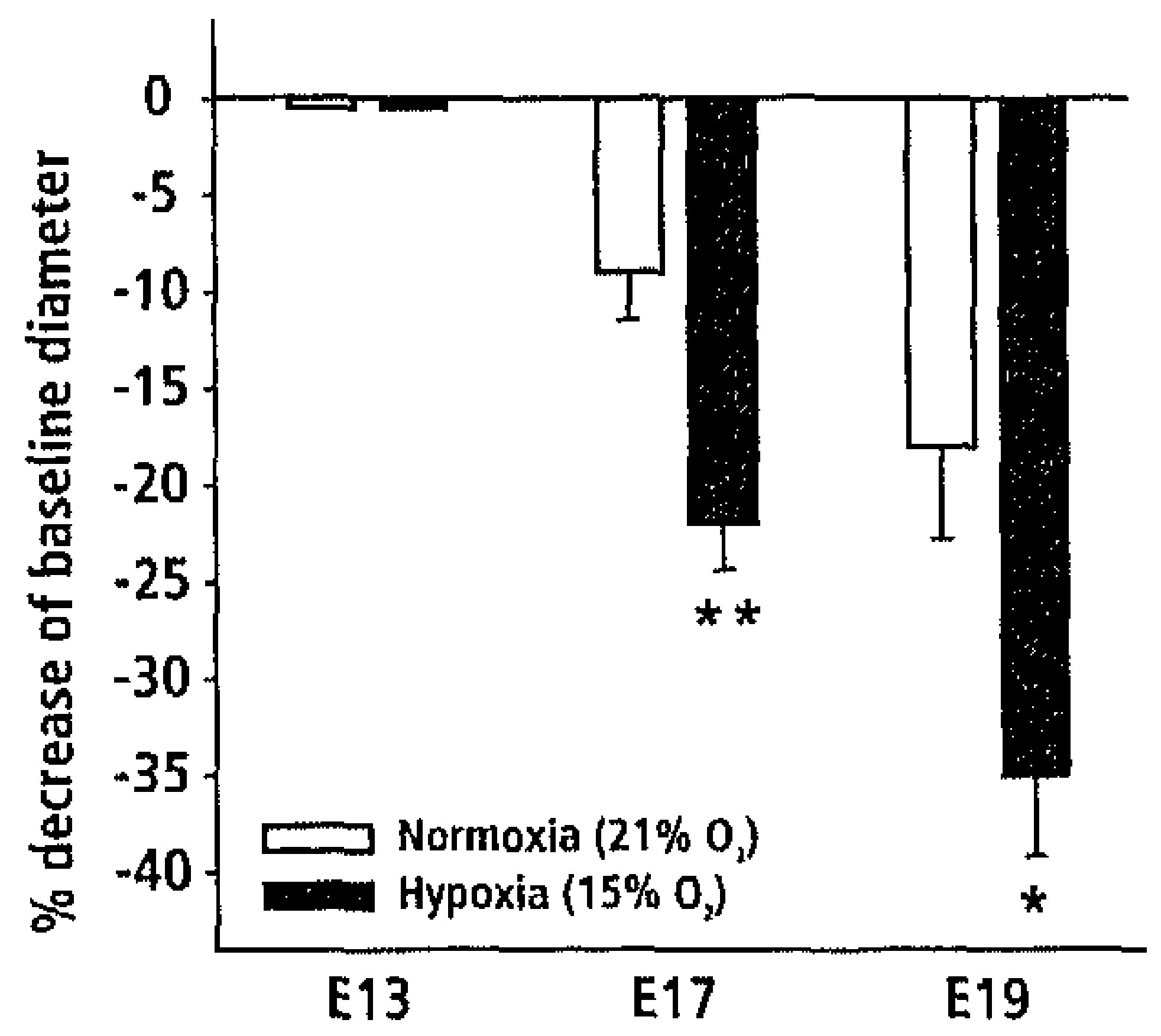

Figure 4 In vivo vasoconstrictor responses to tyramine (10-3 mol/l) of mesenteric arteries at E13, 17 , and 19 in $N$ and $H$ embryos $(n=4,10,6$, and $n=4,14,7$, respectively), expressed as percentage decrease of baseline diameter. Data are shown as mean $\pm S E M ;{ }^{*} P<$ $0.05, * * P<0.01 \mathrm{H}$ versus $\mathrm{N}$.

\section{Systemic Hemodynamics}

The effect of chronic hypoxia on systemic hemodynamic parameters is shown in Table 2 and Figure 5. At E13, mean arterial pressure and heart rate under baseline conditions were significantly higher in the $\mathrm{H}$ as compared with the $\mathrm{N}$ group. During acute hypoxic stress, arterial pressure, heart rate, and peripheral arterial diameter decreased to a similar extent in both groups.

At E17, mean arterial pressure under baseline conditions was significantly lower in $\mathrm{H}$ than in $\mathrm{N}$ embryos, whereas heart rates were not different between the two groups. During acute hypoxic stress, mean arterial pressure was maintained in the $\mathrm{H}$ group, whereas it dropped in the $\mathrm{N}$ group. The degree of bradycardia was equally significant in the two groups. The level of peripheral arterial constriction was significantly greater in the $\mathrm{H}$ than the $\mathrm{N}$ group.

At $\mathrm{E} 19$, baseline mean arterial pressure and heart rate were similar in both groups. During acute hypoxic stress, mean arterial pressure decreased in the $\mathrm{H}$ group, but it was maintained in the $\mathrm{N}$ group. Acute hypoxia induced bradycardia and constriction of the peripheral arteries in both groups. 


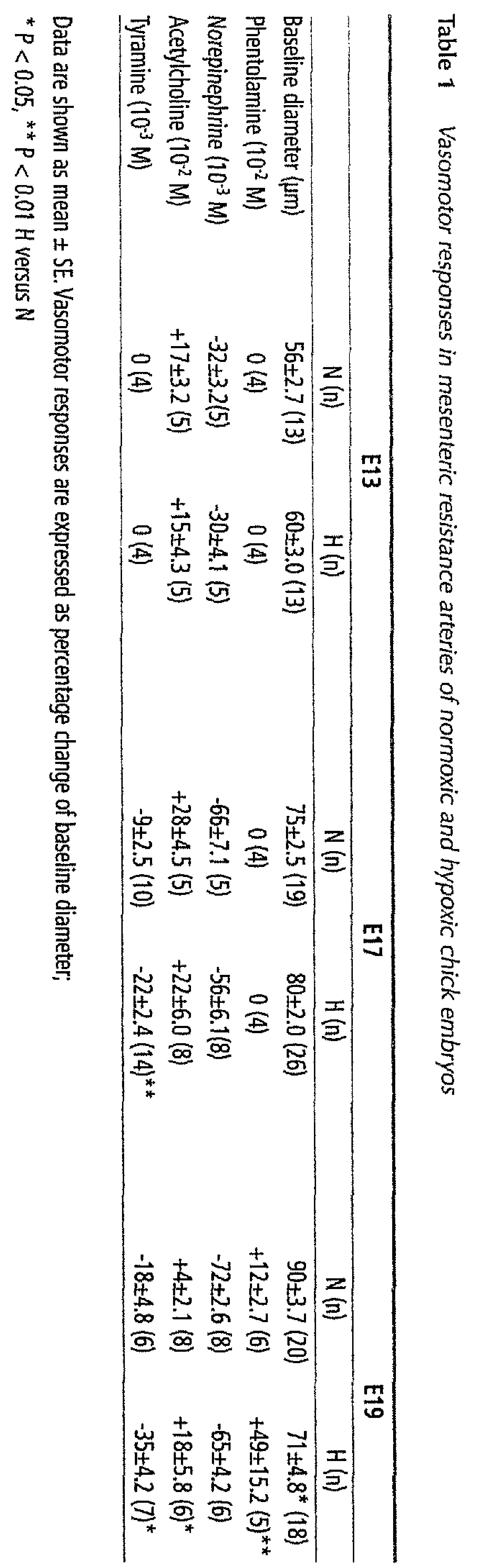




\section{Hypoxia Disturbs Fetal Hemodynamics and Growth}

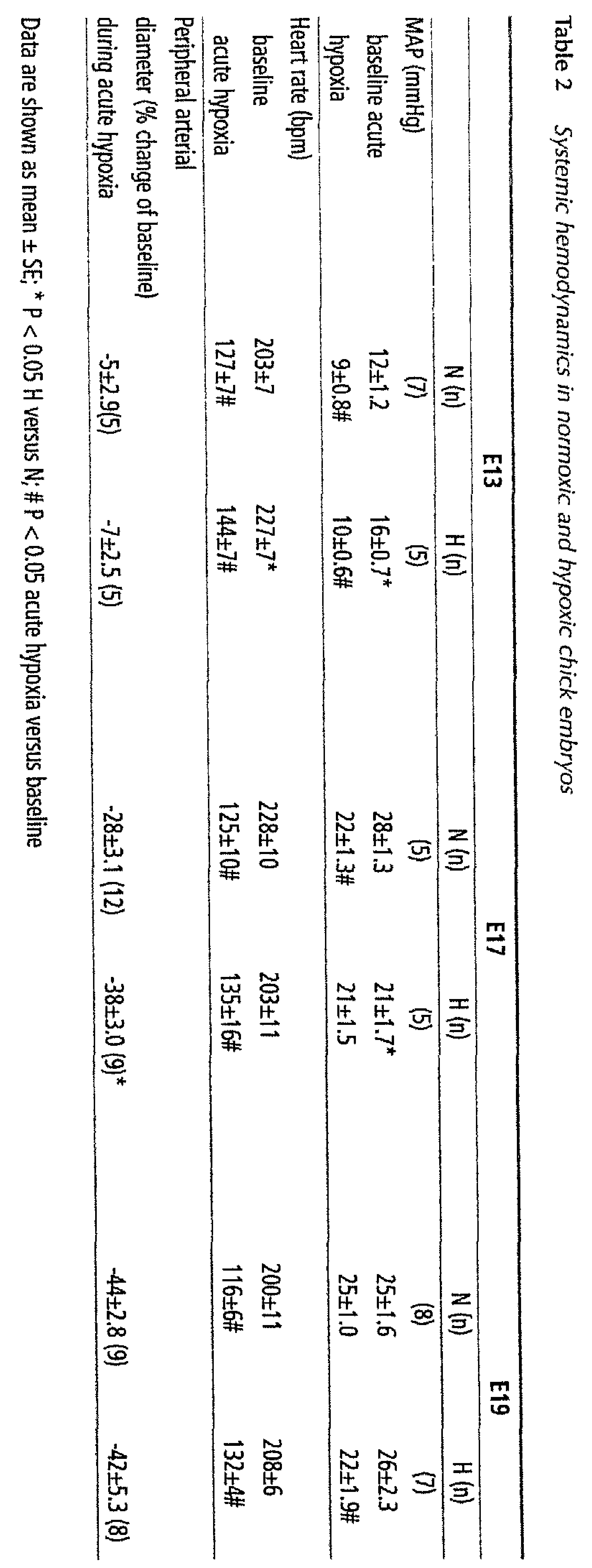




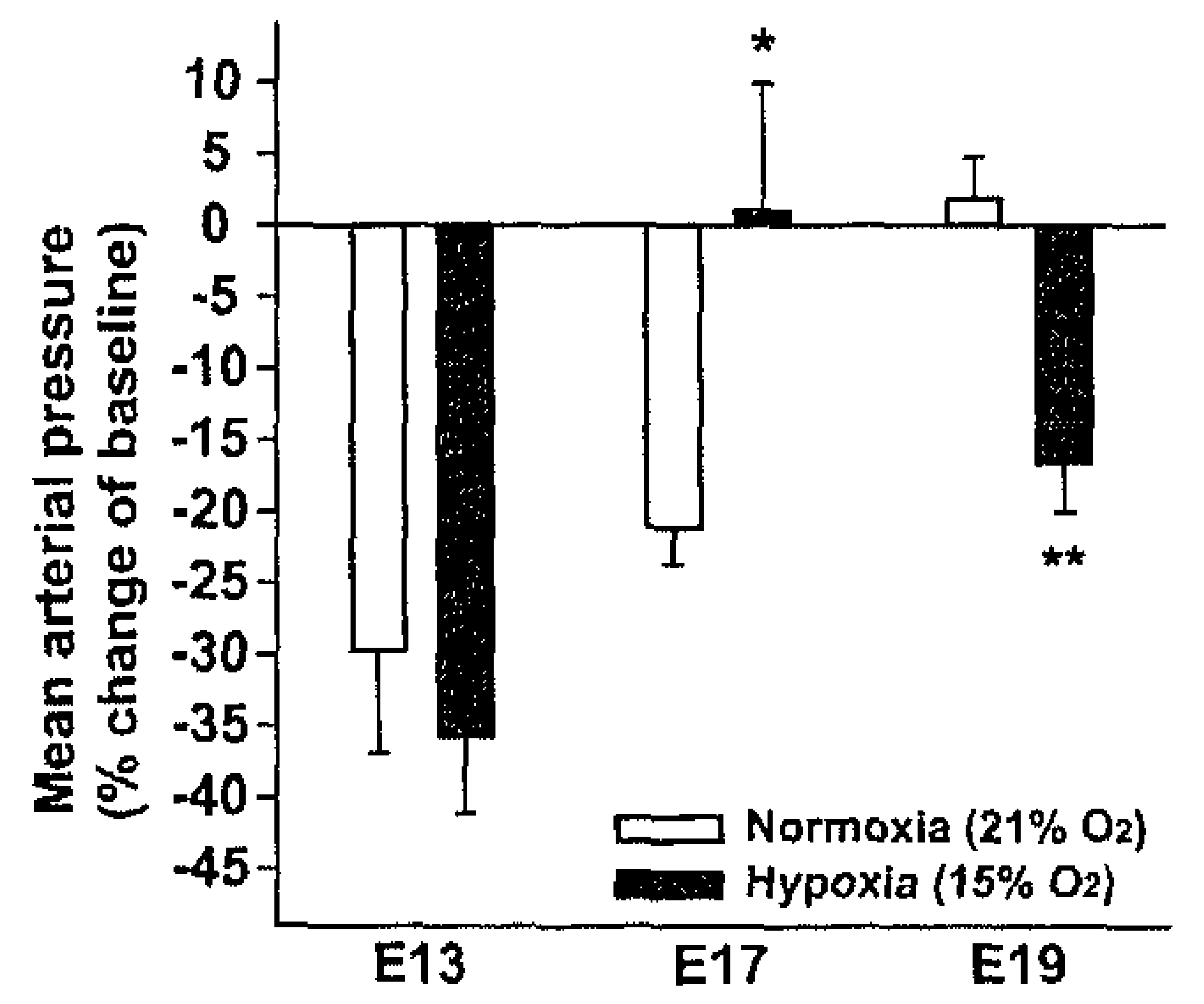

Figure 5 Change in mean arterial pressure during acute hypoxic stress at E13,17, and 19 in $\mathrm{N}$ and $H$ embryos $(n=7,7,8$, and $n=5,5,7$, respectively). Data are shown as mean $\pm S E$; ${ }^{*} P<0.05, * * P<0.01 \mathrm{H}$ versus $\mathrm{N}$.

\section{Cardiac Performance}

At E13, hypoxic and normoxic embryonic hearts (Fig. $6 \mathrm{~A}$ and $\mathrm{B}$ ) displayed similar LV cavity cross-sectional areas $\left(1.6 \pm 0.4\right.$ and $1.8 \pm 0.4 \mathrm{~mm}^{2}$ respectively; $\mathrm{n}=6$ in each group; $\mathrm{P}=\mathrm{n} . \mathrm{s}$.). Hypoxic $\mathrm{E} 17$ embryos displayed dilated left ventricles (Fig. 6C and D). The LV cavity cross-sectional area was 2 -fold larger than in normoxic embryos $\left(2.7 \pm 0.4\right.$ versus $1.4 \pm 0.3 \mathrm{~mm}^{2} ; \mathrm{n}=6$ in each group; $\mathrm{P}<0.05)$. Contractility to increasing concentrations of calcium was significantly lower in hypoxic LV bundles compared with normoxic LV bundles at E17 (Fig. $6 \mathrm{E})$. Furthermore, the contractile responses to increasing pacing frequencies (force frequency relationship) were also significantly lower in hypoxic compared with normoxic LV muscle bundles (Fig. 6F). 

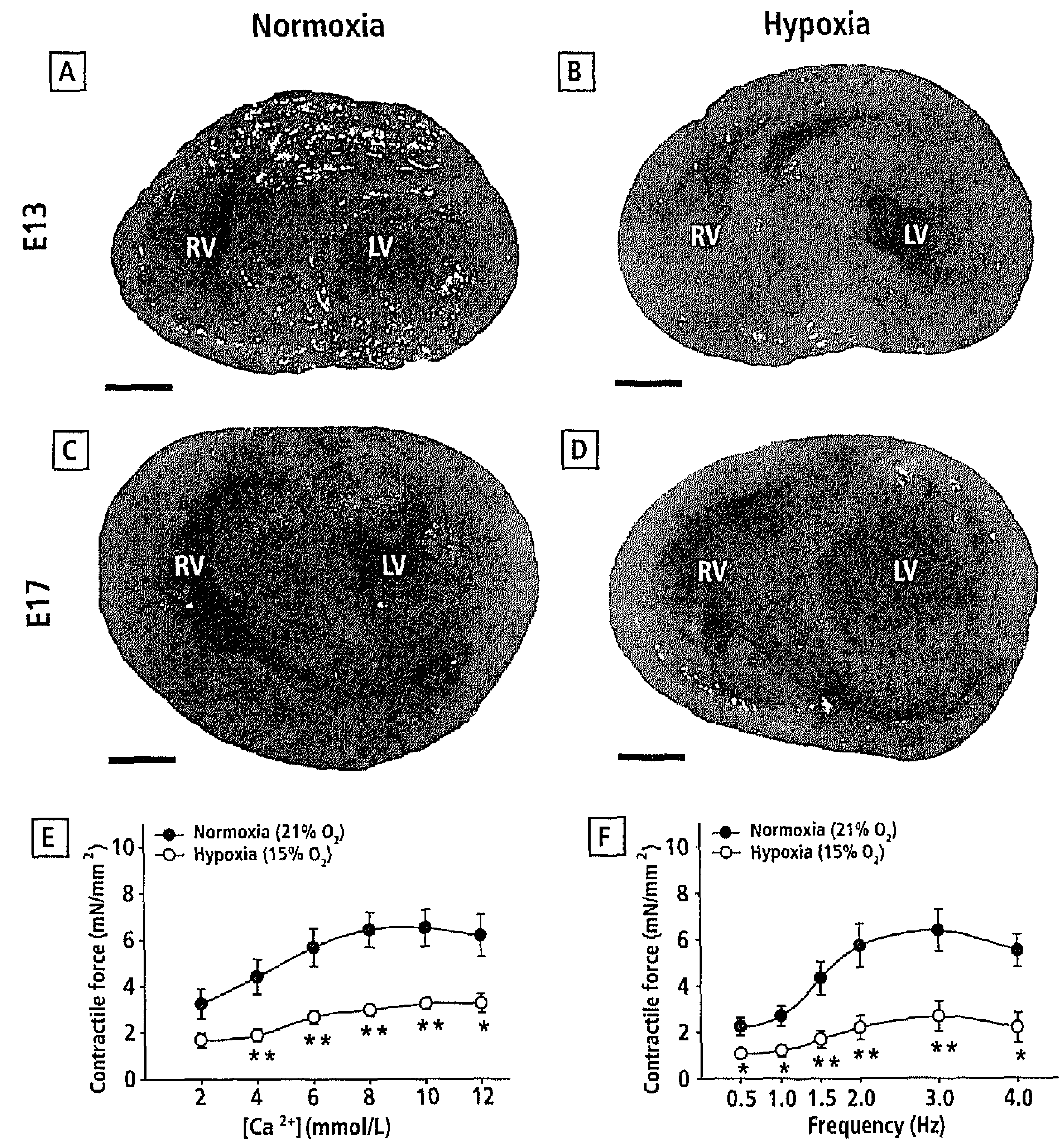

Figure 6 Cardiac morphology of $E 13(A, B)$ and $E 17(C, D)$ chick embryos exposed to normoxia or hypoxia. Scale bars represent $1 \mathrm{~mm}$. $L V$, left ventricle; $R V$, right ventricle. Contractile function to increasing calcium concentrations $(E)$ and pacing frequencies $(F)$ in hypoxic and normoxic left ventricular muscle bundles at $E 17$, both $n=5$. Data are shown as mean $\pm S E ;{ }^{*} P<0.05,{ }^{* *} P<0.01 \mathrm{H}$ versus $N$. 


\section{Discussion}

Here we demonstrate that hypoxia alters cardiovascular development in the embryo. We show that fetal hypoxia induces impaired cardiac performance and aberrant regulation of peripheral arterial tone leading to alterations in fetal hemodynamic regulation preceding changes in fetal growth. We identified three consecutive stages of compensatory cardiovascular responses to the chronic reduction in oxygen availability. Our data show that not only increased peripheral arterial tone, but also cardiac activity plays an important role in fetal growth restriction. ${ }^{16}$

In the first stage, around E13, the arterial pressure in hypoxic chick embryos was higher than in normoxic controls, whereas the arterial responses to norepinephrine, acetylcholine or tyramine were not different. Arterial blood pressure is determined by the product of cardiac output and peripheral vascular resistance. Lacking control of arterial vascular tone implies that blood pressure largely depends on cardiac activity, i.e. heart rate and stroke volume. ${ }^{17}$ Indeed, we also observed an elevated heart frequency in the hypoxic chick embryos, indicating that blood pressure, and not peripheral vasoconstriction, is the main determinant of organ perfusion at E13 in both normoxic and hypoxic chick embryos. Even acute hypoxia failed to provoke an arterial response at this early embryonic stage. As a result of this hyperkinetic circulatory state, total body weight and body weight distribution are not be altered at E13. In human fetuses, such a hyperkinetic phase may support placental growth, accounting for the relatively large placenta that is frequently found in growth restricted fetuses. ${ }^{18}$

In the second stage, around E17, hypoxic chickembryos exhibited a marked dilatation of the left ventricle and a significantly impaired contractility of left ventricular muscle bundles. In agreement, arterial blood pressure was lower in hypoxic embryos than in normoxic controls. In the absence of compensatory changes in arterial tone (baseline arterial diameters were not different), the lower blood pressure may account for reduced perfusion leading to growth retardation. The arterial responses to exogenous vasoactive compounds norepinephrine and acetylcholine were not different between the two groups, but sympathetic stimulation with tyramine led to a higher contractile response in hypoxic than in normoxic embryos. Acute hypoxia increased arterial tone and maintained arterial pressure in the chronically hypoxic chick embryos, whereas blood pressure significantly decreased in the normoxic group. These data indicate an enhanced activity of perivascular sympathetic nerves in chronically hypoxic chick embryoes at this stage of development. This could lead to a redistribution of the cardiac output, 
maintaining organ perfusion and oxygenation. However, since the nervous response only became evident during stress conditions, we postulate that mild hypoxia $\left(15 \% \mathrm{O}_{2}\right)$ is not sufficient to activate the sympathetic nervous system or induce such a sustained chemoreflex.

In the third stage, around E19, not only body weight, but also liver and heart weight were significantly lower in the hypoxic chickembryos, whereas brain weight was unaffected. These changes in body weight distribution comply with the growth characteristics commonly found in small for gestational age babies. ${ }^{19}$,

${ }^{20}$ Although blood pressure and heart rate were not different in normoxic and hypoxic fetuses, the peripheral arterial tone was higher in the hypoxic group. Given the enhanced response to the sympathetic nervous stimulator tyramine, in combination with the sensitivity of arterial tone to local $\alpha$-adrenergic blockade, the data indicate that the increase in peripheral arterial tone is due to sympathetic hyperinnervation. In spite of peripheral vasoconstriction during acute hypoxic stress, hypoxic E19 chick embryos were not able to maintain their blood pressure, whereas normoxic fetuses could. In previous studies we showed that chronic hypoxia is associated with left ventricular dysfunction at this age. ${ }^{10}$

The hypoxia-induced alterations in hemodynamics have important consequences for fetal growth. Since organ blood flow is determined by blood pressure and vascular tone, elevated blood pressure in combination with low arterial tone in hypoxic embryos at E13 may increase organ blood flow to facilitate oxygen and nutrient supply. This compensatory hemodynamic response allows proper organ growth even under hypoxic conditions in E13 embryos. However, the increase in peripheral arterial tone due to sympathetic hyperinnervation toward the end of embryonic development in the presence of a normal or decreased blood pressure may reduce peripheral organ perfusion and growth, as indicated by the lower total body and liver weights in hypoxic embryos. In contrast, brain weight remained similar in hypoxic and normoxic embryos. This brain-sparing effect may be explained by the redistribution of cardiac output resulting from enhanced $\alpha$-adrenoceptor-mediated constriction in peripheral vascular beds combined with prevailing vasodilatory mechanisms in the cerebral circulation. ${ }^{14,21,22}$ The changes in body weight distribution observed in our experimental model comply with the disproportionate growth characteristics commonly found in small for gestational age babies, the population most prone to develop CVD. ${ }^{11,23}$

In conclusion, our work identified that hypoxic stress induces structural and functional alterations in the developing fetal cardiovascular system. Cardiac dysfunction and sympathetic hyperinnervation of the peripheral vasculature lead to aberrant fetal hemodynamics preceding fetal growth 
chapter 3

restriction. In line with the fetal origins hypothesis, this study provides evidence that alterations in fetal hemodynamic regulation are in the causal pathway between disturbances in fetal environment, restricted fetal growth, and CVD. Extrapolation of these experimental data to the human situation suggests that cardiovascular disease is already established before birth in growth restricted fetuses. (see Chapter 5).

\section{Acknowledgments}

Support from the Netherlands Heart Foundation to E.R. (grant number 2002T011) and Netherlands Organization for Scientific Research (NWO) - Vidi to F.I.N. is greatly acknowledged. 


\section{Hypoxia Disturbs Fetal Hemodynamics and Growth}

\section{REFERENCES}

1. Barker DJ, Bull AR, Osmond C, Simmonds SJ. Fetal and placental size and risk of hypertension in adult life. British Medical fournal 1990;301(6746):259-62.

2. Barker DJ, Osmond C, Golding I, Kuh D, Wadsworth ME. Growth in utero, blood pressure in childhood and adult life, and mortality from cardiovascular disease. British Medical Journal 1989;298(6673):564-7.

3. Law CM, Shiell AW, Newsome CA, et al. Fetal, infant, and childhood growh and adult blood pressure: a longitudinal study from birth to 22 years of age. Circulation 2002;105(9):1088-92.

4. Rich-Edwards IW, Stampfor MJ, Manson JE, et al. Birth weight and risk of cardiovascular disease in a cohort of women followed up since 1976. British Medical Journal 1997;315(7105):396-400.

5. Barker DJ. Coronary heart disease: a disorder of growth. Hormone Research 2003;59 Suppl 1:35-41.

6. Eriksson JG, Forsen T, Tuomilehto I, Osmond C, Barker DI. Early growth, adult income, and risk of stroke. Stroke 2000;31(4):869-74.

7. Leon DA, Lithell HO, Vagero D, et al. Reduced fetal growth rate and increased risk of death from ischaemic heart disease: cohort study of 15000 Swedish men and women born 1915-29. British Medical Journal 1998;317(7153):241-5.

8. Leeson CP, Whincup PH, Cook DG, et al. Flow-mediated dilation in 9- to 11-year-old children: the influence of intrauterine and childhood factors. Circulation 1997;96(7):2233-8.

9. Leeson CP, Kattenhorn M, Morley R, Lucas A, Deanfield JE. Impact of low birth weight and cardiovascular risk factors on endothelial function in early adult life. Circulation 2001;103191:1264-8.

10. Rouwet EV, Tintu AN, Schellings MW, et al. Hypoxia induces aortic hypertrophic growth, left ventricular dysfunction, and sympathetic hyperinnervation of peripheral arteries in the chick embryo. Circulation 2002;105(23):2791-6.

11. Resnik R. Intrauterine growth restriction. Obstetrics \& Gynecology 2002;99(3):490-6.

12. Rouwet EV, De Mey JG, Slaaf DW, Heineman E, Ramsay G, Le Noble FA. Development of vasomotor responses in fetal mesenteric arteries. Americal Journal of Physiology Heart and Circulatory Physiology 2000;279(3):H1097-105.

13. Takauchi Y, Yamazaki T, Akiyama T. Tyramine-induced endogenous noradrenaline efflux from in silu cardiac sympathetic nerve ending in cats. Acta Physiologica Scandinavica 2000; 168(2):287-9.3.

14. Mulder AL, van Golde IC, Prinzen FW, Blanco CE. Cardiac output distribution in response to hypoxia in the chick embryo in the second half of the incubation time. Journal of Physiology 1998;508 ( Pr 1):281-7. 
15. Nosek TM, Fogaca RT, Hatcher C., Brotto MA, Godt RF. Effecl of cardiac neural cresl ablation on contractile force and calcium uptake and release in chick heart. American Journal of Physiology 1997;273(3 Pt 2):H1464-71.

16. Nathanielsz PW, Hanson MA. The fetal dilemma: spare the brain and spoil the liver. I Physiol 2003;548(Pt 2):333.

17. le Noble FA, Stassen FR, Hacking WJ, Struijker Boudier HA. Angiogenesis and hypertension. I Hypertens 1998;16(11):1563-72.

18. Barker DJ, Bull AR, Osmond C, Simmonds S). Fetal and placental size and risk of hypertension in adult life. BMI 1990;301(6746):259-62.

19. Resnik R. Intrauterine growth restriction. Obstet Gynecol 2002;99(3):490-6.

20. Lin CC, Santolaya-Forgas I. Current concepts of tetal growth restriction: part 1. Causes, classification, and pathophysiology. Obstel Gynecol 1998;92(6):1044-55.

21. Le Noble FA, Ruijtenbeek K, Gommers S, de Mey JG, Blanco CE. Contractile and relaxing reactivity in carotid and femoral arteries of chicken embryos. Americal Journal of Physiology - Heart and Circulatory Physiology 2000;278(4):H1261-8.

22. Ruijtenbeek K, le Noble FA, Janssen CM, et al. Chronic hypoxia stimulates periarterial sympathetic nerve development in chicken embryo. Circulation 2000;102(23):2892-7.

23. Lin CC, Santolaya-Forgas ]. Current concepts of fetal growth restriction: part 1. Causes, classification, and pathophysiology. Obstetrics \& Gynecology 1998;92(6):1044-55. 
CHAPTER 4

Hypoxia Induces Aortic Hypertrophic Growth, Left Ventricular Dysfunction, and Sympathetic Hyperinnervation of Peripheral Arteries in the Chick Embryo

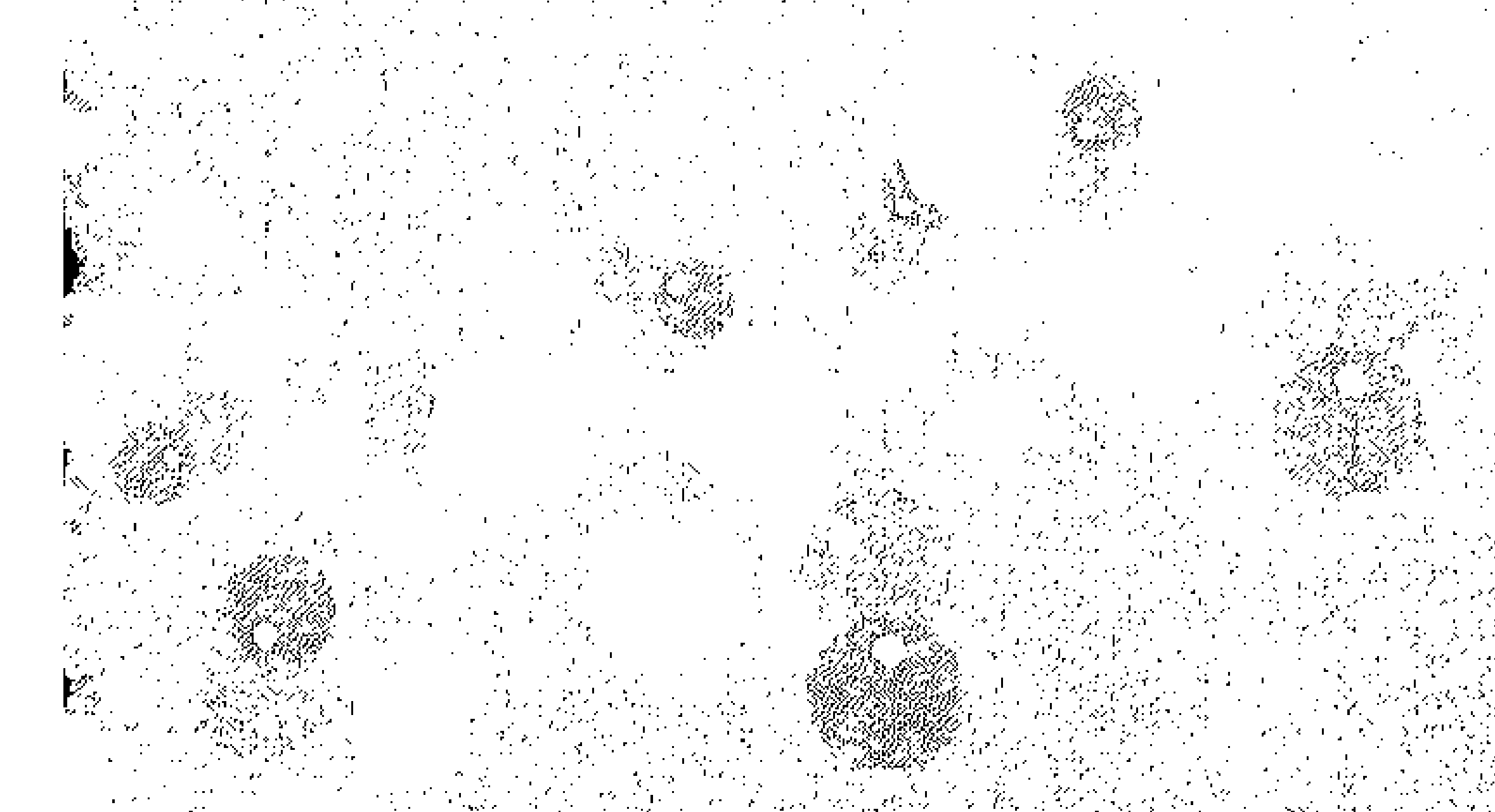

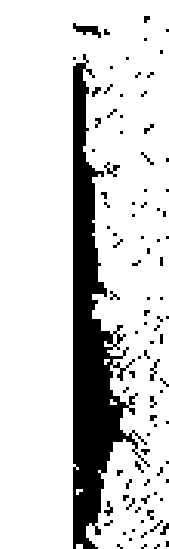




\section{AbStract}

\section{Background}

Low birth weight is associated with an increased incidence of cardiovascular diseases, including hypertension, during later life. This suggests that antenatal insults program for fetal adaptations of the circulatory system. In the present study, we evaluated the effects of mild hypoxia on cardiac function, blood pressure control, and arterial structure and function in the near-term avian embryo.

\section{Methods and Results}

Chick embryos were incubated under normoxic $\left(21 \% \mathrm{O}_{2}\right)$ or hypoxic $\left(15 \% \mathrm{O}_{2}\right)$ conditions, and evaluated at incubation day 19 using histologic techniques, isolated heart preparations, and in vivo measurements of sympathetic arterial tone and systemic hemodynamics. Chronic hypoxia caused a 33\% increase in mortality, and an $11 \%$ reduction in body weight in surviving embryos. The lumen of the ascending aorta in hypoxic embryos was $23 \%$ smaller. Left ventricular systolic pressure was $22 \%$ lower, and heart/body weight ratio was $14 \%$ higher. In resistance arteries of hypoxic embryos, in vivo baseline tone was $23 \%$ higher, norepinephrine sensitivity was similar, and norepinephrine release from sympathetic nerves increased two-fold, indicating sympathetic hyperinnervation. Mean arterial pressure and heart rate were similar under resting conditions, but chronic hypoxic embryos failed to maintain blood pressure during acute stress.

\section{Conclusions}

This study indicates that mild hypoxia during embryonic development induces alterations in cardiac and vascular function and structure, and affects hemodynamic regulation. These findings reveal that antenatal insults have profound effects on the control and design of the circulatory system, which are already established at birth, and may well program for cardiovascular diseases at later age. 


\section{INTRODUCTION}

Cardiovascular diseases account for the highest morbidity and mortality in Western society. Epidemiologic studies have revealed that low birth weight is associated with an increased propensity to coronary heart disease, hypertension, and non-insulin dependent diabetes in later life. ${ }^{1-4}$ Based on these observations it has been proposed that antenatal events, reflected by low weight relative to gestational age at birth, predispose to cardiovascular diseases in adulthood. Furthermore, it has recently been shown that low birth weight independently of the classic risk factors adversely influences endothelial function in childhood and early adult life. ${ }^{5,6}$ These studies suggest that insults at critical phases of development in utero induce permanent alterations in the circulatory system.

In spite of accumulating epidemiologic evidence in support of this fetal programming concept, the physiological mechanism responsible for the association between low birth weight and cardiovascular disease is largely unknown. In addition, one of the critical questions that remains unanswered is whether the circulatory system is already affected at the time of birth. Uteroplacental insufficiency, resulting in chronic impairment in fetal oxygen and nutrient supply, is a major cause of intrauterine growth retardation. The objective of this study was to investigate whether chronic hypoxia during embryonic development 1) induces aberrant formation of the arterial tree, 2) affects cardiac function, and 3) alters functional control of the cardiovascular system. The study was performed in near-term chick embryos which were exposed to a physiologically relevant level of hypoxia of $15 \% \mathrm{O}_{2}$ throughout incubation. The chick embryo is an established experimental model in developmental biology. Since the avian embryo develops independently of its mother animal, this allows a unique comprehensive approach to the effects of isolated hypoxia consisting of histologic techniques, isolated heart preparations, as well as in vivo measurements of arterial tone and systemic hemodynamics. 


\section{Methods}

Experimental procedures were in accordance with the Dutch law on the use of laboratory animals. Fertile Lohman-selected White Leghorn eggs were incubated at a temperature of $37^{\circ} \mathrm{C}$ and relative air humidity of $60 \%$, and were exposed to either $21 \% \mathrm{O}_{2}$ in the normoxic $(\mathrm{N})$ group, or to $15 \% \mathrm{O}_{2}$ in the chronic hypoxic $(\mathrm{CH})$ group from the first day of incubation onward. Experiments were conducted at day 19 of the 21-day incubation period, corresponding to 0.9 of the total incubation time.

\section{General Characteristics}

To assess the effect of chronic hypoxia on general characteristics, we determined survival rate, body weight, and hematocrit. We furthermore investigated whether chronic hypoxia prolonged the time to hatching.

\section{Vascular Morphology}

To determine the effect of chronic hypoxia on vascular morphology, embryos were sacrificed and the arterial tree was perfused at a standardized pressure of 30 $\mathrm{mmHg}$ through a catheter introduced into the left ventricle with PBS and $1 \%$

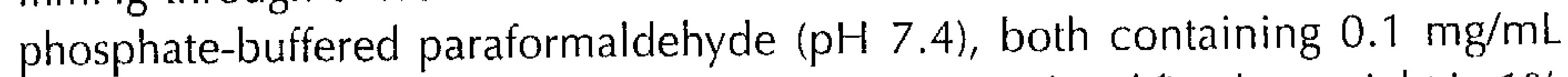
sodiumnitroprusside. ${ }^{7}$ The ascending aorta was excised and fixed overnight in $1 \%$ phosphate-buffered paraformaldehyde. Segments were routinely processed and embedded in paraffin, and $4-\mu \mathrm{m}$ cross sections were stained with hematoxylin and eosin. Consecutive sections were stained with Lawson's solution (a modified elastica von Giesson staining) to visualize elastic laminae, and immunolabeled with -smooth muscle actin (monoclonal, 1:300, FITC-labeled, Sigma Chemical Co) as a smooth muscle cell marker. Immunostaining was performed according to conventional methods with anti-FITChrp labeled secondary antibodies (1:300, Roche Diagnostics Co.) and 3,3'-diaminobenzidine (DAB) as a chromogen. Sections were counterstained with hematoxylin and mounted with coverslips. The internal circumference (IC, the length of the endothelium) and external circumference (EC, the length of the external elastic lamina) were determined using a microscope coupled to a computerized morphometry system (Quantimet 570, Leica, the Netherlands). The lumen diameter, outer vessel diameter, and wall/lumen ratio were calculated from the $\mathrm{IC}$ and $\mathrm{EC}$, respectively, assuming a circular configuration. 


\section{Cardiac Function and Geometry}

The effect of chronic hypoxia on left ventricular performance was evaluated using a retrograde "Langendorff" isolated heart perfusion system, originally designed for the murine heart. ${ }^{8}$ In short, after sacrifice of the embryo, the heart was excised and placed in ice-chilled perfusion buffer. A cannula was inserted into the aortic outflow tract, the heart was placed in the temperature-controlled $\left(37^{\circ} \mathrm{C}\right)$ perfusion setup, and retrograde perfusion with a modified Krebs-Henseleit solution was started. Aortic pressure was measured through a side branch of the aortic cannula and was kept at $30 \mathrm{mmHg}$, which was similar to the mean arterial pressure at this stage of development. The hearts were paced at a physiological rate of 225 beats $/ \mathrm{min}$ via platinum electrodes attached to the right atrium. Left ventricular pressure was measured via a PE-50 catheter inserted into the left ventricular cavity at the apex and connected to a standard pressure transducer (Baxter Uniflow, Baxter B.V., Uden, the Netherlands). After an equilibration period of 15 minutes left ventricular end-diastolic pressure, left ventricular systolic pressure, and aortic pressure were recorded by a data acquisition system. The maxima and minima of the first derivative of left ventricular pressure ( $L V \mathrm{dP} / \mathrm{dt}_{\max }$ and $\mathrm{LV} \mathrm{dP/dt_{ \operatorname {min } }}$ ) were calculated. The effect of chronic hypoxia on cardiac mass was determined on freshly excised hearts. For cardiac histology, hearts were fixed in diastole, excised, put overnight in $1 \%$ phosphate-buffered paraformaldehyde, routinely processed, and embedded in paraffin. Sections of $4 \mu \mathrm{m}$ were cut perpendicular to the long axis of the heart and stained with hematoxylin and eosin. Left ventricular free wall thickness and cross sectional area, as well as ventricular septum thickness were determined using a microscope coupled to a computerized morphometry system (Quantimet 570, Leica, the Netherlands).

\section{Peripheral Arterial Control}

The effect of chronic hypoxia on control of peripheral arterial tone was assessed in vivo, by measuring diameter changes of mesenteric resistance arteries in response to pharmacological and physiological stimuli by means of intravital videomicroscopy, as described in detail elsewhere. ${ }^{9}$ In short, the egg was opened, the chorioallantoic membrane was penetrated, and a segment of the intestine with its mesentery was exposed and stabilized. The egg was placed in a temperature and air flow controlled single-egg chamber $\left(37^{\circ} \mathrm{C}, 4 \mathrm{~L} / \mathrm{min}\right)$. Experiments were performed at an $\mathrm{O}_{2}$ level of $21 \%$, unless stated otherwise. Second order mesenteric resistance arteries were visualized using an intravital microscope setup equipped with a $20 x$ long working distance objective (optical magnification $880 x$, final resolution $1 \mu \mathrm{m})$. Images were recorded on videotape and arterial diameters were analyzed off-line using an image-shearing device (IPM, model 908, San 
Diego, (A). Changes in diameter are presented as percentage of baseline diameter. Alpha-adrenergic arterial tone under baseline conditions was determined by measuring the dilator response to the topically applied $\alpha$-adrenoceptor antagonist phentolamine (Phent, 20- $\mu \mathrm{L}$ aliquots, $10^{-3} \mathrm{M}$ ). Alpha-adrenoceptor mediated vasoconstrictor capacity was assessed by measuring changes in arterial diameter in response to sequential application of increasing concentrations of norepinephrine (NE, 20- $\mu \mathrm{L}$ aliquots, $\left.10^{-6}-10^{-2} \mathrm{M}\right)$. Maximal diameters were determined by measuring the vasodilator response to acetylcholine $\left(\mathrm{ACh}, 20-\mu \mathrm{L}\right.$ aliquots, $10^{-2} \mathrm{M}$ ). Administration of these drug concentrations to the mesentery has previously been shown to result in physiologically relevant vasomotor responses. ${ }^{9}$

Functional autonomic nervous control of the peripheral vasculature was assessed by measuring the arterial constrictor response to topically applied tyramine (Tyr, 20- $\mu \mathrm{L}$ aliquots, $10^{-6}-10^{-2} \mathrm{M}$ ). Tyramine releases norepinephrine from perivascular sympathetic nerve endings without affecting presynaptic reuptake. Since the contractile response to tyramine reflects the total norepinephrine content of the perivascular sympathetic nerve endings, ${ }^{10}$ this is a sophisticated method for assessing sympathetic nerve function in vivo.

Phentolamine, norepinephrine, acetylcholine, and tyramine were obtained from Sigma Chemical Co (St. Louis, MO). Drugs were dissolved in HEPES buffered Krebs with the following composition (in $\mathrm{mM}$ ): $\mathrm{NaCl} 143.3$, $\mathrm{KCl} 4.7, \mathrm{MgSO}_{4} 1.2, \mathrm{KH}_{2} \mathrm{PO}_{4} 1.2, \mathrm{CaCl}_{2} 2.5$, glucose 5.6, HEPES 15; $\mathrm{pH} 7.4$. Drugs were freshly prepared on the day of the experiment; temperature of the solutions at the time of administration was $37^{\circ} \mathrm{C}$.

\section{Systemic Hemodynamics}

To investigate the influence of chronic hypoxia on central hemodynamic control, we measured mean arterial pressure and heart rate according to a previously described method. ${ }^{9}$ In short, a catheter was inserted into a branch of the chorioallantoic artery and connected to a pressure transducer (Baxter Uniflow, Baxter B.V., Uden, the Netherlands) which was placed at egg height. Pressure signals were recorded on a computer using a data acquisition system and the heart rate was calculated. In addition to measurements under baseline conditions (at $21 \% \mathrm{O}_{2}$ ), blood pressure, heart rate, and peripheral arterial tone were also measured during acute severe hypoxic stress. An acute reduction in blood oxygen level is a standard stimulus for triggering a stress response in the embryo, which is characterized by bradycardia and enhanced autonomic nervous system output aimed at maintaining blood pressure. Acute hypoxia was induced by replacing the ambient air in the egg chamber by $100 \% \mathrm{~N}_{2}(4 \mathrm{~L} / \mathrm{min})$ for 5 minutes. 
Embryonic Hypoxia Induces Cardiovascular Abnormalities

\section{Statistics}

Data are expressed as mean \pm SE. The term $n$ refers to the number of embryos. All experiments were performed in separate series of embryos. Statistical comparisons between groups were made using the Mann-Whitney $U$ test. Statistical comparisons within groups were made using the Wilcoxon signed ranks test. Statistical significance was defined as $\mathrm{P}<0.05$.

\section{RESULTS}

\section{General Characteristics}

Survival rate at 0.9 incubation time was lower in the $\mathrm{CH}\left(15 \% \mathrm{O}_{2}, \mathrm{n}=22\right)$ group as compared with the $\mathrm{N}\left(21 \% \mathrm{O}_{2}, \mathrm{n}=21\right)$ group (50\% vs. $\left.71.4 \%\right)$. Surviving chronic hypoxic embryos had a lower body weight $(21.9 \pm 0.49$ vs. $24.7 \pm 0.40 \mathrm{~g}$, $P<0.001)$ and higher hematocrit $(0.34 \pm 0.014$ vs. $0.30 \pm 0.010, P<0.05)$ as

A

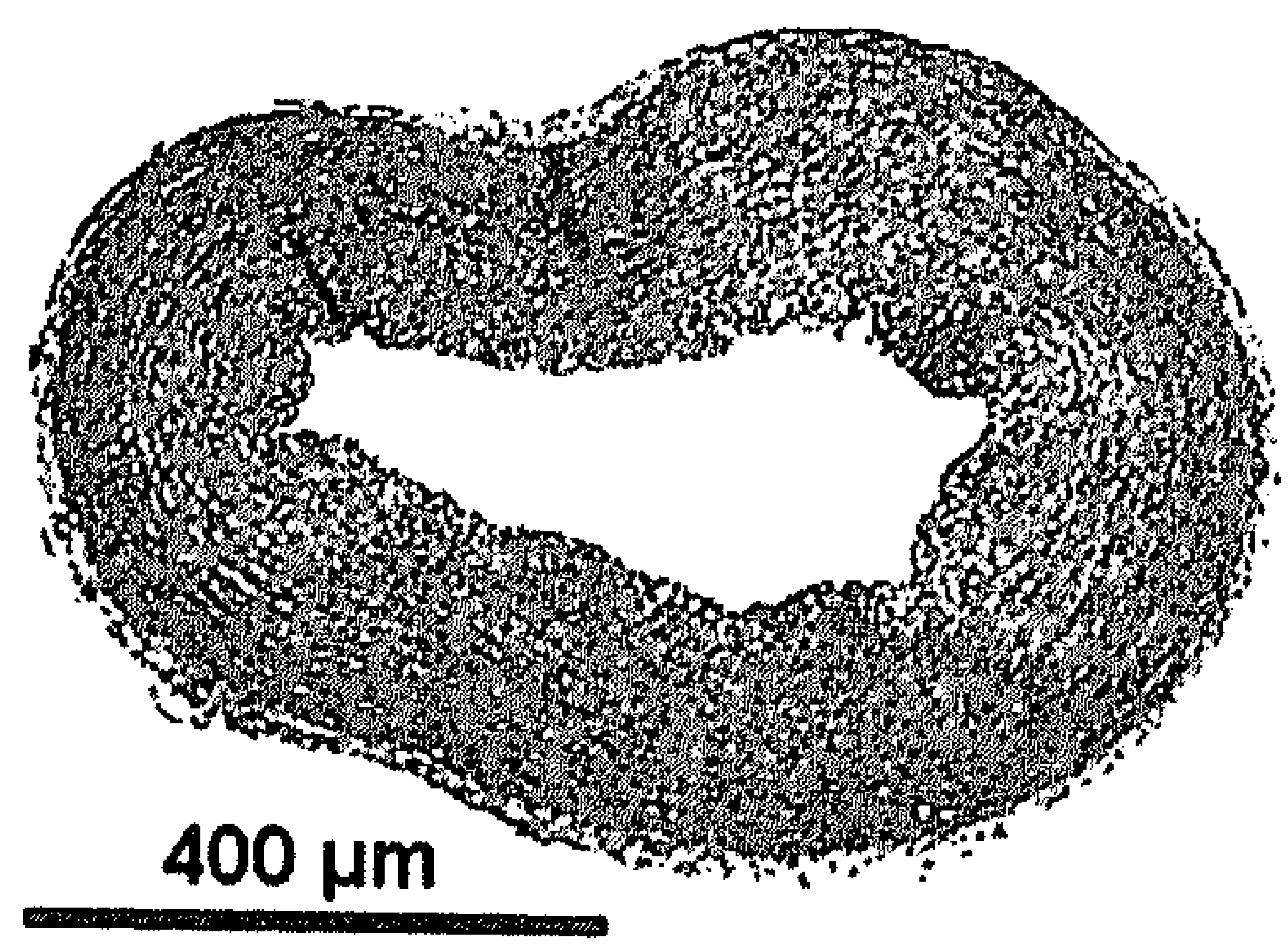

B

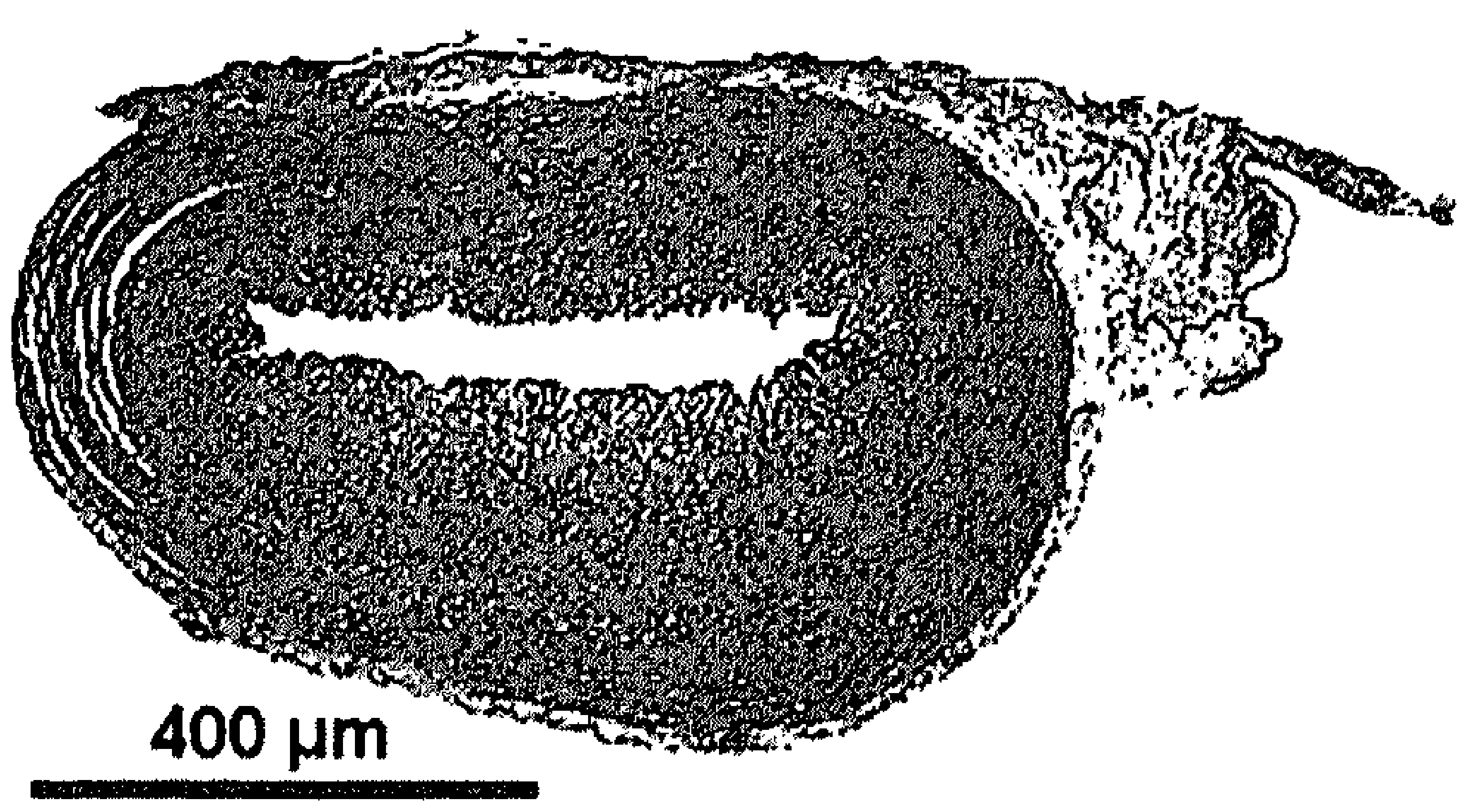

Figure 1 Lawson-stained sections of the ascending aorta of $N(A)$ and $C H$ embryos (B). 
compared with normoxic embryos. Hamilton stages ( $\mathrm{HH} \mathrm{43/44)} \mathrm{at} \mathrm{the} \mathrm{time} \mathrm{of}$ experiments, as well as the time to hatching (day 21 of incubation) were similar in chronic hypoxic and normoxic embryos. This confirms that the experimental protocol induced small embryos, without apparent developmental retardation.
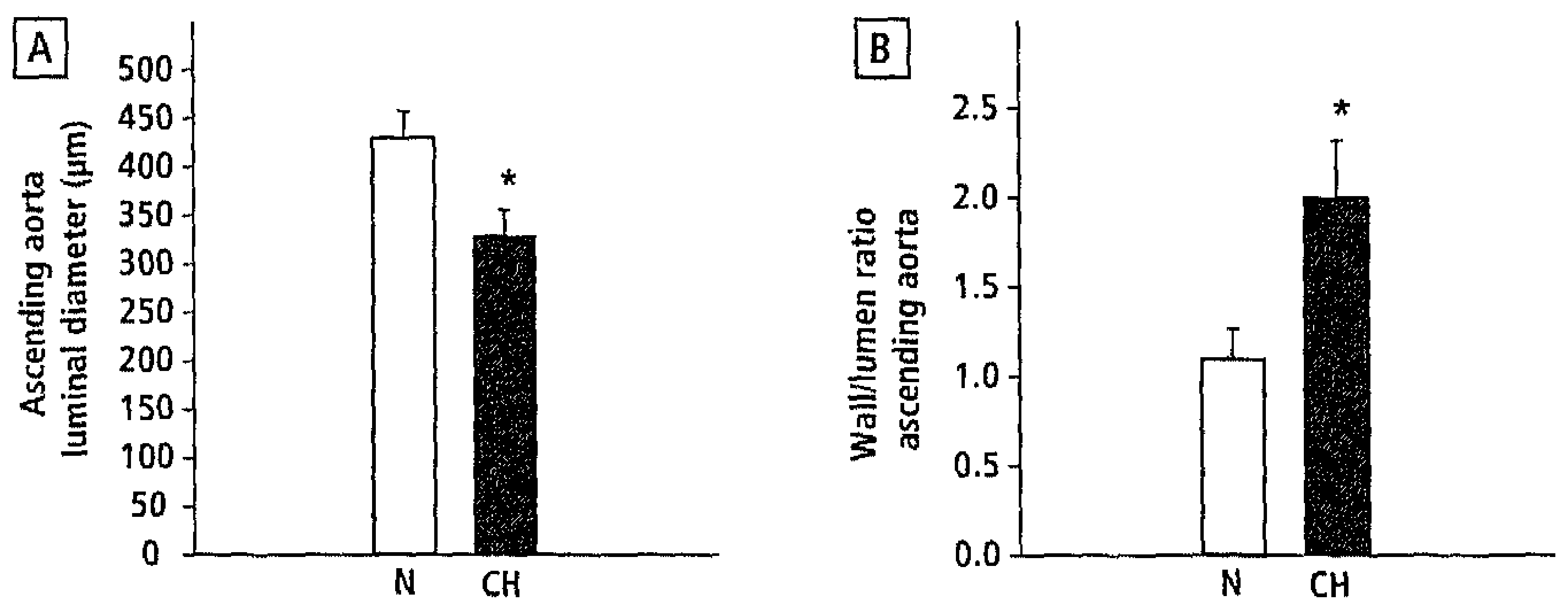

Figure 2 Luminal diameter $(A)$ and wall/lumen ratio $(B)$ of the ascending aorta of $\mathrm{CH}(n=11)$ and $N$ embryos $(n=7)$. Values are mean $\pm S E ;{ }^{*} P<0.05 \mathrm{CH}$ vs. $N$.

\section{Vascular Morphology}

The effect of chronic hypoxia on vascular morphology is shown in Figure 1. The luminal diameter of the ascending aorta was smaller in the $\mathrm{CH}(n=11)$ as compared with the $N(n=7)$ group ( $328 \pm 28$ vs. $430 \pm 28 \mu \mathrm{m}, P<0.05$; Fig. $2 A)$, whereas the outer vessel diameters were not different between the two groups $(896 \pm 40$ vs. $890 \pm 68 \mu \mathrm{m})$. As a result, the wall/lumen ratio was higher in the $\mathrm{CH}$ compared with the $N$ group ( $2.0 \pm 0.32$ vs. $1.1 \pm 0.17, P<0.05$; Fig. $2 B$ ). These data indicate that hypoxia is associated with reduced lumen size of the ascending aorta, in the presence of hypertrophic growth.

\section{Cardiac Function and Geometry}

Left ventricular function was determined under similar conditions (aortic pressure $30 \mathrm{mmHg}$, heart rate 225 beats $/ \mathrm{min}$ ) in the $\mathrm{CH}$ and $\mathrm{N}$ group (both $n=5$ ). These values resembled the in vivo measured mean arterial pressure and heart rate at this stage of development (see below). There was no significant difference in end-diastolic pressure between the two groups ( $8 \pm 2.4$ vs. $8 \pm 2.3$ $\mathrm{mmHg}$ ). Left ventricular systolic pressure was $22 \%$ lower in the $\mathrm{CH}$ as compared with the $\mathrm{N}$ group $(35 \pm 1.0$ vs. $45 \pm 3.5 \mathrm{mmHg}, \mathrm{P}<0.05$; Fig. 3 ). LV

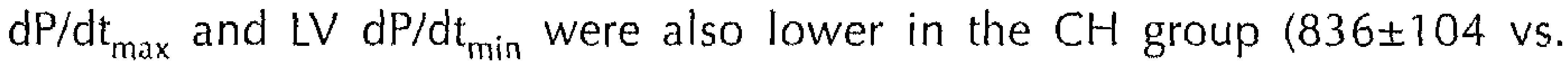
$1109 \pm 101 \mathrm{mmHg} / \mathrm{s}, \mathrm{P}=0.076 ; 679 \pm 29$ vs. $957 \pm 68 \mathrm{mmHg} / \mathrm{s}, \mathrm{P}<0.01)$. 


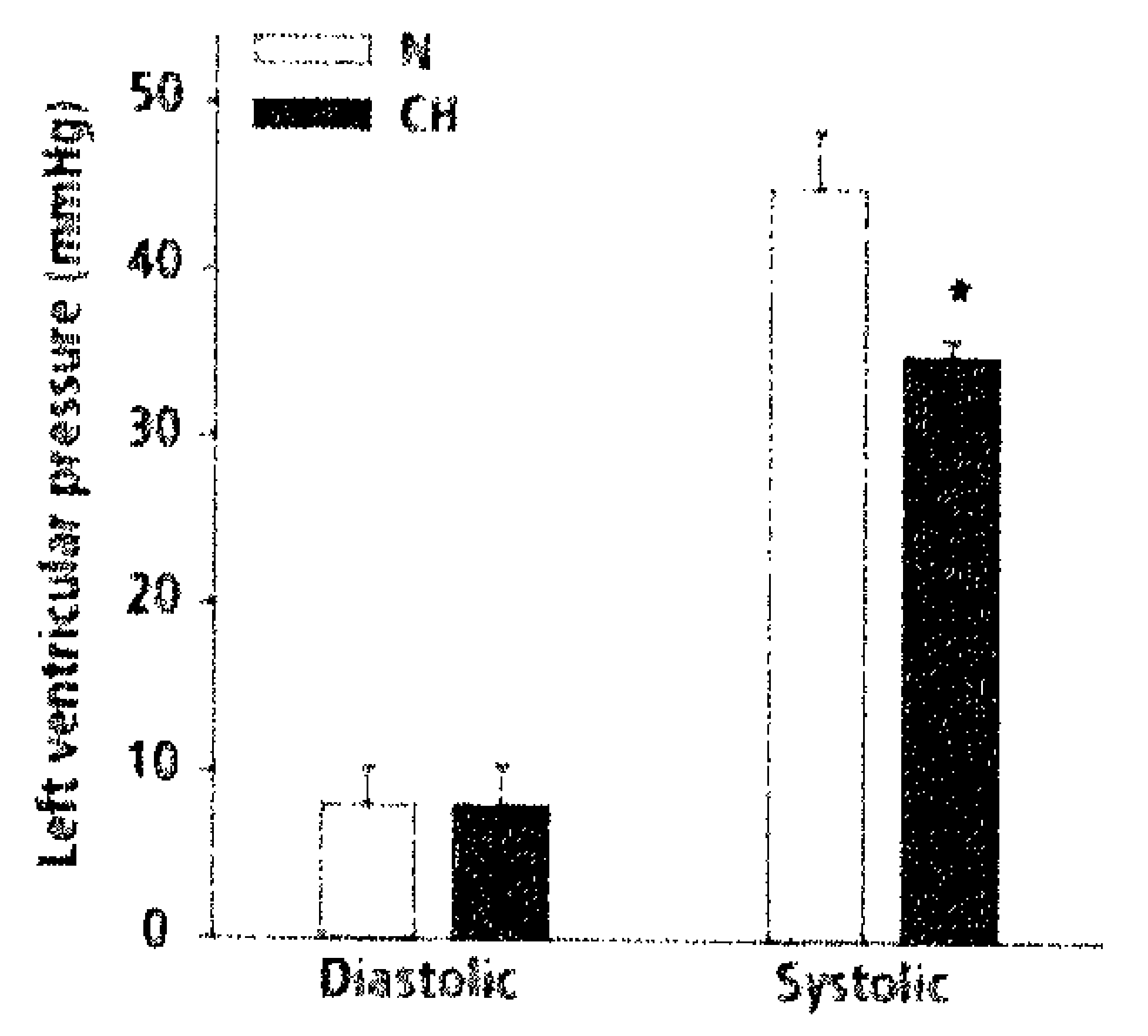

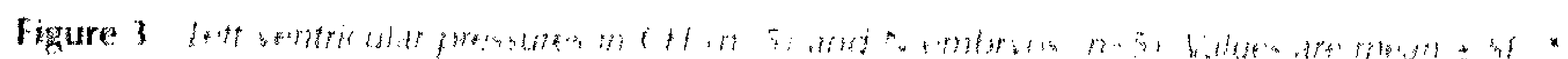

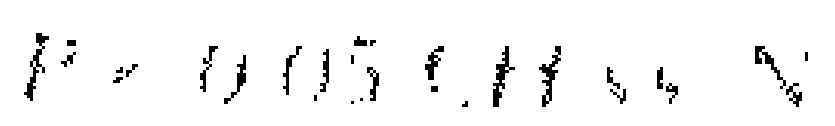

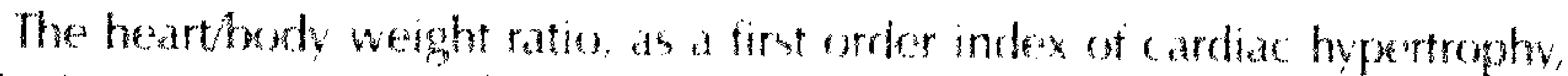

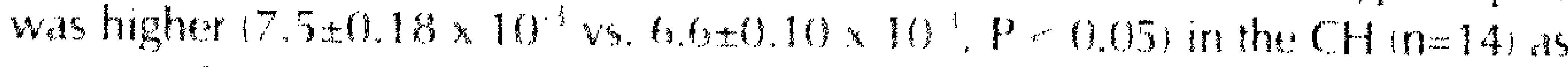
compared with the $\mathrm{N}$ group $n=81$. Let vestricular frese wall thickness and area were compable between the twa groups $0.73+0.0625 .0 .730 .07 \mathrm{~mm}$ and

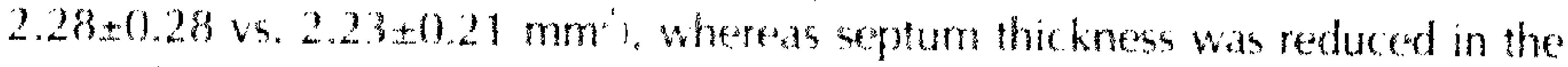
CH embryos $10.77 \pm 0.02$ w. $1.18 \pm 0.07 \mathrm{~mm}^{2} \mathrm{P}$ \& 0.0011 . These data indicate that hypoxia is assodated with disturbed cardiat contractile function in the presence of mild hipertrophr.

\section{Peripheral Arterial Control}

Absolute arterial diameters unler baseline conditions were smaller in the $\mathrm{CH}$ group as compared with the $N$ group $174 \pm 4.0$ vs. $91 \pm 3.4 \mathrm{\mu m}$. Alphaadrenoceptor blockade with phentolamine induced a significantly stronger dilation of the mesenteric resistance arteries in the $\mathrm{CH}(\mathrm{n}=5)$ group as compared with the $N$ in $=7$ group $10134 \pm 3.4 \%$ vs. $111 \pm 2.4 \%$ of baseline. $P$ 0.01: Fig. 4 , indicating a $23 \%$ higher baseline arterial tone in the $\mathrm{CH}$ group. Application of increasing concentrations of norepinephrine (NE) caused a decrease in arterial diameter in the $\mathrm{CH}(\mathrm{n}=8)$ and $\mathrm{N}(\mathrm{n}=9)$ group. Maximal constrictor response at $10^{\prime} \mathrm{M}$ NE was similar in both groups to $34 \pm 3.6 \%$ and $29 \pm 2.0 \%$ of baseline: Fig. 51. Absolute maximal diameters in response to $10^{\circ}$ M ACh were similar in both groups $(104 \pm 5.0$ and $104 \pm 4.9 \mu \mathrm{m})$.

Application of ine reasing concentrations of tyramine (Tyr) induced a gradual reduction in mesenteric arterial diameter in both the: $\mathrm{CH}$ and $\mathrm{N}$ group thoth n -8 , data not shown). Maximal arterial constriction was always obtained at $10^{\circ} \mathrm{M}$ Tyr, and was grester in the $\mathrm{CH}$ compared with the $\mathrm{N}$ group $(37+1.6 \%$ 


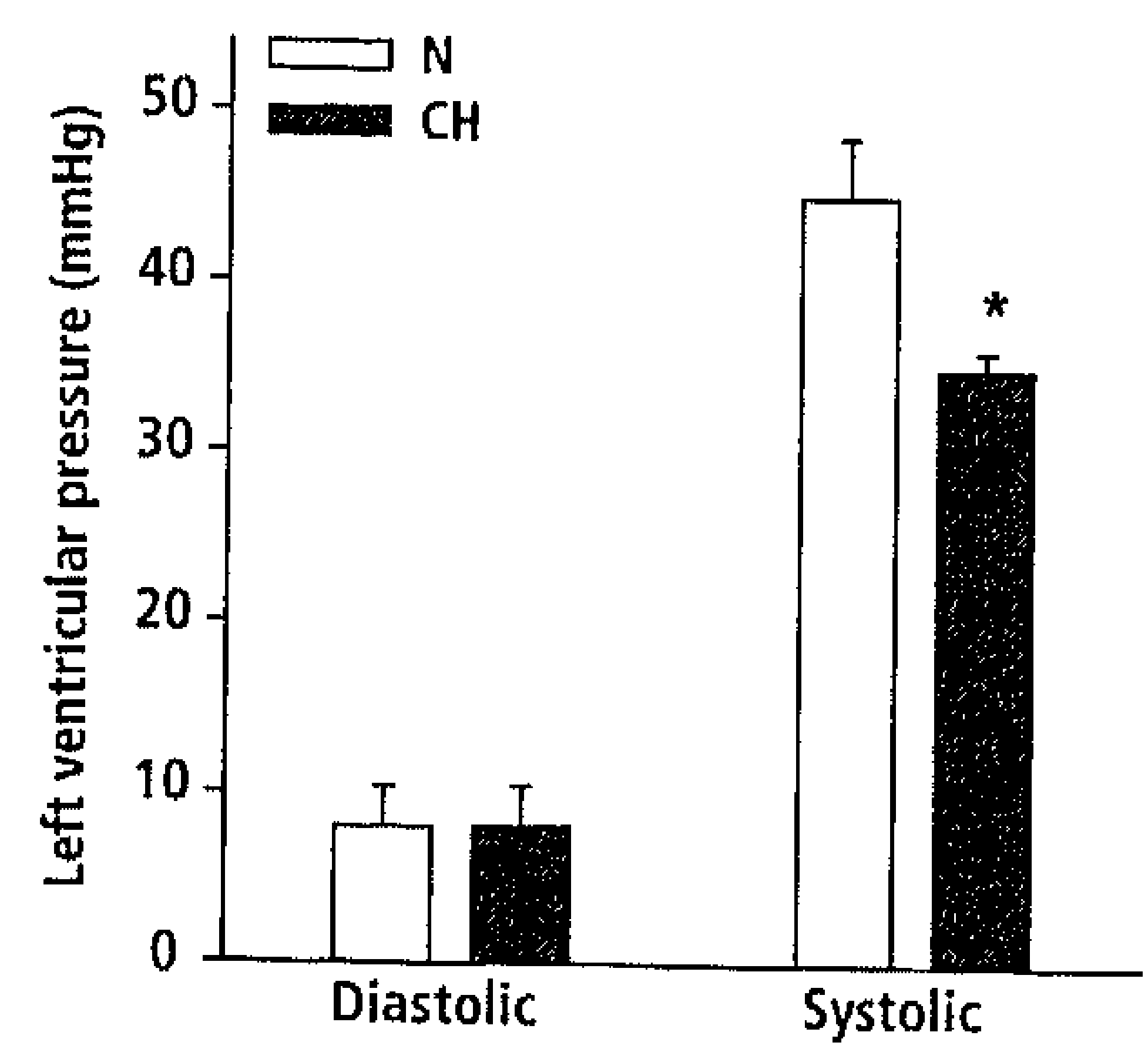

Figure 3 Left ventricular pressures in $C H(n=5)$ and $N$ embryos (n=5). Values are mean $\pm S E$; * $P<0.05 \mathrm{CH}$ vs. N.

The heart/body weight ratio, as a first order index of cardiac hypertrophy, was higher $\left(7.5 \pm 0.18 \times 10^{-3}\right.$ vs. $\left.6.6 \pm 0.10 \times 10^{-3}, \mathrm{P}<0.05\right)$ in the $\mathrm{CH}(\mathrm{n}=14)$ as compared with the $\mathrm{N}$ group $(n=8)$. Left ventricular free wall thickness and area were comparable between the two groups $(0.73 \pm 0.06 \mathrm{vs}$. $0.73 \pm 0.07 \mathrm{~mm}$, and $2.28 \pm 0.28$ vs. $\left.2.23 \pm 0.21 \mathrm{~mm}^{2}\right)$, whereas septum thickness was reduced in the $\mathrm{CH}$ embryos $\left(0.77 \pm 0.02\right.$ vs. $\left.1.18 \pm 0.07 \mathrm{~mm}^{2}, \mathrm{P}<0.001\right)$. These data indicate that hypoxia is associated with disturbed cardiac contractile function in the presence of mild hypertrophy.

\section{Peripheral Arterial Control}

Absolute arterial diameters under baseline conditions were smaller in the $\mathrm{CH}$ group as compared with the $N$ group $(74 \pm 4.0$ vs. $91 \pm 3.4 \mu \mathrm{m})$. Alphaadrenoceptor blockade with phentolamine induced a significantly stronger dilation of the mesenteric resistance arteries in the $\mathrm{CH}(n=5)$ group as compared with the $N(n=7)$ group (to $134 \pm 3.4 \%$ vs. $111 \pm 2.4 \%$ of baseline, $P<$ 0.01 ; Fig. 4), indicating a $23 \%$ higher baseline arterial tone in the $\mathrm{CH}$ group. Application of increasing concentrations of norepinephrine (NE) caused a decrease in arterial diameter in the $\mathrm{CH}(\mathrm{n}=8)$ and $\mathrm{N}(\mathrm{n}=9)$ group. Maximal constrictor response at $10^{-3} \mathrm{M} \mathrm{NE}$ was similar in both groups (to $34 \pm 3.6 \%$ and $29 \pm 2.0 \%$ of baseline; Fig. 5). Absolute maximal diameters in response to $10^{-2}$ M ACh were similar in both groups $(104 \pm 5.0$ and $104 \pm 4.9 \mu \mathrm{m})$.

Application of increasing concentrations of tyramine (Tyr) induced a gradual reduction in mesenteric arterial diameter in both the $\mathrm{CH}$ and $\mathrm{N}$ group (both $n=8$, data not shown). Maximal arterial constriction was always obtained at $10^{-3} \mathrm{MTyr}$, and was greater in the $\mathrm{CH}$ compared with the $\mathrm{N}$ group $(37 \pm 3.6 \%$ 


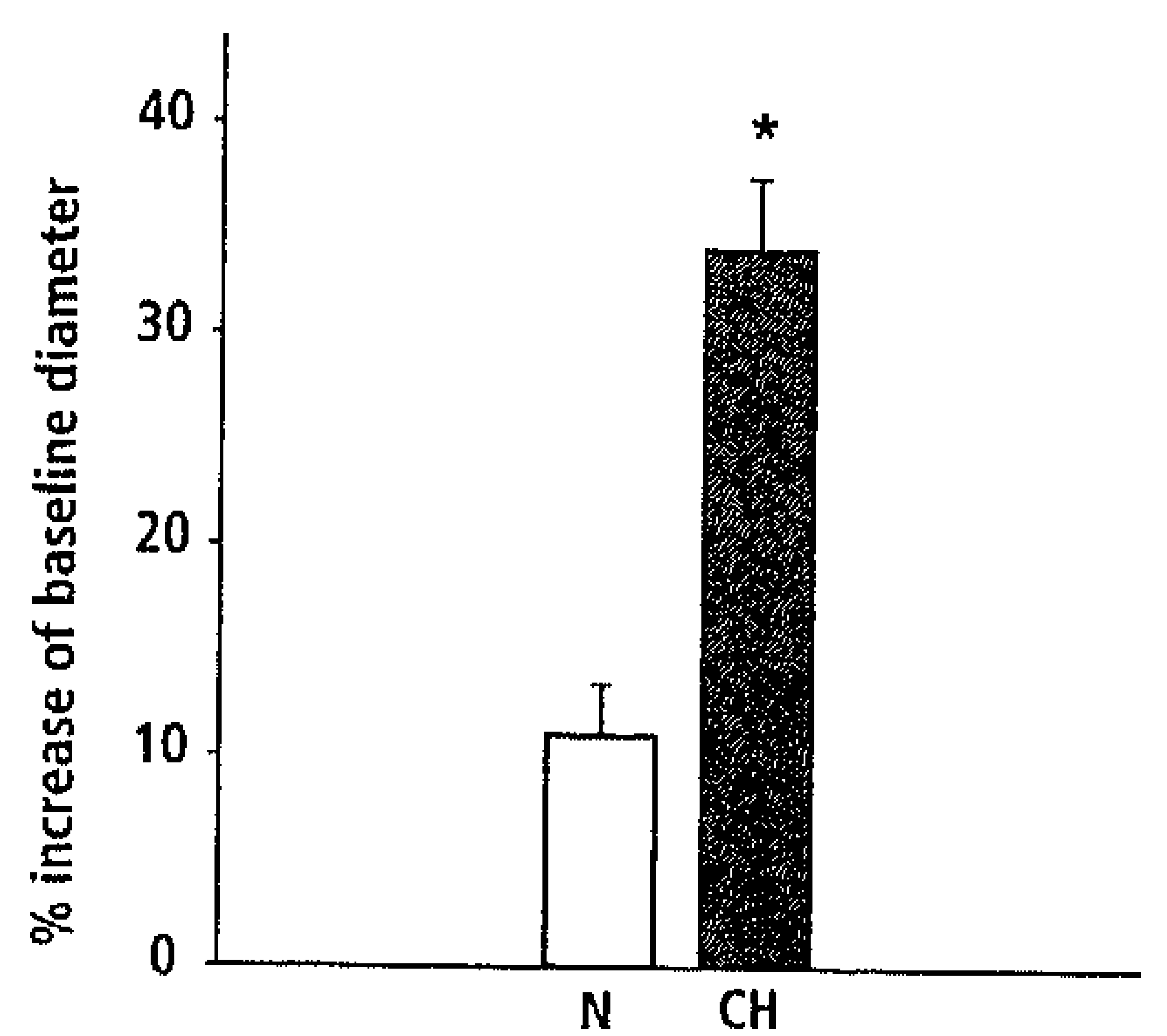

Figure 4 In vivo dilator responses to exogenous phentolamine $\left(10^{-3} \mathrm{M}\right)$ in mesenteric resistance arteries of $\mathrm{CH}(n=5)$ and $N$ embryos $(n=7)$, expressed as percentage increase of baseline diameter. Values are mean $\pm S E ;{ }^{*} P<0.05 \mathrm{CH}$ vs. $N$.

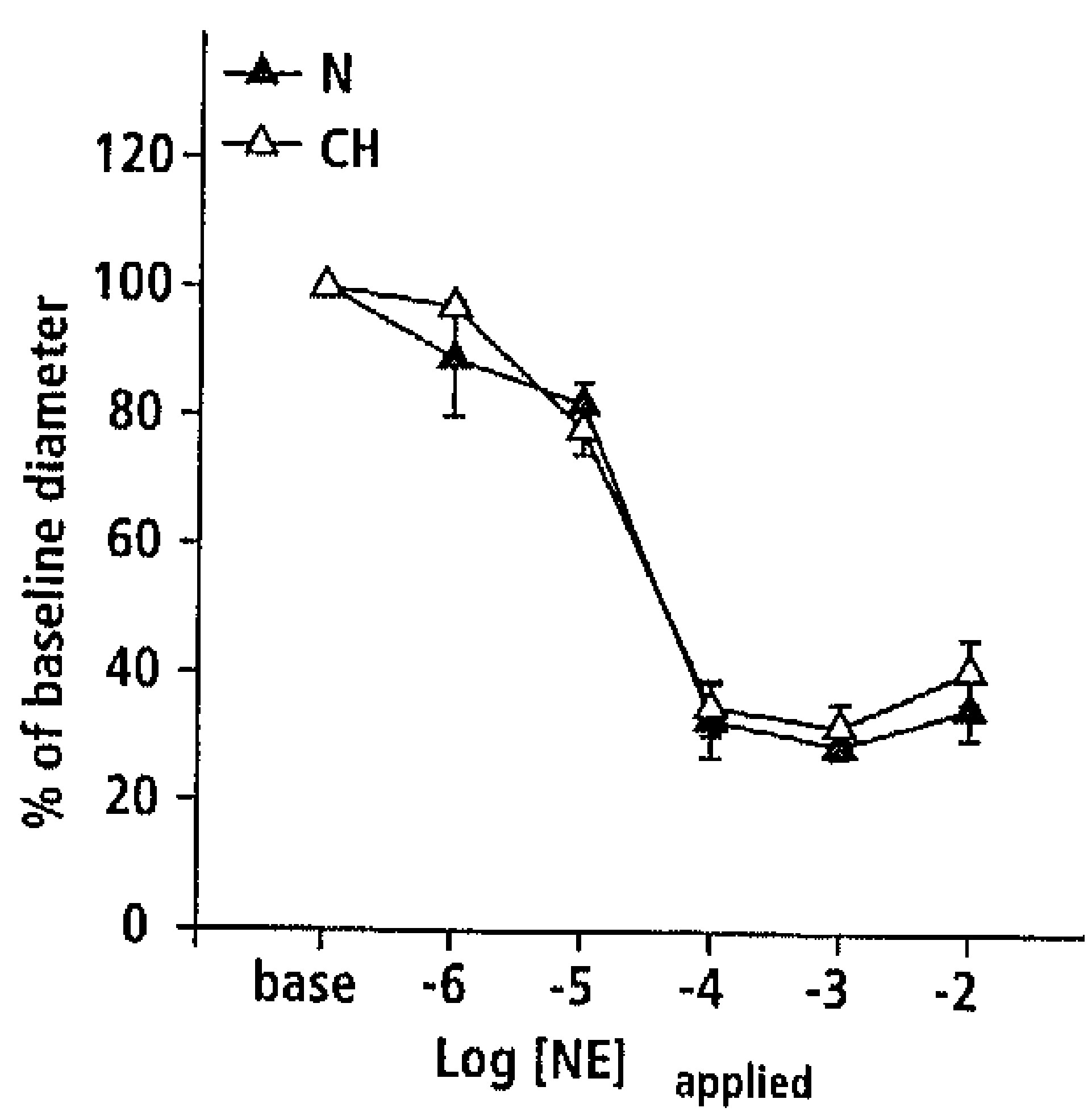

Figure 5 In vivo constrictor responses to exogenous norepinephrine in mesenteric resistance arteries of $\mathrm{CH}(n=8)$ and $\mathrm{N}$ embryos $(n=9)$, expressed relative to baseline diameter $(100 \%)$. Values are mean $\pm S E$.

vs. $19 \pm 5.2 \%$ decrease of baseline, $\mathrm{P}<0.01$; Fig. 6 ). These data indicate that peripheral arterial tone was enhanced in $\mathrm{CH}$ embryos, due to increased functional sympathetic innervation in the presence of similar $\alpha$-adrenergic sensitivity of the peripheral vasculature. 


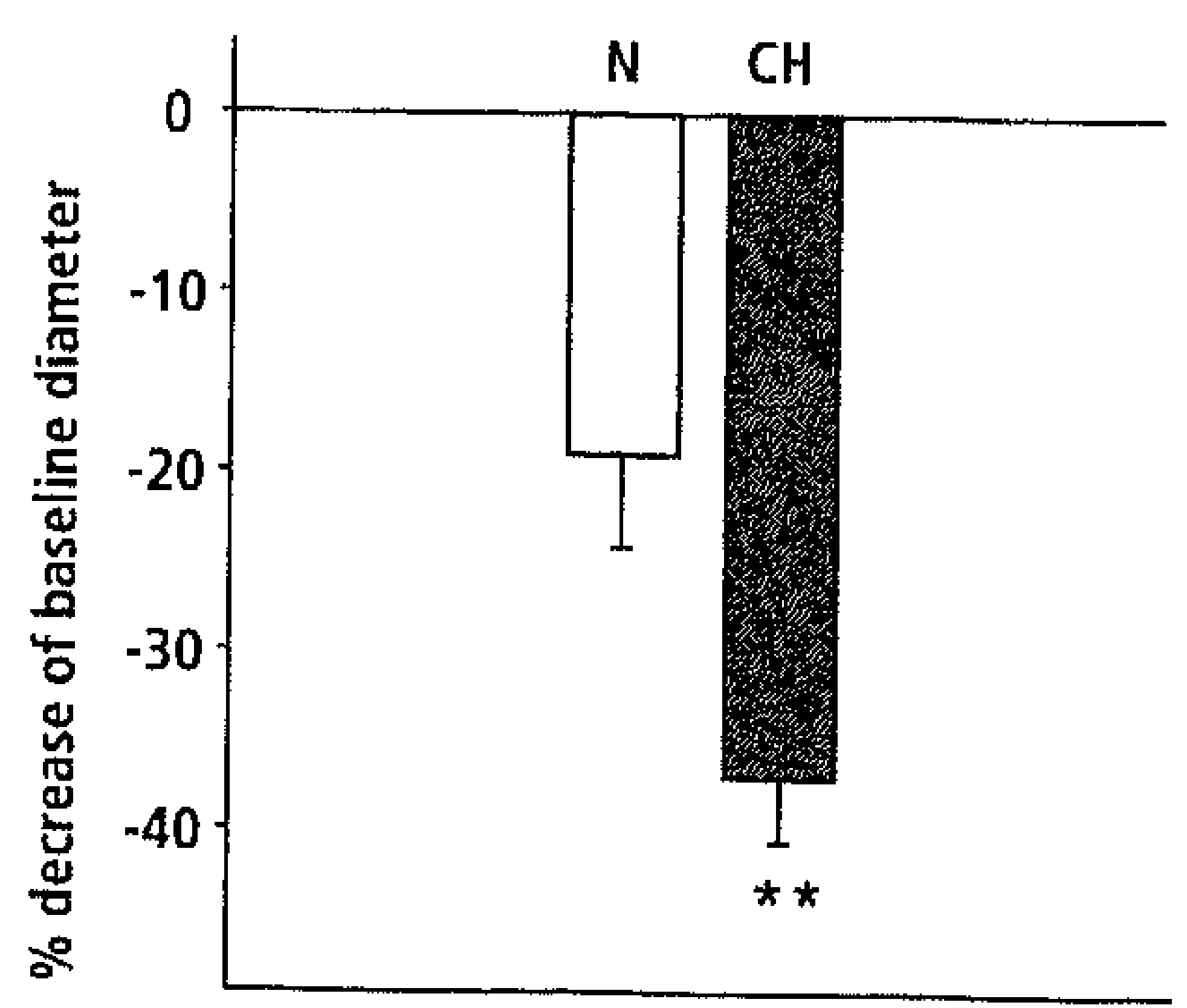

Figure 6 In vivo constrictor responses to exogenous tyramine $\left(10^{3} \mathrm{M}\right)$ in mesenteric resistance arteries of $\mathrm{CH}(n=8)$ and $\mathrm{N}$ cmbryos $(n=8)$, expressed as percentage decrease of baseline diameter. Values are mean $\pm S F ; * * P<0.01 \mathrm{CH}$ vs. $N$.

\section{Systemic Hemodynamics}

Under baseline conditions mean arterial pressure and heart rate were similar in the $\mathrm{CH}(27 \pm 2.2 \mathrm{mmHg}$ and $205 \pm 6$ beats/min, $\mathrm{n}=8)$ and $\mathrm{N}$ group $(25 \pm 1.4$ $\mathrm{mmHg}$ and $199 \pm 9$ beats/min, $n=9$ ). However, during acute hypoxic stress mean arterial pressure significantly decreased in the $\mathrm{CH}$ group (to $22 \pm 1.8 \mathrm{mmHg}, \mathrm{P}<$ 0.05; Fig. 7A), whereas it remained constant in the $\mathrm{N}$ group $(27 \pm 1.0 \mathrm{mmHg})$. Acute hypoxia was associated with a significant $(P<0.01)$ degree of bradycardia ( $132 \pm 3$ and $117 \pm 6$ beats $/ \mathrm{min})$, and an equally significant $(P<0.01)$ constriction of the mesenteric resistance arteries in the $\mathrm{CH}(n=9)$ and $\mathrm{N}(\mathrm{n}=10)$ group (to $42 \pm 2.5 \%$ and $46 \pm 5.3 \%$ of baseline; Fig. $7 \mathrm{~B}$ ). These data indicate that hypoxia is accompanied by failure to maintain blood pressure during stress.
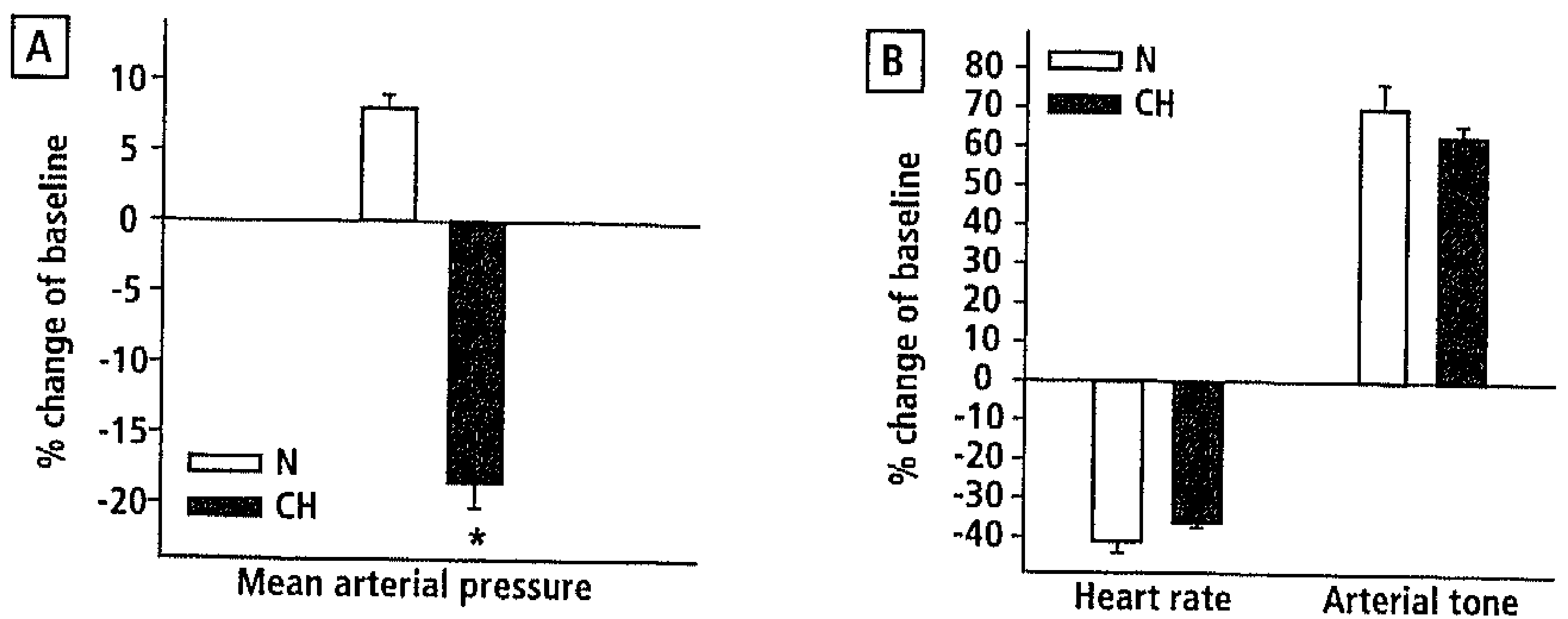

Figure 7 Change in mean arterial pressure $(A)$, heart rate, and peripheral arterial tone $(B)$ during acute hypoxic stress in $\mathrm{CH}(n=8$ and $n=9)$ and $N$ embryos ( $n=9$ and $n=10)$. Values are mean $\pm S E ; * P<0.05 \mathrm{CH}$ vs. $N$. 


\section{Discussion}

Our work demonstrates that mild hypoxia during embryonic development induces structural abnormalities of the ascending aorta, cardiac pump dysfunction, and sympathetic hyperinnervation of the resistance vasculature in the near-term embryo. As a consequence of these profound alterations at all levels of the cardiovascular system, the avian embryo showed signs of circulatory failure, as evidenced by the fall in blood pressure under stress conditions. In contrast with previous studies on fetal programming, this study reveals that chronic exposure of the embryo to hypoxia leads to structural and functional cardiovascular abnormalities already present at the time of birth.

We observed that, as a consequence of media hypertrophy, the lumen size of the ascending aorta was smaller in chronic hypoxic embryos. These changes in structural characteristics of the aortic wall are associated with an increase in resistance and a decrease in elastic properties, leading to reduced compliance. Similar alterations are implied in the pathogenesis of essential hypertension. ${ }^{11}$

Our in vivo measurements in the mesenteric vascular bed revealed an increase in arterial tone under baseline conditions. Furthermore, the contractile responsiveness to direct stimulation of perivascular sympathetic nerves by tyramine was two-fold higher in chronic hypoxic embryos, whereas maximal responsiveness and sensitivity to norepinephrine were not altered. Together, these data indicate that chronic hypoxia induces sympathetic hyperinnervation of resistance arteries, leading to an increase in adrenergic arterial tone.

Both reduced arterial lumen size and increased arterial tone play a fundamental role in the origin of essential hypertension. Therefore, our study for the first time shows that chronic embryonic hypoxia establishes the structural and functional basis for today's most common cardiovascular disease.

We found a $22 \%$ reduction in left ventricular systolic pressure and lower positive and negative $\mathrm{dP} / \mathrm{dt}$ in chronic hypoxic embryos, pointing to significantly diminished cardiac contractile function after chronic hypoxia. The heart/body weight ratio was $14 \%$ higher in hypoxic embryos, which is suggestive of a mild hypertrophic response. Together, these data indicate that chronic hypoxia induces alterations in function and mass of the embryonic heart compatible with moderate cardiac failure.

To extend this idea, we evaluated the regulation of systemic hemodynamics during acute severe hypoxic stress. This is a well known stimulus for triggering a chemoreflex, which in the near-term fetus is normally characterized by bradycardia, elevated peripheral vascular resistance, and maintenance of the blood pressure. This response is essential to maintain perfusion of the vital 
organs during an episode of acute hypoxia. ${ }^{12}$ Interestingly, we observed that arterial pressure significantly dropped in chronic hypoxic embryos during acute hypoxic stress, in contrast with the expected constant blood pressure in their normoxic counterparts. Since the degree of bradycardia and level of constriction in peripheral resistance arteries were similar in both groups, it is highly likely that the decline in cardiac function in chronic hypoxic embryos accounts for this effect. These data provide the first evidence that hypoxia-associated alterations in the cardiovascular system lead to hemodynamic collapse under stress conditions in the near-term embryo.

Both molecular and hemodynamic mechanisms may account for the morphological and functional defects in the heart and vasculature of chronic hypoxic embryos. Endothelin-1 which, like vascular endothelial growth factor (VEGF), is a downstream target molecule of the hypoxia sensitive transcription factor HIF- $1,{ }^{13}$ is a trophic factor for vascular smooth muscle cells and influences the development of neural crest derived organs like the aortic outflow tract and the enteric nervous system. ${ }^{14}$ Since we find alterations at similar levels of the cardiovascular system, endothelin-1 may be a potential mediator and an interesting subject for future pharmacological interventions. We also observed a twofold increase in the constrictor response to tyramine after hypoxia, implicating enhanced norepinephrine release from perivascular sympathetic nerves. This may be explained by hypoxia/HIF-2 driven enhanced activity of the enzyme tyrosine hydroxylase, the rate limiting enzyme in norepinephrine synthesis in sympathetic nerves. ${ }^{15,16}$ Finally, in line with our observations, mice with mild overexpression of VEGF-A show severe fetal cardiac and vascular abnormalities and die at midgestation. ${ }^{17}$ Genetic deletion of the HIF-1 response element or VEGF co-receptor neuropilin-1 affects neuronal projection implicating a role for hypoxic signaling in neural regulation. ${ }^{18,19}$ Thus, based on the fundamental role of these factors in the embryonic design of the circulatory system, we postulate that hypoxia may alter the orchestration of the expression of these factors during a critical period of embryonic development.

Additionally, observed changes, such as enhanced sympathetic tone in the resistance vasculature, may reflect secondary hemodynamic adaptations. It is well known that patients with heart failure trigger similar compensatory neuroendocrine mechanisms aimed at restoring systemic arterial pressure. It may therefore be postulated that the decreased aortic lumen size imposes an increased workload on the heart, resulting in cardiac hypertrophy with subsequent left ventricular dysfunction, which enhances sympathetic nervous activity.

By using an integrative physiological approach the current study for the first time clearly identified that exposure of the embryo to mild hypoxia leads to 
chapter 4

abnormalities in cardiovascular structure and function, that may be related to the origin of essential hypertension. Our future investigations will address whether the observed changes in the chick embryo persist postnatally. Clinical research is needed to identify whether our postulates hold in human low birth weight neonates, for example by non-invasive imaging of the heart and ascending aorta, and nailfold microvascular microscopy to establish in vivo regulation of vascular tone.

\section{Acknowledgments}

The excellent technical assistance of Jodil Willems is greatly appreciated. 


\section{REFERENCES}

1. Barker DI, Osmond C, Golding J, Kuh D, Wadsworth MF. Growth in utero, bloud pressure in childhood and adult life, and mortality from cardiovascular discase. BMI 1989;298(6673):564-7.

2. Barker DJ, Osmond C, Simmonds SI, Wield GA. The relation of small herat circumference and thinness at birth to death from cardiovascular disease in adult life. Bmj 1993;306(6875):422-6.

3. Hales CN, Barker Dy, Clark PM, et al. Fetal and infant growth and inpaired glucoset tolerance at age 64. Bmj 1991;303(6809):1019-22.

4. Loos RJ, Fagard R, Beunen G, Derom C, Vlietinck R. Birth weight and blood pressure in young adults: a prospective twin study. Circulation 2001;104(14):1633-8.

5. Leeson CP, Kattenhorn M, Morley R, Lucas A, Deanifeld IE. Impact of low birth weight and cardiovascular risk factors on endothelial function in early adult life. Circulation $2001 ; 103(9): 1264-8$.

6. Leeson CP, Whincup PH, Cook DG, of al. Flow-mediated dilation in 9- to 11-year-old children: the influence of intrauterine and childhood factors. Circulation 1997;96(7):2233-8.

7. Lutgens $E$, Daemen $M$, Kockx $M$, et al. Atherosclerosis in APOE3-Leiden transgenic mice: from proliferative to atheromatous stage. Circulation 1999;99(2):276-83.

8. De Windt LI, Willems I, Reneman RS, Van der Vusse GJ, Arts T, Van Bilsen M. An improved isolated, leit ventricular ejecting, murine heart model. Functional and metabolic evaluation. Pilugers Arch 1999;437(2):182-90.

9. Rouwet EV, De Mey JG, Slaaf DW, Heineman E, Ramsay G, Le Noble FA. Development of vasomotor responses in fetal mesenteric arteries. Am f Physiol Heart Circ Physiol 2000;279(3):H1097-105.

10. Takauchi $Y$, Yamazaki T, Akiyama T. Tyramine-induced endogenous noradrenaline efiflux from in situ cardiac sympathetic nerve ending in cats. Acta Physiol Scand 2000;168(2):287-93.

11. van Gorp AW, Schenau DS, Hoeks AP, Boudier HA, de Mey JG, Reneman RS. In spontaneously hypertensive rats alterations in aortic wall properties precede development of hypertension. An / Physiol Heart Circ Physiol 2000;278(4):H1241-7.

12. Inoue $M$, Fujishiro $N$, Imanaga 1. Hypoxia and cyanide induce depolarization and catecholamine release in dispersed guinea-pig chromaffin cells. I Physiol 1998;507 ( Pt 3):807-18.

13. Semenza GL. Hypoxia-inducible factor 1 : master regulator of $\mathrm{O}_{2}$ homeostasis. Curr Opin Genet Dev 1998;8(5):588-94. 
14. Kempf H, Linares C, Corvol P, Gasc IM. Pharmacological inactivation of the endothelin type A receptor in the early chick embryo: a model of mispatterning of the branchial arch derivatives. Development 1998;125(24):4931-41.

15. Tian H, Hammer RE, Matsumoto AM, Russell DW, MCKnight SL. The hypoxiaresponsive transcription factor EPAS1 is essential for catecholamine homeostasis and protection against heart failure during embryonic development. Genes Dev 1998;12(21):3320-4.

16. Favier J, Kempf H. Corvol P, Gasc IM. Cloning and expression pattern of EPAS1 in the chicken embryo. Colocalization with tyrosine hydroxylase. FEBS Lett 1999;462(12):19-24.

17. Miquerol L, Langille $B \mathrm{~L}$, Nagy A. Embryonic development is disrupted by modest increases in vascular enclothelial growth factor gene expression. Development 2000);127(18):3941-6.

18. Oosthuyse B, Moons L, Storkebaum E, et al. Deletion of the hypoxia-response element in the vascular endothelial growth factor promoter causes motor neuron degeneration. Nat Genet 2001:28(2):131-8.

19. Chen $\mathrm{H}$, He Z, Bagri A, Tessier-Lavigne $M$. Semaphorin-neuropilin interactions underlying sympathetic axon responses to class III semaphorins. Neuron 1998;21(6):1283-90. 
CHAPTER 5

Prenatal hypoxic stress programs for cardiomyopathy involving cardiomyocyte specific VEGF-A/VEGFR-2/NRP1 signaling

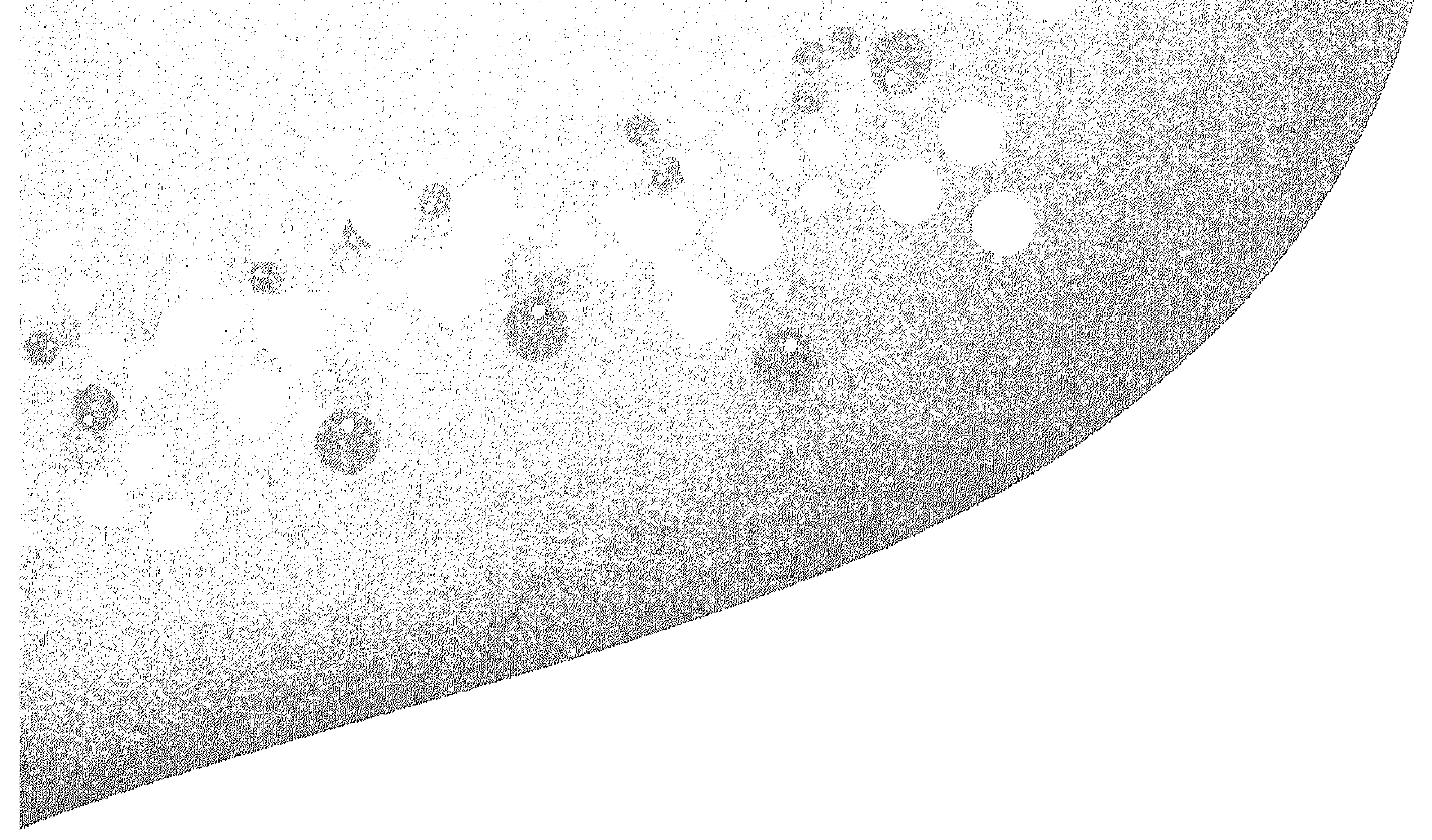




\begin{abstract}
Background

Cardiovascular diseases in adulthood can be programmed in utero. The mechanism is unknown but may involve prenatal hypoxia.

\section{Methods}

We performed intrauterine echocardiography and measured umbilical artery blood levels of NT-proBNP, an indicator of cardiomyopathy, in 19 human fetuses with hypoxic growth restriction and 24 normal fetuses. We determined apoptosis, glycogen content and expression of the hypoxia-sensitive cytokine vascular endothelial growth factor (VEGF) and its receptors VEGFR-2 and neuropilin-1 (NRP1) by immunohistochemistry in cardiac biopsies from 5 fetuses who died of severe hypoxia. The cardiac response to hypoxia was further defined in a chick embryo model.
\end{abstract}

\title{
Results
}

Hypoxic human fetuses displayed cardiac dysfunction as evidenced by prolonged isovolumetric contraction time, decreased ejection time, prolonged acceleration time, and elevated umbilical artery NT-proBNP levels. Cardiac biopsies of hypoxic human fetuses displayed histological signs of cardiomyopathy, including glycogen accumulation and enhanced cardiomyocyte apoptosis, and demonstrated upregulation of VEGF-A, VEGFR-2 and NRP1 in cardiomyocytes. Hypoxic chick embryos showed impaired left ventricular contractility and histological signs of cardiomyopathy at birth, persisting into adulthood. Cardiomyocyte-specific expression of VEGF-A, VEGFR-2 and NRP1 was elevated in hypoxic hearts. The NRP1 binding isoform $\mathrm{VEGF}_{165}$ exerted direct negative inotropic effects on cardiomyocytes, which was abolished by blocking VEGFR-2 signaling. Prenatal treatment with the VEGF-A scavenger soluble VEGF receptor-1 or NRP1 ligand Sema3A rescued the embryos from cardiomyopathy.

\section{Conclusions}

Adult cardiomyopathy can be programmed in utero by prenatal hypoxic stress. The data establish the VEGF/NEGFR-2/NRP1 axis as the intrauterine modulator of fetal programming of cardiomyopathy. 
Prenatal Hypoxia Induces Cardiomyopathy

\section{INTRODUCTION}

Fetal growth restricted (FGR) babies have an increased risk of cardiovascular diseases (CVD) in adulthood, including hypertension, stroke, coronary artery disease, and diabetes mellitus. ${ }^{1,2}$ Exposure of the developing fetus to a suboptimal environment increases its risk of acquiring CVD in later life through a process known as fetal programming. ${ }^{3}$ Intrauterine hypoxic stress caused by perturbations along the fetal supply line is thought to be involved, but the pathophysiological mechanism is unknown. ${ }^{4.5}$

Prolonged fetal hypoxia due to uteroplacental insufficiency is a common event which can result in fetal growth restriction, prematurity, and stillbirth. An estimated $5-10 \%$ of all newborns have experienced an episode of hypoxia during fetal development. ${ }^{6,7}$ We have shown that chick embryos exposed to a clinically relevant level of hypoxia, ${ }^{8,9}$ display the typical characteristics of FGR babies, including low body weight and increased brain to liver weight ratio. Analysis of the cardiovascular system in these embryos revealed aberrant autonomic nerve activity, abnormal blood pressure control, and cardiac dysfunction. ${ }^{10}$ This provided the first clue for a potential epigenetic link between hypoxia, intrauterine stress and CVD. However, the relevance of these preclinical findings to the initiation of cardiomyopathy in humans remains to be determined.

Exposure to hypoxia induces adaptive physiological responses, including increased hematocrit and stimulation of angiogenesis, which are aimed at restoring tissue oxygen delivery. ${ }^{11}$ Essential for this adaptive response is the oxygen-sensitive transcription factor hypoxia inducible factor- 1 which activates genes like erythropoietin and vascular endothelial growth factor (VEGF). ${ }^{11}$ VEGF plays a pivotal role in many aspects of embryonic cardiovascular development, including formation of blood vessels, cardiac morphogenesis, and development of the nervous system. ${ }^{12-15}$ VEGF levels have to be maintained within an extremely narrow range to ensure normal cardiovascular development and embryo survival. ${ }^{16-19}$

The aim of this study was to investigate whether intrauterine hypoxia predisposes human fetuses to cardiomyopathy through an elevated cardiac expression of VEGF. We report that intrauterine hypoxia is associated with impaired systolic function in human fetal hearts. Intrauterine echocardiography of hypoxic human fetuses showed prolonged isovolumetric contraction time (ICT), shortened ejection time (ET), and prolonged time-to-peak velocity in the aorta (acceleration time, AT). Presence of cardiomyopathy was furthermore established by elevated levels of the biomarker $\mathrm{N}$-terminal pro-brain natriuretic 
peptide (NT-proBNP) in umbilical artery blood of human newborns who suffered from prenatal hypoxia. Analysis of cardiac biopsies of hypoxic human fetuses confirmed the presence of cardiomyopathy and demonstrated increased expression of VEGF-A and its receptors VEGF receptor-2 (VEGFR-2) and neuropilin-1 (NRP1) in cardiomyocytes. In an experimental study we show that exposure to hypoxia induced cardiomyopathy in near-term chick embryos, which persisted into adulthood. Prenatal administration of soluble VEGF receptor- 1 (sFlt-1), a VEGF-A scavenger, or semaphorin3A (Sema3A), a ligand of the VEGF co-receptor NRP1, prevented this cardiomyopathy. These data establish the VEGF/NEGFR-2/NRP1 signaling axis as an important modulator of fetal programming in the development of adult cardiomyopathy.

\section{METHODS}

\section{Patients}

We evaluated cardiac function and NT-proBNP levels in two separate patient cohorts. Permission for the studies was granted by the institutional review boards and written informed consent had been obtained from the parents. A total number of 43 singleton pregnancies were studied. Gestational age was determined according to the onset of the last menstrual period and confirmed by ultrasound before 20 weeks of gestation. Fetal growth was documented by prenatal ultrasound and confirmed by measuring weight at birth. Neonatal weight, sex and APGAR scores were routinely recorded in the obstetrics database at the time of birth. Appropriate for gestational age (AGA) fetuses had normal growth, were delivered at term, and had birth weights between the $10^{\text {th }}$ and $90^{\text {th }}$ percentile. FGR was diagnosed prenatally by serial ultrasound examinations demonstrating a reduction of growth rate of the abdominal circumference, and was confirmed at birth by neonatal weight less than the $10^{\text {th }}$ percentile of age-related reference values. ${ }^{20,21}$ Severe FGR was defined when Doppler velocimetry of the umbilical artery showed absent or reversed end-diastolic umbilical artery blood flow, which is consistent with the presence of intrauterine hypoxia. ${ }^{9}$ Exclusion criteria were the presence of fetal structural or chromosomal abnormalities, cytomegalovirus infection, and pharmacologic treatment which could influence pregnancy outcome and fetal growth. 


\section{Evaluation of Cardiac Function in Human Fetuses}

In 28 fetuses (14 AGA, $14 \mathrm{FGR}$ ) cardiac function was determined by means of fetal echocardiography. All FGR fetuses had clearly abnormal values of the Doppler pulsatility index in the middle cerebral artery and ductus venosus, and abnormal aortic isthmus flow index, which are consistent with the presence of fetal hypoxia (Table 1). ${ }^{22}$ Fetuses underwent serial cardiac ultrasound examinations; the last evaluation before delivery was used for analysis. Systolic function of the left ventricle was assessed by recording the isovolumetric contraction time (ICT), the ejection time (ET), and the time-to-peak velocity in the aorta (acceleration time, AT); the ICT/ET ratio, AT/ET ratio and modified myocardial performance index (Mod-MPl) were calculated..$^{23}$

\section{Measurement of NT-proBNP in Human Fetuses}

In 15 fetuses (10 AGA, 5 FGR) umbilical artery blood was collected at the time of cesarean section to assess plasma NT-proBNP levels (Table 2). Indications for cesarean sections in AGA fetuses were not related to fetal growth (breech, previous cesarean section, maternal request). Arterial blood samples were drawn from double clamped umbilical cord immediately after delivery and sampled into heparin-coated vials. After centrifugation, plasma was isolated and frozen at $-20^{\circ} \mathrm{C}$. Quantitative determination of NT-proBNP was performed with an enzyme immunoassay kit (Biomedica $\mathrm{GmbH}$ ).

\section{Immunohistochemistry of Human Fetal Hearts}

Biopsies were obtained from left ventricular (LV) myocardium of ten autopsied human fetal hearts of 18-37 weeks gestation, as determined by biometric characteristics. Five fetuses displayed macroscopic and microscopic signs of prolonged intrauterine hypoxia, including fetal growth restriction, terminal villus deficiency and immature villi in the placenta, placental infarction, ischemic liver cell damage, prominent extramedullary hematopoiesis in the liver, and apoptotic pontine lesions in the brain. Five fetuses served as normoxic age-matched controls (Table 3). Paraffin-embedded 5- $\mu \mathrm{m}$ tissue sections were stained with periodic acid Schiff (PAS) to visualize glycogen, and were immunostained with rabbit polyclonal antibody against human caspase-3a (Cell Signaling), rabbit polyclonal antibody against human VEGF-A (Santa Cruz Biotechnology, A-20), mouse monoclonal antibody against human VEGFR-2 (Abcam, ab9530), and rabbit polyclonal antibody against mouse NRP1 (Abcam, ab16786). The expression levels were graded semiquantitatively by two independent observers. 


\section{Experimental Model}

Animals

Fertile White Leghorn eggs were incubated at $21 \% \mathrm{O}_{2}$ (normoxia; $\mathrm{N}$ ), or $15 \%$ $\mathrm{O}_{2}$ (hypoxia; $\mathrm{H}$ ) throughout embryonic development. ${ }^{10}$ Experiments in chick embryos were performed between embryonic days 13 and 20 (E13-E20). To evaluate the effects of prenatal hypoxia on the adult heart, normoxic and hypoxic chick embryos were allowed to hatch (E21) and both groups were raised under normal oxygen levels after birth $\left(21 \% \mathrm{O}_{2}\right)$. In a separate set of experiments we investigated the effects of very mild hypoxia by exposing developing chick embryos to $18 \% \mathrm{O}_{2}$ and evaluated cardiac function at E20. Experiments were approved by the institutional animal ethics committee.

\section{Cardiac Histology}

Left ventricular cross-sectional area was measured on formalin-fixed sections (Image), National Institutes of Health). Consecutive paraffin-embedded 5- $\mu \mathrm{m}$ sections were stained with hematoxylin and eosin (HE) to visualize tissue architecture, periodic acid Schiff (PAS) to visualize glycogen, and pimonidazole hydrochloride (Hypoxyprobe-1, NPI Inc, Belmont, MA; $60 \mathrm{mg} / \mathrm{kg}$ ) to assess cardiac hypoxia. ${ }^{24}$ Ultrastructural analysis of epoxy resin embedded hearts was performed on 70-nm sections.

\section{Cardiac Contractility}

Isometric contractile force development was measured in isolated LV muscle bundles. ${ }^{25} \mathrm{~A}$ thin subendocardial LV muscle bundle was excised in parallel with fiber direction, mounted in an organ bath with HEPES buffer $\left(2 \mathrm{mmol} / \mathrm{L} \mathrm{Ca}{ }^{2+}, \mathrm{pH}\right.$ 7.4, gassed with $100 \% \mathrm{O}_{2}, 37^{\circ} \mathrm{C}$ ) between a rigid hook and a force transducer connected to a micromanipulator for length adjustment, and stimulated by bipolar electrical field stimulation at $1 \mathrm{~Hz}$ (pulse width $5 \mathrm{~ms}, 5-10 \%$ above threshold). Generated force was defined as peak systolic minus diastolic force and normalized to cross-sectional area $\left(\mathrm{mN} / \mathrm{mm}^{2}\right)$ by optical measurement of the smallest diameter of the bundle assuming cylindrical geometry. ${ }^{25}$ Contractile force was measured in response to increasing extracellular calcium (2-12 $\mathrm{mmol} / \mathrm{L})$ and to increasing pacing frequencies $(0.5-4 \mathrm{~Hz})$.

In separate experiments, LV muscle bundles from E20 normoxic embryos were incubated for $4 \mathrm{~h}$ with rhVEGF $165,{ }^{26}$ rhVEGF $_{121}{ }^{26}$ placental growth factor1 (rhPlGF-1), rhVEGF 165 sflt-1, rhSema3A (all R\&D Systems), VEGF $165+\mathrm{SU} 5416$ (Sigma), or in HEPES buffer alone. Contractility was measured after the 4-h incubation period. LV muscle bundles from adult chick heart were evaluated according to the same protocol. 
Molecular Analysis

Total RNA from chick embryo hearts was isolated using TRIzol reagent (Gibco $B R L$ ) and transcribed to CDNA with iScript reverse transcriptase (Bio-Rad) according to manufacturer's instructions. Expression of atrial natriuretic factor (ANF) was normalized to $18 \mathrm{~S}$ rRNA with custom designed PCR primers (Table 5). The My iQ iCycler and IQ SYBR Green Supermix (both Bio-Rad) were utilized for quantitative real-time PCR analysis. PCR products were verified by DNA sequencing.

Northern blot analysis of VEGF-A mRNA expression in chick embryo hearts was performed using a ${ }^{32} \mathrm{P}$-labelled oligonucleotide probe (kindly provided by Dr. A. Eichmann). Additionally, PCR analysis was performed to detect the expression of VEGF-A mRNA splice variant isoforms. ${ }^{24}$

Cardiomyocyte apoptosis was assessed by in vivo molecular imaging using annexin- $V^{27}$

In situ hybridization with antisense probes (kindly provided by Dr. A. Eichmann) for VEGF-A, VEGFR-2, and NRP1 was performed on paraffinembedded $8-\mu \mathrm{m}$ sections.

Prenatal Treatment with Soluble VEGF Receptor-1 or Sema3A

To reduce the biological availability of VEGF-A, we treated hypoxic embryos with sFlt-1 or Sema3A (R\&D Systems) from E10 to E19. ${ }^{28}$ Controls received equal volumes of saline. Cardiac morphometry and contractility were analyzed at E2O.

\section{Statistics}

Data are expressed as mean \pm SE. The term $n$ refers to the number of patients or animals. Multiple comparisons were performed by Kruskal-Wallis testing. Statistical comparisons in the experimental model were made using the nonparametric Mann-Whitney $U$ test. Statistical significance was defined as $\mathrm{P}<0.05$. 


\section{RESULTS}

\section{Hypoxic Human Fetuses Display Signs of Cardiomyopathy}

Fetal cardiac function was assessed in 28 fetuses, 14 normal AGA and 14 hypoxic FGR, at a gestational age of 29 weeks using echocardiography (Table 1). The presence of hypoxia was demonstrated by significantly reduced middle cerebral artery pulsatility index, reduced aortic isthmus flow index, and elevated ductus venosus pulsatility index (Table 1 ). These three standard noninvasive

Table 1

\begin{tabular}{lcc}
\hline \multicolumn{1}{c}{ Characteristics of Fetuses Included for Intrauterine Echocardiography } \\
\cline { 2 - 3 } & AGA $(n=14)$ & FGR $(n=14)$ \\
\hline Birth weight $(g)$ & $3210 \pm 81$ & $795 \pm 74^{\star * *}$ \\
Gestational age $(w)$ & & \\
at examination & $29.2 \pm 0.7$ & $29.4 \pm 0.7$ \\
Middle cerebral artery pulsatility index & $1.96 \pm 0.10$ & $1.31 \pm 0.10^{* * * *}$ \\
Aortic isthmus flow index & $1.3 \pm 0.01$ & $0.21 \pm 0.20^{* * *}$ \\
Ductus venosus pulsatility index & $0.65 \pm 0.01$ & $1.35 \pm 0.20^{* * *}$ \\
\hline
\end{tabular}

Values are mean \pm SE. ${ }^{* * *} P<0.001,{ }^{* * * *} P<0.0001$ FGR versus AGA.

parameters were used as indicators of hypoxemia, since direct blood sampling in fetuses at this stage of development would be unethical. The modified myocardial performance index (Mod-MPI) was significantly elevated in hypoxic fetuses (Fig. 1C). Isovolumetric contraction time (ICT) was significantly

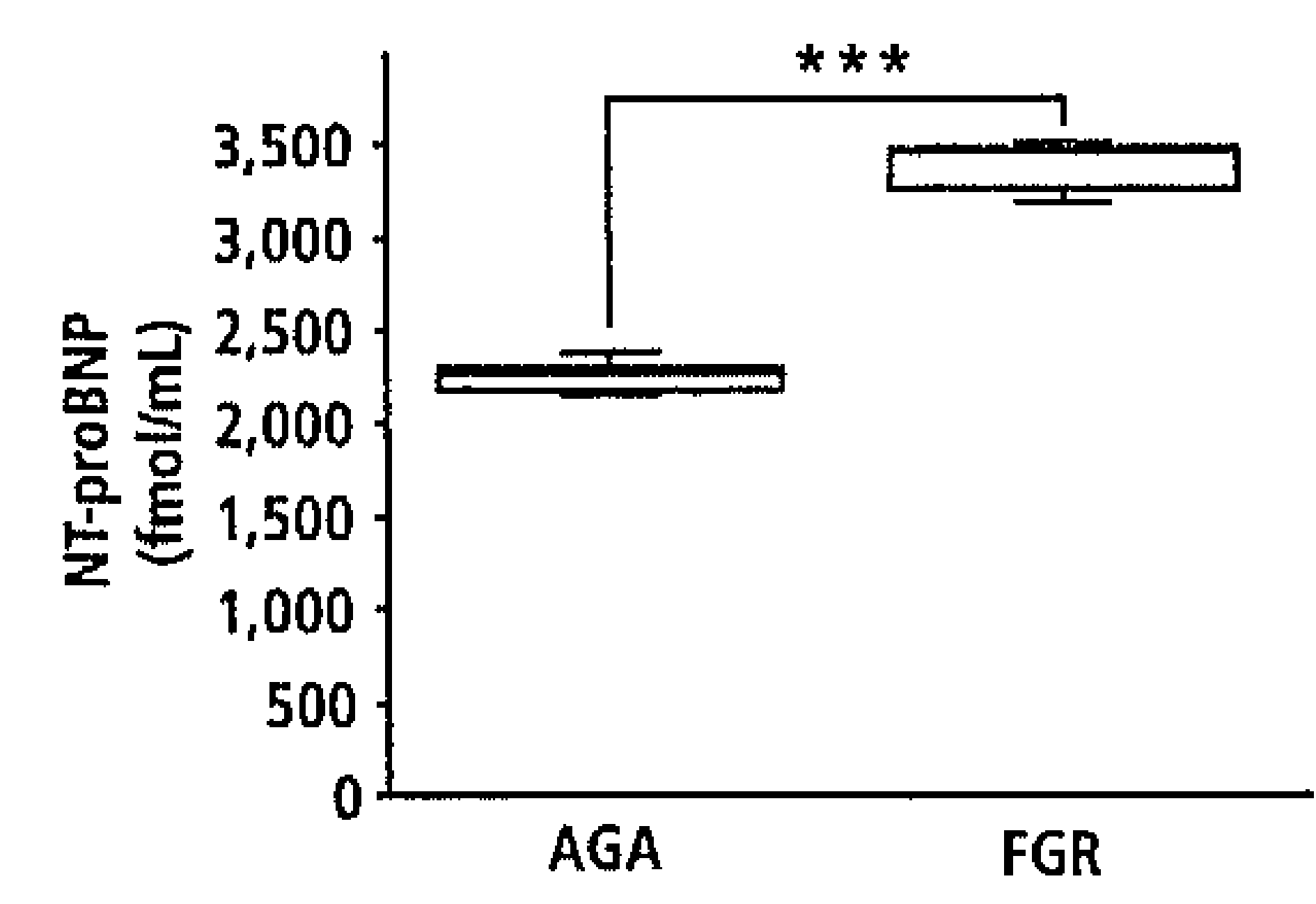

Figure 2 Plasma levels of the heart failure biomarker NT-proBNP are elevated in hypoxic FGR fetuses at birth. Box whisker representation of median NT-proBNP levels in umbilical artery blood of $A C A$ and hypoxic FGR fetuses. Error bars represent values in the 10th and 90th percentile in each category. ${ }^{* * *} P<0.001$ FGR versus ACA. 

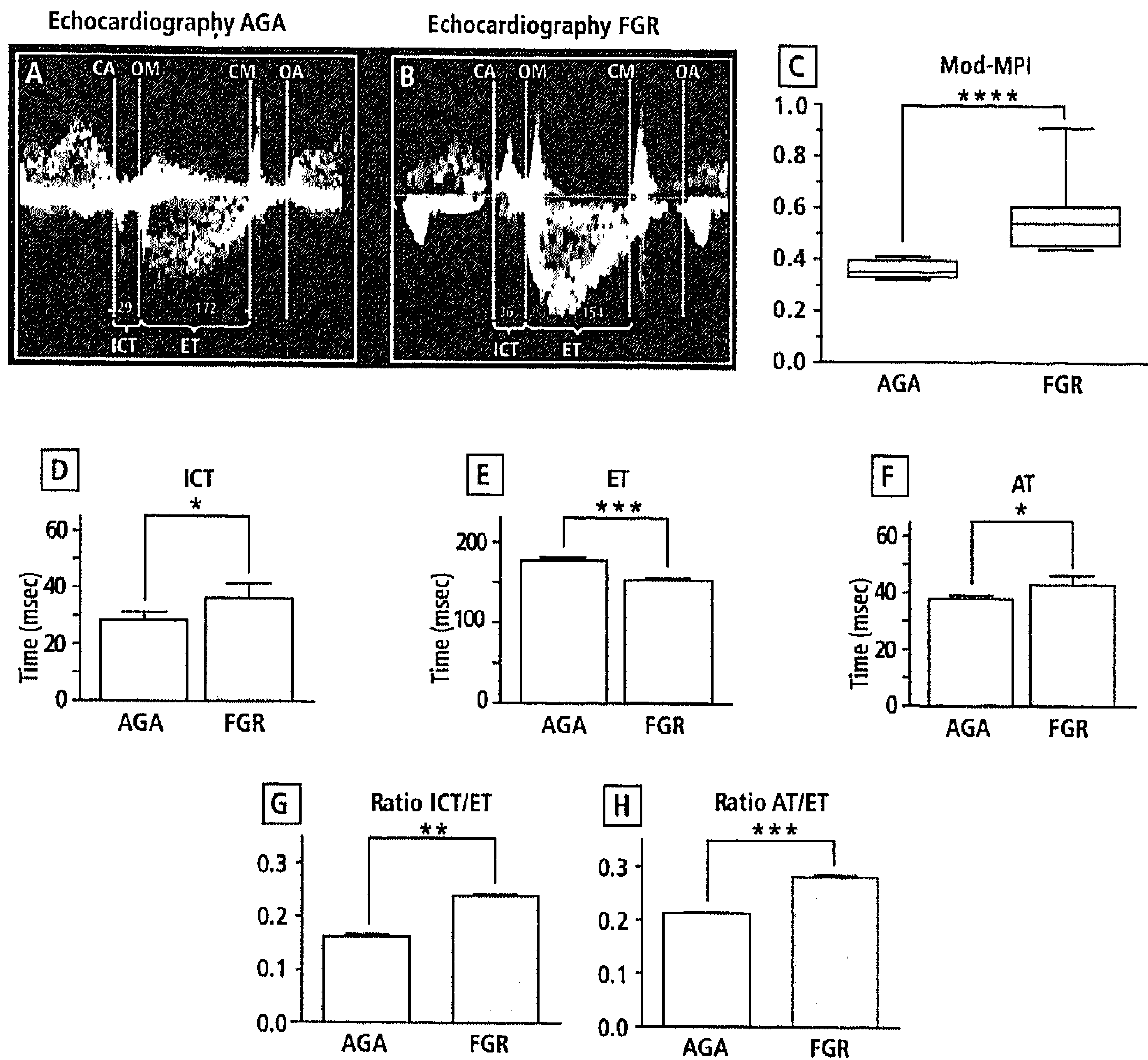

Figure 1 Panels $A$ and $B$, typical Doppler tracings of the left ventricle obtained in an appropriate for gestational age fetus (ACA) and in a severely growth restricled fetus (FCR). Isovolumetric contraction time (ICT) is prolonged, ejection time (ET) is shortened, and acceleration time (AT) is prolonged (values are expressed in milliseconds). Dotted yellow lines indicate opening and closure of the mitral and aortic valves (CA,OM, CM, $O A)$ which are used as landmarks to define the duration of each period evaluated. Panel C, Mod-MPI of the left ventricle is clearly abnormal in FCR fetuses. Box whisker representation of median Mod-MPI in AGA and FGR fetuses. Error bars represent values in the 10th and 90th percentile in each category. ${ }^{* * * *} P<0.0001$ FGR versus ACA. Panels $D$ to $H$, systolic function is impaired in FGR fetuses. ICT is significantly prolonged in FGR fetuses (panel D). ET is significantly shorter in FCR fetuses (panel E). $A T$ is significantly longer in FGR fetuses (pane/ F). The ICT/ET and acceleration time and ejection time (AT/ET) ratios in the left ventricle are significantly increased in FGR fetuses (panels $C$ and $H$ ). Values are mean $\pm S E .{ }^{*} P<0.05,{ }^{* *} P<0.01,{ }^{* * *} P<0.001$ FCR versus $A G A$. 
prolonged in hypoxic FGR compared with AGA fetuses $(37 \pm 3.5$ milliseconds (ms) versus $29 \pm 0.8 \mathrm{~ms}, \mathrm{P}<0.05$, Fig. 1D). The cardiac ejection time (ET) was significantly reduced $(153 \pm 2.1 \mathrm{~ms}$ versus $177 \pm 3.5 \mathrm{~ms}, \mathrm{P}<0.001$, Fig. 1E) in hypoxic FGR compared with AGA fetuses. The acceleration time (AT) was significantly prolonged $(43 \pm 2.5 \mathrm{~ms}$ versus $37 \pm 1.4 \mathrm{~ms}, P<0.05$, Fig. $1 F)$ in hypoxic FGR fetuses. Taken together, the functional data derived from intrauterine echocardiography indicate cardiac systolic dysfunction in hypoxic FGR fetuses.

To confirm the presence of cardiomyopathy biochemically, we measured umbilical arterial blood levels of NT-proBNP, an indicator of cardiomyopathy which is secreted by ventricular cardiomyocytes following myocardial stretch. ${ }^{29,} 30$ Plasma NT-proBNP levels at birth were higher in FGR compared

Table 2

\begin{tabular}{lcc}
\hline \multicolumn{3}{c}{ Characteristics of Fetuses Included for NT-proBNP Measurement at Birth } \\
\hline & AGA $(n=10)$ & FGR $(n=5)$ \\
\hline Birth weight $(\mathrm{g})$ & $3106 \pm 96$ & $1071 \pm 94^{* *}$ \\
Gestational age $(\mathrm{w})$ & $38.6 \pm 0.3$ & $30.0 \pm 1.0^{* * *}$ \\
$\mathrm{PO}_{2}$ (mmHg) & $27 \pm 2.0$ & $16 \pm 2.5^{* *}$ \\
P $\mathrm{O}_{2}$ (mmHg) & $43 \pm 1.5$ & $54 \pm 4.0$ \\
APGAR 1 min & $8.9 \pm 0.2$ & $6.0 \pm 0.7^{*}$ \\
APGAR 5 min & $9.6 \pm 0.2$ & $8.2 \pm 0.6$ \\
Male/Female $(n)$ & $7 / 3$ & $4 / 1$ \\
Maternal age $(\mathrm{y})$ & $33 \pm 1.7$ & $31 \pm 3.0$ \\
\hline
\end{tabular}

Values are mean $\pm S E$. ${ }^{*} P<0.05{ }^{* *} P<0.01,{ }^{* * *} P<0.001$ FGR versus AGA.

Table 3

\begin{tabular}{|c|c|}
\hline \multicolumn{2}{|c|}{ Characteristics of Fetuses Included for Postmortem Cardiac Biopsy } \\
\hline Normoxic fetuses $(n=5)$ & Hypoxic fetuses $(n=5)$ \\
\hline Female, $20 \mathrm{w}$, trisomy 13 & Female, $18 \mathrm{w}$, placental insufficiency \\
\hline Male, 23 w, severe hydrocephaly & Female, $29 \mathrm{w}$, placental insufficiency \\
\hline Female, 24 w, meningomyelocele & Male, 31 w, placental insufficiency \\
\hline Female, 28 w, meningomyelocele & Female, $37 \mathrm{w}$, placental insufficiency \\
\hline Male, 34 w, multiple dysmorphisms & Male, $37 \mathrm{w}$, intrauterine pneumonia \\
\hline
\end{tabular}


with AGA fetuses (Fig. 2). FGR fetuses had significantly lower umbilical arterial blood $\mathrm{PO}_{2}$ and reduced APGAR scores, indicating fetal hypoxia (Table 2). There was no difference between $A G A$ and $F G R$ with respect to fetal sex, $\mathrm{PCO}_{2}$, or maternal age (Table 2). Although gestational age was lower in FGR compared with AGA, no correlation was established between NT-proBNP and gestational age (data not shown).

In postmortem left ventricular biopsy specimens of human fetuses exposed to hypoxia (Table 3) we found clear histological signs of cardiomyopathy, including glycogen accumulation and cardiomyocyte apoptosis (Fig. 3A-D). Collectively these results demonstrate that human fetuses suffering from hypoxia display signs of cardiomyopathy before birth.

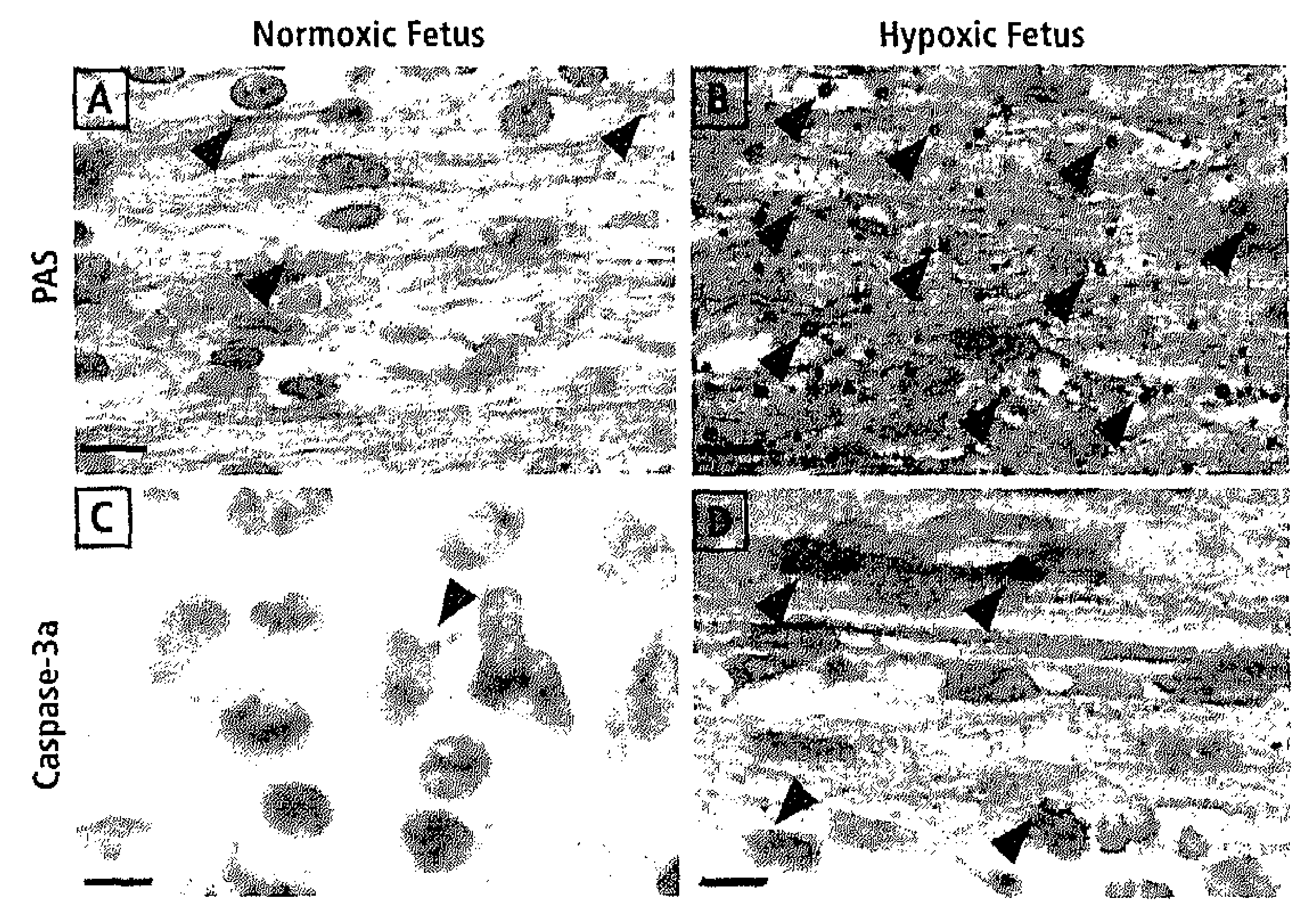

Figure 3 Panels $A$ and $B$, PAS staining for glycogen in left ventricular myocardium of human fetuses. Note the increased glycogen deposition in hypoxic (panel $B$, arrowheads) compared with normoxic fetal hearts (panel $A$, arrowheads). Panels $C$ and $D$, immunostaining of normoxic and hypoxic fetal myocardium for apoptotic cells with the caspase3a antibody. Note more apoptotic cardiomyocytes in hypoxic hearts (panel D, arrowheads) compared with normoxic controls (panel $C$, arrowhead).

\section{Hypoxic Human Fetal Hearts Express more VEGF-A, VEGFR-2 and NRP1}

To examine the potential involvement of VEGF in fetal programming of heart failure we next investigated the protein expression of VEGF-A and its receptors in postmortem left ventricular biopsy specimens of human fetuses that suffered from intrauterine hypoxia (Fig. 4A-F). Cardiomyocyte-specific expression of 


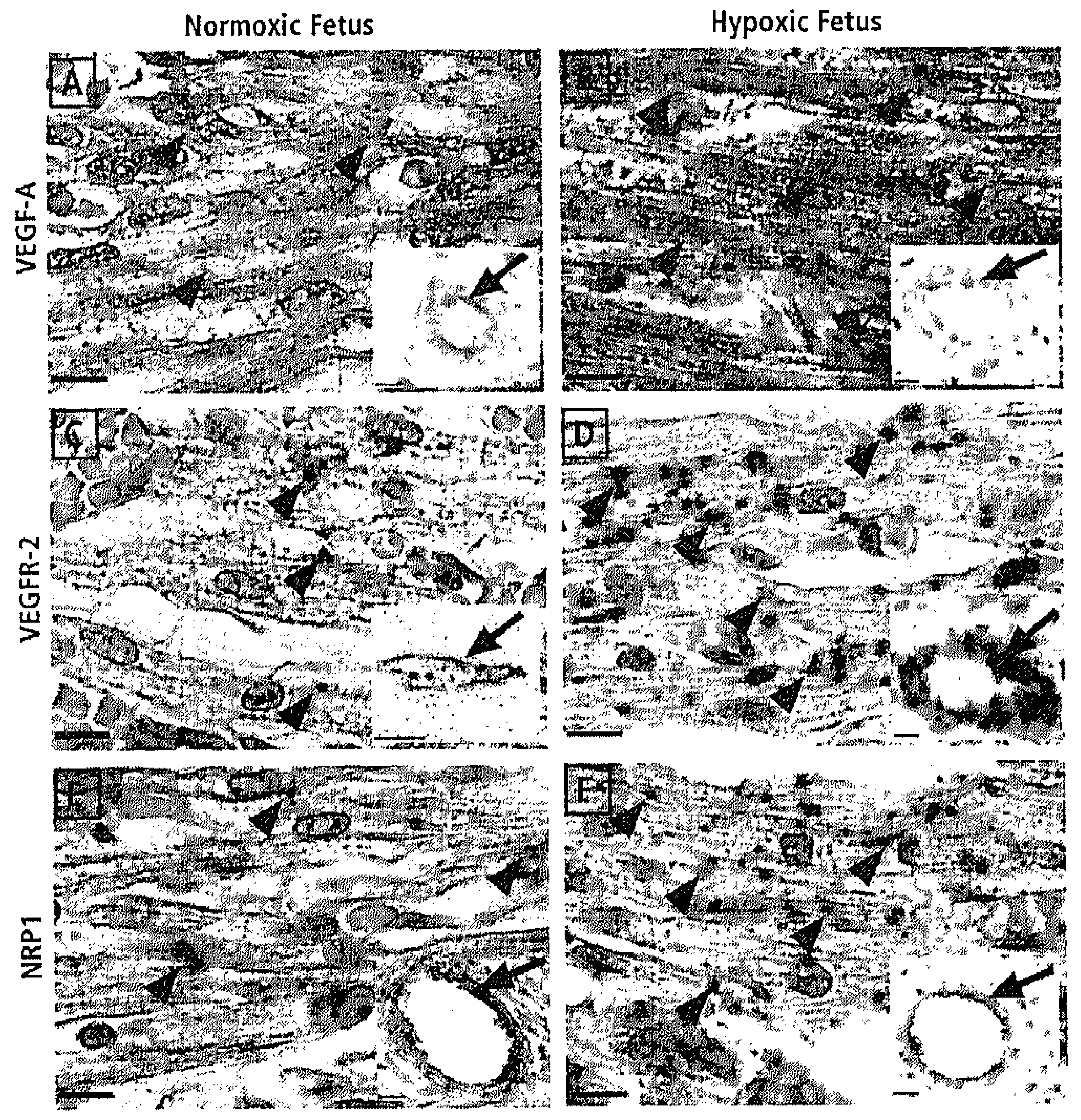

Figure 4 Panels $A$ and $B, V E C F-A$ immunostaining of sections of myocardium. Note the upregulated expression of VEGF-A in cardiomyocytes of hypoxic (panel $B$, arrowheads) compared with normoxic fetuses (panel $A$, arrowheads). In both groups myocardial blood vessels express VEGF-A normally (insets, arrows). Panels $C$ and D, VEGFR-2 immunostaining of myocardium. Cardiomyocyte expression of VEGFR-2 is more abundant in hypoxic (panel $D$, arrowheads) compared with normoxic fetuses (panel $C$, arrowheads). VECFR-2 is also expressed in myocardial blood vessels (insets, arrows). Panels $E$ and F, NRP1 immunostaining of myocardium. Cardiomyocyte-specific expression of NRP1 is more abundant in hypoxic (panel F, arrowheads) compared with normoxic fetal myocardium (panel $E$, arrowheads). NRP1 is present in myocardial blood vessels of both groups (insets, arrows). Scale bars represent $100 \mu \mathrm{m}$.

VEGF-A (Fig. 4A and B), VEGFR-2 (Fig. 4C and D), and NRP1 (Fig. 4E and F) was more abundant in hypoxic than in normoxic human fetal hearts. VEGF-A, VEGFR-2, and NRP1 were also expressed in myocardial blood vessels of both groups (Fig. 4A-F, insets). 


\section{Proof-of-Concept Study in Chick}

Hypoxia Induces Cardiomyopathy Prior to Birth

To address whether prenatal hypoxia induces cardiomyopathy before birth, we
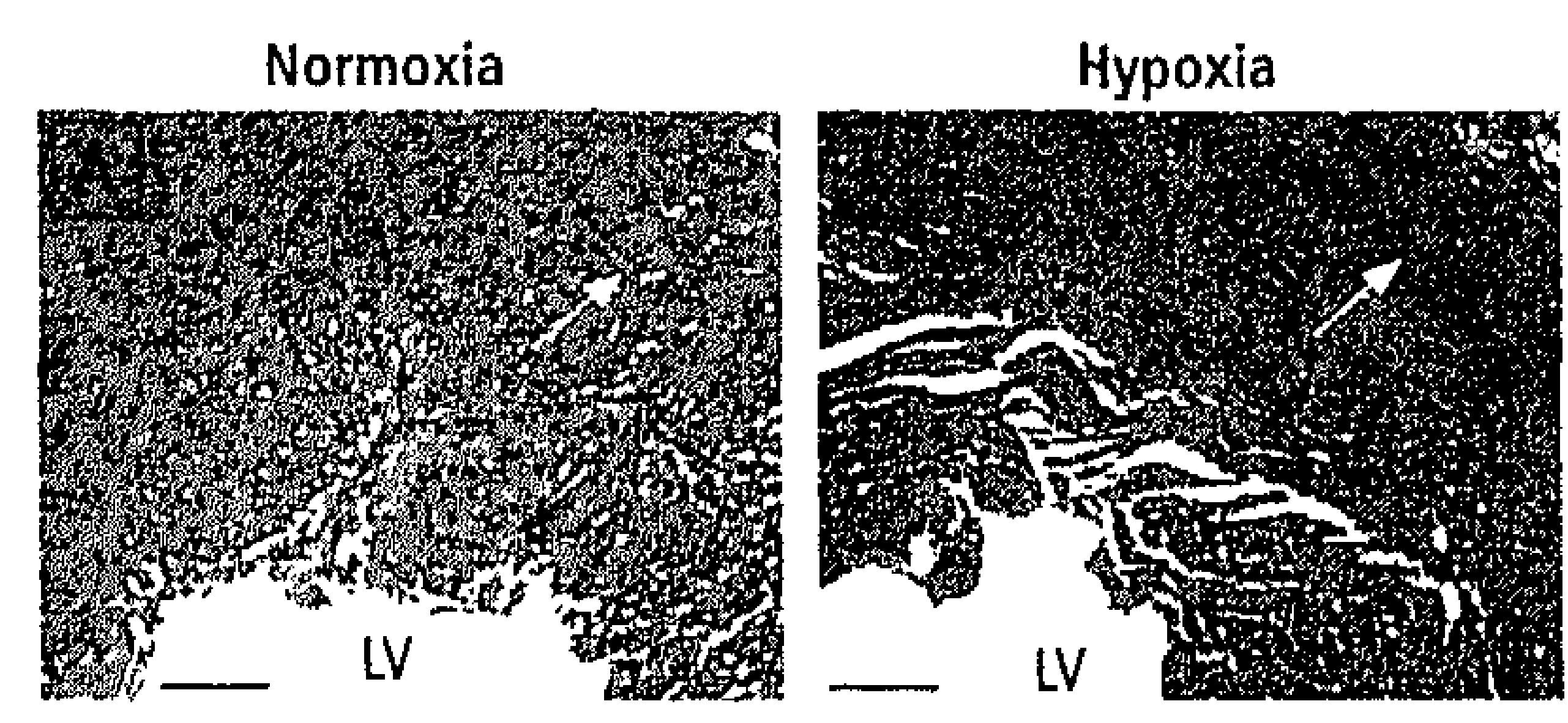

C

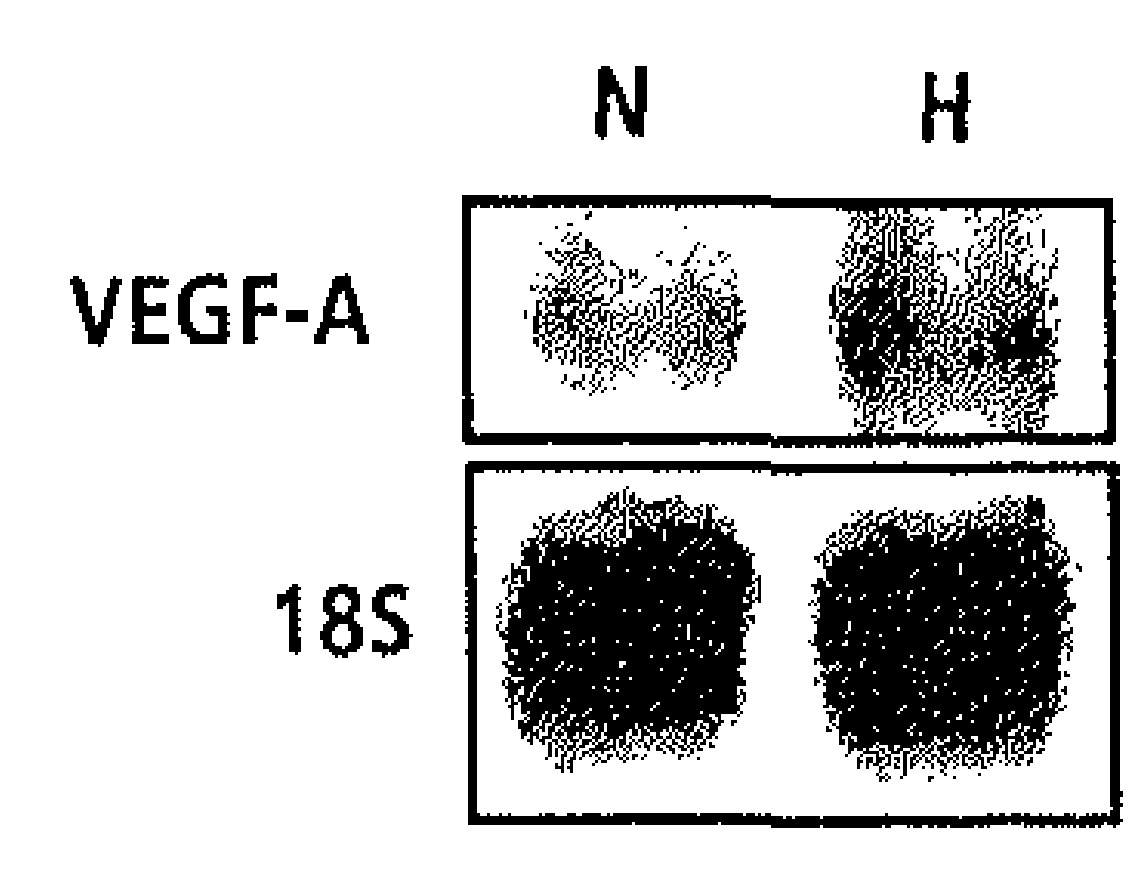

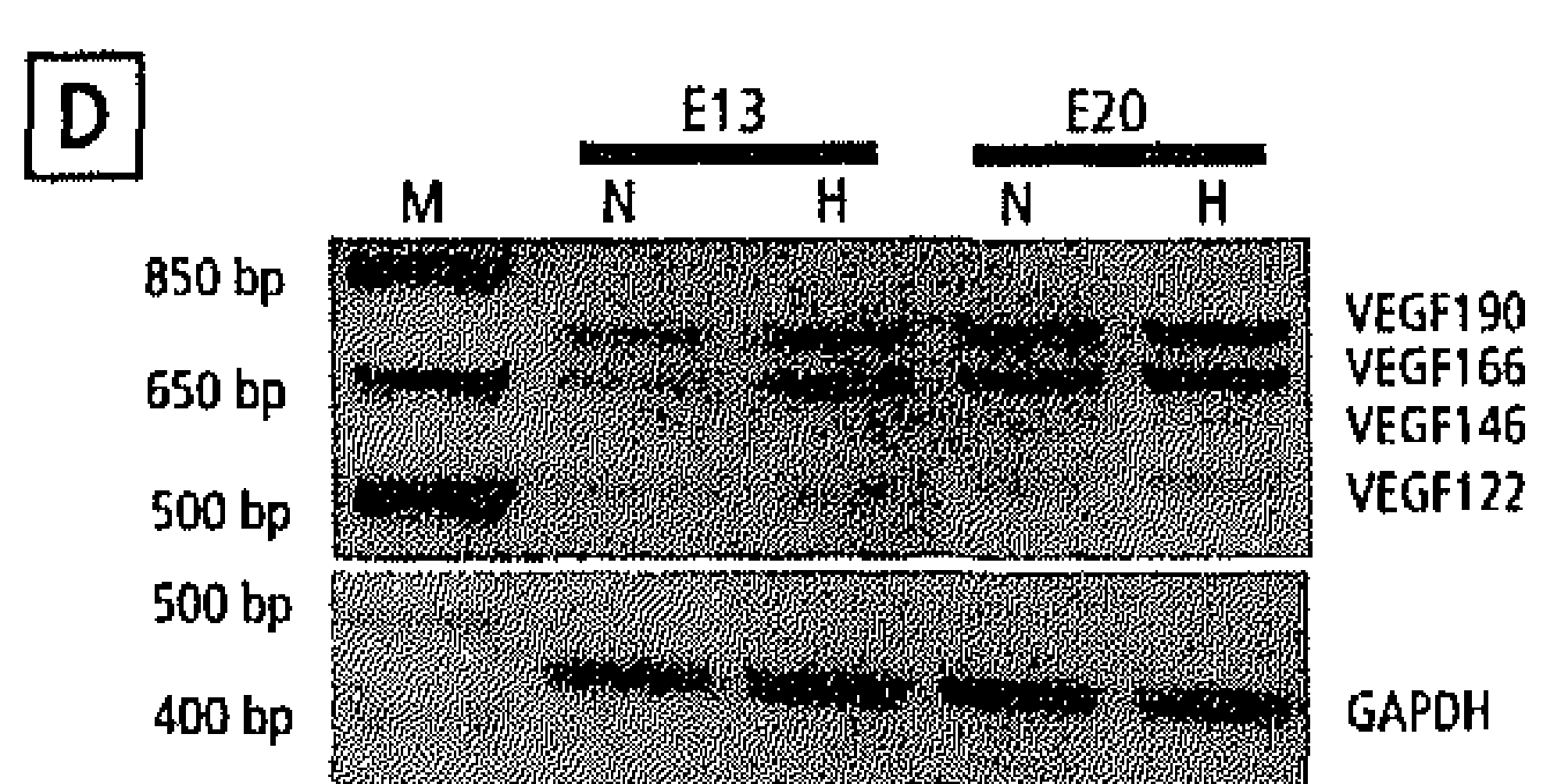

Figure 5 Panels $A$ and $B$, hypoxyprobe immunostaining of transverse sections of the left ventricle (LV) at E19 demonstrates large hypoxic zones in $H$ hearts, both $n=4$; arrows denote corresponding regions in the midmyocardium of $N$ and $H$. Scale bars represent 100 $\mu \mathrm{m}$. Panel $C$, northern blot analysis of VEGF-A expression in hearts at E2O showing increased expression in $H$ as compared to $N$, both $n=5$. Panel $D, P C R$ analysis of VECF isoform expression showing predominant expression of $V E G F_{166}$ and $V E C F_{190}$ in the embryonic heart, $n=5$ in each group.

Table 4

\begin{tabular}{lll}
\hline & \multicolumn{3}{c}{ Characteristics of Chick Embryos } \\
\hline & Normoxia $(\mathrm{n})$ & Hypoxia $(\mathrm{n})$ \\
\hline Body weight $(\mathrm{g})$ & $31 \pm 0.8(35)$ & $25 \pm 1.0(35)^{*}$ \\
Wet/dry body weight ratio & $5.5 \pm 0.1(6)$ & $6.5 \pm 0.3(6)^{* *}$ \\
Heart weight $(\mathrm{g})$ & $0.23 \pm 0.01(35)$ & $0.20 \pm 0.01(35)^{*}$ \\
Liver weight $(\mathrm{g})$ & $0.54 \pm 0.01(35)$ & $0.46 \pm 0.01(35)^{* * *}$ \\
Brain weight $(\mathrm{g})$ & $0.87 \pm 0.02(35)$ & $0.81 \pm 0.03(35)$ \\
Heart failure characteristics & none & edema \\
\hline
\end{tabular}

Values are mean $\pm S E .^{*} P<0.05,{ }^{* *} P<0.01,{ }^{* *} P<0.001$ Hypoxia versus Normoxia 
evaluated cardiac structure and function in hypoxic chick embryos at E20. Incubating developing chick embryos below $15 \% \mathrm{O}_{2}$ resulted in $100 \%$ mortality at E14 (data not shown). We therefore evaluated embryos exposed to $15 \% \mathrm{O}_{2}$ (hypoxia, $\mathrm{H}$ ) or $18 \% \mathrm{O}_{2}$ (very mild hypoxia, $\mathrm{VMH}$ ) and compared them to those exposed to $21 \% \mathrm{O}_{2}$ (normoxia, $\mathrm{N}$ ).

Exposure of chick embryos to $15 \% \mathrm{O}_{2}$ induced hypoxia in the heart (Fig. $5 \mathrm{~A}$ and $B$ ), lower body weight and altered body weight distribution (Table 4), resembling FGR babies. Cardiac expression of VEGF-A was elevated in hypoxic compared to normoxic embryos (Fig. 5C and D). Capillary density was significantly augmented
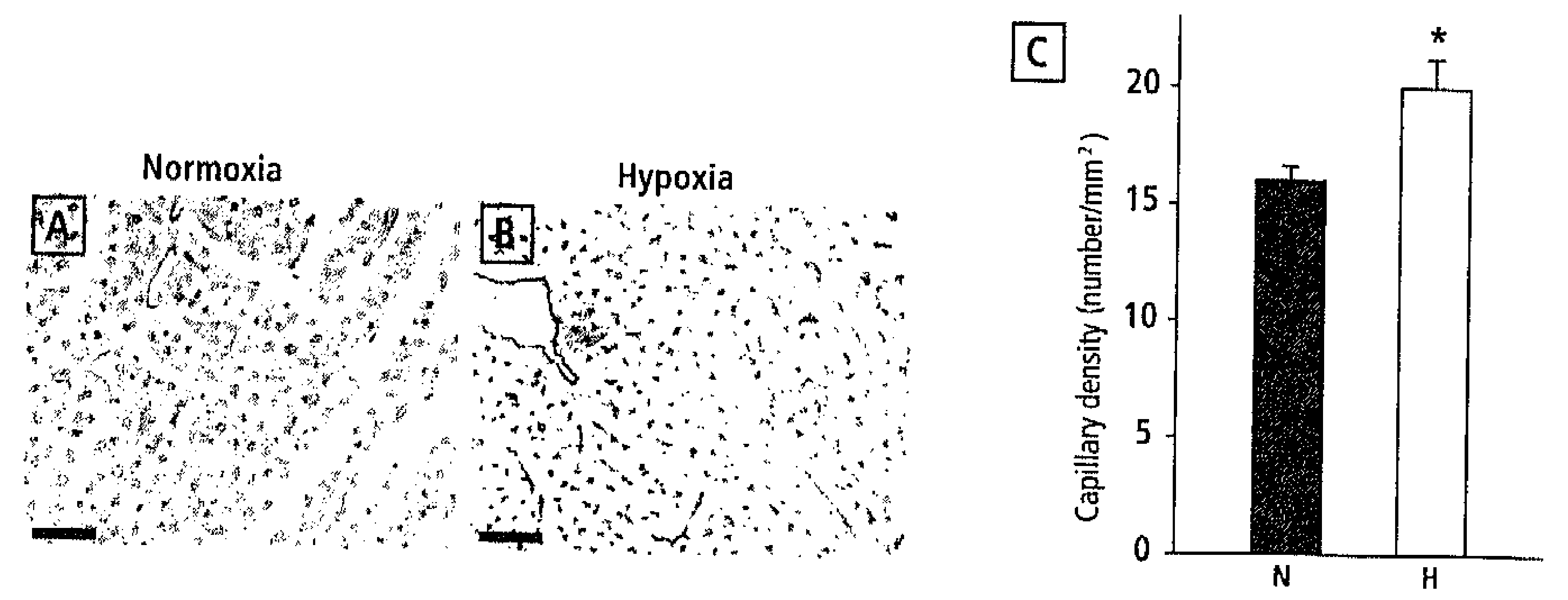

Figure 6 Panel $A$ to $C$, immunostaining of capillaries with Sambucus nigra lectin showing a higher capillary density in $H$ embryos ( $P$ anel $B$ and $C$ ) as compared with $N$ embryos (panel $A$ and $C$ ), $n=5$ in each group. Scale bars represent $100 \mu \mathrm{m}$. Data are shown as mean $\pm S E * P<0.05 H$ versus $N$.

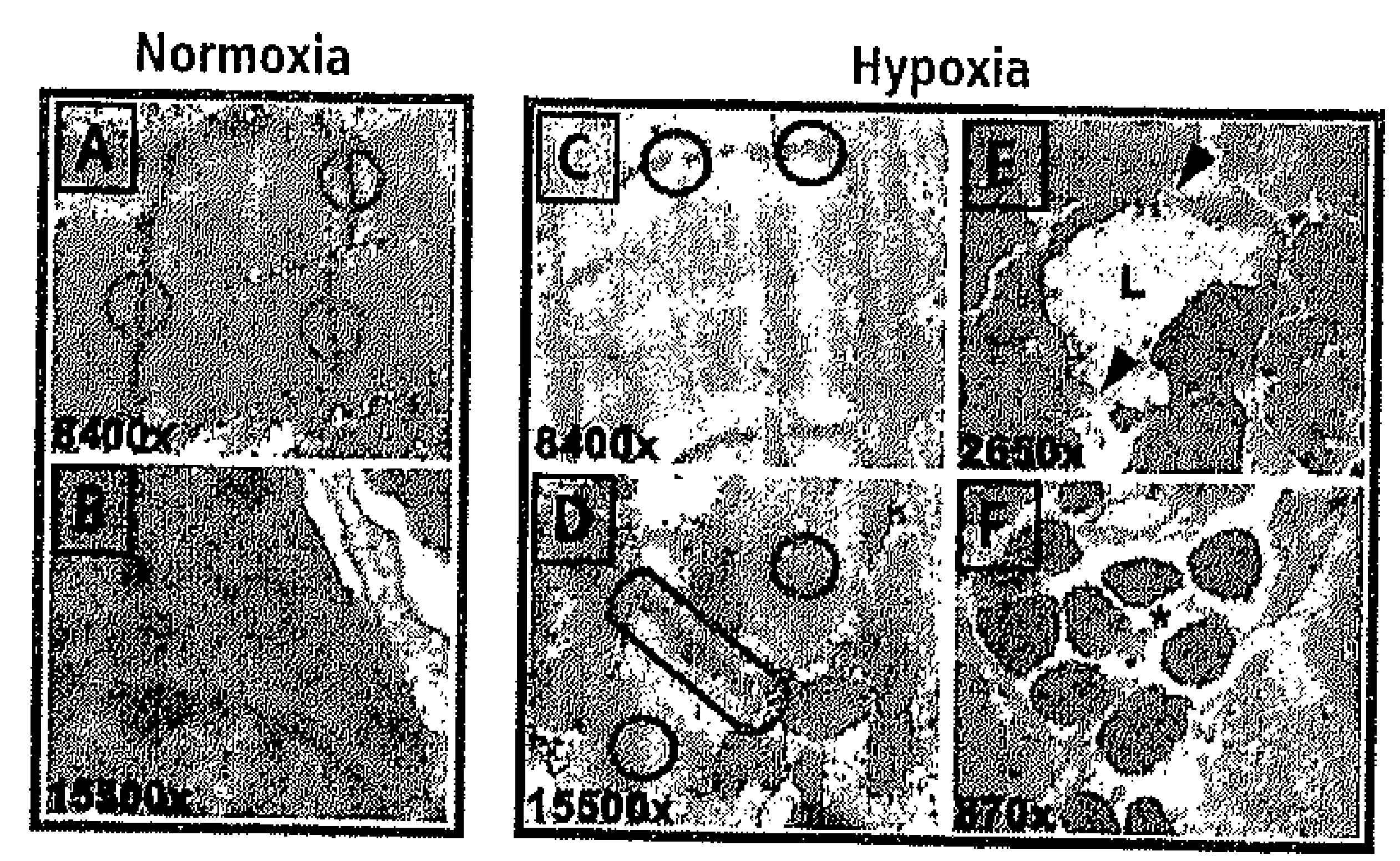

Figure 8 Panels A to F, ultrastructural analysis of E20 normoxic (Panels A and B, blue frame) and $E 20$ chronic hypoxic hearts (Panels $C$ to $F$, red frame), both $n=7$. Hypoxic hearts show myofibrillar disarray with disruption of sarcomeric architecture (Pane/s $C$ and D, red circles), endothelial gaps in capillaries (Panel E, arrowheads; L, lumen) and infiltration of inflammatory cells (Panel $F$, asterisk). 
(Fig. 6A-C) indicating that angiogenesis in the left ventricle was not disrupted. Hearts of these hypoxic embryos displayed LV dilatation (Fig. 7A and B), without other congenital heart defects. The LV cavity cross-sectional area was 2-fold larger than in normoxic embryos $\left(3.96 \pm 0.5 \mathrm{~mm}^{2}\right.$ versus $1.96 \pm 0.2 \mathrm{~mm}^{2} ; \mathrm{n}=11$ in each group; $\mathrm{P}<$ $0.01)$. Histological analysis of the myocardium revealed increased glycogen deposition in hypoxic hearts (Fig. 7C and D). in vivo molecular imaging using annexin- $\mathrm{V}$ labeling identified more apoptotic cardiomyocytes in hypoxic hearts (Fig. 7E and F). Expression of ANF was elevated in hypoxic hearts (Fig. 7G). Ultrastructural
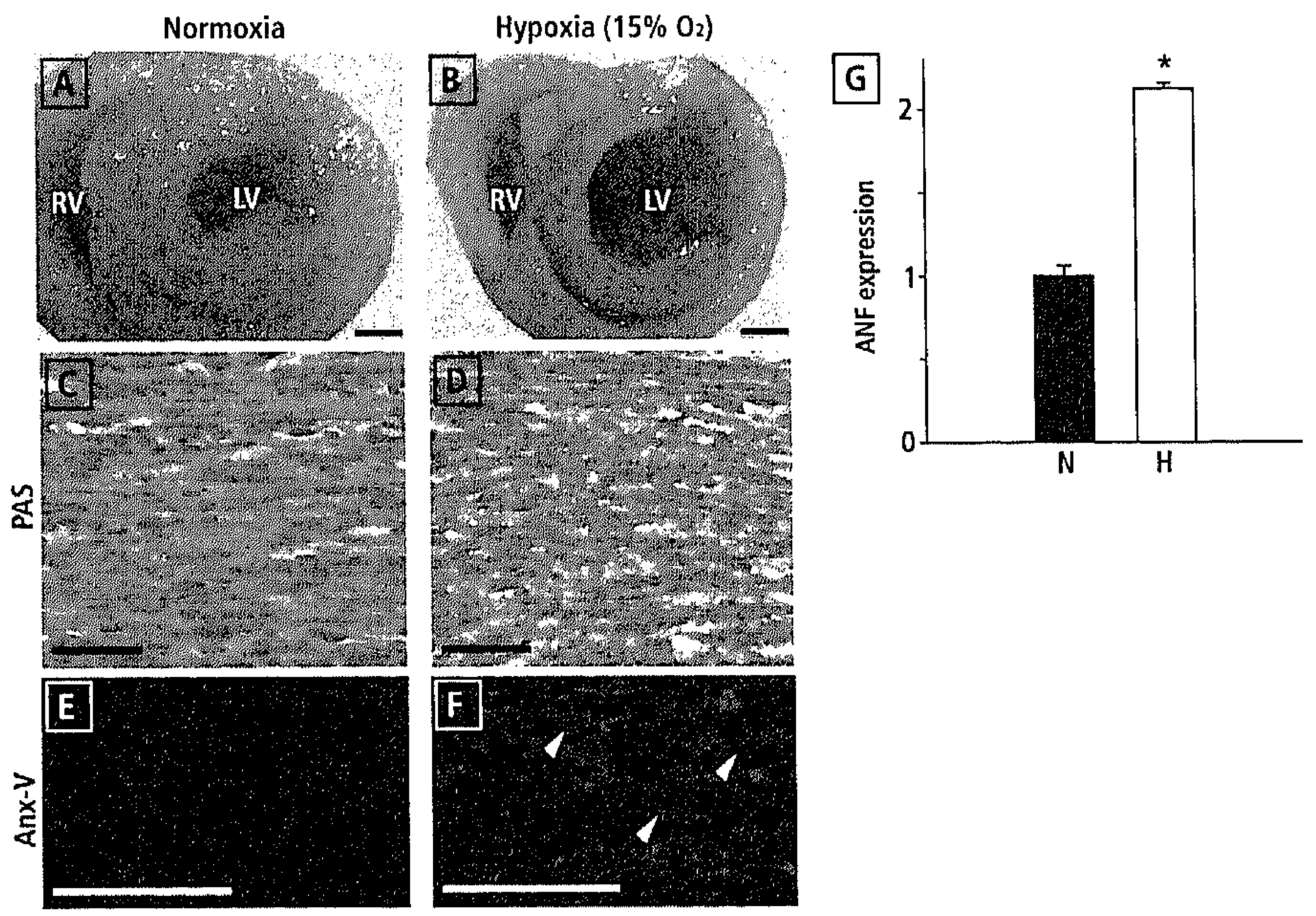

Figure 7 Panels $A$ and $B$, cardiac morphology at E2O showing severe left ventricular dilatation in hypoxic $(H$, panel $B)$ compared with normoxic hearts ( $N$, panel $A)$. Scale bars represent $1 \mathrm{~mm}$. $L V$, left ventricle; $R V$, right ventricle. Panels $C$ and $D$, PAS staining for glycogen in left ventricular myocardium of chick embryos. Note the increased glycogen deposition (red) in hypoxic (panel D) compared with normoxic hearts (panel C), both $n=6$. Scale bars represent $100 \mu \mathrm{m}$. Panels $E$ and $F$, in vivo molecular imaging of apoptosis using fluorescent annexin-V showing an increased number of apoptotic cardiomyocytes in the left ventricle of hypoxic (panel F) compared with normoxic hearts (panel E), both $n=5$. Arrowheads denote apoptotic cardiomyocytes. Scale bars represent $100 \mu \mathrm{m}$. Panel $\mathrm{G}$, quantitative real-time $P C R$ analysis of the heart failure biomarker ANF showing increased expression in hypoxic compared with normoxic hearts at $E 20, n=9$ and $n=8$, respectively. Data are shown as mean $\pm S E ;{ }^{*} P<0.05 \mathrm{H}$ versus $\mathrm{N}$. 


\section{A}

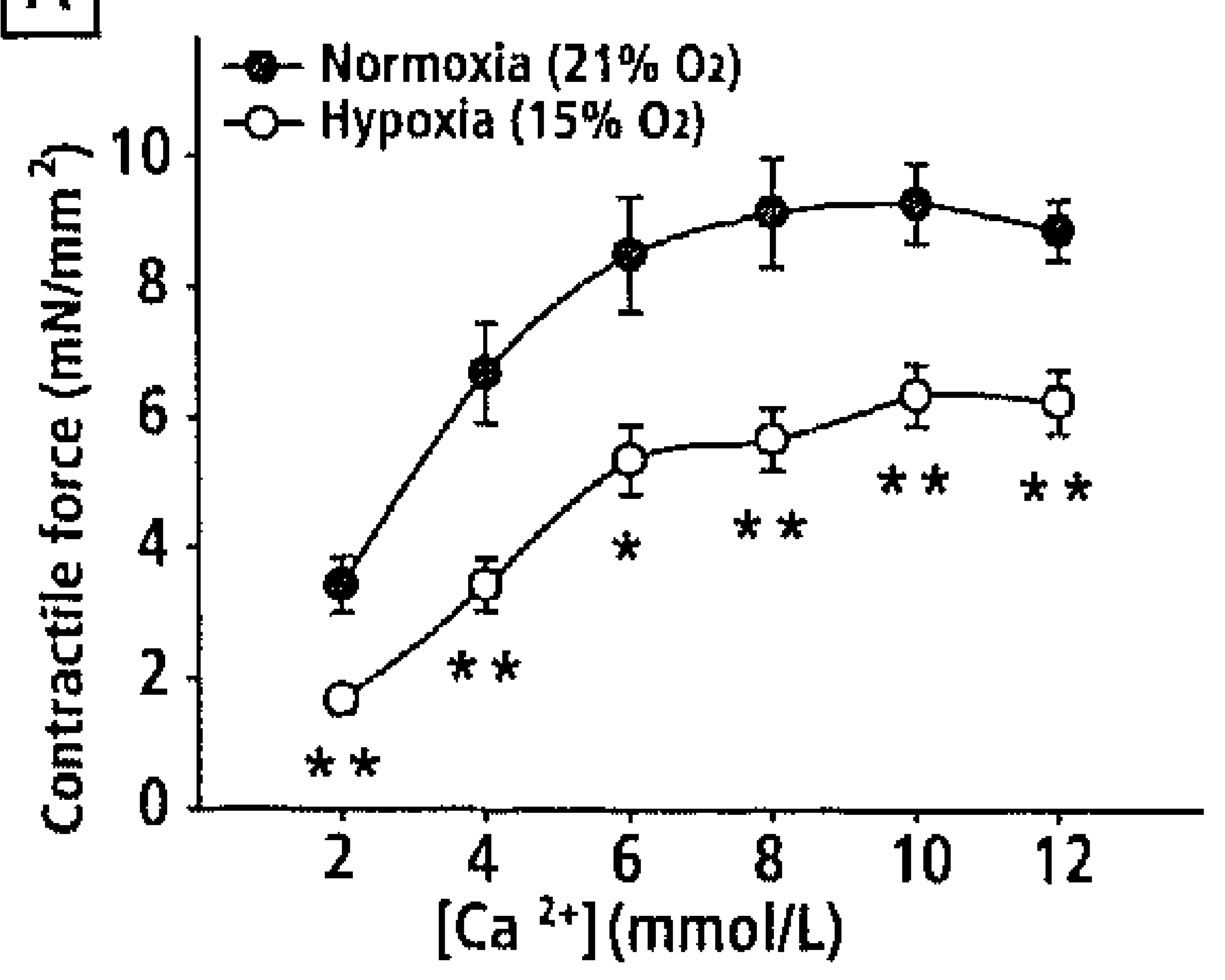

B

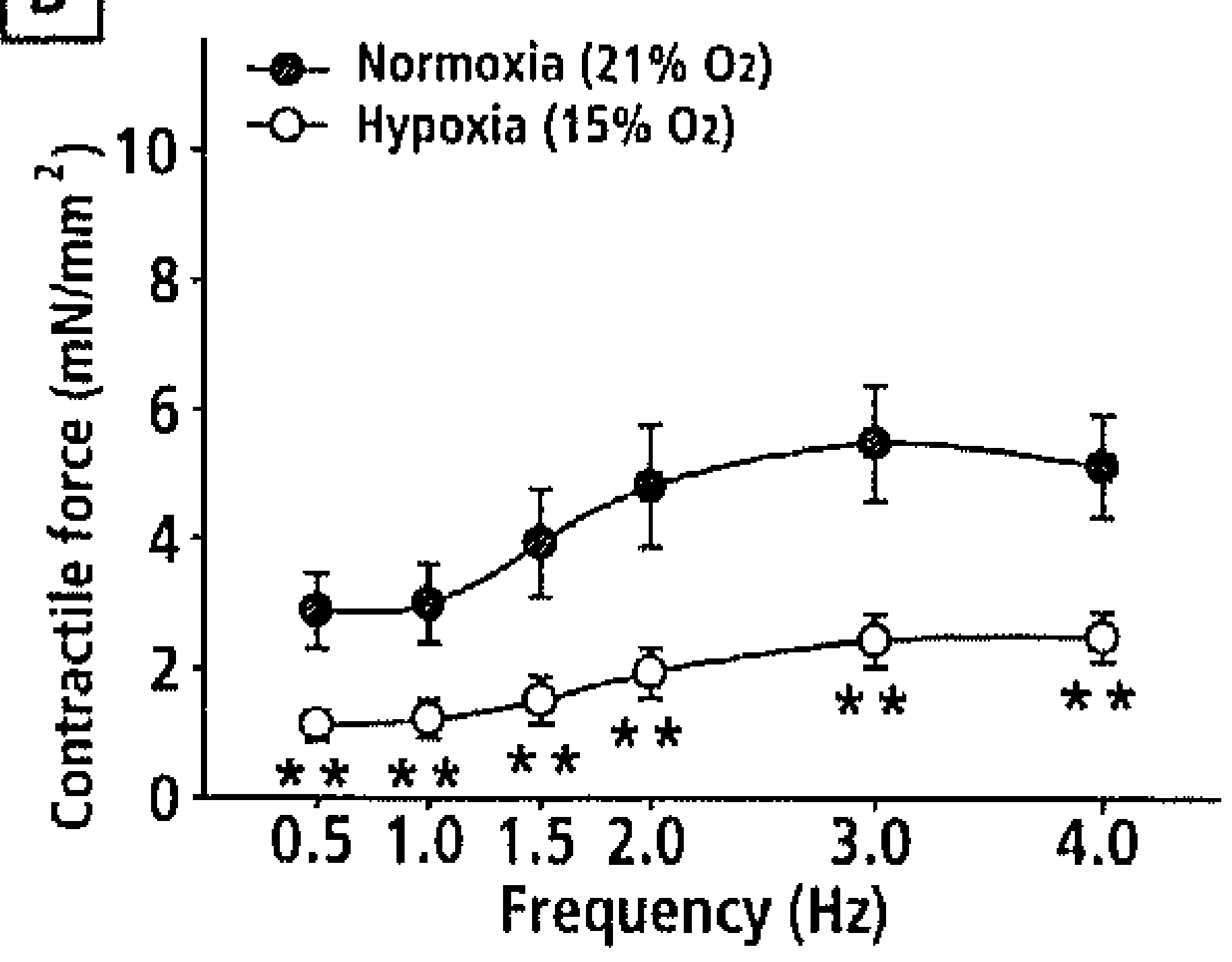

Figure 9 Panel A, contractile force generation of left ventricular muscle bundles isolated from E20 chick embryo hearts. Contractility to calcium is lower in hypoxic compared with normoxic hearts, $n=6$ and $n=8$, respectively. Data are shown as mean $\pm S E ;{ }^{*} P<0.05$, ** $P<0.01 \mathrm{H}$ versus $N$. Panel $B$, contractile responses to increasing pacing frequencies are lower in E2O chronic hypoxic $(H)$ compared with $E 20$ normoxic $(N)$ hearts, $n=9$ and $n=14$. Data are shown as mean $\pm S E ; * * P<0.01 \mathrm{H}$ versus $\mathrm{N}$.

$21 \% \mathrm{O}_{2}$

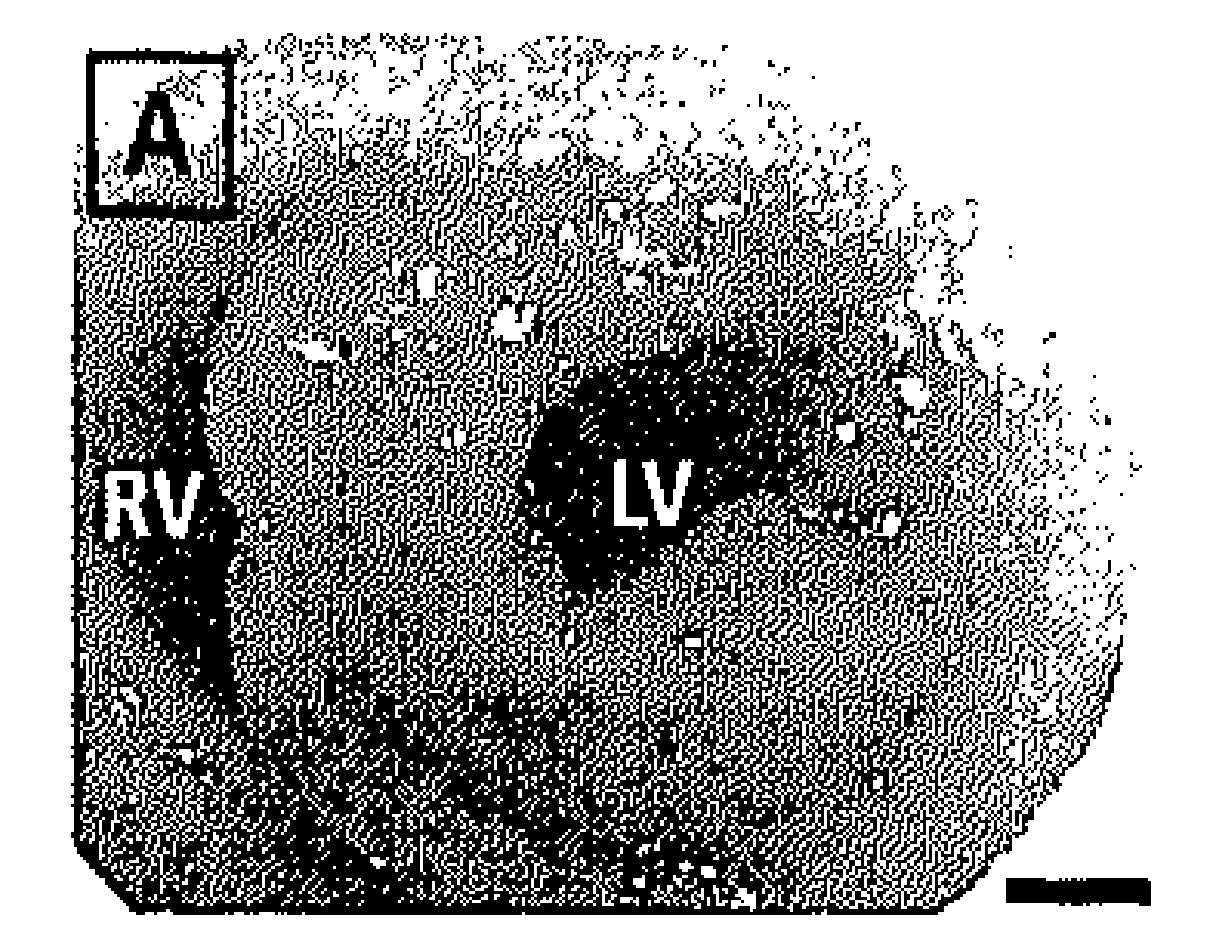

$18 \% \mathrm{O}_{2}$

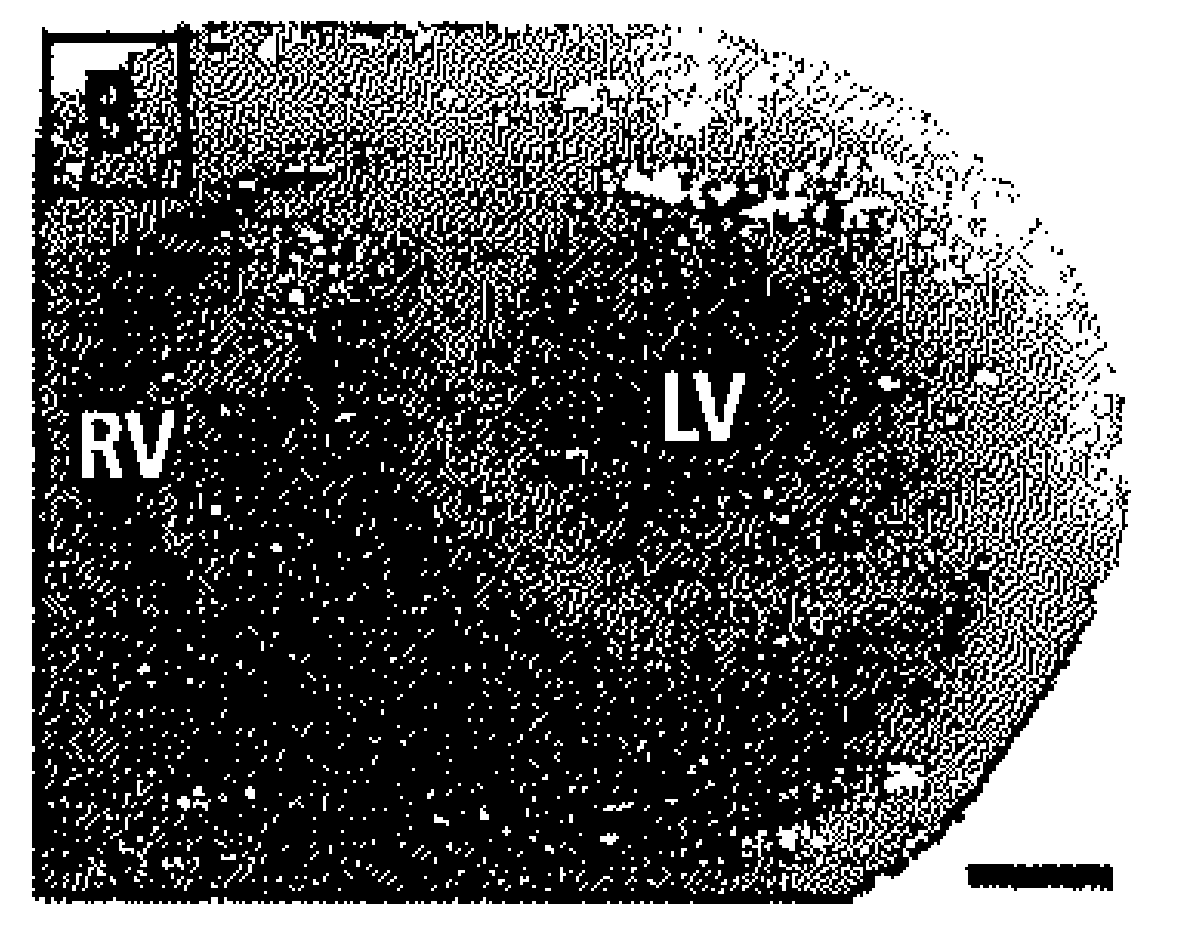

$15 \% \mathrm{O}_{2}$

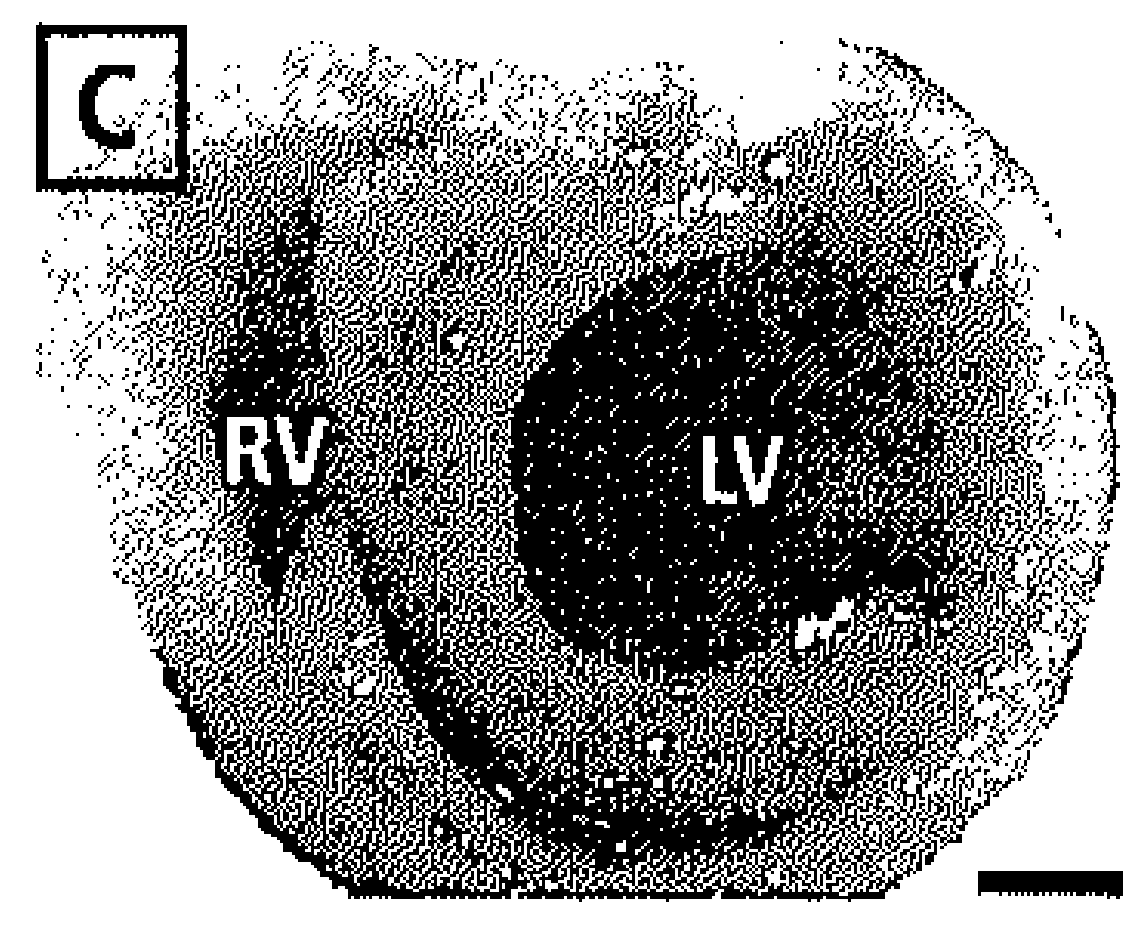

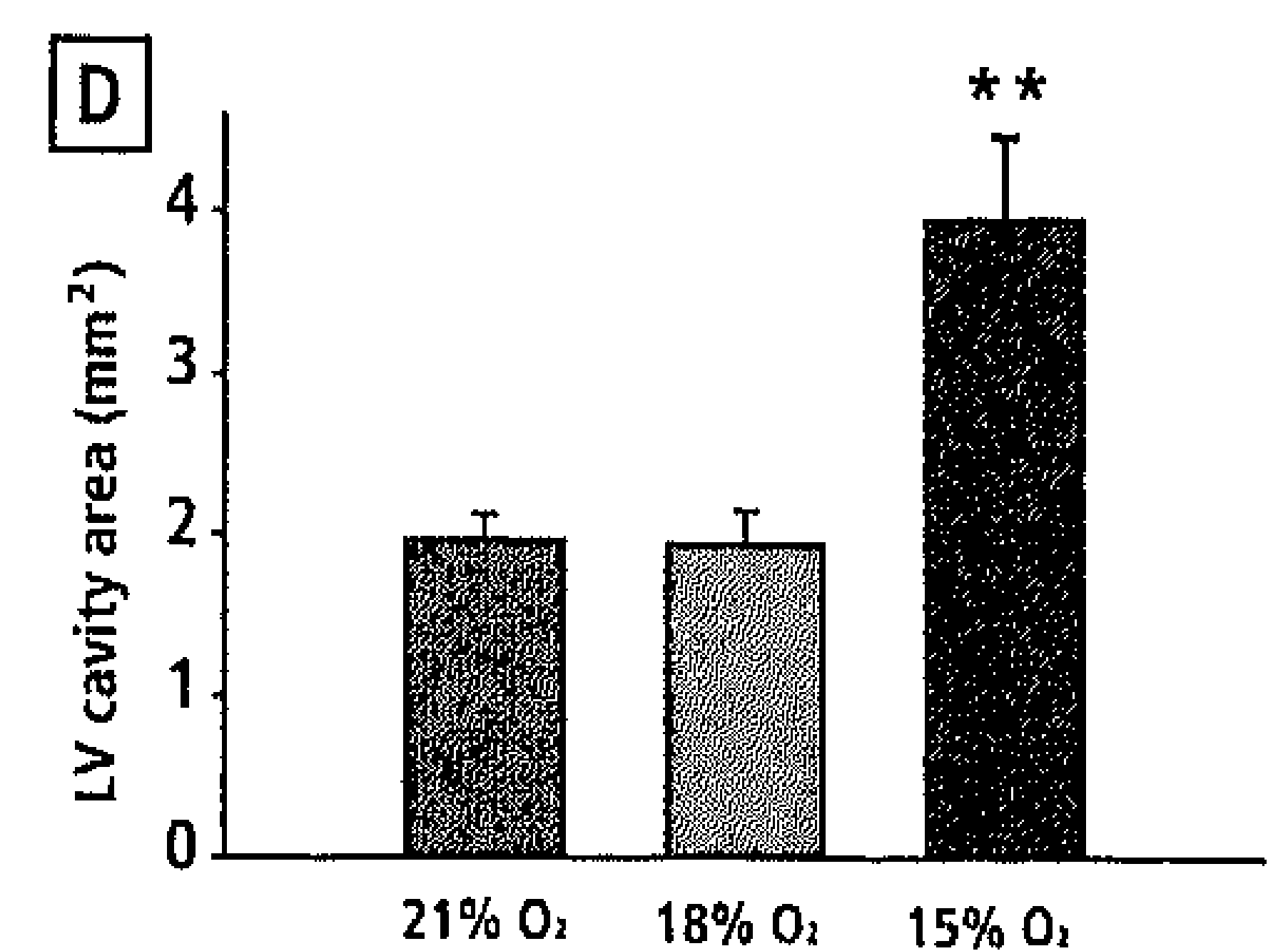

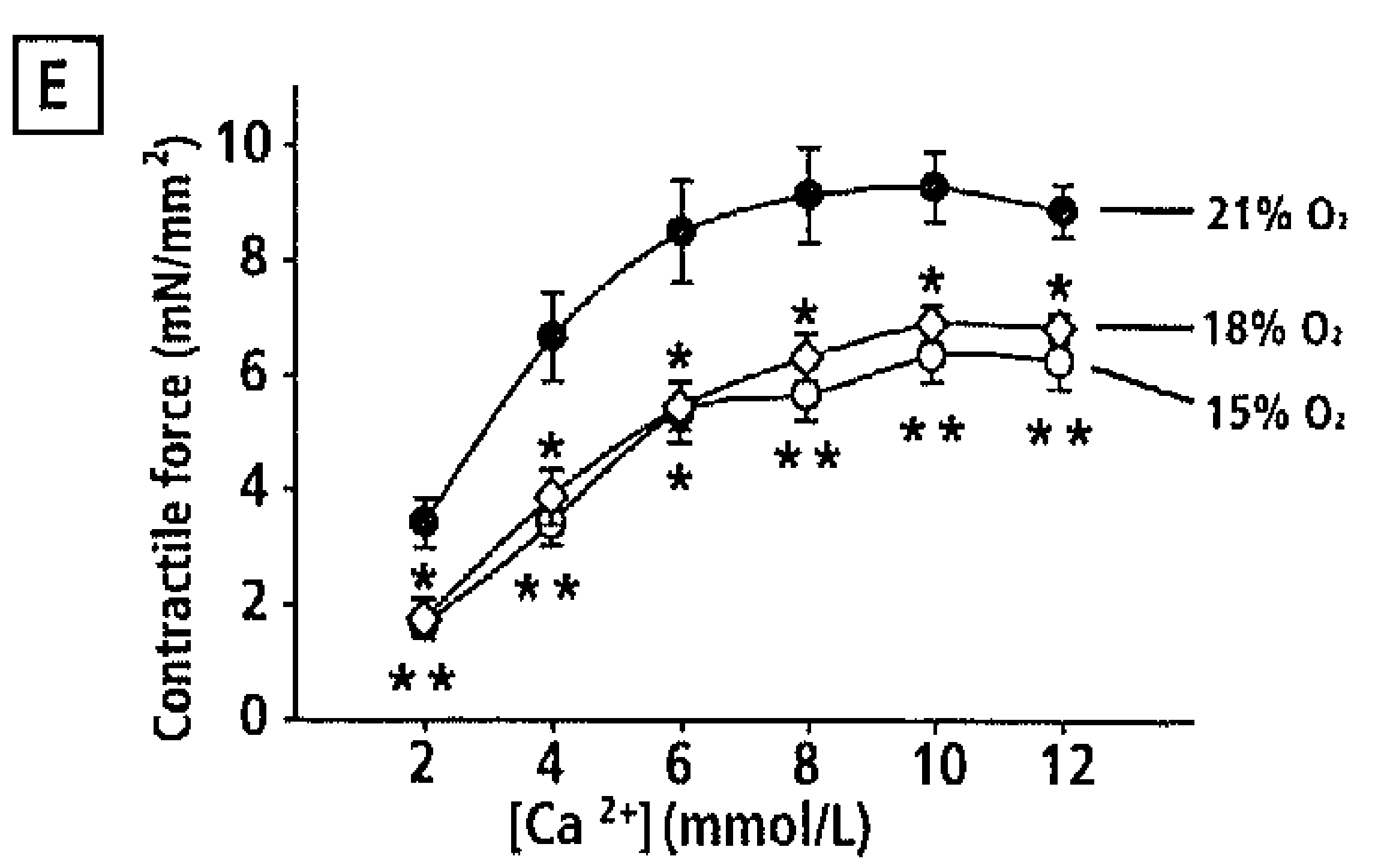

Figure 10 Panels $A$ to E, morphological and functional analysis of chick embryo hearts after exposure to different grades of $\mathrm{PO}_{2}(21 \%, 18 \%$, and $15 \%)$. Note the left ventricular dystunction in both $15 \% \mathrm{O}_{2}$ and $18 \% \mathrm{O}_{2}$ group (panel E). Left ventricular dilatation was only observed in the $15 \% \mathrm{O}_{2}$ group (panel $\mathrm{C}$ ) and not in the $18 \% \mathrm{O}_{2}$ group (panel B). Scale bars represent $1 \mathrm{~mm}$. 
analysis showed myocyte degeneration, myofibrillar disarray with disruption of sarcomeric architecture, leaky blood vessels, and infiltration of inflammatory cells in hypoxic hearts (Fig. 8A-F). Thus, exposing the developing embryo to $15 \% \mathrm{O}_{2}$ resulted in morphological and histological changes compatible with cardiomyopathy.

We next examined the contractile performance of $\mathrm{LV}$ muscle bundles at E20. Diameters and length of the muscle bundles were not significantly different between $H$ and $N$ group $(0.5 \pm 0.04$ versus $0.5 \pm 0.02 \mathrm{~mm}$ and $4.6 \pm 0.30$ versus $5.1 \pm 0.30 \mathrm{~mm}$, respectively). The contractile force to increasing concentrations of calcium was on average $40 \%$ lower in hypoxic compared to normoxic muscle bundles (Fig. 9A). A similar reduction in contractility was observed to increasing pacing frequencies (Fig. 9B). Since the contractile force was normalized to cross-sectional area, the reduction in contractility cannot solely be explained by simple loss of mass, but reflects a true intrinsic disorder of cardiomyocyte contractile capacity. Collectively these data indicate that introducing hypoxic stress by exposing embryos to $15 \% \mathrm{O}_{2}$ induces loss of cardiac contractility evolving into dilated cardiomyopathy before birth.

Exposing chick embryos to very mild hypoxia $\left(18 \% \mathrm{O}_{2}\right)$ still resulted in a significant reduction of left ventricular contractile force generation (Fig. 10E), albeit in the absence of dilatation (Fig. 10B). Thus, very mild hypoxic stress is sufficient to induce cardiomyopathy.

\section{Heart after}

Prenatal Normoxia $\left(21 \% \mathrm{O}_{2}\right)$

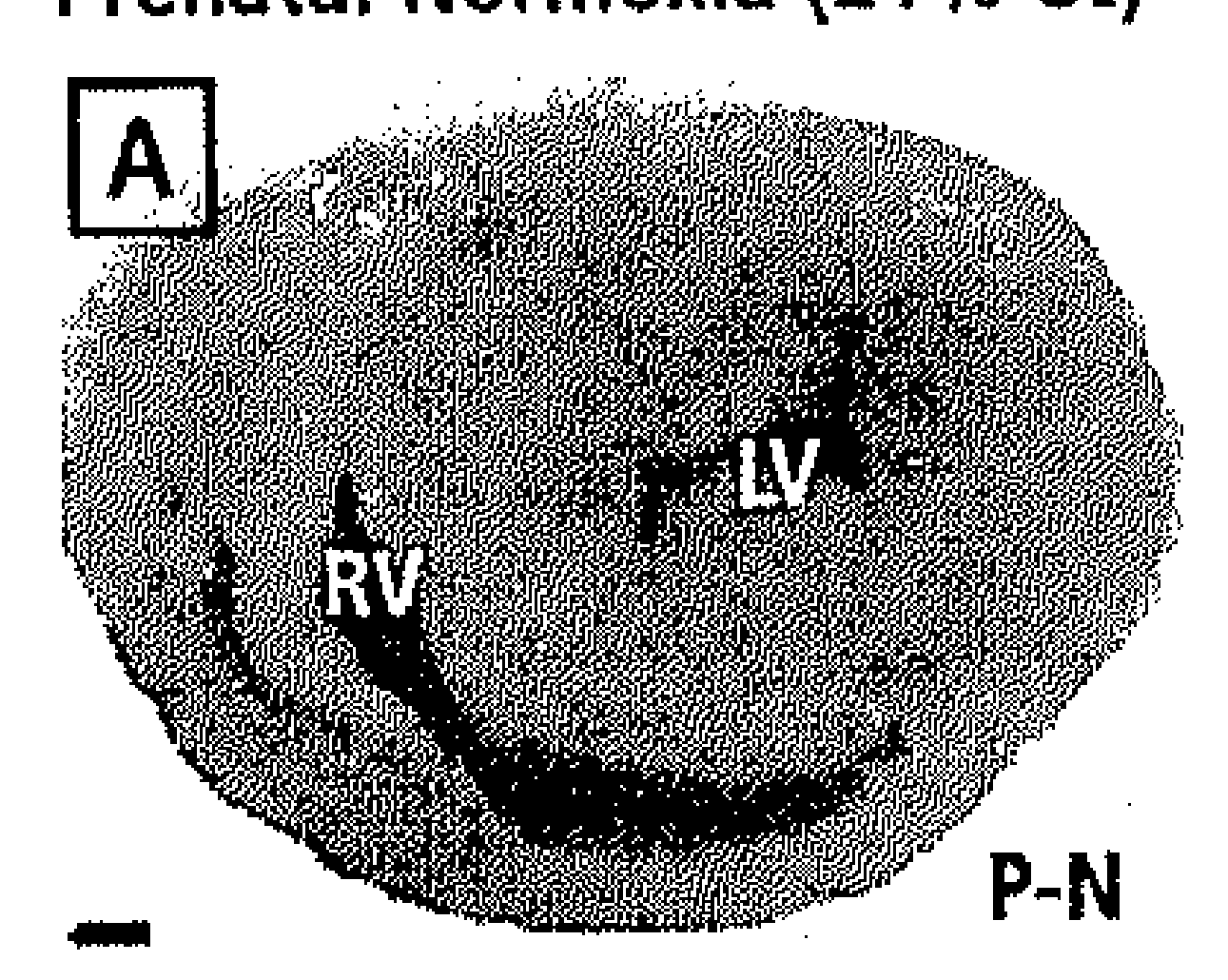

Heart after

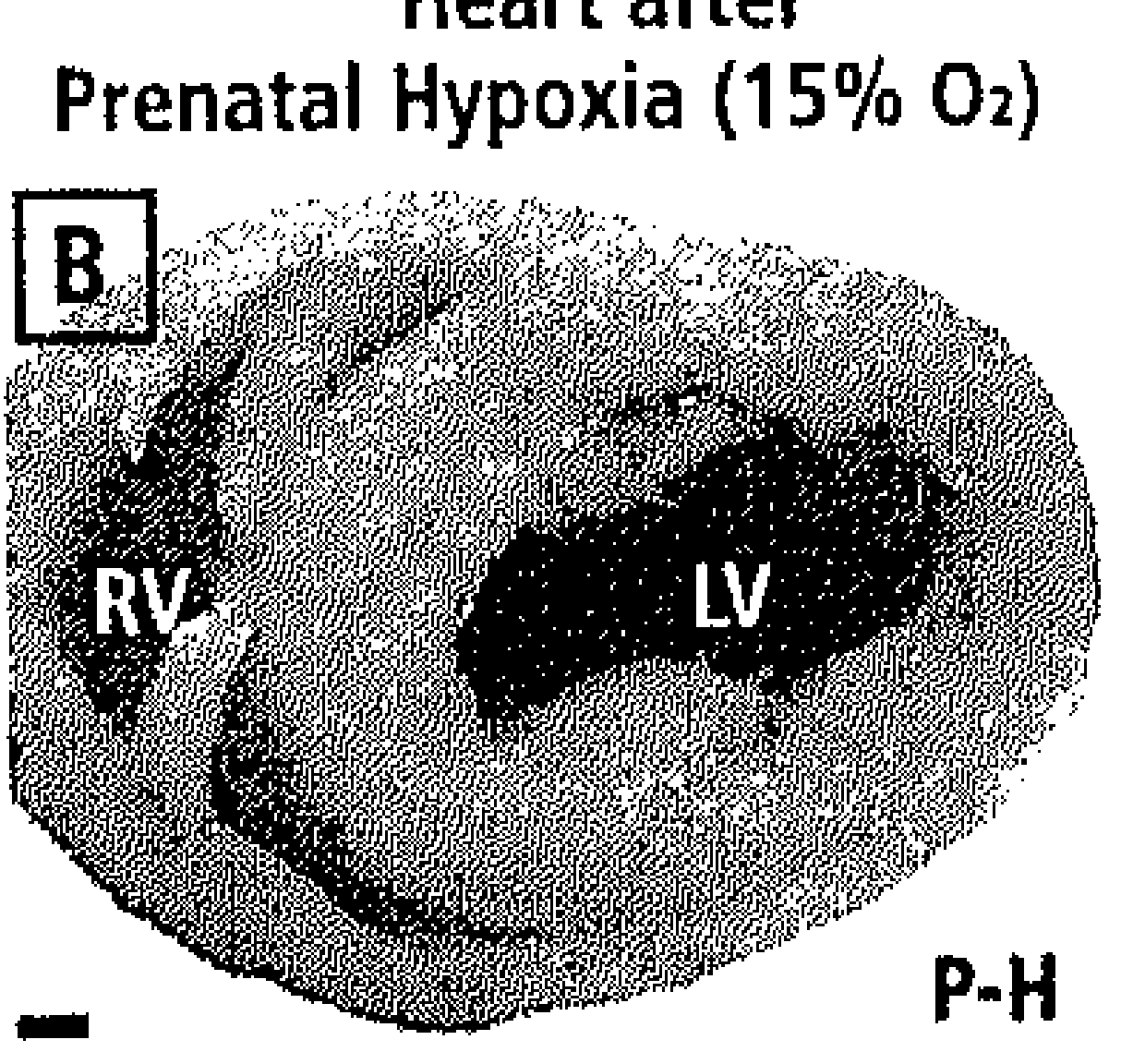

C

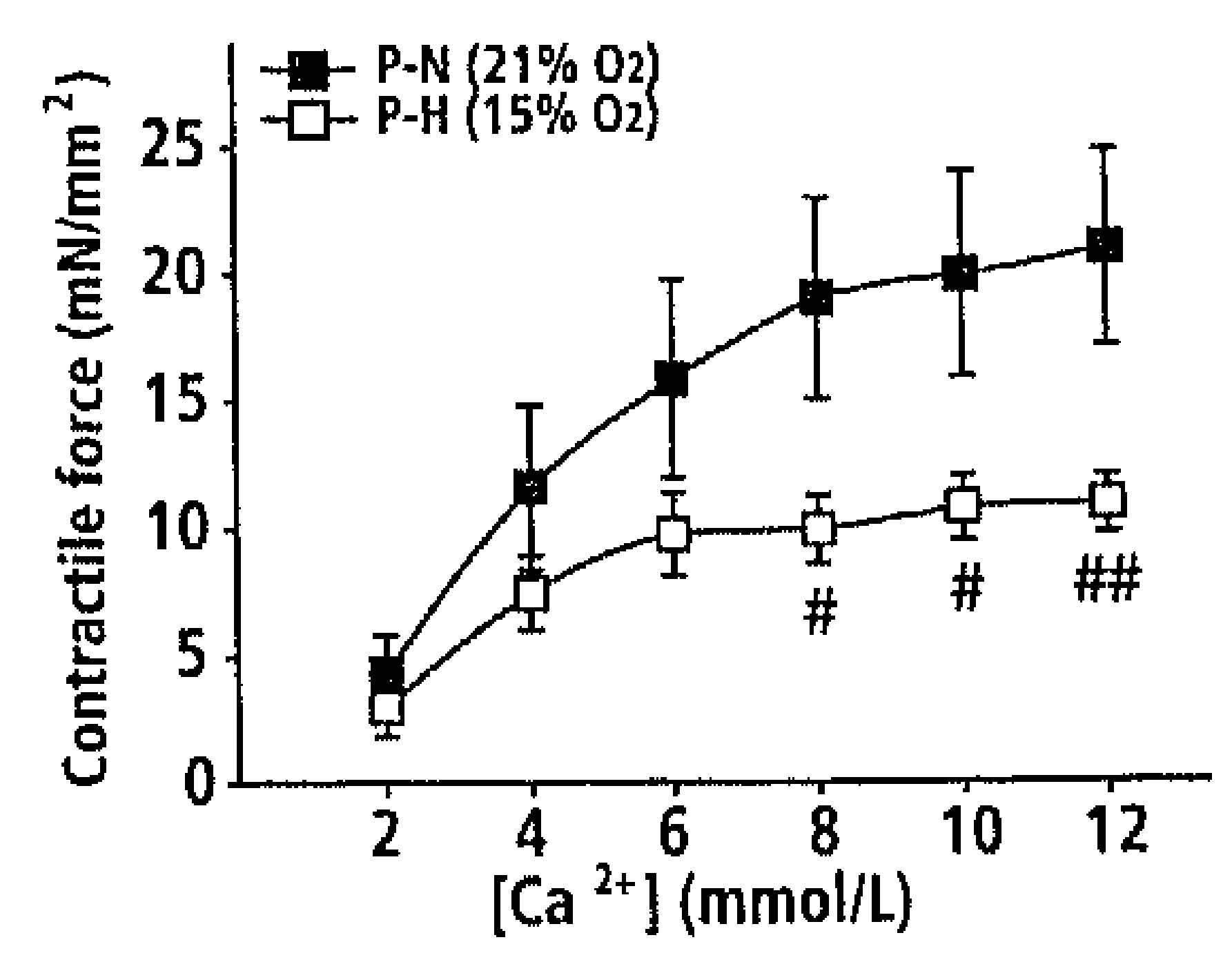

Figure 11 Panels $A$ and $B$, morphology of adult hearts. Note the left ventricular dilatation in adult animals prenatally exposed to hypoxia $(P-H$, panel $B)$ compared with adult animals prenatally exposed to normoxia ( $P-N$, panel $A)$. Note that the normal adult chicken heart appears as in panel l and is not hypertrophied. Scale bars represent $1 \mathrm{~mm}$. LV, left ventricle; $R V$, right ventricle. Panel $C$, contractile force generation of left ventricular muscle bundles isolated from adult chicken hearts. Contractility to calcium is significantly lower in adult animals prenatally exposed to hypoxia $(P-H)$ compared with adult animals prenatally exposed to normoxia $(P-N)$, both $n=7$. Data are shown as mean $\pm S E ; \# P<0.05, \# P<0.01$ P $H$ H versus $P$-N . 


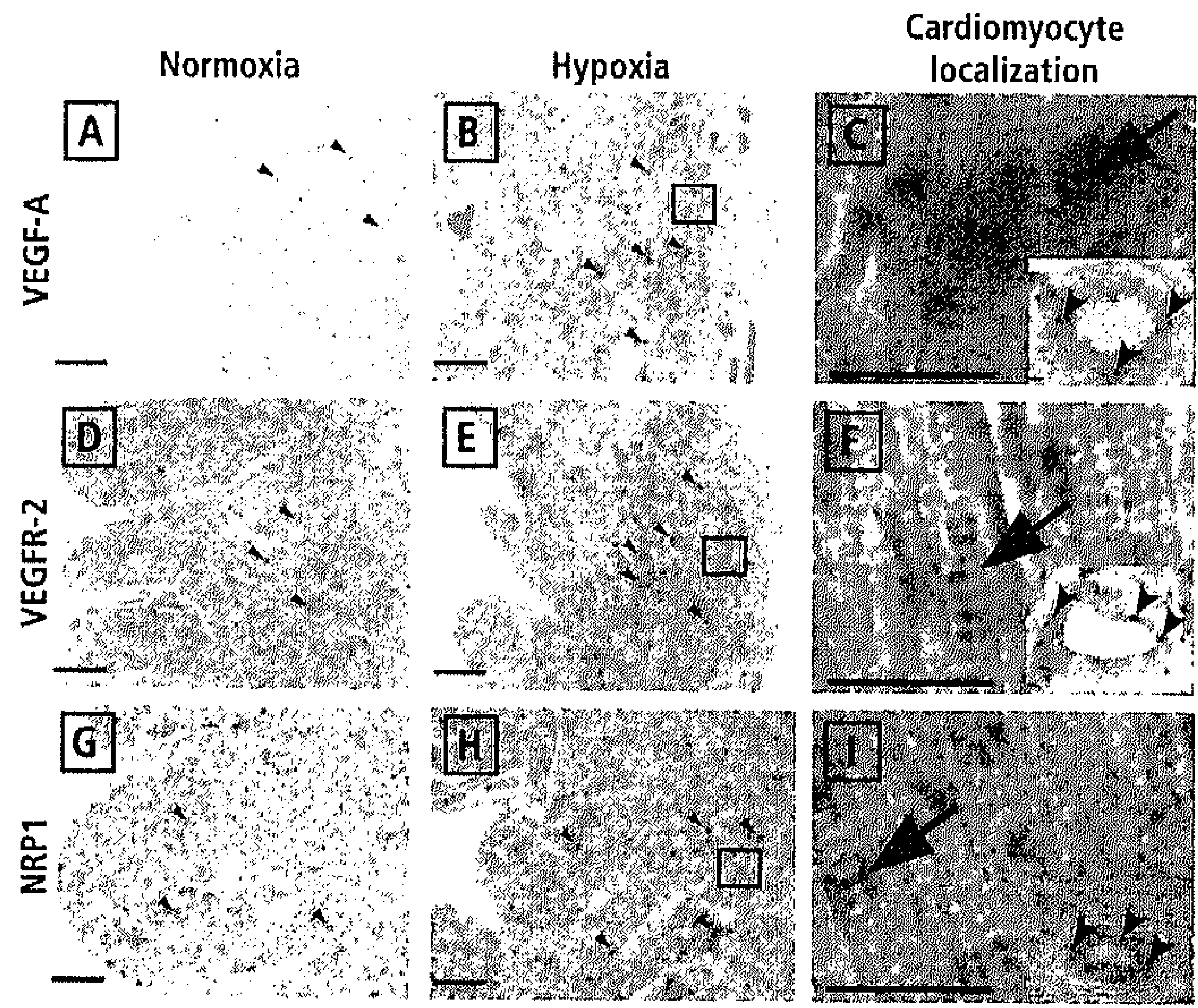

Figure 12 Pane/s $A$ and $B$, in situ hybridization for VEGF-A on sections of the left ventricle of normoxic and hypoxic E2O hearts. Expression of VECF-A (arrowheads) is more abundant in hypoxic myocardium (panel B) compared with normoxic myocardium (panel A). Panel $C$, high magnification of boxed area in panel B. Note the specific expression of VEGF-A in cardiomyocytes (arrows) and blood vessels (inset, arrowheads). Panels $D$ and $E$, in situ hybridization for VEGFR-2 on sections of the left ventricle of normoxic and hypoxic 220 hearts. Expression of VEGFR-2 (arrowheads) is more abundant in hypoxic myocardium (panel E) compared with normoxic myocardium (panel D). Panel F, high magnification of boxed area in panel E. Note the specific expression of VEGFR-2 in cardiomyocytes (arrows) and blood vessels (inset, arrowheads). Panels $G$ and $H$, in situ hybridization for NRP1 on sections of the left ventricle of normoxic and hypoxic E2O hearts. Expression of NRP1 (arrowheads) is elevated in hypoxic myocardium (pane/ H) compared with normoxic myocardium (panel G). Panel l, high magnification of boxed area in panel $\mathrm{H}$. Note the specific expression of NRP1 in cardiomyocytes (arrows) and blood vessels (inset, arrowheads). Scale bars represent $100 \mu \mathrm{m}$.

Prenatal Hypoxia Leads to Cardiomyopathy that Persists into Adulthood We next investigated cardiac structure and function in adult chickens prenatally exposed to $15 \% \mathrm{O}_{2}$. These animals displayed LV dilatation (Fig. 11A and B). LV cavity cross-sectional area was 4-fold larger compared to adult animals prenatally exposed to normoxia $\left(18.6 \pm 1.3 \mathrm{~mm}^{2}\right.$ versus $4.6 \pm 0.6 \mathrm{~mm}^{2} ; \mathrm{n}=7$ in each group; $\mathrm{P}<0.05)$. Furthermore, contractile responses to calcium in LV 


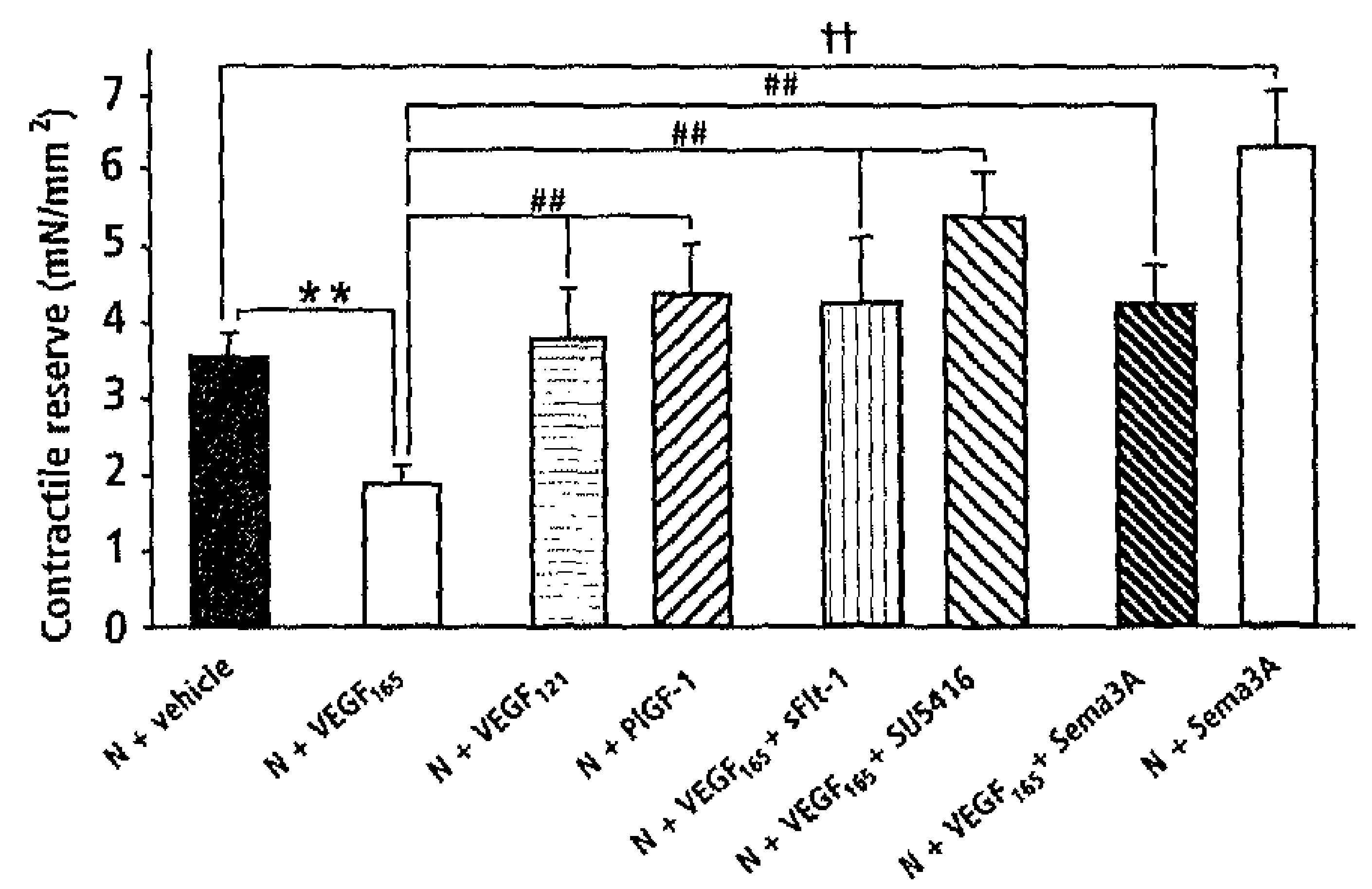

Figure 13 Contractility of normal left ventricular muscle bundles from normoxic E20 hearts after 4 hours ex vivo incubation with rhVECF 11,5 (red bar, $n=6)$, rhVECF 121 (blue bar, $n=7$ ), mPICF-1 (purple bar, $n=6$ ), rhVEGF $165+$ sFlt-1 (green bar, $n=6$ ), rhVEGF $165+5 U 5416$ (yellow bar, $n=8$ ), rhVECF ${ }_{16,5}+$ Sema3A (yellow bar, $n=7$ ), and Sema3A alone (purple bar, $n=8)$. Only rhVEGF 16.5 exerts a negative inotropic effect compared to vehicle (black bar, $n=13$ ), which is abolished when co-incubated with the VECF-A scavenger sFlt-1 or the VECFR-2 inhibitor SU5416. Sema3A alone (purple bar) significantly increases contractile reserve compared to vehicle. Data are shown as mean $\pm S E ;{ }^{* *}$ $P<0.01$ VECF $_{165}$ versus vehicle incubated 220 normoxic muscle bundles. \#\# $P<0.01$ versus VECF 165 incubated 220 normoxic $L V$ muscle bundles. $t+P<0.01$ Sema3A versus vehicle incubated $E 20$ normoxic $L V$ muscle bundles.

muscle fibers from these hearts were significantly decreased compared to hearts prenatally exposed to normoxia (Fig. 11C). The data show that adult chickens prenatally exposed to hypoxia display cardiomyopathy, indicating that prenatal hypoxic stress can predispose the adult to CVD.

\section{Hypoxia Associated VEGF Signaling Accounts for Programming of Cardiomyopathy}

To address the contribution of VEGF to hypoxia-associated cardiomyopathy we examined the expression and function of VEGF in the embryonic myocardium and tested prenatal scavenging of VEGF as a rescue therapy. Expression of VEGF-A, VEGFR-2, and NRP1 mRNA was significantly more pronounced in hypoxic than in normoxic ventricular myocardium as evidenced by in situ hybridization (Fig. 12A1). In hypoxic hearts pronounced expression of VEGF-A, VEGFR-2, and NRP1 was noted in the cardiomyocytes (Fig. 12 C,F,I). VEGF-A and its receptors were also detectable in coronary vessels of both normoxic and hypoxic embryos (Fig. 12 $C, F, l$ insets). Elevated expression of VEGF-A, VEGFR-2, and NRP1 in hypoxic 
hearts was confirmed by quantitative real-time PCR (data not shown). All major VEGF-A isoforms were expressed in the heart (Fig. 5D) with the large isoforms $V \mathrm{EGF}_{166}$ (the chick embryo equivalent to human $\mathrm{VEGF}_{16.5}$ ) and $\mathrm{VEGF}_{190}$ being more abundant than $V_{E G F_{146}}$ and $V E G F_{122}$. Both VEGF 166 and $V E G F_{190}$ expression was higher in hypoxic than in normoxic hearts. These data show that VEGF-A as well as VEGFR-2 and NRP1 are expressed in the embryonic myocardium, with their expression levels being augmented in response to hypoxia.

VEGF Impairs the Contractility of the Embryonic Heart

To test the acute effects of VEGF on cardiac contractility, LV muscle bundles from normoxic E20 embryos were exposed to the VEGF-A isoforms VEGF 165 and $V_{E G F}{ }_{121}$, and to PIGF-1. Only VEGF ${ }_{165}$ dramatically reduced the contractile reserve to calcium in normoxic muscle bundles (Fig. 13). The negative inotropic effect of VEGF ${ }_{165}$ was abolished when VEGF 165 was co-incubated with sFlt-1 or with the VEGFR-2 tyrosine kinase inhibitor SU5416 ${ }^{31}$ (Fig. 13), indicating the involvement of VEGFR-2 signaling. The used VEGF isoforms exhibit differential affinity to VEGFR-1, VEGFR-2 and the VEGF co-receptor NRP1. Since only $\mathrm{VEGF}_{165}$, but not VEGF 121 or PIGF-1, binds to NRP1, we next investigated the potential role of NRP1 using the NRP1 ligand Sema3A. To achieve competitive antagonism of $\mathrm{VEGF}_{165}$ binding to NRP1, muscle bundles were co-incubated with the NRP1 ligand Sema3A. Antagonizing VEGF 165 with Sema3A rescued from loss of contractile reserve (Fig. 13). In contrast to the negative inotropic effect of $\mathrm{VEGF}_{165}$ in embryonic hearts, VEGF 165 did not affect contractility in LV muscle bundles from adult hearts (Fig. 14).

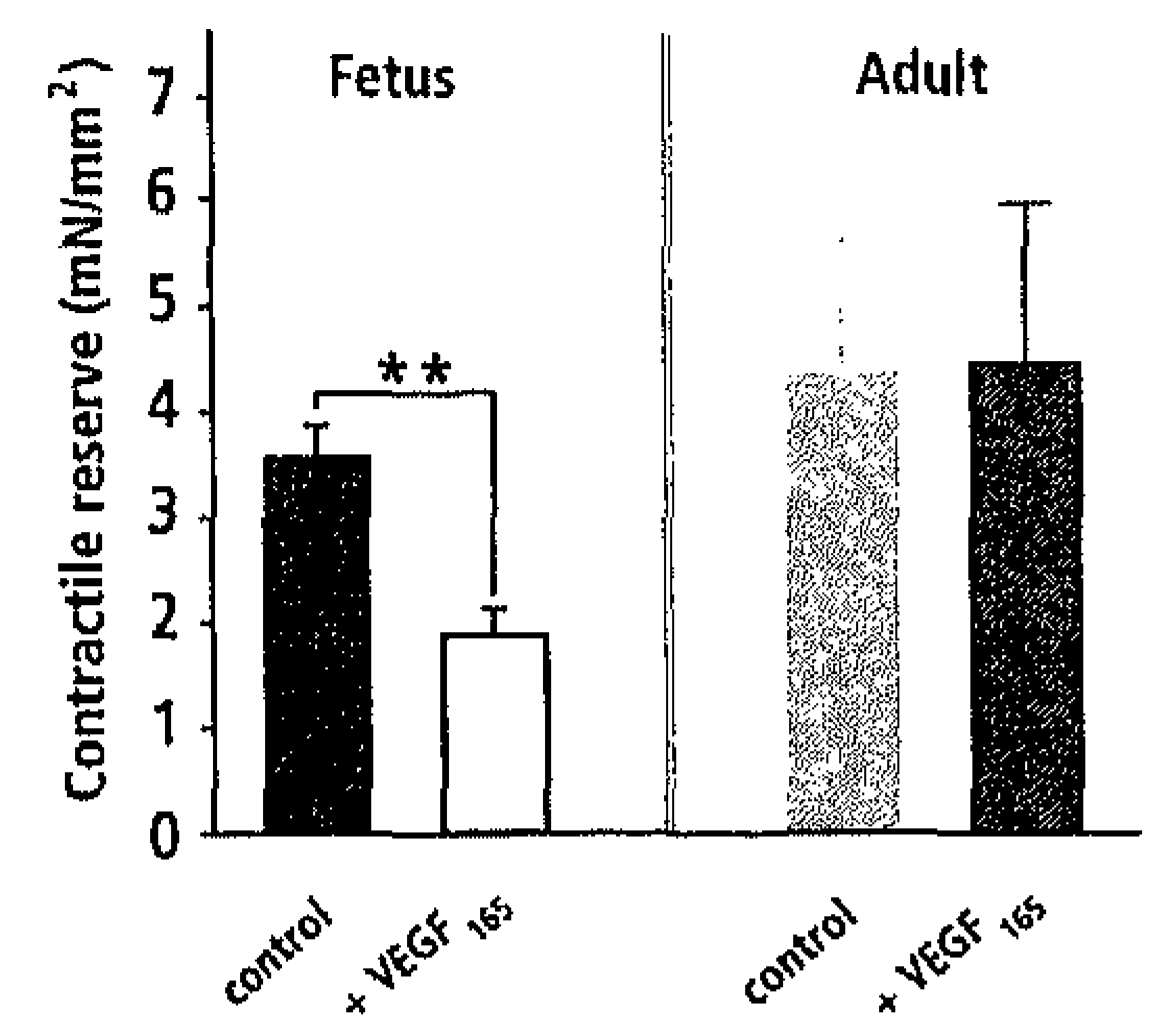

Figure 14 VEGF 165 impairs cardiac contractility only in the embryonic heart (left, embryo). Contractility of adult LV muscle bundles (right) is not affected by incubation with $V_{E G F_{165}}$. 
Prenatal Treatment with sFlt-1 or Sema3A Prevents Ventricular Dilatation and Restores Cardiac Function in Hypoxic Embryos

To determine the role of VEGF-A in mediating dilatation of the left ventricle and contractile dysfunction in vivo, we blocked VEGF-A activity by systemic administration of sFlt-1 to hypoxic embryos from E10 to E19. Treatment with sFlt-1 completely prevented LV dilatation in hypoxic embryos at E20 (Fig. 15A and B). Hearts from hypoxic embryos treated with sFlt-1 were macroscopically indistinguishable from normoxic embryos, and other signs of heart failure including edema were absent (data not shown). Administration of sFlt-1 also restored LV contractility in E20 hypoxic embryos, equaling the contractile responses to calcium of normoxic hearts (Fig. 15D). Survival of hypoxic
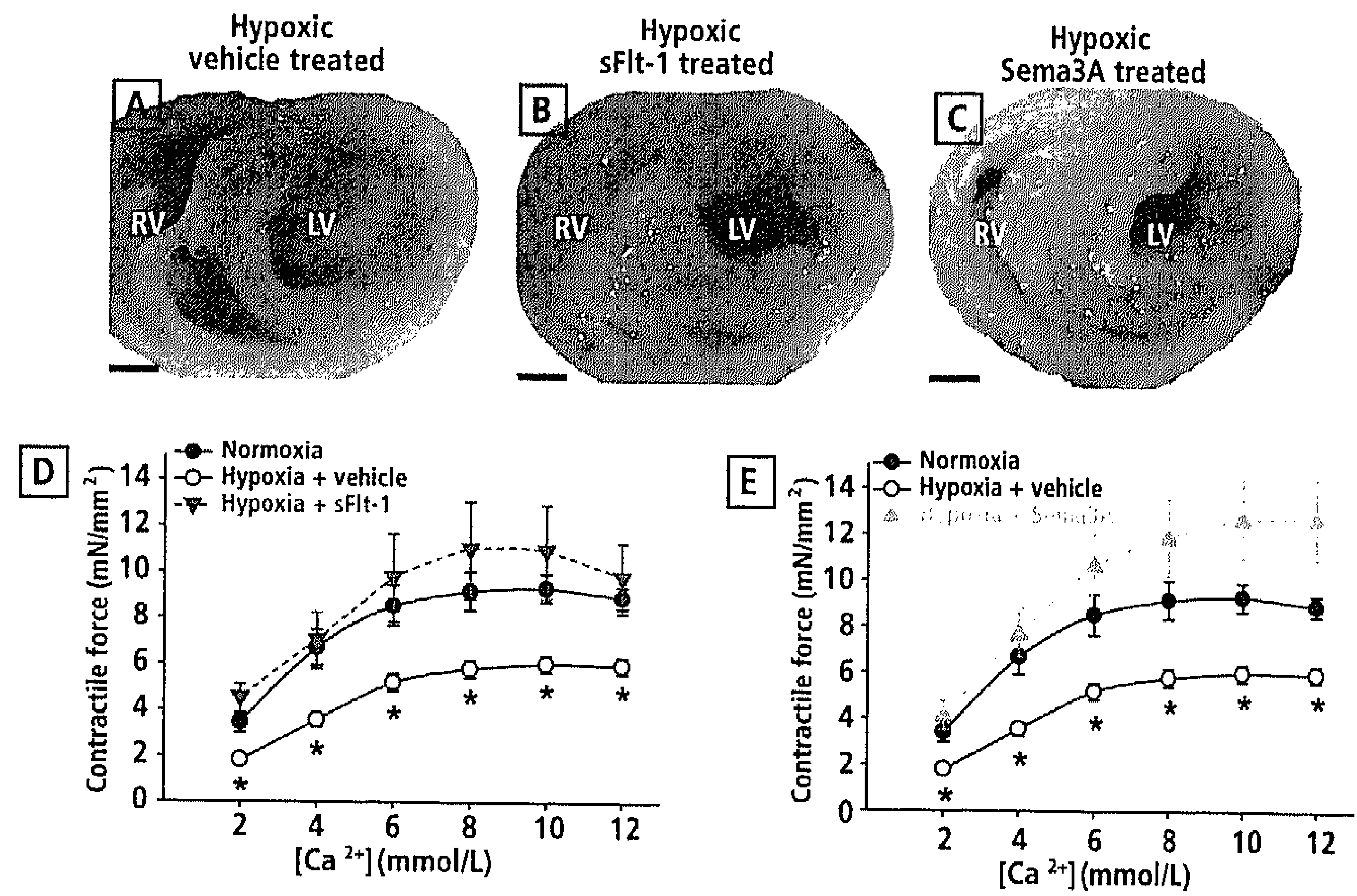

Figure 15 Panel A to C, cardiac morphology of hypoxic E2O embryos after vehicle, soluble VEGFR-1 (sFlt-1), or Sema3A treatment in vivo. Note the dilated left ventricle in vehicletreated embryos (panel $A$ ). Left ventricular dilatation is absent in hypoxic embryos treated with sFlt-1 or Sema3A (panel $B$ and $C$, respectively), $n=9$ in both groups. Scale bars represent $1 \mathrm{~mm}$. $L V$, left ventricle; $R V$, right ventricle. Panel $D$ and $E$, contractile force generation of isolated left ventricle muscle bundles from hypoxic embryonic hearts after treatment with VECF scavenger sF/t-1 or with Sema3A. Treatment of hypoxic embryos with sFlt-1 or Sema3A restores the contractile response to calcium as opposed to vehicle treated hypoxic embryos, both $n=5$. Data are shown as mean $\pm S E$; * $P<0.05 \mathrm{sFlt}-1$ or Sema3A treated versus vehicle treated hypoxic embryos. 
embryos was significantly improved by treatment with sFlt-1 compared with vehicle $(42 \%$ versus $18 \% ; n=24$ and $n=39$, respectively; $P<0.05$, Fig. $16 \mathrm{~A})$. Thus, scavenging VEGF rescues from progression to cardiomyopathy.
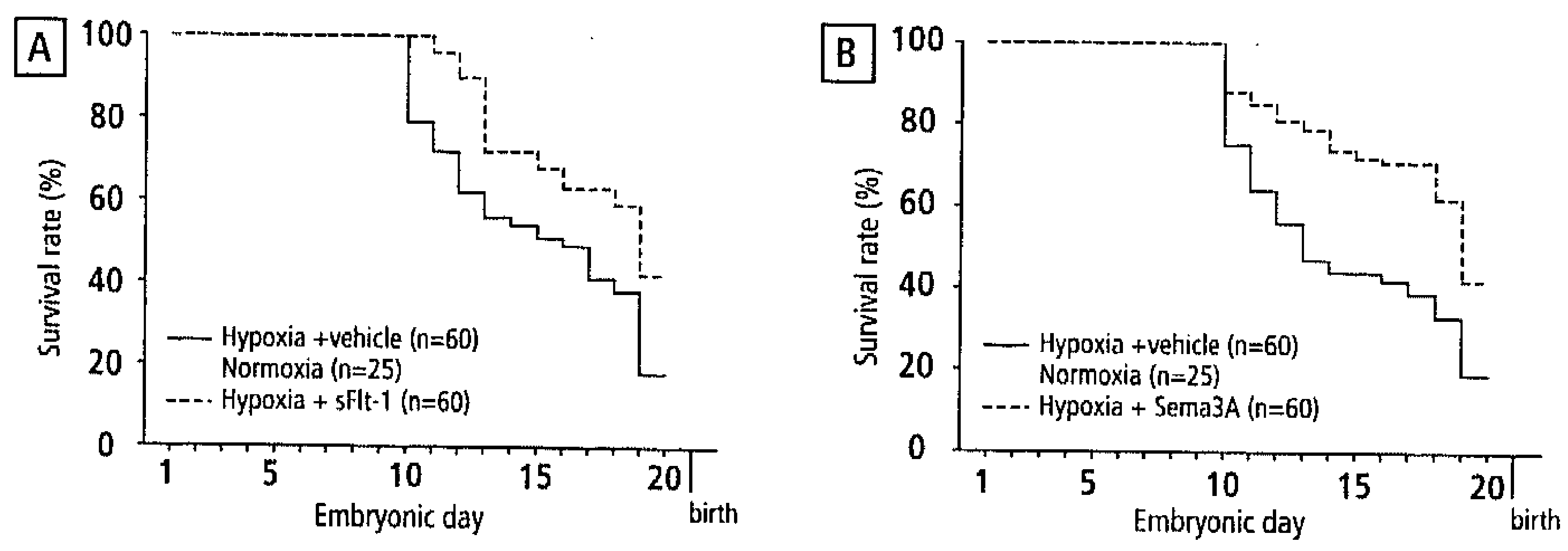

Figure 16 Embryonic survival is improved in hypoxic chick embryos treated with sFlt-1 or Sema3A.

We next explored whether antagonizing VEGF ${ }_{165}$ binding to NRP1 using Sema3A could also rescue hypoxic embryos from developing cardiomyopathy. Administration of Sema3A to hypoxic embryos prevented the development of left ventricular dilatation (Fig. 15C). Hearts from hypoxic embryos treated with Sema3A were macroscopically indistinguishable from normoxic embryos. Treatment with Sema3A also restored cardiac contractile function (Fig. 15E). The equipotent effects of sFlt-1 and Sema3A indicate a potential role for VEGF $_{165}$ NEGFR-2/NRP1 signaling in hypoxia-induced cardiac dysfunction in the embryo.

Table 5

\begin{tabular}{llll}
\hline \multicolumn{4}{c}{ Quantitative Real-Time PCR Primers } \\
\hline Gene & Accession Number & Sense Primer & Antisense Primer \\
\hline ANF & NM_204925 & AGCAGAGCCAACCCCATCTA & TTGGACTCCAGGGCTTCAAT \\
18S & AF173612 & ATGGCCGTTCTTAGTTGGTG & GAACGCCACTTGTCCTCTA \\
\hline
\end{tabular}




\section{Discussion}

The biological basis of fetal programming of adult CVD is largely unknown., 5 Here we report that cardiomyopathy can be programmed in utero by prenatal hypoxia acting via the VEGF/VEGFR-2/NRP1 axis.

Intrauterine echocardiography of hypoxic human fetuses showed reduced ejection time, prolonged acceleration time, and prolonged isovolumetric contraction time, all compatible with systolic dysfunction. ${ }^{32}$ In addition, NTproBNP, a biomarker of cardiac failure, was significantly elevated in umbilical cord blood of human FGR newborns with intrauterine hypoxia, suggestive of cardiomyopathy at time of birth. These functional and biochemical data indicate that intrauterine hypoxia is associated with the presence of cardiomyopathy before birth. These findings were paralleled by histological signs of cardiomyopathy, including glycogen accumulation and cardiomyocyte apoptosis, in postmortem cardiac biopsy specimens of hypoxic human fetuses. Immunostaining revealed elevated expression of VEGF-A and its receptors VEGFR-2 and NRP1 in cardiomyocytes of hypoxic human fetuses.

To test the hypothesis that intrauterine hypoxia initiates cardiomyopathy through elevating VEGF during critical phases of embryonic cardiovascular development, we designed an experimental model of hypoxia in chick embryos. The chick embryo is an established model in developmental biology, and since it develops independently of the mother animal it allows a unique approach to study the effects of isolated hypoxia. ${ }^{10,33}$ Incubating chick embryos below $15 \% \mathrm{O}_{2}$ resulted in $100 \%$ embryonic lethality. We therefore evaluated the consequences of exposure to $15 \% \mathrm{O}_{2}$ or $18 \% \mathrm{O}_{2}$. The hypoxemia levels in chick embryos after exposure to $15-18 \% \mathrm{O}_{2}$ are comparable to those that have previously been reported in human FGR fetuses. ${ }^{8,9}$

The embryos exposed to $15 \% \mathrm{O}_{2}$ showed dilated cardiomyopathy with loss of contractile function, elevated levels of the heart failure biomarker ANF, glycogen accumulation, cardiomyocyte apoptosis, and disarray of cardiomyocyte myofibrils at E20. In addition, we previously reported cardiac pump dysfunction as evidenced by decreased LV end-systolic pressure at E19 in this model. ${ }^{10}$ In line with the molecular findings in hypoxic human fetal hearts, VEGF-A, VEGFR-2, and NRP1 were upregulated in LV cardiomyocytes. Examination of adult chickens prenatally exposed to $15 \% \mathrm{O}_{2}$ also revealed cardiomyopathy including left ventricular dilatation and contractile dysfunction. This supports the hypothesis that hypoxic stress acting on critical stages of prenatal development can have long-term effects on cardiac performance and programs for CVD in adulthood. Even prenatal exposure to $18 \% \mathrm{O}_{2}$, a very mild level of hypoxia, resulted in 
impaired cardiac contractility, albeit without LV dilation. We conclude that prenatal hypoxic stress is an important risk factor for developing cardiomyopathy, the severity depending on the level of hypoxia.

To test the critical involvement of excessive VEGF-A levels, we reduced its biological availability by scavenging with sFlt-1. Prenatal treatment with sFlt-1 prevented the hypoxia-evoked left ventricular dilatation, restored cardiac contractility and improved survival. This shows that hypoxia associated elevated VEGF-A levels during intra uterine development may initiate cardiomyopathy. We next investigated the molecular mechanism responsible for VEGF-A induced cardiomyopathy. VEGF-A is spliced in several isoforms which show distinct affinity for VEGFR-2 and NRP1. ${ }^{13}$ The isoform VEGF ${ }_{165}$ but not VEGF 121 or the VEGF family member PIGF-1 impaired contractility in normal embryonic hearts. The negative inotropic effect of $\mathrm{VEGF}_{165}$ was abolished by blocking VEGFR-2 with SU5416. This indicates that VEGFR-2 signaling is crucial for VEGF ${ }_{165}$ action. The marked difference in effect of $\mathrm{VEGF}_{165}$ and $\mathrm{VEGF}_{121}$ on cardiac contractility may reflect the inability of $\mathrm{VEGF}_{121}$ to bind to NRP1. NRP1 is a receptor for two ligands with disparate activities, $V_{E G F}{ }_{165}$, widely known for its angiogenic activity, ${ }^{34}$ and Sema3A, a neural guidance factor. ${ }^{3.5}$ NRP1 can dimerize with VEGFR-2 and modulate activity of VEGFR-2 receptors. It is suggested that in blood vessels the major role of NRP1 is to act as a VEGF ${ }_{165}$ co-receptor independent of Sema3A. In this case, Sema3A may be used as a pharmacological tool to antagonize $\mathrm{VEGF}_{165}$ binding to NRP1, a strategy indeed successful for inhibiting VEGF-dependent angiogenesis. ${ }^{36}$ We show that NRP1 is expressed on cardiomyocytes and its expression is augmented during hypoxia indicating that it may contribute to the $V_{E G F}{ }_{165}$ response. We examined the therapeutic potential of Sema3A and found that prenatal administration of Sema3A to hypoxic chick embryos prevented dilatation of the left ventricle and normalized contractile function. Ex vivo analysis of isolated left ventricular muscle bundles from normal heart shows that Sema3A blocks $V E G F_{165}$-induced loss of contractility. Our data suggest that antagonizing $\mathrm{VECF}_{165}$ binding to NRP1 may prevent hypoxia-induced cardiomyopathy. Taken together, we postulate that VEGF/VEGFR-2/NRP1 signaling is responsible for hypoxia-induced cardiomyopathy. In the cardiac biopsies of hypoxic human fetuses we found upregulation of VEGF, VEGFR-2 and NRP1 protein indicating that the molecular mechanism responsible for cardiomyopathy in the chick embryo is also active in human fetal cardiomyocytes during corresponding stages of development and may thus account for cardiomyopathy in human neonates.

Marked differences exist between the actions of hypoxia and VEGF-A on the embryonic versus the adult heart. Although several studies and our work show that excessive VEGF-A is deleterious for cardiac development, 18 studies in adult 
mouse heart indicate that low VEGF-A levels, through impaired angiogenesis and local hypoxia, induce cardiac dysfunction. ${ }^{37}$ These studies suggest that hypoxia per se causes heart failure, and that VEGF-A through maintaining vascular network architecture and subsequent oxygen delivery is essential for normal cardiac function. In our work however, angio-architecture is not disrupted, in fact vascular density is significantly increased in the left ventricle of hypoxic embryos. Using isolated left ventricular muscle bundles of normal embryonic hearts incubated in a normoxic organ bath, we show that addition of VEGF-A reduces contractile reserve acutely. This suggests that VEGF-A can modulate embryonic cardiomyocyte function directly, independent of angio-architecture or oxygen tension. The in vivo rescue experiments in hypoxic embryos with $\mathrm{sFlt}-1$ and Sema3A demonstrate that indeed $\mathrm{VECF}_{165}$ and not hypoxia per se is the modulator of cardiomyopathy in our model. Whereas in vitro studies with cardiomyocytes obtained from postnatal rat heart show that VEGFR-1 signaling may be important for cardiomyocyte function $^{38}$, in our chick embryo hearts the VEGFR-1 agonist PIGF-1 did not affect contractility. The marked difference may reflect the developmental origin of the cardiac tissue we investigated. In support of this, we found that VEGF ${ }_{165}$ does not impair contractility of adult chick ventricular muscle bundles, in contrast to its effect on the embryonic heart. Compared to the embryonic heart, expression of NRP1 is markedly reduced in the adult chick heart suggesting that NRP1 may be necessary for mediating the negative inotropic response to VEGF-A. Taken together, cardiac VEGF-A levels have to be well balanced, because both low (adult) and high (embryo) levels can be detrimental.

Intriguingly, hypoxia-associated cardiomyopathy becomes already established before birth both in humans and in the experimental model. This suggests that the critical period for hypoxia-induced programming of CVD is prenatally and that FGR babies are in a "diseased" state from then onwards. However, a second risk window may exist postnatally, as indicated by studies linking CVD to infant catch-up growth. ${ }^{39}$

The identification of prenatal hypoxia as an epigenetic factor involved in the development of cardiomyopathy may have great impact on health care, since prenatal hypoxia is a common event. An estimated $5-10 \%$ of newborns suffered from intrauterine hypoxia, and an additional 40 per 10.000 third trimester fetuses die as a direct consequence of hypoxia. ${ }^{6}$ The causes of hypoxia range from perturbations in the fetal supply line and placental dysfunction to maternal life style including smoking. ${ }^{40}$ In line with observations on the effect of prenatal insults on nephron number in hypertension, ${ }^{4}$ our data suggest that at least part of the etiology of adult cardiomyopathy could relate to prenatal hypoxic stress. Additional epidemiological studies are needed to establish this relationship. 
We conclude that maintenance of fetal cardiac function is critically dependent on fine-tuning of VEGF-A levels. Prenatal hypoxia results in excessive cardiac expression of VEGF-A, causing cardiac dysfunction at birth which may extend into adulthood.

\section{Acknowledgments}

We thank A Eichmann for providing the VEGF-A, VEGFR-2, and NRP1 probes. We thank E Gratacos, F Crispi, and E Hernandez-Andrade (Dept. of MaternalFetal Medicine, University of Barcelona, Spain), A Ahmed and S Ahmad (Dept. of Reproductive \& Vascular Biology, University of Birmingham, UK), AC Staff (Dept. of Obstetrics and Gynecology, Ulleval University Hospital, Oslo, Norway) and I Cetin (Institute of Obstetrics and Gynecology, University of Milan, Italy) for providing the human data presented in this chapter.

Support from the Netherlands Heart Foundation to E.R., the British Heart Foundation and Medical Research Council to A.A., the Thrasher Fund to E.G. and Netherlands Organization for Scientific Research (NWO) - Vidi to F.I.N. is greatly acknowledged. 


\section{REFERENCES}

1. Barker DJ, Osmond C, Golding J, Kuh D, Wadsworth ME. Growth in utero, blood pressure in childhood and adult life, and mortality from cardiovascular disease. BMI 1989;298(6673):564-7.

2. Leeson CP, Kattenhorn M, Morley R, Lucas A, Deanfield JE. Impact of low birth weight and cardiovascular risk factors on endothelial function in early adult life. Circulation 2001;103(9):1264-8.

3. Gillman MW. Developmental origins of health and disease. $N$ Engl I Med 2005;353(17):1848-50.

4. Ingelfinger JR. Pathogenesis of perinatal programming. Curr Opin Nephrol Hypertens $2004 ; 13(4): 459-64$.

5. Louey S, Thomburg KL. The prenatal environment and later cardiovascular disease. Early Hum Dev 2005;81(9):745-51.

6. Bell R, Glinianaia SV, Rankin I, Wright C, Pearce MS, Parker L. Changing patterns of perinatal death, 1982-2000: a retrospective cohort study. Arch Dis Child Fetal Neonatal Ed 2004;89(6):F531-6.

7. Lee PA, Chernausek SD, Hokken-Koclega AC., Czernichow P. International Small for Gestational Age Advisory Board consensus development conference statement: management of short children born small for gestational age, April 24-October 1, 2001. Pediatrics 2003;11116 Pt 1):1253-61.

8. Nicolaides $\mathrm{KH}$, Economides DL, Soothill PW. Blood gases, $\mathrm{PH}$, and lactate in appropriate- and small-for-gestational-age retuses. Am I Obstet Gynecol 1989;161(4):996-1001.

9. Pardi $G$, Cetin I, Marconi AM, et al. Diagnostic value of blood sampling in fetuses with growth retardation. N Engl I Med 1993:328(10):692-6.

10. Rouwet EV, Tintu AN, Schellings MW, et al. Hypoxia induces aortic hypertrophic growth, left ventricular dysfunction, and sympathetic hyperinnervation of peripheral arteries in the chick embryo. Circulation 2002;105(23):2791-6.

11. Schofield CJ, Ratcliffe PJ. Oxygen sensing by HIF hydroxylases. Nat Rev Mol Cell Biol 2004;5(5):343-54.

12. Dor $Y$, Camenisch TD, Itin A, et al. A novel role for VEGF in endocardial cushion formation and its potential contribution to congenital heart defects. Development 2001;128(9):1531-8.

13. Ferrara N, Gerber HP, LeCouter J. The biology of VEGF and its receptors. Nat Med 2003;9(6):669-76.

14. Giordano FI, Gerber HP, Williams SP, et al. A cardiac myocyle vascular endothelial growth factor paracrine pathway is required to maintain cardiac function. Proc Natl Acad Sci U S A 2001;98(10):5780-5. 


\section{chapter 5}

15. Storkebaum E, Lambrechts D, Dewerchin $M$, et al. Treatment of motoneuron degeneration by intracerebroventricular delivery of VEGF in a rat model of ALS. Nat Neurosci 2005;8(7):85-92.

16. Carmeliet P, Ferreira V, Breier G, et al. Abnormal blond vessel development and lethality in embryos lacking a single VEG.F allele. Nature 1996;380(6573):435-9.

17. Ferrara $\mathrm{N}$, Carver-Moore $\mathrm{K}$, Chen $\mathrm{H}$, ef al. Heterozygous embryonic lethality induced by targeted inactivation of the VEGF gene. Nature 1996;380(6573):439-42.

18. Miquerol L, Langille BL, Nagy A. Embryonic devolopment is disrupled by modest increases in vascular endothelial growth factor genc expression. Development 2000;127(18):3941-6.

19. Feucht $M$, Christ $B$, Wilting J. VEGiF induces cardiovascular malformation and embryonic lethality. Am I Pathol 1997;151(5):1407-16.

20. Parazzini F, Cortinovis I, Bortolus R, Fedele L. [Standards of birth weight in Italy]. Ann Ostet Ginecol Med Perinat 1991;112(4):203-46.

21. Resnik R. Intrauterine growth restriction. Obstet Gynecol 2002;99(3):490-6.

22. Baschat AA. Arterial and venous Doppler in the diagnosis and management of early onset fetal growth restriction. Early Hum Dev 2005;81(11):877-87.

23. Hernandez-Andrade E, Lopez-Tenorio J, Figucroa-Diesel $H$, et al. A modified myocardial performance (Tei) index based on the use of valve clicks improves reproducibility of fetal left cardiac function assessment. Ultrasound Obstet Gynecol $2005 ; 26(3): 227-32$.

24. Sugishita $Y$, Watanabe $M$, Fisher $S A$. Role of myocardial hypoxia in the remodeling of the cmbryonic avian cardiac outflow tract. Dev Biol 2004;267(2):294-308.

25. Nosek TM, Fogaca RT, Hatcher C), Brotto MA, Godt RE. Effect of cardiac neural crest ablation on contractile force and calcium uptake and release in chick heart. Am I Physiol 1997;273(3 Pt 2):H1464-71.

26. Yue X, Tomanek RJ. Effects of VEGF(165) and VEGF(121) on vasculogenesis and angiogenesis in cultured embryonic quail hearts. Am J Physiol Hearl Circ Physiol 2001;280(5): $\mathrm{H} 2240-7$.

27. Dumont $E A$, Reutelingsperger $C P$, Smits JF, et al. Real-time imaging of apoptotic cellmembrane changes at the single-cell level in the beating murine heart. Nat Med $2001 ; 7(12): 1352-5$.

28. Sugimoto $H$, Hamano $Y$, Charytan $D$, et al. Neutralization of circulating vascular endothelial growth factor (VEGF) by anti-VEGF antibodies and soluble VEGF receptor 1 (sFlt-1) induces proteinuria. J Biol Chem 2003;278(15):12605-8.

29. Costello-Boerrigter LC, Boerrigter $G$, Redfield $M M$, et al. Amino-terminal pro-B-type natriuretic peptide and $B$-type natriuretic peptide in the general community: determinants and detection of left ventricular dysfunction. I Am Coll Cardiol 2006;47(2):345-53. 
30. Kragelund C, Gronning B, Kober L., Hildebrandt P, Steffensen R. N-terminal pro-B-type natriuretic peptide and long-term mortality in stable coronary heart disease. $N$ Engl I Med 2005;:352(7):666-75.

31. Fong TA, Shawer LK, Sun L, et al. SU5416 is a potent and selective inhibitor of the vascular endothetial growth factor receptor (F/k-1/KDR) that inhibits tyrosine kinase catalysis, tumor vascularization, and growth of multiple tumor types. Cancer Res 1999;59(1):99-106.

32. Falkensammer $C B$, Paul J, Huhta JC. Fetal congestive heart failure: correlation of Teiindex and Cardiovascular-score. I Perinat Merd 2001;2915):390)-8.

33. Ruijtenbeek $K$, le Noble FA, lanssen CiM, et al. Chronic hypoxia stimulates periarterial sympathetic nerve development in chicken cmbryo. Circulation 2000; 102123):2892-7.

34. Carmeliet $P$. Angiogenesis in life, disease and medicine. Nature 2005;438(70701):932-6.

35. Kawasaki T, Bekku $Y$, Suto $F$, et al. Requirement of neuropilin 1-mediated Sema3A signals in patterning of the sympathetic nervous system. Development 2002;129(3):671-80).

36. Miao HQ, Soker $S$, Feiner L, Alonso IL, Raper A, Klagsbrun M. Neuropilin-1 mediates collapsin-1/semaphorin III inhibition of endothelial cell motility: runctional competition of collapsin-1 and vascular endothelial growth factor-165. J Cell Biol 1999;146(1):233-42.

37. Dor $Y$, Djonov $V$, Abramovitch $R$, et al. Conditional switching of VEGF provides new insights into adult neovascularization and pro-angiogenic therapy. Embo I 2002;21(8):1939-47.

38. Rottbauer $W$, Just $S$, Wessels $G$, et al. VEGF-PLCgamma1 pathway controls cardiac contractility in the embryonic hearl. Genes Dev 2005;19(13):1624-34.

39. Barker DI, Osmond C, Forsen TI, Kajantie E, Eriksson IG. Trajectories of growth among children who have coronary events as adults. N Engl I Med 2005;353(17):1802-9.

40. Brodsky D, Christou $\mathrm{H}$. Current concepts in intrauterine growth restriction. I Intensive Care Med 2004;19(6):307-19. 


\title{
CHAPTER 6
}

\author{
Prenalal Hypoxia Causes Diastolic \\ Dysfunction
}




\section{ABSTRACT}

\section{Background}

We hypothesize that hypoxic stress during critical stages of fetal development can have long-term effects on cardiac performance and may program for cardiovascular diseases in adulthood. We previously showed that prenatal hypoxia causes left ventricular contractile dysfunction involving cardiomyocytespecific VEGF-A signaling. The aim of the present study was to investigate the extent to which diastolic function of the heart is affected by prenatal hypoxia and whether this also involves VEGF.

\section{Methods}

Diastolic function was determined by intrauterine echocardiography in 14 human growth restricted fetuses with evidence of chronic intrauterine hypoxia and 14 normal fetuses. The cardiac diastolic response to hypoxia was further defined in a chick embryo model of hypoxia-induced dilated cardiomyopathy.

\section{Results}

Hypoxic human fetuses displayed left and right ventricular diastolic dysfunction on echocardiography as evidenced by prolonged isovolumetric relaxation time, increased preload index, and increased mitral and tricuspid E/A ratios. Hypoxia-induced diastolic dysfunction was confirmed in the experimental model. Hypoxic chick embryos showed increased passive tension and impaired relaxation of the left ventricle, which was accompanied by increased collagen and decreased cardiac titin expression. Prenatal administration of soluble VEGF receptor-1 to scavenge VEGF-A did not prevent the development of diastolic dysfunction in hypoxic embryos. Diastolic dysfunction persisted in adult animals exposed to prenatal hypoxia.

\section{Conclusions}

These findings identify fetal hypoxia as a modulator of the relaxation properties of the heart and suggest a role for fetal hypoxia in the origin of diastolic heart failure. 


\section{INTRODUCTION}

Epidemiologic studies have shown that babies with low body weight at birth have an increased risk of cardiovascular diseases (CVD) in adulthood, including hypertension, stroke, and coronary artery disease. ${ }^{1,2}$ One of the most common adverse intrauterine conditions causing fetal growth restriction (FGR) and low birth weight is prolonged fetal hypoxia. ${ }^{3,4}$ In a recent study we have shown that human growth restricted fetuses with evidence of chronic intrauterine hypoxia display systolic cardiac dysfunction as evidenced by decreased ejection time and prolonged isovolumetric contraction time on echocardiography. At the molecular level this involved elevated levels of VEGF 16,5 signaling through VEGFR-2 and NRP1. However, the extent to which diastolic function was affected by hypoxic stress and whether this also involves VEGF was not addressed.

The importance of ventricular relaxation, i.e. diastolic, properties for cardiac pump function has gained increasing attention. ${ }^{5}$ The aim of the present study was to investigate whether fetal hypoxia induces diastolic cardiac dysfunction, and whether VEGF is involved herein. We report that hypoxic human FGR fetuses display LV diastolic dysfunction on echocardiography. Hypoxia-induced LV diastolic dysfunction was confirmed in a chick embryo model of hypoxia-induced dilated cardiomyopathy (DCM), and was accompanied by decreased titin expression and increased collagen in the left ventricle. The VEGF scavenger sFlt-1 did not prevent the development of diastolic dysfunction in hypoxic chick embryos. Interestingly, hypoxia-induced diastolic dysfunction persisted in adult chickens exposed to prenatal hypoxia. These findings identify fetal hypoxia as a modulator of the relaxation properties of the heart and suggest a role for fetal hypoxia in the origin of diastolic heart failure. 


\section{METHODS}

\section{Evaluation of Cardiac Diastolic Function in Human Fetuses}

Permission for the study was granted by the institutional review board and written informed consent had been obtained from the parents. A total number of 28 singleton pregnancies were studied. Gestational age was determined according to the onset of the last menstrual period and confirmed by ultrasound before 20 weeks of gestation. Fetal growth was documented by prenatal ultrasound and confirmed by measuring weight at birth. Neonatal weight, sex and APGAR scores were routinely recorded in the obstetrics database at the time of birth. Appropriate for gestational age ( $A G A, n=14$ ) fetuses had normal growth, were delivered at term, and had birth weights between the $10^{\text {th }}$ and $90^{\text {th }}$ percentile. Fetuses with growth restriction ( $F G R, n=14$ ) were diagnosed prenatally by serial ultrasound examinations demonstrating a reduction of growth rate of the abdominal circumference, and was confirmed at birth by neonatal weight less than the $10^{\text {th }}$ percentile of age-related reference values. ${ }^{6,7}$ All FGR fetuses had clearly abnormal values of the Doppler pulsatility index in the middle cerebral artery and ductus venosus, and abnormal aortic isthmus flow index, which are consistent with the presence of fetal hypoxia. ${ }^{8}$ Exclusion criteria were the presence of fetal structural or chromosomal abnormalities, cytomegalovirus infection, and pharmacologic treatment which could influence pregnancy outcome and fetal growth.

All fetuses underwent serial cardiac ultrasound examinations; the last evaluation before delivery was used for analysis. Diastolic function was assessed by Doppler echocardiography. The following parameters were determined: left ventricular isovolumetric relaxation time (IRT), ratio of early to atrial inflow velocities across the mitral and tricuspid valves (mitral E/A ratio, tricuspid E/A ratio), and preload index (PLI) in the inferior vena cava. ${ }^{9-12}$

\section{Experimental Model}

\section{Animals}

Fertile White Leghorn eggs were incubated at $21 \% \mathrm{O}_{2}$ (normoxia; $\mathrm{N}$ ) or $15 \%$ $\mathrm{O}_{2}$ (hypoxia; $\mathrm{H}$ ) throughout embryonic development. ${ }^{13}$ Experiments in chick embryos were performed at embryonic day 20 (E20) of the 21-day incubation period. To evaluate the effects of prenatal hypoxia on the adult heart, normoxic and hypoxic chick embryos were allowed to hatch (E21) and both groups were raised under normal oxygen levels after birth $\left(21 \% \mathrm{O}_{2}\right)$ until 8 months of age. In a separate set of experiments we investigated the effects of very mild hypoxia by exposing chick embryos to $18 \% \mathrm{O}_{2}$ and evaluated cardiac function at E20. Experiments were approved by the institutional animal ethics committee. 
Left Ventricular Muscle Bundle Preparation

E20 chick embryos were sacrificed by means of decapitation. The chest was opened and the heart perfused with $0.2 \mathrm{~mL}$ heparin $(5000 \mathrm{U} / \mathrm{mL})$. Immediately after surgical resection, the heart was placed in a $\mathrm{Ca}^{2+}$-free solution gassed with $100 \% \mathrm{O}_{2}$. The solution contained (in $\mathrm{mM}$ ): $135 \mathrm{NaCl}, 5.4 \mathrm{KCl}, 0.33 \mathrm{NaH}_{2} \mathrm{PO}_{4} \times \mathrm{H}_{2} \mathrm{O}, 10$ HEPES, $10 \mathrm{C}_{6} \mathrm{H}_{12} \mathrm{O}_{6} \times \mathrm{H}_{2} \mathrm{O}, 1 \mathrm{MgCl}_{2} \times 6 \mathrm{H}_{2} \mathrm{O}$, and $30 \mathrm{BDM}$. The $\mathrm{pH}$ was adjusted with $\mathrm{NaOH}$ to 7.4. A thin subendocardial $\mathrm{LV}$ muscle bundle was excised in parallel with fiber direction, mounted in an organ bath with HEPES buffer $\left(2 \mathrm{mmol} / \mathrm{L} \mathrm{Ca}^{2+}, \mathrm{pH}\right.$ 7.4, gassed with $100 \% \mathrm{O}_{2}, 37^{\circ} \mathrm{C}$ ) between a rigid hook and a force transducer connected to a micromanipulator for length adjustment.

\section{Length-Active Tension Relationship and Passive Tension}

After an equilibration period of 10 minutes, the muscle bundle was paced by external field stimulation with rectangular pulses $(5 \mathrm{~ms}, 5 \%$ to $10 \%$ above threshold) at a frequency of $1 \mathrm{~Hz}$. This resulted in isometric contraction of the fiber. Subsequently, the muscle was stretched in steps of $218 \mu \mathrm{m}$. Passive tension was determined by measuring force during diastole, i.e. unstimulated force, at incremental bundle lengths. ${ }^{14}$ The length-active tension relation, i.e. Frank-Starling relation, was assessed by measuring active force generation during field stimulation at incremental bundle lengths. Bundle length was expressed as a percentage of $L_{\max }$. Generated force was defined as peak systolic minus diastolic force and normalized to cross-sectional area $\left(\mathrm{mN} / \mathrm{mm}^{2}\right)$ by optical measurement of the smallest diameter of the bundle assuming cylindrical geometry. Muscle bundles were stretched until the fiber length was reached which provided maximal active force generation $\left(L_{\max }\right)$. For standardization purposes, all further experiments were performed at $L_{\max }$ after a resting period of 5 minutes.

\section{Relaxation Properties}

To assess relaxation properties of LV muscle bundles, fibers were stimulated with increasing pacing frequencies $(0.5-4 \mathrm{~Hz})$ or with increasing extracellular calcium (2-12 $\mathrm{mmol} / \mathrm{L})$. The time to $50 \%$ relaxation during diastole was determined at each pacing frequency and at each calcium concentration.

\section{Cardiac Histology}

Formalin-fixed LV muscle bundles were embedded in paraffin and longitudinal $5-\mu \mathrm{m}$ sections were stained with trichrome Masson to visualize tissue fibrosis. The area of fibrotic tissue was quantified by computer software (Quantimet 570, Leica). 
Titin Protein Levels

Hearts from normoxic and hypoxic E20 embryos were excised, snap-frozen, and stored at $-80{ }^{\circ} \mathrm{C}$. On the day of the experiments, tissue samples were homogenized in $4 \mathrm{~mL}$ SET-buffer ( $0.25 \mathrm{M}$ sucrose, $0.01 \mathrm{M} \mathrm{Tris-HCl}, 0.002 \mathrm{M} \mathrm{diNa-}$ EDTA; $\mathrm{pH}$ 7.4). Leupeptin was added to the solutions $(0.5 \mathrm{mM})$ to prevent protein degradation. Protein concentration was determined by Micro BCA. Samples $(20 \mu \mathrm{g}$ protein) were loaded and run using a Mini-PROTEAN II electrophoresis system (BioRad, Hercules, USA). A $2 \%$ polyacrylamide slab gel reinforced with agarose was used for separation of titin protein bands. ${ }^{15} \mathrm{~A}$ standard Fairbanks running buffer was used. Electrophoresis was performed at $7.5 \mathrm{~mA} /$ plate for $30 \mathrm{~min}$ and 15 $\mathrm{mA}$ plate in succession until bromophenol blue (marker dye) reached to about 10 $\mathrm{mm}$ from the end of the gel. It required about 5 hours. After the run, the gel was stained for 5 min with $0.1 \%$ Comassie Brilliant Blue R-250 solution containing $50 \%$ methanol and $10 \%$ acetic acid and destained overnight with $5 \%$ methanol and $7.5 \%$ acetic acid. No molecular weight standards exist for titin.

\section{Role of VEGF in Cardiac Diastolic Function}

To reduce the biological availability of VEGF-A, we treated hypoxic embryos with soluble VEGF receptor-1 from E10 to E19. Controls received equal volumes of saline. Cardiac diastolic function was analyzed at E2O.

\section{Statistics}

Data are expressed as mean \pm SE. The term $n$ refers to the number of patients or animals. Statistical comparisons were made using the non-parametric MannWhitney $U$ test. Statistical significance was defined as $P<0.05$.

\section{RESULTS}

\section{Human Hypoxic FGR Fetuses Display Diastolic Dysfunction}

Fetal diastolic cardiac function was assessed in 28 fetuses, 14 normal AGA and 14 hypoxic FGR, at a gestational age of 29 weeks using intrauterine Doppler echocardiography (Fig. 1A and B). The isovolumetric relaxation time (IRT) of the left ventricle was significantly prolonged in hypoxic FGR fetuses (Fig. 1C). The mitral E/A ratio and the tricuspid E/A ratio were significantly higher in hypoxic fetuses (Fig. 1D and E). In addition, the preload index (PLI) in the inferior vena cava was significantly increased in hypoxic FGR compared with AGA fetuses (Fig. 1F). These data indicate left and right ventricular diastolic dysfunction in hypoxic fetuses. 
Echocardiography AGA

Echocardiography FGR
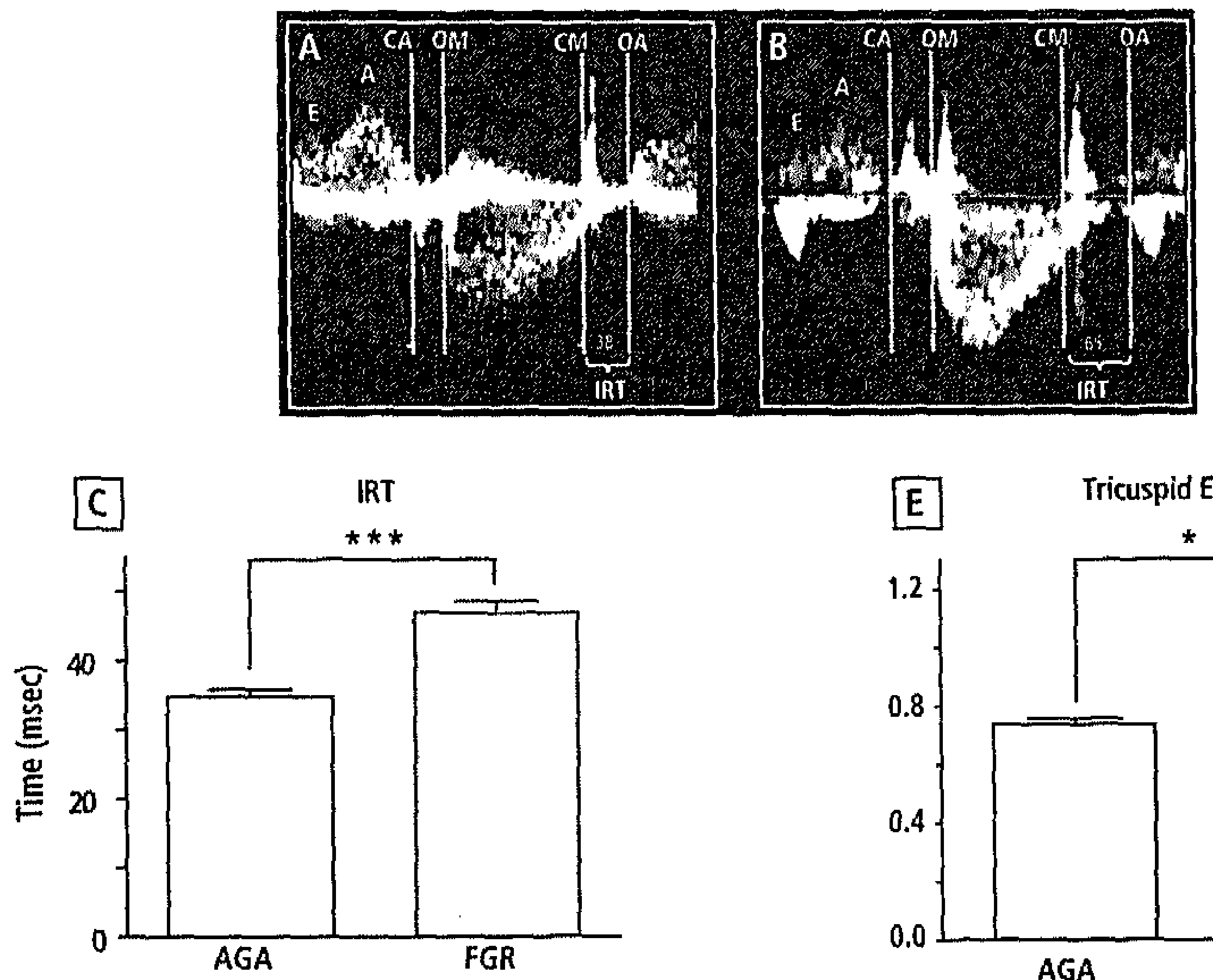

[E] Tricuspid E/A ratio
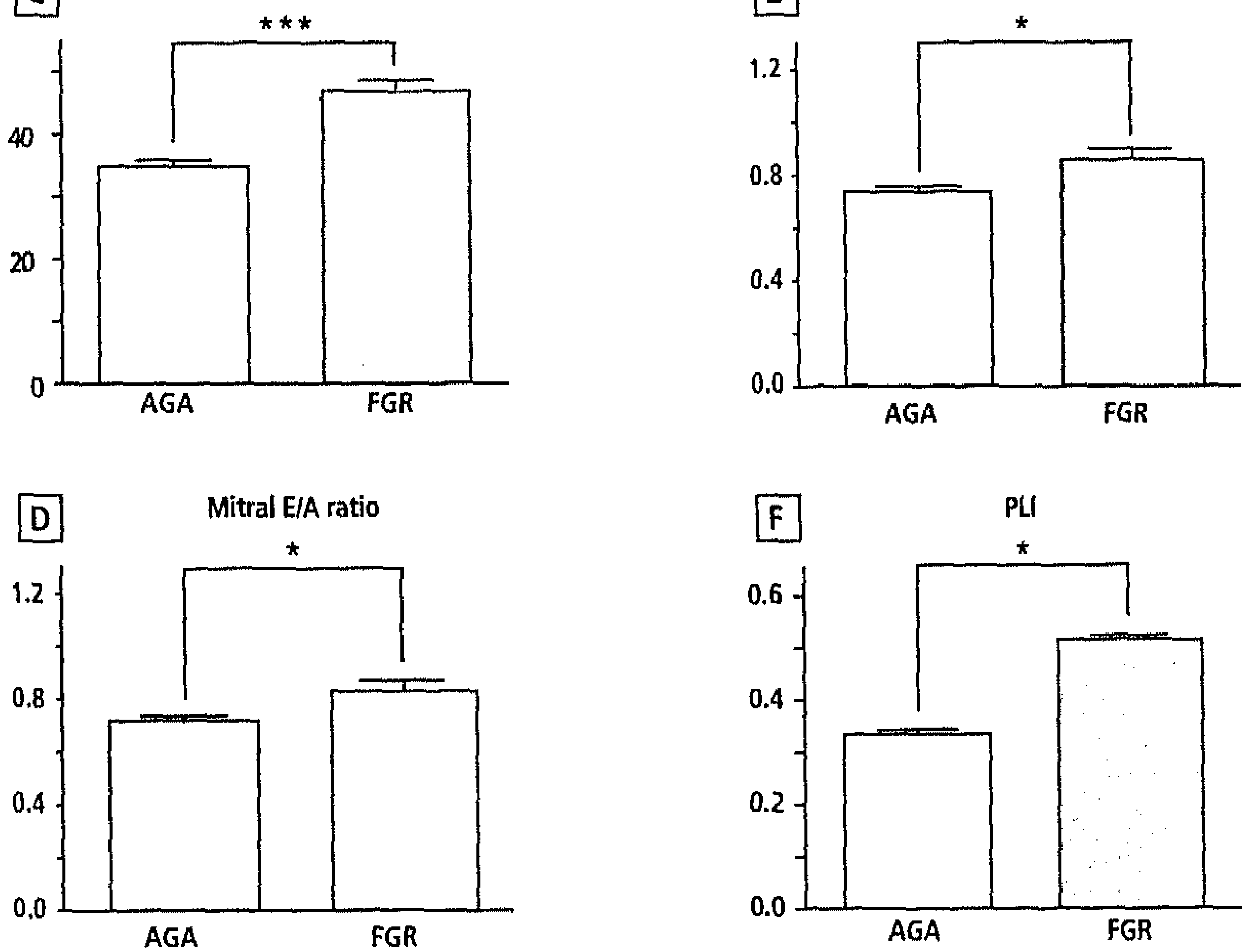

Figure 1 Human hypoxic FGR fetuses display diastolic dysfunction

Intrauterine Doppler echocardiography tracings of the left ventricle of appropriate for gestational age (ACA) and hypoxic growth restricted fetuses (FGR), $n=14$ in each group (panels $A$ and $B$ ). Dotted yellow lines indicate opening and closure of the mitral and aortic valves ( $C A, O M, C M, O A)$ which are used as landmarks to define the duration of each period evaluated. The $E$ and $A$ waves of ventricular filling are indicated in the figure. Panels $C$ and $D$, left ventricular diastolic function is impaired in FGR fetuses. The isovolumetric relaxation time (IRT, panel $C$ ) is prolonged (values are expressed in milliseconds) and the E/A inflow velocity ratio across the mitral valve (panel $D$ ) is increased in FGR fetuses. Panels $E$ and $F$, diastolic function of the right ventricle is also impaired in FCR fetuses. The E/A ratio across the tricuspid valve (panel $E$ ) and preload index ( $P L I$, panel $F$ ) are increased in FCR compared with ACA fetuses. Values are mean $\pm S E .{ }^{*} P<0.05,{ }^{* * *} P<0.001 F G R$ versus $A G A$. 


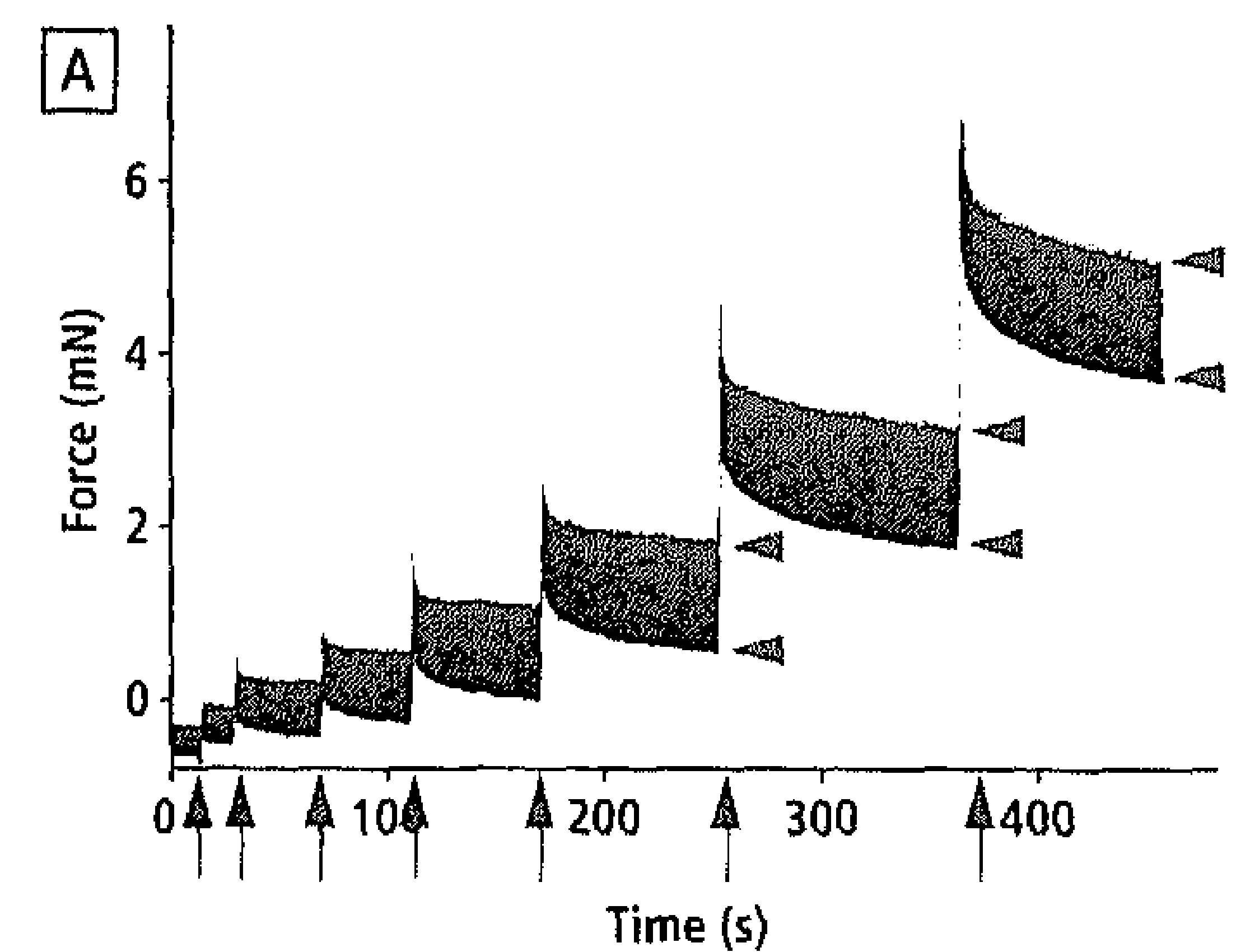

B

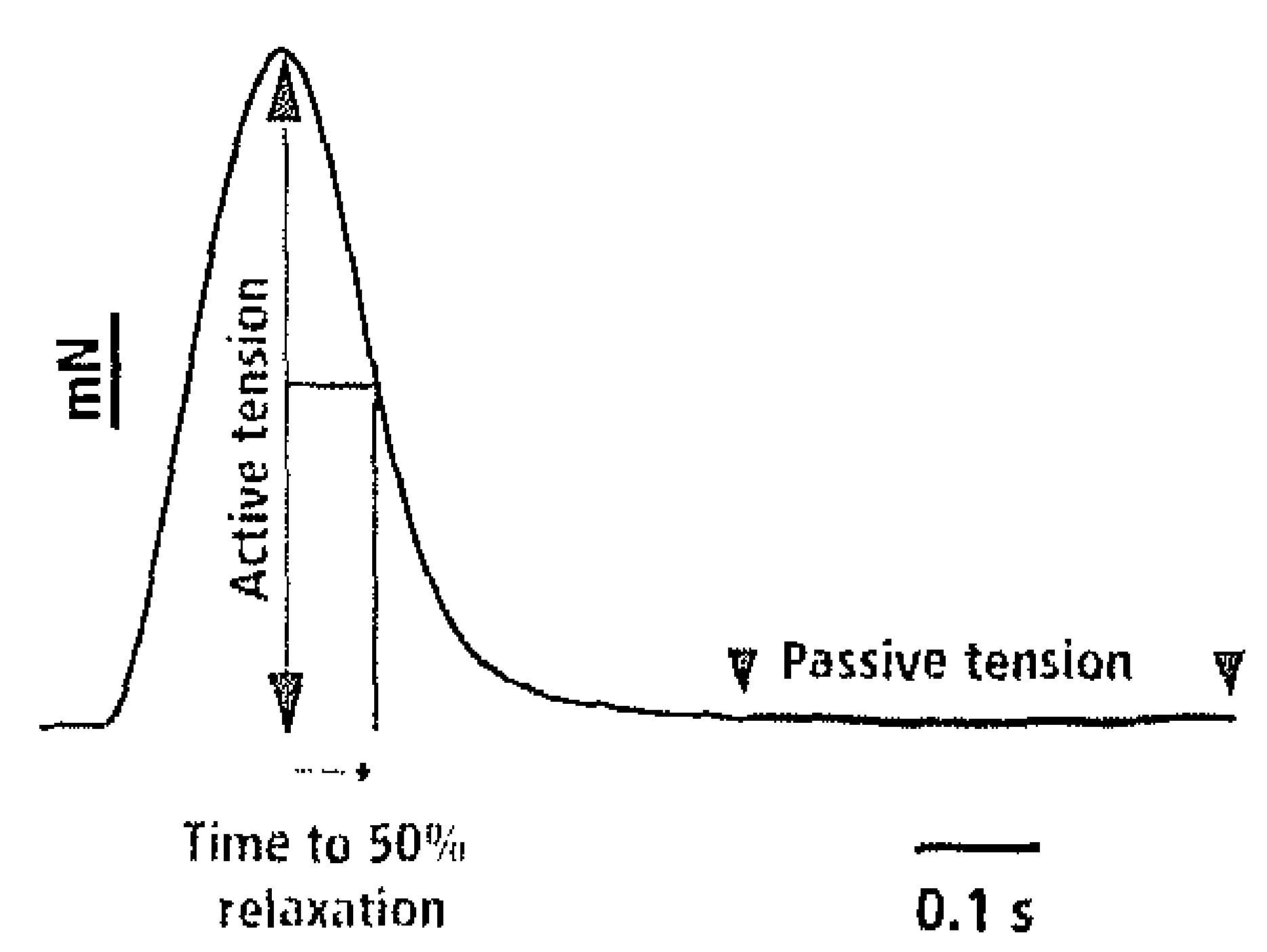

Figure 2 Length-tension relationship and relaxation parameters of the chick embryo heart Panel A. Force tracing during stretching of a $L V$ muscle bundle isolated from a normoxic E20 chick embryo. Difference between the arrowheads represents the force development of the muscle bundle after each distension step of $218 \mu \mathrm{m}$ (arrows). Fibers are distended until the maximal Frank-Starling response is obtained. Active tension, passive tension, and time to $50 \%$ relaxation are determined as shown in panel $B$.

\section{Hypoxic Chick Embryos Display Left Ventricular Diastolic Dysfunction}

Length-Active Tension Relation is Depressed in Hypoxic Hearts

Muscle bundles were stretched from their resting lengths in steps of $218 \mu \mathrm{m}$ until the muscle length providing maximal active force generation was reached. Figure $2 \mathrm{~A}$ shows the Frank-Starling response of a normoxic LV muscle bundle. Active tension, passive tension, and time to $50 \%$ relaxation were determined as shown in Figure 2B.

The capacity to increase contractile force in response to increased stretching was significantly lower in LV bundles of $\mathrm{H}$ hearts compared with $\mathrm{N}$ hearts at E20 (Fig. 3A). This indicates that the Frank-Starling relationship is impaired in hypoxic hearts.

Myocardial Stiffness is Increased in Hypoxic Hearts

Passive tension as determined by diastolic force during stretching of the muscle bundles was significantly higher in LV muscle bundles of $\mathrm{H}$ as compared with $\mathrm{N}$ hearts at E2O, indicating increased myocardial stiffness (Fig. 3B).

Relaxation is Impaired in Hypoxic Hearts

We next examined the relaxation properties of $L V$ muscle bundles at E20. The time to $50 \%$ relaxation at each pacing frequency was significantly prolonged in 
the $\mathrm{H}$ as compared with the $\mathrm{N}$ group (Fig. 3C). A similar increase in relaxation time was observed to increasing concentrations of calcium (Fig. 3D).

Exposing chick embryos to very mild hypoxia $\left(18 \% \mathrm{O}_{2}\right)$ still resulted in impaired left ventricular relaxation (Fig. 3D), indicating that very mild hypoxic stress is sufficient to induce diastolic dysfunction.
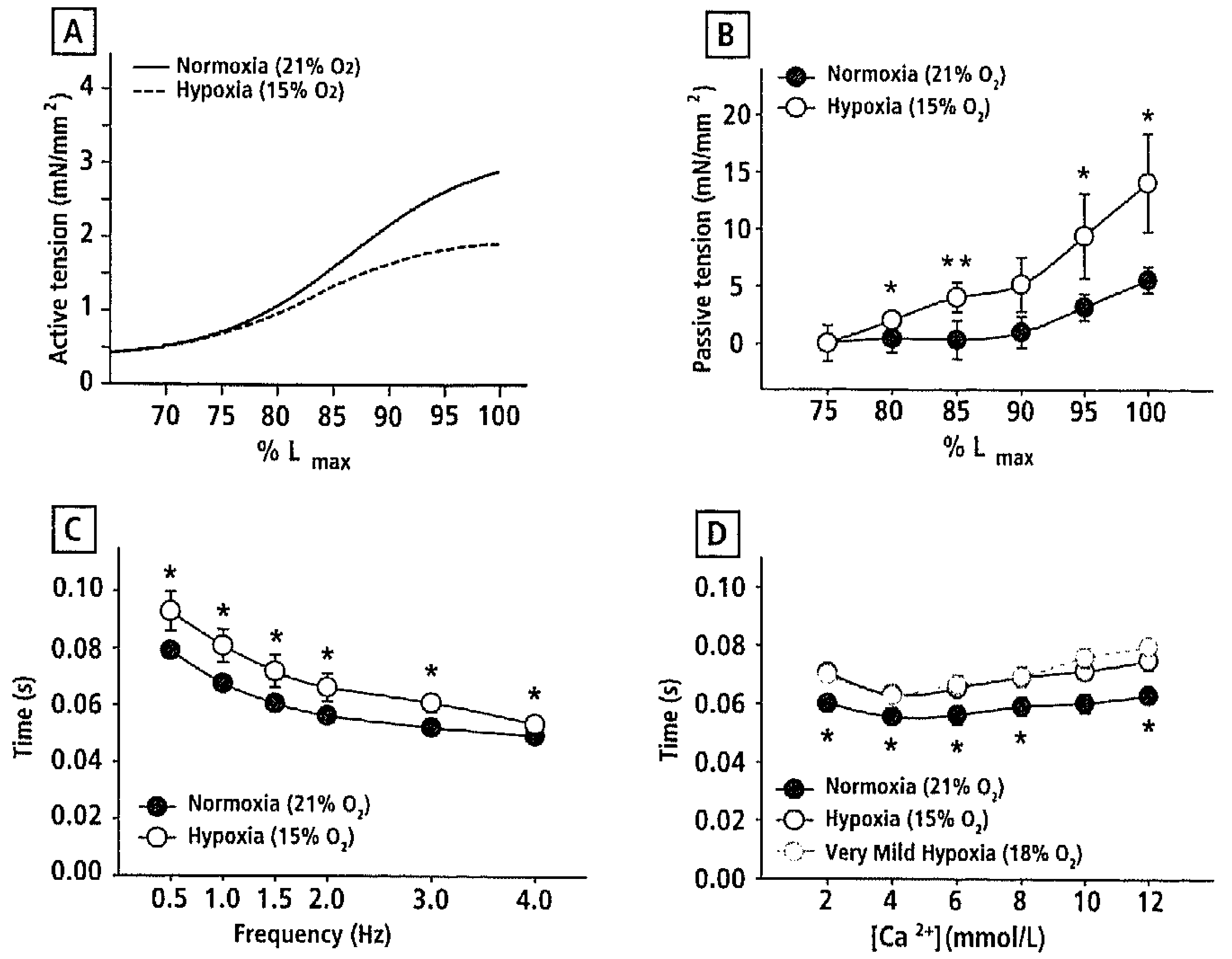

Figure 3 Hypoxic chick embryos display left ventricular diastolic dysfunction

The length-active tension relationship of $L V$ muscle bundles is depressed in hypoxic $E 20$ chick embryo hearts (panel A). Passive tension during stretching of $L V$ muscle bundles is significantly higher in hypoxic as compared with normoxic 220 hearts (panel $B$ ), $n=6$ and $n=8$, respectively. The time to $50 \%$ relaxation is significantly prolonged in hypoxic as compared with normoxic hearts, both in response to increasing pacing frequencies (pane/ C) and to increasing calcium concentrations (panel D). Even chick embryos exposed to very mild hypoxia $\left(18 \% \mathrm{O}_{2}\right.$ ) display impaired $\mathrm{LV}$ relaxation (panel $D$ ), bolh $n=9$. Data are shown as mean $\pm S E ;{ }^{*} P<0.05,{ }^{* *} P<0.01$ hypoxia versus normoxia. 
Collagen Content is Increased and Titin Level is Decreased in Hypoxic Hearts Hearts of $\mathrm{E} 20 \mathrm{~N}$ and $\mathrm{H}$ chick embryos were stained with trichrome Masson (Fig. $4 \mathrm{~A}$ and $\mathrm{B}$ ). All normoxic animals exhibited an inconspicuous myocardium with regularly distributed and sparse perivascular and interstitial collagenous connective tissue. Collagen content was $40 \%$ higher in $\mathrm{H}$ hearts as compared with $\mathrm{N}$ hearts (Fig. 4C). Myocyte content was $9 \%$ lower in $\mathrm{H}$ hearts (data not shown). Titin protein content as determined by gel electrophoresis was $27 \%$ lower in $\mathrm{H}$ as compared with $\mathrm{N}$ hearts at E20 (Fig. 4D).
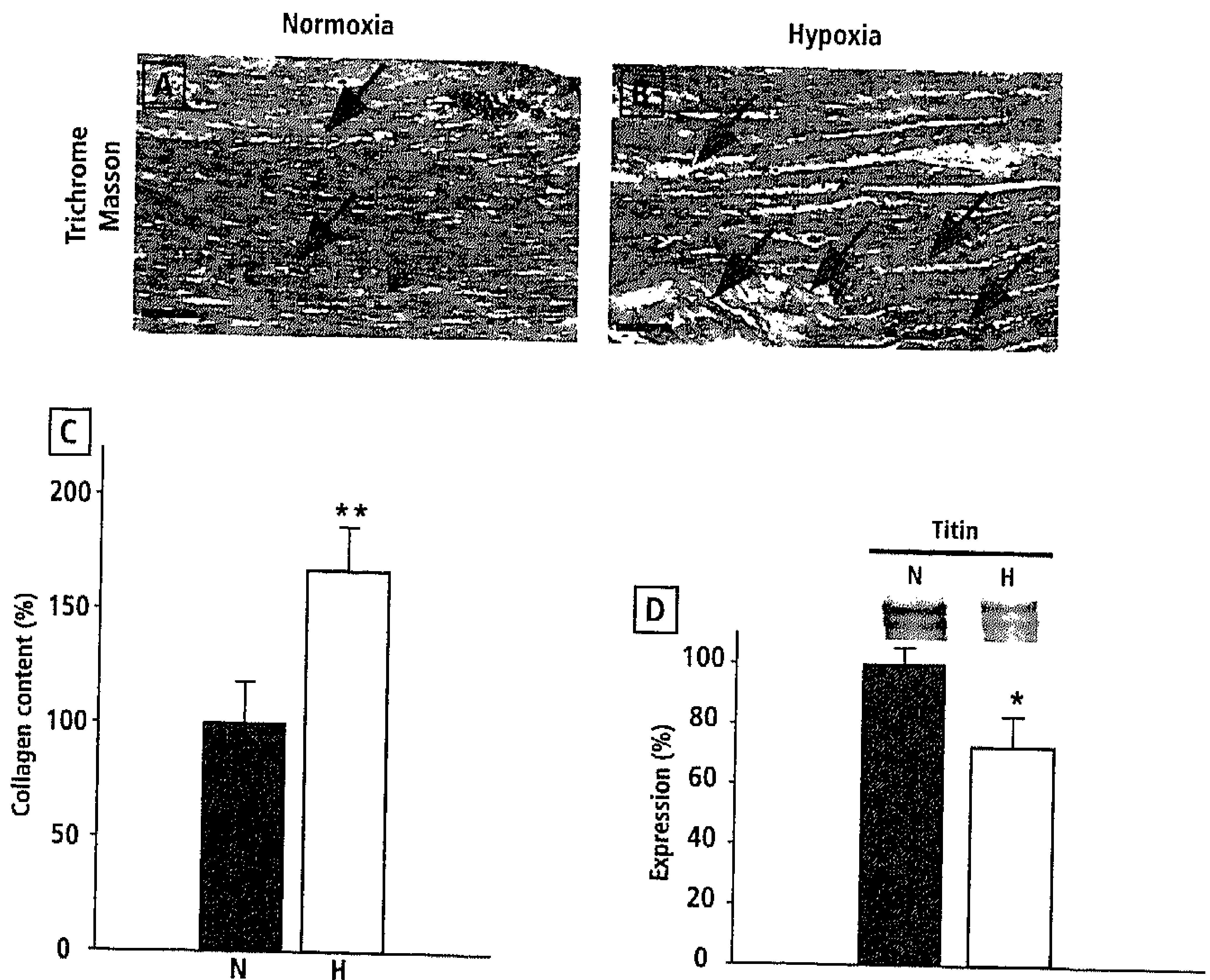

Figure 4 Collagen content is increased and titin level is decreased in hypoxic hearts Trichrome Masson staining of left ventricular myocardium of E2O chick embryos. Note the increase in interstitial collagen deposition in hypoxic (panel B) compared with normoxic (panel $A$ ) hearts, both $n=6$. Arrows denote collagen (blue). Scale bars represent $100 \mu \mathrm{m}$. Collagen content ss significantly higher in hypoxic hearts (pane/ C). Panel D, gel electrophoresis showing decreased titin protein expression in hypoxic E2O chick embryo hearts normalized to the protein expression in normoxic hearts, both $n=8$. Data are shown as mean $\pm S E ;{ }^{*} P<0.05,{ }^{* *} P<0.01 \mathrm{H}$ versus $\mathrm{N}$. 
Scavenging VEGF-A Does Not Prevent Diastolic Dysfunction in Hypoxic Embryos To determine the role of VEGF-A in impaired relaxation of the left ventricle, we blocked VEGF-A activity by systemic administration of sFlt-1 to hypoxic embryos from E10 to E19. Treatment with sFlt-1 did not improve relaxation properties of LV muscle bundles of hypoxic hearts (Fig. 5). These data suggest that VEGF-A does not impair diastolic function of the embryonic heart.

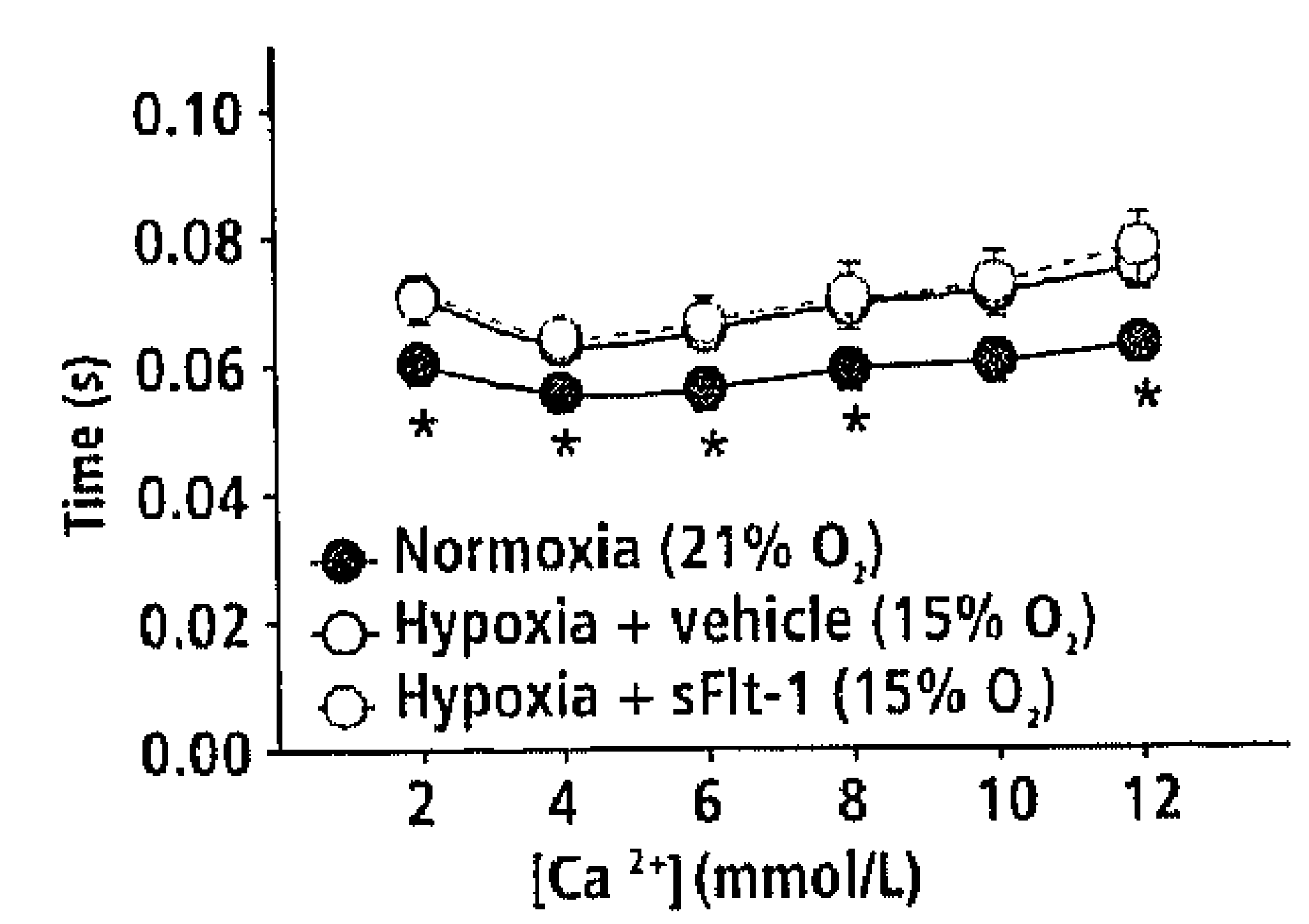

Figure 5 Scavenging VEGF-A does not prevent diastolic dysfunction in hypoxic embryos The time to $50 \%$ relaxation at increasing calcium concentrations of isolated leit ventricular muscle bundles of 220 hypoxic chick embryos. There is no difference between sFlt-1 treated and vehicle treated embryos, both $n=5$. Data are shown as mean $\pm S E$. 
Prenatal Hypoxia-Induced Diastolic Dysfunction Persists into Adulthood We next investigated LV diastolic properties in adult chickens prenatally exposed to $15 \% \mathrm{O}_{2}$. The time to $50 \%$ relaxation in response to increasing calcium concentrations was significantly prolonged in LV muscle fibers from these hearts as compared with hearts prenatally exposed to normoxia (Fig. 6). The data show that adult chickens prenatally exposed to hypoxia display diastolic dysfunction.

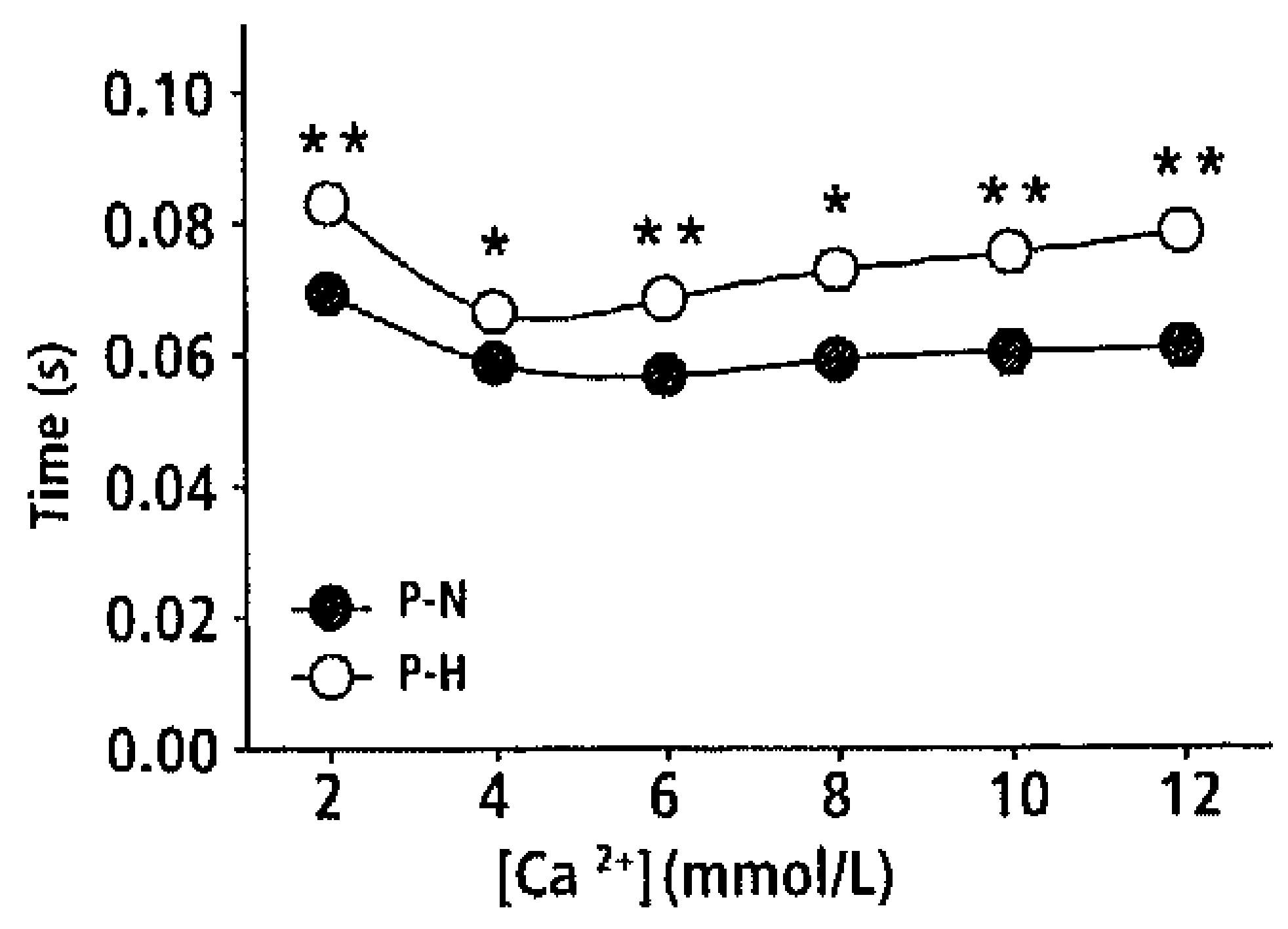

Figure 6 Prenatal hypoxia-induced diastolic dysfunction persists into adulthood

Relaxation properties of left ventricular muscle bundles isolated from adult chicken hearts. The time to $50 \%$ relaxation in response to increasing calcium concentrations is significantly prolonged in adult animals prenatally exposed to hypoxia $(P-H)$ compared with adult animals prenatally exposed to normoxia $(P-H)$, both $n=7$. Data are shown as mean $\pm S E ;{ }^{*} P<0.05,{ }^{*} P<0.01 P-H$ versus $P-N$. 


\section{Discussion}

Here we report that growth restricted human fetuses suffering from intrauterine hypoxia exhibit diastolic cardiac dysfunction. Using intrauterine Doppler echocardiography we demonstrated that hypoxic human fetuses display prolonged isovolumetric relaxation time, increased mitral and tricuspid E/A ratios, and increased preload index in the inferior vena cava, reflecting left and right ventricular diastolic dysfunction. ${ }^{10-12,16}$

The relation between prenatal hypoxia and diastolic dysfunction was further investigated in an experimental model of dilated cardiomyopathy. In line with the findings in human fetuses, chick embryos that were exposed to $15 \%$ $\mathrm{O}$, during development displayed delayed relaxation of LV muscle bundles. In addition to impaired relaxation, LV muscle bundles of hypoxic chick embryo hearts also displayed increased stiffness as indicated by the passive tension curves. Even prenatal exposure to $18 \% \mathrm{O}_{2}$, a very mild level of hypoxia, resulted in impaired cardiac relaxation.

Impaired relaxation and increased chamber stiffness are characteristics of diastolic cardiac dysfunction. ${ }^{17}$ Muscle relaxation mechanics may be altered by abnormalities in the extracellular matrix and in cardiomyocytes. ${ }^{18,}{ }^{19}$ At the extracellular level we identified that hypoxia-induced diastolic dysfunction was accompanied by increased interstitial collagen deposition. Fibrosis is a well known cause of increased myocardial stiffness. At the cardiomyocyte level we found reduced expression of the sarcomeric protein titin in hearts of hypoxic chick embryos. Titin is a giant elastic protein $(3000-3700 \mathrm{kDa})$ of the myofibrillar cytoskeleton which bridges the half-sarcomere from the $Z$ disk to the M-line. Titin provides elastic recoil during diastole of the heart and contributes substantially to passive-tension development and shortening velocity. ${ }^{20-24}$ A reduction in titin expression is associated with increased myocardial stiffness and impaired relaxation. ${ }^{25}$ To our knowledge, the link between hypoxia and decreased titin expression has not been described before and will be subject of future studies.

Hypoxic chick embryos display the features of patients with diastolic heart failure, including impaired myocardial relaxation during diastole and increased passive stiffness of the left ventricle. ${ }^{18,26}$ The diastolic dysfunction observed in hypoxic chick embryos was associated with decreased levels of the cytoskeleton protein titin and increased collagen accumulation. Similarly, biopsy specimens from human failing hearts with end-stage DCM show reduction of titin expression and interstitial fibrosis. ${ }^{27-29}$ Furthermore, familial DCM is associated with mutations in titin. ${ }^{30-32}$ 


\section{REFERENCES}

1. Barker Df, Osmond C, Golding I, Kuh D, Wadsworth ME. Growth in utero, blood pressure in childhood and adult lite, and mortality irom cardiovascular disease. BMI $1989 ; 298(6673): 564-7$.

2. Leeson CP, Kattenhorn M, Morley R, Lucas A, Deanfield JE. Impact of low birth weight and cardiovascular risk factors on endothelial function in early adult life. Circulation 2001;103(9):1264-8.

3. Bell R, Glinianaia SV, Rankin I, Wright C, Pearce MS, Parker L. Changing patterns of perinatal death, 1982-2000: a retrospective cohort study. Arch Dis Child Fetal Neonatal Ed 2004;89(6):F531-6.

4. Lee PA, Chernausek SD, Hokken-Koelega AC, Czernichow P. International Small for Gestational Age Advisory Board consensus development conference statement: management of short children born small for gestational age, April 24-October 1, 2001. Pediatrics 2003;1116 Pt 1):1253-61.

5. Kass DA, Bronzwaer JG, Paulus WI. What mechanisms underlie diastolic dysiunction in heart failure? Circ Res 2004;94(12):1533-42.

6. Resnik R. Intrauterine growth restriction. Obstet Gynecol 2002;99(3):490-6.

7. Parazzini F, Cortinovis I, Bortolus R, Fedele L. [Standards of birth weight in Italy]. Ann Ostet Ginecol Med Perinat 1991;112(4):203-46.

8. Baschat AA. Arterial and venous Doppler in the diagnosis and management of early onset fetal growth restriction. Early Hum Dev 2005;81(11):877-87.

9. Pedra SR, Smallhorn JF, Ryan G, et al. Fetal cardiomyopathies: pathogenic mechanisms, hemodynamic findings, and clinical outcome. Circulation 2002;106(5):585-91.

10. DeVore GR. Assessing fetal cardiac ventricular function. Semin Fetal Neonatal Med 2005; 10(6):515-41.

11. Moller JE, Pellikka PA, Hillis GS, Oh JK. Prognostic importance of diastolic function and filling pressure in patients with acute myocardial infarction. Circulation 2006;114(5):438-44.

12. Ommen SR, Nishimura RA. A clinical approach to the assessment of left ventricular diastolic function by Doppler echocardiography: update 2003. Heart 2003;89 Suppl 3:iii18-23.

13. Rouwet EV, Tintu AN, Schellings MW, et al. Hypoxia induces aortic hypertrophic growth, left ventricular dystunction, and sympathetic hyperinnervation of peripheral arteries in the chick embryo. Circulation 2002;105(23):2791-6.

14. Holubarsch C, Ruf T, Goldstein DJ, et al. Existence of the Frank-Starling mechanism in the failing human heart. Investigations on the organ, tissue, and sarcomere levels. Circulation 1996;94(4):683-9. 
15. Tatsumi R. Hattori A. Detection of giant myofibrillar proteins connectin and nebulin by electrophoresis in $2 \%$ polyacrylamide slab gels strengthened with agarose. Anal Biochem 1995:224(1):28-31.

16. Oh IK, Hatle L, Tajik AJ, Little WC. Diastolic heart failure can be diagnosed by comprehensive two-dimensional and Doppler echocardiography. I Am Coll Cardiol 2006; $47(3): 500-6$.

17. Katz AM, Zile MR. New molecular mechanism in diastolic heart failure. Circulation $2006 ; 113(16): 1922-5$.

18. Zile MR, Brutsaert DL. New concepts in diastolic dysfunction and diastolic heart tailure: Part II: causal mechanisms and treatment. Circulation 2002;105(12):1503-8.

19. Lile MR, Brutsdert DL. New concepts in diastolic dystunction and diastolic heart failure: Part l: diagnosis, prognosis, and measurements of diastolic function. Circulation 2002;105(11):1387-93.

20. Labeit S, Kolmerer B, Linke WA. The giant protein titin. Fmerging roles in physiology and pathophysiology. Circ Res 1997;80(2):2901-4.

21. Linke WA, Fernandez IM. Cardiac titin: molecular basis of elasticity and cellular contribution to clastic and viscous stiffness components in myorardium. I Muscle Res Cell Motil 2002;23(5-6):483-97.

22. Li H, Linke WA, Oberhauser AF, et al. Reverse engineering of the giant muscle protein titin. Nature 2002;418(6901):998-1002.

23. Granzier $H$, Labeit $S$. Cardiac titin: an adjustable multi-functional spring. I Physiol 2002;541(Pt 2):335-42.

24. Opitz CA, Kulke $M$, Leake $M C$, et al. Damped elastic recoil of the titin spring in myofibrils of human myocardium. Proc Natl Acad Sci U SA 2003;100(22):12688-93.

25. Nagueh SF, Shah G, Wu Y, et al. Altered titin expression, myocardial stiffness, and left ventricular function in patients with dilated cardiomyopathy. Circulation 2004;110(2):155-62.

26. Zile MR, Baicu CF, Gasch WH. Diastolic heart failure--abnormalities in active relaxation and passive stiffness of the left ventricle. N Engl f Med 2004;350(19):1953-9.

27. Schaper I, Froede R, Hein S, et al. Impairment of the myocardial ultrastructure and changes of the cytoskeleton in dilated cardionyopathy. Circulation 1991;83(2):504-14.

28. Hein S, Scholz D, Fujitani $N$, el al. Altered expression of titin and contractile proteins in railing human myocardium. J Mol Cell Cardiol 1994;26(10):1291-306.

29. Hein S, Kostin S, Heling A, Maeno Y, Schaper 1. The role of the cytoskelelon in heart failure. Cardiovasc Res 2000;45(2):273-8.

30. Gerull B, Gramlich M, Atherton 1, el al. Mutations of TTN, encoding the giant muscle filament titin, cause familial dilated cardiomyopathy. Nat Genet 2002;30(2):201-4.

31. Itoh-Satoh $M$, Hayashi $T$, Nishi $H$, et al. Titin mutations as the molecular basis for dilated cardiomyopathy. Biochem Biophys Res Commun 2002;291(2):385-93. 
32. Xu X, Meiler SE, Zhong TP, et al. Cardiomyopathy in zebrafish due to mutation in an alternatively spliced exon of titin. Nat Genet 2002;30/2):205-9.

33. Owan TE, Hodge DO, Herges RM, Jacobsen SI, Roger VL, Redfield MM. Trends in prevalence and outcome of heart failure with preserved ejection fraction. N Engl I Med 2006;355(3):251-9. 


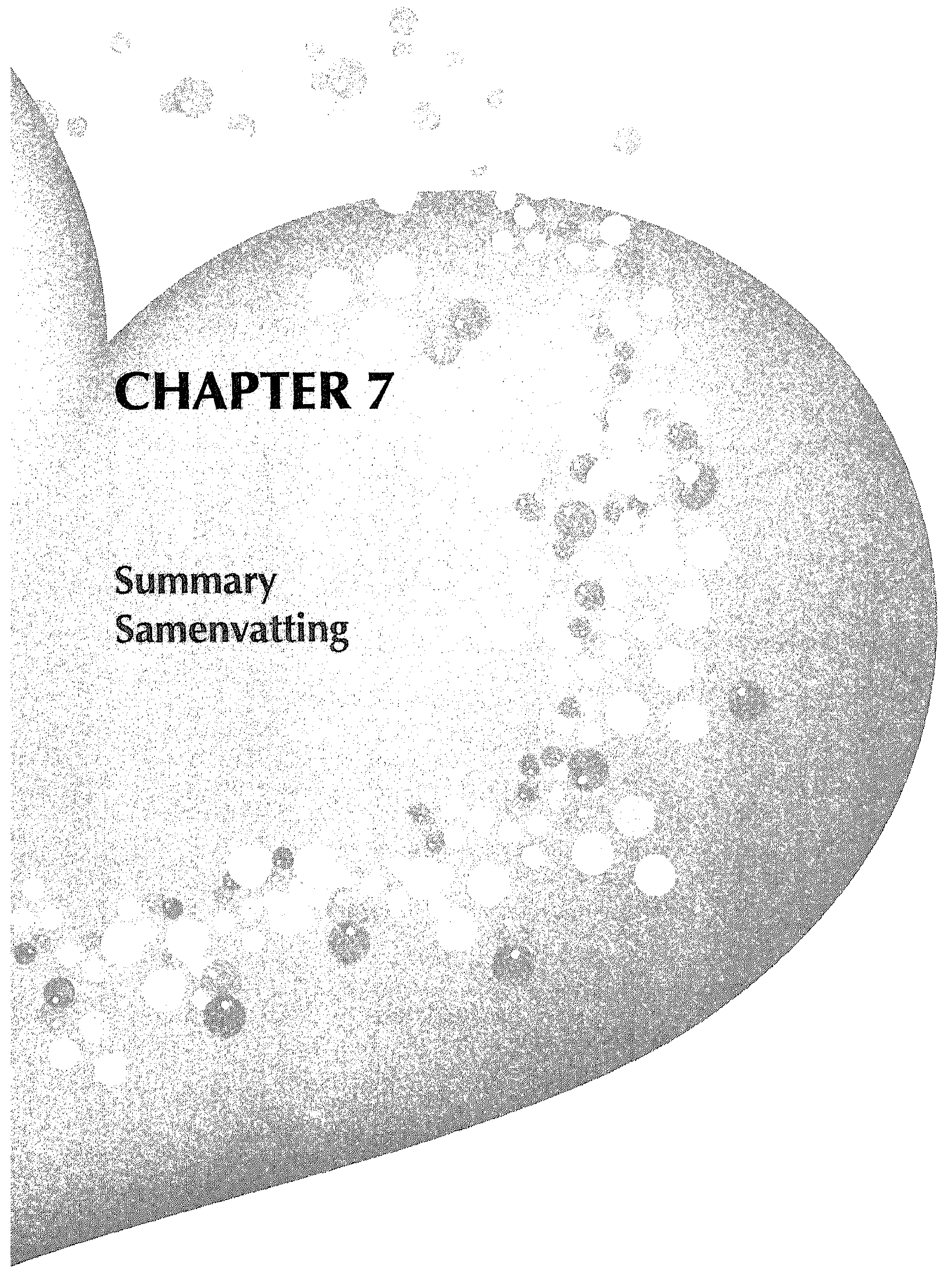


In the last decade numerous studies have demonstrated a relation between low body weight at birth and the occurrence of cardiovascular disease (CVD) in later life. Low birth weight babies have an increased risk of CVD in adulthood, including hypertension, coronary artery disease, and stroke. Based on these observations it is hypothesized that adverse conditions during fetal development, as reflected in low birth weight, play a crucial role in the origin and/or progression of CVD. This concept of fetal programming of adult disease is introduced in Chapter 1.

A large array of adverse intrauterine conditions can lead to low birth weight. Most common Western etiologies of fetal growth restriction include uteroplacental insufficiency, preeclampsia, maternal smoking, and maternal cardiovascular or pulmonary disease. These conditions can hamper oxygen supply to the fetus, resulting in chronic fetal hypoxia. At the cellular level, adaptations to decreased oxygen supply are achieved via the transcription factor hypoxia-inducible factor 1 (HIF-1). In Chapter 2 an overview is given of the molecular biology of HIF-1 and one of its main target genes, vascular endothelial growth factor (VEGF). This review focuses on VEGF and its receptors as major intrauterine modulators of cardiovascular development.

The aim of the thesis is to investigate the effect of prolonged fetal hypoxia on the developing cardiovascular system and the role of VEGF herein. We hypothesize that chronic prenatal hypoxia, through altered VEGF action, induces permanent alterations in cardiovascular structure and function which lead to CVD.

The effect of hypoxia on the developing cardiovascular system was investigated in a chick embryo model. Chick embryos exposed to hypoxia (15\% $\mathrm{O}_{2}$ ) displayed disturbed growth during the second half of embryonic development. The biometric characteristics of hypoxic chick embryos resembled those of growth restricted human fetuses, in particular SGA babies, establishing the validity of the experimental model as presented in Chapter 3 . The disturbances in fetal growth were preceded by alterations in fetal hemodynamic control that may account for changes in body weight distribution in the fetus.

Chapter 4 focuses on the effects of prenatal hypoxia on the three main components of the circulatory system, i.e. the heart, vascular system, and sympathetic nervous system, at the end of fetal development. We identified that near-term hypoxic chick embryos exhibit left ventricular dysfunction, stenosis of the aortic outflow tract, and sympathetic hyperinnervation of resistance arteries 
with increased peripheral vascular tone. As a result of these changes, hypoxic embryos displayed hemodynamic instability when exposed to acute stress. These findings reveal that prenatal insults have profound effects on the design of the circulatory system, and that hypoxia-induced programming of cardiovascular diseases occurs before birth.

In Chapter 5 the effect of prenatal hypoxia on the heart is investigated in detail. Human growth restricted fetuses with hypoxia displayed contractile dysfunction on fetal echocardiography, as evidenced by decreased ejection time and prolonged isovolumetric contraction time. In addition, serum levels of the heart failure biomarker NT-proBNP were elevated in hypoxic growth restricted fetuses. Cardiomyopathy was confirmed by the finding of glycogen deposition and increased cardiomyocyte apoptosis in cardiac biopsy specimens of hypoxic human fetuses, and was associated with increased cardiomyocyte-specific expression of VEGF-A, VEGF receptor 2 (VEGFR-2), and neuropilin-1 (NRP1).

The molecular mechanism underlying hypoxia-induced cardiomyopathy was further elucidated in the chick embryo model. Hypoxic chick embryos displayed severe left ventricular dilatation with impaired contractility of isolated $\mathrm{LV}$ muscle bundles. The last trimester of embryonic development was established as the hypoxia-sensitive window, and even a very slight reduction in oxygen supply $\left(18 \% \mathrm{O}_{2}\right)$ was sufficient to cause loss of cardiac pump function. The hypoxia-induced dilated cardiomyopathy persisted in adult animals and was associated with increased mortality.

Hypoxic chick embryo hearts displayed increased cardiomyocyte-specific expression of VEGF-A, VEGFR-2 and NRP1. We identified that the VEGF 165 isoform exerts a negative inotropic effect on the embryonic heart, which is mediated via VEGFR-2 and NRP1. Prenatal treatment of hypoxic chick embryos with the VEGF scavenger sFIt-1 prevented the development of dilated cardiomyopathy and restored cardiac function as did semaphorin3A (Sema3A), a neural guidance molecule that blocks VEGF binding to NRP1. This chapter establishes VEGF/VEGFR-2/NRP1 axis as the intrauterine modulator of fetal programming of hypoxia-induced dilated cardiomyopathy and suggests that cardiomyocyte-specific VEGFR-2/NRP1 inhibitors constitute potential therapeutic candidates against heart failure. 
In addition to contractile dysfunction, we identified that prenatal hypoxia also caused diastolic dysfunction of the fetal heart, as described in Chapter 6 . Intrauterine echocardiography revealed prolonged isovolumetric relaxation time and increased preload index indicating left and right ventricular diastolic dysfunction in hypoxic human fetuses. Analogous to the human fetuses, hypoxic chick embryos also displayed cardiac diastolic dysfunction, including impaired ventricular relaxation and increased myocardial stiffness. Similar to the systolic dysfunction, diastolic function of the heart remained disturbed in adult animals prenatally exposed to hypoxia. Scavenging VEGF-A with sFlt-1 did not prevent the development of impaired myocardial relaxation in hypoxic chick embryos. This indicates that VEGF was not involved in hypoxia-induced cardiac diastolic dysfunction, in contrast with the prominent role of VEGF-A in systolic dysfunction of the fetal heart.

In conclusion, the clinical and experimental data presented in this thesis show that fetal hypoxia induces permanent alterations in the design of the cardiovascular system which program for CVD, in particular cardiomyopathy. In addition to the classic risk factors for CVD, such as tobacco smoking, high blood cholesterol, physical inactivity, obesity, and diabetes mellitus, and a genetically based propensity for acquiring CVD, this thesis shows that epigenetic influences prior to birth may determine the susceptibility to develop CVD in later life. The identification of fetal hypoxia as a risk factor for CVD offers a novel strategy for the prevention, screening, and early treatment of CVD. 
Hart- en vaatziekten (HVZ) vormen de belangrijkste doodsoorzaak in de westerse wereld. In het laatste decennium hebben talrijke epidemiologische studies een relatie aangetoond tussen een laag geboortegewicht en het ontwikkelen van HVZ op latere leeftijd, zoals hartinfarct, beroerte en hoge bloeddruk. Op basis van deze observaties wordt verondersteld dat foetale stress een rol speelt in het ontstaan en/of de progressie van HVZ. Dit concept van foetale programmering wordt geïntroduceerd in Hoofdstuk 1.

Een van de belangrijkste oorzaken van foetale stress is een langdurig tekort aan zuurstof, bijvoorbeeld als gevolg van verminderde doorbloeding van de placenta. Foetale hypoxie kan leiden tot foetale groeivertraging, laag geboortegewicht, vroeggeboorte, en intra-uteriene dood. Op cellulair niveau worden aanpassingen aan hypoxie gemedieerd door veranderingen in expressie van de transcriptiefactor hypoxia-inducible factor 1 (HIF-1). Hoofdstuk 2 biedt een overzicht van de biologie van HIF-1 en één van zijn doelgenen, vascular endothelial growth factor (VEGF).

Het mechanisme dat aan foetale programmering van HVZ ten grondslag ligt is onbekend. De hypothese die centraal staat in dit proefschrift is dat chronische foetale hypoxie structurele en functionele veranderingen in de aanleg van het hart- en vaatstelsel veroorzaakt die na de geboorte blijven voortbestaan en resulteren in HVZ. Het effect van hypoxie op de ontwikkeling van het hart- en vaatstelsel werd onderzocht in kippenembryo's. In Hoofdstukken 3 en 4 wordt aangetoond dat blootstelling aan chronische hypoxie uitgebreide veranderingen veroorzaakt in de functie van het hart, het vaatstelsel en het sympathische zenuwstelsel, die resulteren in foetale groeivertraging en een laag geboortegewicht.

Op basis van de bevindingen in hoofdstukken 3 en 4 werd de rol van foetale hypoxie in het ontstaan van hartfalen onderzocht in Hoofdstukken 5 en 6. Kippenembryo's die waren blootgesteld aan hypoxie vertoonden een dilatatie van de linker hartkamer en beschadiging van het hartspierweefsel. Zowel de contractiekracht als de relaxatiecapaciteit van spierbundels uit de linker hartkamer van deze embryo's was gehalveerd ten opzichte van normale embryo's. Deze veranderingen in de structuur en de pompfunctie van het hart bleven ook na de geboorte voortbestaan. Vervolgens werd aangetoond dat de groeifactor VEGF een belangrijke rol speelt in het ontstaan van hypoxie-geïnduceerd hartfalen. De expressie van VEGF en de VEGF receptoren VEGFR-2 en NRP1 was verhoogd in hypoxisch hartspierweefsel. Door de werking van VEGF tijdens de 
tweede helft van de embryonale ontwikkeling te blokkeren kon het hartdefect volledig worden voorkomen. Vervolgens werd onderzocht of dit mechanisme ook vertaald kon worden naar de humane situatie. Met behulp van foetale hartecho's en biochemische bepalingen werd aangetoond dat ook hypoxische humane foetussen tekenen van hartfalen vertonen. In hartspierweefsel van foetussen die aan de gevolgen van hypoxie waren overleden was hartspierschade en een verhoogde expressie van VEGF en VEGF receptoren aantoonbaar, vergelijkbaar met het experimentele model. Op basis van deze onderzoeksresultaten werd geconcludeerd dat foetale hypoxie predisponeert tot hartfalen via een VEGFafhankelijk mechanisme. Onze bevindingen ondersteunen de hypothese dat foetale hypoxie structurele en functionele veranderingen in de aanleg van het hart- en vaatstelsel veroorzaakt die leiden tot HVZ.

Dit proefschrift identificeert foetale hypoxie als een nieuwe risicofactor voor HVZ en biedt een moleculair mechanisme voor de embryonale origine van HVZ, in het bijzonder cardiomyopathie. De onderzoeksresultaten vormen een basis voor nieuwe screenings-, preventie-, en behandelingsstrategieën. De prevalentie van foetale hypoxie wordt momenteel geschat op 5-10\%, maar dit percentage zal naar verwachting toenemen. Screening van de hartfunctie bij alle pasgeborenen met intra-uteriene groeivertraging biedt de mogelijkheid baby's met een verhoogd risico vroegtijdig te identificeren. Onze resultaten tonen aan dat preventie van hart- en vaatziekten reeds vóór de geboorte dient te beginnen, onder andere door meer aandacht te vestigen op het voorkomen en behandelen van foetale hypoxie. Behandeling met specifieke VEGF antagonisten kan in de toekomst mogelijk leiden tot een nieuwe therapie voor hypoxie gerelateerd hartfalen. In conclusie: strategieën gericht op detectie en preventie van foetale hypoxie bieden een nieuwe mogelijkheid tot het reduceren van HVZ in toekomstige generaties. 


\section{List of SCIENTIfic PAPers}




\section{CURRiculum Vitae}

Andrei Nicolae Tintu was born on July 23, 1976 in Bucharest, Romania. He moved to the Netherlands on his 13 th birthday. He attended secondary school at the Jeanne d'Arc College in Maastricht, and graduated in 1997. After one year of information technology in Eindhoven, he started his study in health sciences at Maastricht University, and obtained his MSc degree in February 2003. Thereafter, he started his PhD research project entitled "Embryonic Origin of Cardiovascular Disease" at the departments of surgery and anatomy/ embryology of Maastricht University. Since February 2007 he is engaged as a postdoctoral fellow in a collaboration project between the Cardiovascular Research Institute Maastricht and the Max Delbrück Center for Molecular Medicine in Berlin, Germany. 


\section{List of Scientific Papers}

Rouwet EV, Tintu AN, Schellings MWM, van Bilsen M, Lutgens E, Hofstra L, Slaaf DW, Ramsay G, le Noble FAC. Hypoxia induces aortic hypertrophic growth, left ventricular dysfunction, and sympathetic hyperinnervation of peripheral arteries in the chick embryo. Circulation 2002;105:2791-2796.

Tintu AN*, Rouwet EV*, Ahmad S, van Bilsen M, Carmeliet P, Cetin I, Harks E, Hofstra L, Jacobs M, Lamers W, Gratacos E, Crispi F, Hernandez-Andrade E, Narula J, Staff AC, Brinkmann J, Ahmed A, le Noble FAC. Prenatal hypoxic stress programs for cardiomyopathy involving cardiomyocyte specific VEGFA/VEGFR-2/NRP1 signaling. Submitted for publication. (* These authors contributed equally to this work)

Tintu AN, Verlohren S, le Noble FAC, Rouwet EV. Fetal origin of CVD, identification of prenatal hypoxia as a risk factor for CVD. Submitted for publication.

Tintu AN, le Noble FAC, Rouwet EV. Hypoxia disturbs fetal hemodynamics and growth. Submitted for publication.

De Graaf R, Kloppenburg G, Tintu AN, Kitslaar PJHM, Van Hooff JP, Bruggeman CA, Stassen FRM. The new immunosuppressive agent FK778 attenuates neointima formation in an experimental bypass model. Submitted for publication.

De Graaf R, Stassen FRM, Kloppenburg G, Bruggeman CA, Kitslaar PJHM, Tintu $A N$, Rouwet EV. $\mathrm{N}$-acetylcysteine attenuates hyperoxia induced venous smooth muscle cell proliferation and neointima formation in a rat venous graft model. Submitted for publication. 